\title{
The Dynamic Transformation of Deformed Austenite at Temperatures above the $\mathrm{Ae}_{3}$
}

By

Chiradeep Ghosh

A Thesis Submitted to the Faculty of Graduate Studies and Research in Partial Fulfillment of the Requirements for the Degree of Doctor of Philosophy

Department of Mining and Materials Engineering

McGill University

Montreal, Canada

February 2013 


\begin{abstract}
The dynamic transformation behavior of deformed austenite was studied in four steels of increasing carbon contents that had been deformed over the temperature range $743-917^{\circ} \mathrm{C}$. These experiments were carried out in torsion under an atmosphere of argon and $5 \% \mathrm{H}_{2}$ and the experimental temperatures were above the ortho and para-equilibrium $\mathrm{Ae}_{3}$ temperatures of the steels. Strains of $0.15-5$ were applied at strain rates of $0.4-4.5 \mathrm{~s}^{-1}$. The experimental parameters were varied in order to determine the effects of strain and temperature on the formation of strain-induced ferrite and cementite. The structures observed are Widmanstätten in form and appear to have nucleated displacively.
\end{abstract}

The onsets of dynamic transformation and dynamic recrystallization were detected in the four steels using the double-differentiation method. Two sets of second derivative minima were found to be associated with all the flow curves. It is shown that double minima can only be obtained when the polynomial order is at least 7. The first set of minima corresponds to the initiation of dynamic transformation (DT). The second set is associated with the nucleation of dynamic recrystallization (DRX). The critical strain for DT is always lower than for DRX in this range and increases slightly with temperature. Conversely, the critical strain for DRX decreases with temperature in the usual way.

The mean flow stresses (MFS's) pertaining to each experimental condition were calculated from the flow curves by integration. These are plotted against the inverse absolute temperature in the form of Boratto diagrams. The stress drop temperatures, normally defined as the upper critical temperature $A_{r 3}{ }^{*}$, were determined from these diagrams. These are shown to be about $40^{\circ} \mathrm{C}$ above the paraequilibrium and about $20-30^{\circ} \mathrm{C}$ above the orthoequilibrium upper critical 
transformation temperatures. This type of behavior is ascribed to the occurrence of the dynamic transformation of austenite to ferrite during deformation.

The effect of deformation on the Gibbs energy of austenite in these steels was estimated by assuming that the austenite continues to work harden after initiation of the transformation and that its flow stress and dislocation density can be derived from the experimental flow curve by making suitable assumptions about two-phase flow. By further taking into account the inhomogeneity of the dislocation density, Gibbs energy contributions (driving forces) are derived that are sufficient to promote transformation as much as $100^{\circ} \mathrm{C}$ above the $\mathrm{Ae}_{3}$. The carbon diffusion times required for formation of the observed ferrite plates and cementite particles are calculated; these are consistent with the occurrence of interstitial diffusion during deformation. Similar calculations indicate that substitutional diffusion does not play a role during dynamic transformation. The Gibbs energy calculations suggest that growth of the Widmanstätten ferrite is followed by $\mathrm{C}$ diffusion at the lower carbon contents, while it is accompanied by C diffusion at the higher carbon levels. 


\section{RÉSUMÉ}

Le comportement de la transformation dynamique de l'austénite lors de sa déformation a été étudié dans quatre aciers, dont les teneurs en carbone sont croissantes, déformés à des températures allant de 743 à $917^{\circ} \mathrm{C}$. Ces expériences ont été réalisées par torsion sous une atmosphère contrôlée (mélange argon et $5 \% \mathrm{H}_{2}$ ) et les températures de déformation étaient au-dessus des températures d'ortho et para-équilibre $\mathrm{Ae}_{3}$ pour chaque acier. Des taux de déformation de 0,15 à 5 ont été utilisés avec des vitesses de déformation allant de 0,4 à 4,5 s $\mathrm{s}^{-1}$. Les paramètres expérimentaux ont été modifiés afin de déterminer les effets du taux de déformation et de la température sur la formation de ferrite et de cémentite induite par déformation. Les structures observées sont de type Widmanstätten et semblent avoir nucléées de façon displacive.

Les départs de la transformation dynamique et de la recrystallization dynamique ont été détectés pour les quatre aciers en utilisant la méthode de double différenciation. Deux ensembles de minima sur les dérivés secondes se trouvent être associés à toutes les courbes d'écoulement. II est montré qu'un double minimum ne peut être obtenu que lorsque l'ordre du polynôme utilisé dans la procédure d'ajustement de l'intégralité de la courbe découlement est supérieur ou égale à 7. Le premier ensemble de minima correspond à l'initialisation de la transformation dynamique. Le second ensemble est associé à la nucléation de la recrystallization dynamique. Le taux de déformation critique de la transformation dynamique est toujours inférieur à celui de la recrystallization dynamique, dans la gamme de température étudiée, et augmente légèrement avec la température. A l'inverse, le taux de déformation critique de la recrystallization dynamique diminue, de manière connue, avec la température.

Les contraintes d'écoulement moyennes relatives à chaque condition expérimentale sont calculées à partir de l'intégration des courbes d'écoulement. 
Celles-ci sont représentées en fonction de l'inverse de la température absolue sous la forme de diagrammes de Boratto. Les températures auxquelles la chute de contrainte se produit, normalement définie comme étant la température critique supérieure $A_{r 3}{ }^{*}$, sont déterminées à partir de ces diagrammes. Celles-ci sont d'environ $40^{\circ} \mathrm{C}$ au-dessus de la température critique supérieure de paraéquilibre et d'environ 20 à $30^{\circ} \mathrm{C}$ au-dessus de celle d'ortho-équilibre.

L'effet de la déformation sur l'énergie de Gibbs de l'austénite dans ces aciers est estimé en supposant que l'austénite continue de s'écrouir après l'initiation de la transformation et que sa contrainte d'écoulement et sa densité de dislocations peuvent être dérivées à partir des courbes d'écoulement expérimentales en émettant des hypothèses appropriées sur l'écoulement conjoint de deux phases. En prenant en outre en compte l'hétérogénéité de la densité de dislocation, les contributions à l'énergie de Gibbs obtenues (forces motrices) sont suffisantes pour promouvoir une transformation jusqu'à $100^{\circ} \mathrm{C}$ au-dessus de la température $\mathrm{Ae}_{3}$. Le temps de diffusion du carbone requis pour la formation des plaques de ferrite observées est calculé; les résultats obtenus sont cohérents avec l'apparition de diffusion interstitielle au cours de la déformation. Des calculs similaires indiquent que la diffusion substitutionnelle ne joue aucun rôle lors de la transformation dynamique. Les calculs de l'énergie de Gibbs suggèrent que la croissance de la ferrite de Widmanstätten est suivie de la diffusion du carbone dans le cas des plus faibles teneurs en carbone tandis qu'elle est accompagnée par celle-ci pour les teneurs les plus fortes. 


\section{PREFACE}

\section{Contributions of the various co-authors to the papers arising out of this investigation}

The following manuscripts are based on this thesis:

1. "The Dynamic Transformation of Deformed Austenite at Temperatures above the $\mathrm{Ae}_{3}$ ", C. Ghosh, V.V. Basabe, J.J. Jonas, Y.M. Kim, I.H. Jung and S. Yue; Acta Mater., Vol. 61, (2013), p. 2348-2362.

2. “Dynamic Transformation Behavior of a Deformed High Carbon Steel at Temperatures above the $\mathrm{Ae}_{3}{ }^{\prime \prime}, \mathrm{C}$. Ghosh, V.V. Basabe, J.J. Jonas, S. Yue and X.Y. Xiong; ISIJ Int., Vol. 53, (2013), p. 900-908.

3. "Determination of the Critical Strains for the Initiation of Dynamic Transformation and Dynamic Recrystallization in Four Steels of Increasing Carbon Contents", C. Ghosh, V.V. Basabe and J.J. Jonas; Steel Res. Int., in press (DOI: 10.1002/srin.201200188).

4. "The Critical Strain for Dynamic Transformation in Hot Deformed Austenite", J.J. Jonas, C. Ghosh, X. Quelennec and V.V. Basabe; ISIJ Int., Vol. 53, (2013), p. 145-151.

5. "Predicting the Occurrence of Dynamic Transformation and of Rolling Mill Load Drops by Hot Torsion and Compression Testing", J.J. Jonas, C. Ghosh, X. Quelennec and V.V. Basabe; Proceedings of SimPro'12, $3^{\text {rd }}$ Int. Conf. on Thermo-Mechanical Simulation and Processing of Steel, RDCIS, SAIL, Ranchi, India, Dec. 12-14, (2012), p. 3-13.

6. "Effect of Dynamic Transformation on the Mean Flow Stress", J.J. Jonas, C. Ghosh and V.V. Basabe; Steel Res. Int., Vol. 84, (2013), p. 253-258.

With regard to Ref. 1, Professor In-Ho Jung provided me with expert guidance on the use of the FactSage ${ }^{\mathrm{TM}}$ software and I also received useful advice regarding my thermodynamic calculations from Dr. Young-Min Kim. The EBSD micrographs 
included in the paper were produced by Dr. V.V. Basabe, a member of Professor Jonas' research group. The TEM and APT results included in Ref. 2 emanated from an investigation of the present material carried out by Dr. Xiang Y. Xiong of Monash University, Australia. Dr. Basabe assisted me in performing the torsion tests described in that paper and supplied some of the flow curves analyzed using the methods developed in this project in Ref. 3. With regard to publications 4 and 5, Dr. Xavier Quelennec taught me how to calculate the critical strain from stress-strain data, the procedure employed in these manuscripts. I am indebted to Dr. V.V. Basabe for providing some of the flow curves analyzed by the present techniques in these papers as well as in Ref. 6. Apart from the data received as described above, all the experiments and calculations were performed by the present author. 


\section{ACKNOWLEDGEMENTS}

First and foremost, I would like to express my sincere gratitude to my research supervisors, Professor John J. Jonas and Professor Stephen Yue, for their excellent guidance and consistent support since my very first day at McGill University. They provided me with every opportunity, a very conducive atmosphere for research and believed in me in all aspects of my education. Their personal generosity, extremely quick response, and their dedication towards their work and their students are sources of encouragement to me. It was indeed a real pleasure for me to work with professors who have a profound knowledge, not only of academic subjects, but also of many other aspects of life.

Special thanks are due to Professor In-Ho Jung and Dr. Young-Min Kim for helping me in carrying out the thermodynamic calculations, something that is an integral part of this work. I am indebted to Dr. V.V. Basabe for his assistance in the EBSD and SEM parts of this investigation, as well as for providing flow curves for three steels. I am not ashamed to say that without his help this journey would have been much more difficult. I would like to thank Dr. Xavier Quelennec for helping me to understand the critical strain calculations. I am thankful to Professor Elena V. Pereloma of Wollongong University, Australia, as well as Dr. Ilana Timokhina and Dr. Xiang Y. Xiong of Monash University, Australia for providing some results of their TEM and APT investigations of the present materials. Stimulating comments on many parts of this work by Professor Peter Hodgson and Dr. Hossein Beladi of Deakin Univeristy, Australia are gratefully acknowledged. Many thanks to Mr. Pierre Vermette especially for helping me so promptly in purchase-related issues and to Mr. Edwin Fernandez for preparing the torsion samples. 
I am thankful for the financial support provided by the "Leon and Suzanne Fattal Graduate Fellowships" of the Faculty of Engineering at McGill University. I am also indebted to the management of Tata Steel, Jamshedpur, for giving me study leave to pursue research at McGill. I would like to take this occasion to thank Professor R.K. Ray for his moral support.

I extend my sincere thanks to all my colleagues and especially to the hotdeformation research group, who made my stay at McGill unforgettable.

Last, but not the least, I warmly acknowledge the delightful encouragement and interest that I have always received from my family, and especially from my wife, Pampa. I cherish her immense patience and active support throughout this research program. This story will not be over if I do not mention the name of my lovely little daughter, Misti, whose ever smiling face has escorted me through to the completion of this thesis. 


\section{TABLE OF CONTENTS}

Abstract

Résumé

Preface v v

Acknowledgements vii

Table of Contents ix

List of Figures $\quad$ xiv

List of Tables $\quad x x$

Chapter 1

$\begin{array}{lr}\text { Introduction } & 1\end{array}$

References 3

\section{Chapter 2}

Literature Review $\quad 5$

2.1 Hot Rolling Process

$\begin{array}{ll}2.1 .1 \text { Recovery } & 7\end{array}$

$\begin{array}{ll}\text { 2.1.2 Recrystallization } & 7\end{array}$

2.1.2.1 Static Recrystallization 8

2.1.2.2 Dynamic Recrystallization 8

2.1.2.3 Metadynamic Recrystallization $\quad 9$

2.2 Iron-Carbon Phase Diagram 9

2.3 Phase Transformation of Austenite 11

2.3.1 Reconstructive Transformation 11

2.3.1.1 Allotriomorphic Ferrite $\quad 11$ 
2.3.2 Displacive Transformation

2.3.2.1 Widmanstätten Ferrite

2.3.2.2 Bainite

2.3.2.3 Martensite

2.4 Effect of Deformation on Austenite Phase Transformation

2.4.1 Reversion of DT Ferrite to Austenite

2.4.2 Modeling the Dynamic Transformation of

Austenite

2.4.3 Change in Equilibrium $\mathrm{Ae}_{3}$ Temperature

References

\section{Chapter 3}

Experimental Procedure

3.1 Experimental Materials

3.2 Torsion Testing

3.2.1 Theory

3.2.2 Hot Torsion Machine

3.3 Sample Preparation

3.4 Thermomechanical Schedule 40

3.5 Microstructural Characterization

42

3.6 Hardness Measurements

3.7 Quantification of the Phase Measurements

3.8 Thermodynamic Calculations 
3.8.3 Addition of Deformation Energy to Bulk

Gibbs Energy in FCC

References

49

\section{Chapter 4}

$\begin{array}{ll}\text { Microstructural Characterization } & 51\end{array}$

4.1 $0.06 \% \mathrm{C}$ and $0.09 \% \mathrm{C}$ Steels $\quad 51$

$\begin{array}{ll}4.20 .21 \% C \text { Steels } & 53\end{array}$

4.2.1 SEM Results

4.2.2 EBSD Results $\quad 57$

4.2.3 Effect of Strain on Phase Proportions $\quad 58$

$\begin{array}{ll}4.30 .79 \% C \text { Steel } & 59\end{array}$

4.3.1 SEM Results $\quad 59$

4.3.2 TEM Results $\quad 66$

4.3.3 Atom Probe Analysis $\quad 69$

4.3.4 Effect of Strain on Phase Proportions 71

4.3.5 Effect of Temperature on Phase Proportions and Microhardness Values $\quad 73$

4.4 Summary of the Microstructural Observations 74

$\begin{array}{ll}4.5 \text { Discussion } & 74\end{array}$

4.5.1 Likely Mechanisms of DT $\quad 74$

4.5.2 Application to Industrial Processing 80

$\begin{array}{ll}4.6 \text { Conclusions } & 80\end{array}$

$\begin{array}{ll}\text { References } & 81\end{array}$ 


\section{Chapter 5}

$\begin{array}{lr}\text { Critical Strain Determinations } & 83\end{array}$

5.1 Background $\quad 83$

5.2 Method of Analysis $\quad 84$

$\begin{array}{ll}5.3 \text { Results } & 86\end{array}$

5.3.1 Effect of Polynomial Order 94

$\begin{array}{ll}\text { 5.4 Discussion } & 97\end{array}$

$\begin{array}{ll}5.5 \text { Conclusions } & 102\end{array}$

$\begin{array}{ll}\text { References } & 103\end{array}$

\section{Chapter 6}

Effect of Dynamic Transformation on the Mean Flow Stress 105

$\begin{array}{ll}6.1 \text { Background } & 105\end{array}$

$\begin{array}{ll}\text { 6.2 Method of Analysis } & 107\end{array}$

$\begin{array}{ll}6.3 \text { Results } & 107\end{array}$

$\begin{array}{ll}\text { 6.4 Discussion } & 110\end{array}$

$\begin{array}{ll}6.5 \text { Conclusions } & 114\end{array}$

$\begin{array}{ll}\text { References } & 115\end{array}$

\section{Chapter 7}

Thermodynamics of Dynamic Transformation 116

$\begin{array}{ll}7.1 \text { Background } & 116\end{array}$

$\begin{array}{ll}\text { 7.2 Current Approach } & 117\end{array}$

$\begin{array}{ll}\text { 7.2.1 Dislocation Energy } & 118\end{array}$

$\begin{array}{ll}\text { 7.2.2 Grain Boundary Energy } & 119\end{array}$ 
7.2.4 The Stored Energy of Deformation

7.2.5 Inhomogeneity of the Dislocation Density

126

7.2.6 Gibbs Energy Implications

7.2.6.1 0.06\%C Steel

7.2.6.2 0.09\%C Steel

128

7.2.6.3 0.21\%C Steel

131

7.2.6.4 0.79\%C Steel

7.2.7 Effect of Strain on the Phase Diagram

References

\section{Chapter 8}

Conclusions

139

\section{Chapter 9}

Contributions to Original Knowledge 


\section{LIST OF FIGURES}

Fig. 2.1: Schematic layout of a hot rolling mill [1].

Fig. 2.2: Effect of DRX given by stress-strain curve during hot working [5].

Fig. 2.3: Fe-C phase diagram, indicating the phases that are thermodynamically stable as a function of carbon concentration and temperature [11]. 10

Fig. 2.4: Formation of allotriomorphic and idiomorphic ferrite [14].

Fig. 2.5: Schematic representation of pearlite formation by nucleation and growth; (a) through (d) indicate successive steps in time sequence [16]. 13

$\begin{array}{ll}\text { Fig. 2.6: Microstructure of pearlite. } & 14\end{array}$

Fig. 2.7: Formation of Widmanstätten ferrite [17]. 15

Fig. 2.8: Schematic representation of bainite formation [18]. 17

Fig. 2.9: Thin foil transmission electron micrograph of the $0.11 \% \mathrm{C}$ steel quenched immediately after $75 \%$ deformation at $800^{\circ} \mathrm{C}$ (i.e. $13^{\circ} \mathrm{C}$ above the $A_{r 3}$ ) at a strain rate of $50 \mathrm{~s}^{-1}[26]$.

Fig. 2.10: Change in ferrite fraction produced by isothermal holding above the paraequilibrium $\mathrm{Ae}_{3}$ after hot deformation [27]. Dotted lines added by author. 20

Fig. 2.11: A schematic diagram of the in-situ X-ray experimental setup [28].

Fig. 2.12: Typical X-ray diffraction patterns (a) before heating, (b) at the austenitizing temperature, and (c) on the application of torsional deformation at the austenitizing temperature [28].

Fig. 2.13: Schematic of the Gibbs energy changes during dynamic phase transformation and the reverse transformation of ferrite to austenite above the $\mathrm{Ae}_{3}$ after the latter has undergone deformation [30].

Fig. 2.14: Dilatation curves of specimens held isothermally after deformation at various temperatures above the $\mathrm{Ae}_{3}[32]$.

Fig. 2.15: Microstructures of a specimen (a) quenched immediately after deformation at $850^{\circ} \mathrm{C}\left(\mathrm{Ae}_{3}+15^{\circ} \mathrm{C}\right)$ and (b) subjected to $1200 \mathrm{~s}$ of holding following deformation and then quenched [32]. 
Fig. 2.16: Micrographs of specimens deformed at $856^{\circ} \mathrm{C}\left(\mathrm{Ae}_{3}+20^{\circ} \mathrm{C}\right)$ at $0.4 \mathrm{~s}^{-1}$ and held isothermally after deformation for (a) $0 \mathrm{~s}$, (b) $200 \mathrm{~s}$, (c) $400 \mathrm{~s}$. The reverse transformation began after $200 \mathrm{~s}$ of holding, as revealed by the presence of the martensite needles (arrows) [34].

Fig. 2.17: (a) Carbon diffusion kinetics in austenite at different logarithmic strains; (b) schematic curves of the free energy vs. carbon concentration showing the effect of austenite deformation on the equilibrium carbon concentration in ferrite and austenite [36].

Fig. 2.18: Schematic representation of the effect of deformation on the Fe-C phase diagram. $\bar{X}$ represents the mean $C$ concentration of a particular steel. The lowest plot is the conventional orthoequilibrium diagram. An increase in strain raises the effective diagram (blue lines) sufficiently that the experimental temperature $\mathrm{T}_{\exp }$ is now below the effective $\mathrm{Ae}_{3}$. Additional deformation raises it still further (red lines) so that the experimental temperature is now below the $\mathrm{Ae}_{1}[38]$.

Fig. 2.19: Schematic of ferrite nucleation at a ledge on deformed austenite grain boundaries. (a) a ledge on a grain boundary; (b) ferrite nucleation at a ledge [42].

Fig. 3.1: Schematic diagram of the torsion machine [10]. 38

Fig. 3.2: The torsion machine at McGill University.

Fig. 3.3: Schematic diagram of a cylindrical torsion specimen.

Fig. 3.4: Thermomechanical schedules for the torsion tests of (a) Steels 1 and 2 $[11,12]$ and (b) Steels 3 and $4[13,14]$.

Fig. 3.5: Position of the thermocouple with respect to the torsion sample. $\quad 41$

Fig. 3.6: Sample cutting for microstructural characterization.

Fig. 3.7: Schematic diagram of the Vickers hardness test (a) Vickers indentation; (b) measurement of the impression diagonals [18]; (c) an example of the indentation it produces.

Fig. 3.8: Quantification of the ferrite grain areas.

Fig. 4.1: EBSD micrographs of a transverse cross-section of the $0.06 \% \mathrm{C}$ steel strained to $\varepsilon=0.25$ at $887^{\circ} \mathrm{C}\left(\mathrm{Ae}_{3}+10^{\circ} \mathrm{C}\right)$ : (a) orientation image map of the ferrite phase (radial direction), black regions are martensite, (b) IPF and IQ map of the ferrite phase (circumferential direction), (c) orientation image map of the martensite phase, black regions are ferrite (circumferential direction), (d) misorientations measured along the line in (b). The $60^{\circ}$ misorientation indicates the presence of a twinned region in the prior austenite [3]. 
Fig. 4.2: EBSD micrographs of a transverse cross-section of the $0.09 \% \mathrm{C}$ steel strained to $\varepsilon=0.5$ at $856^{\circ} \mathrm{C}\left(\mathrm{Ae}_{3}+20^{\circ} \mathrm{C}\right)$ : (a) orientation image map of the ferrite phase (radial direction), black regions are martensite, (b) orientation image map of the ferrite phase (longitudinal direction), (c) orientation image map of the martensite phase, black regions are ferrite (radial direction), (d) misorientations measured along the line in (a). The $60^{\circ}$ misorientation indicates the presence of a twinned region in the prior austenite [3].

Fig. 4.3: Scanning electron micrographs illustrating the formation of: (a) plate ferrite and (c) cementite particles. The specimen was deformed in torsion at $862^{\circ} \mathrm{C}\left(\mathrm{Ae}_{3}+40^{\circ} \mathrm{C}\right)$ to a strain of $\varepsilon=0.15$ in $33 \mathrm{~ms}$ and then quenched. The austenite present after straining was converted to martensite.

54

Fig. 4.4: Scanning electron micrograph of a specimen deformed to a strain of 0.25 at $4.5 \mathrm{~s}^{-1}$ at $862^{\circ} \mathrm{C}\left(\mathrm{Ae}_{3}+40^{\circ} \mathrm{C}\right)$. The deformed and quenched specimen contains ferrite, cementite and martensite.

55

Fig. 4.5: Presence of ferrite and cementite particles in the microstructure after deformation to a strain of 3 at $4.5 \mathrm{~s}^{-1}$ at the following temperatures: (a) $842^{\circ} \mathrm{C}$ $\left(\mathrm{Ae}_{3}+20^{\circ} \mathrm{C}\right)$, (b) $892^{\circ} \mathrm{C}\left(\mathrm{Ae}_{3}+70^{\circ} \mathrm{C}\right)$. Here the $\mathrm{Ae}_{3}$ is the orthoequilibrium temperature; the paraequilibrium temperatures are $14^{\circ} \mathrm{C}$ lower.

56

Fig. 4.6: EBSD micrographs of a transverse cross-section of the $0.21 \% \mathrm{C}$ steel strained to $\varepsilon=0.25$ at $862^{\circ} \mathrm{C}\left(\mathrm{Ae}_{3}+40^{\circ} \mathrm{C}\right)$ : (a) orientation image map of the ferrite phase (radial direction), black regions are martensite, (b) orientation image map of the ferrite phase (longitudinal direction), (c) orientation image map of the martensite phase, black regions are ferrite (radial direction), (d) misorientations measured along the line in (a). The $60^{\circ}$ misorientation indicates the presence of a twinned region in the prior austenite [3].

Fig. 4.7: Effect of strain on the percentage of austenite that transforms dynamically into ferrite and cementite at $862^{\circ} \mathrm{C}\left(\mathrm{Ae}_{3}+40^{\circ} \mathrm{C}\right)$ at $4.5 \mathrm{~s}^{-1}$.

Fig. 4.8: Scanning electron micrographs showing the presence of Widmanstätten ferrite plates and carbide precipitates. The specimen was deformed at $753^{\circ} \mathrm{C}$ $\left(\mathrm{Ae}_{3}+20^{\circ} \mathrm{C}\right)$ to a strain of 0.25 in $62 \mathrm{~ms}$ and then quenched. The austenite present after straining was converted into martensite. Some characteristic straight interfaces are highlighted with white arrows [6].

Fig. 4.9: Scanning electron micrographs showing the presence of Widmanstätten ferrite plates and carbide precipitates. The specimen was deformed at $783^{\circ} \mathrm{C}$ $\left(\mathrm{Ae}_{3}+50^{\circ} \mathrm{C}\right)$ to a strain of 0.25 in $62 \mathrm{~ms}$ and then quenched. The austenite present after straining was converted into martensite. Some characteristic straight interfaces are highlighted with white arrows. 
Fig. 4.10: Scanning electron micrograph of a specimen deformed to a strain of 0.5 at $4 \mathrm{~s}^{-1}$ at $753^{\circ} \mathrm{C}\left(\mathrm{Ae}_{3}+20^{\circ} \mathrm{C}\right)$. The deformed and quenched specimen contains Widmanstätten ferrite, cementite and martensite [6].

Fig. 4.11: Presence of ferrite and cementite in the microstructure after deformation to a strain of 4 at $4 \mathrm{~s}^{-1}$ at the following temperatures: (a) $743^{\circ} \mathrm{C}\left(\mathrm{Ae}_{3}\right.$ $\left.+10^{\circ} \mathrm{C}\right)$, (b) $753^{\circ} \mathrm{C}\left(\mathrm{Ae}_{3}+20^{\circ} \mathrm{C}\right),(\mathrm{c}) 763^{\circ} \mathrm{C}\left(\mathrm{Ae}_{3}+30^{\circ} \mathrm{C}\right)$, (d) $773^{\circ} \mathrm{C}\left(\mathrm{Ae}_{3}+40^{\circ} \mathrm{C}\right),(\mathrm{e})$ $783^{\circ} \mathrm{C}\left(\mathrm{Ae}_{3}+50^{\circ} \mathrm{C}\right)$, (f) $793^{\circ} \mathrm{C}\left(\mathrm{Ae}_{3}+60^{\circ} \mathrm{C}\right)$, (g) $803^{\circ} \mathrm{C}\left(\mathrm{Ae}_{3}+70^{\circ} \mathrm{C}\right)$, (h) $823^{\circ} \mathrm{C}\left(\mathrm{Ae}_{3}+\right.$ $\left.90^{\circ} \mathrm{C}\right)$ and (i) $863^{\circ} \mathrm{C}\left(\mathrm{Ae}_{3}+130^{\circ} \mathrm{C}\right)$. Here the $\mathrm{Ae}_{3}$ is the orthoequilibrium temperature; the paraequilibrium intervals are $24^{\circ} \mathrm{C}$ greater [6].

Fig. 4.12: Transmission electron micrograph illustrating the simultaneous presence of a ferrite plate (F) and martensite (M), i.e. austenite, in the microstructure. The sample was deformed to a strain of 4 at $4 \mathrm{~s}^{-1}$ at $763^{\circ} \mathrm{C}\left(\mathrm{Ae}_{3}+\right.$ $\left.30^{\circ} \mathrm{C}\right)[6]$.

Fig. 4.13: Transmission electron micrographs displaying (a) the ferrite plate (F) morphology (diffraction pattern inset); (b) three cementite precipitates indicated by arrows and their corresponding diffraction pattern (inset). The sample was deformed in torsion to a strain of 4 at $4 \mathrm{~s}^{-1}$ at $763^{\circ} \mathrm{C}\left(\mathrm{Ae}_{3}+30^{\circ} \mathrm{C}\right)$ and quenched immediately afterwards [6].

Fig. 4.14: Transmission electron micrographs of the martensite showing the two different morphologies observed: (a) lath-like and (b) plate-like. The sample was deformed in torsion to a strain of 4 at $4 s^{-1}$ at $763^{\circ} \mathrm{C}\left(\mathrm{Ae}_{3}+30^{\circ} \mathrm{C}\right)$ [6].

Fig. 4.15: $C$ atom maps from representative (a) martensitic; (b) plate ferritic regions. (c) $\mathrm{C}$ concentration profile across a sub-boundary in the plate ferrite. The specimen was deformed to a strain of $\varepsilon=4.0$ at $4.0 \mathrm{~s}^{-1}$ at $763^{\circ} \mathrm{C}\left(\mathrm{Ae}_{3}+30^{\circ} \mathrm{C}\right)$ [6].

Fig. 4.16: (a) $\mathrm{C}$ atom map of plate ferrite; (b) concentration profile measured in the sample shown in (a). The specimen was deformed to a strain of $\varepsilon=4.0$ at 4.0 $s^{-1}$ at $763^{\circ} \mathrm{C}\left(\mathrm{Ae}_{3}+30^{\circ} \mathrm{C}\right)[6]$.

Fig. 4.17: Effect of strain on the percentage of austenite that transforms dynamically into ferrite and cementite at $753^{\circ} \mathrm{C}\left(\mathrm{Ae}_{3}+20^{\circ} \mathrm{C}\right)$ and $783^{\circ} \mathrm{C}\left(\mathrm{Ae}_{3}+\right.$ $50^{\circ} \mathrm{C}$ ) during deformation at $4 \mathrm{~s}^{-1}[6]$.

Fig. 4.18: Dependences of the ferrite plus cementite volume fraction and microhardness on $\Delta T$ (Experimental Temperature - $\mathrm{Ae}_{3}$ ). The specimens were deformed to strains of $\varepsilon=4.0$ at $4.0 \mathrm{~s}^{-1}$ and then quenched [6].

Fig. 4.19: (a) Scanning electron micrographs of $0.79 \% C$ steel strained to $\varepsilon=4.0$ at $4 \mathrm{~s}^{-1}$ at $763^{\circ} \mathrm{C}\left(\mathrm{Ae}_{3}+30^{\circ} \mathrm{C}\right)$, (b) and (c) TEM micrographs showing the presence of ferrite and cementite (diffraction patterns inset) [3]. 
Fig. 4.20: Schematic of a hot rolling mill illustrating the time available for DT to take place. Here a true strain of $\varepsilon=0.5$ (i.e. $35 \%$ reduction) is being applied at a strain rate of $100 \mathrm{~s}^{-1}$. Under these conditions, the time in the deformation zone is $5 \mathrm{~ms}$ and the elapsed time during a strain increment of $1 \%$ is about $100 \mu \mathrm{s}$ [3]. 76

Fig. 4.21: Estimated mean diffusion distances of (a) $\mathrm{C}$ and (b) $\mathrm{Mn}$ in ferrite over the experimental temperature range [6].

Fig. 4.22: Time scales for the three kinds of transformations [3].

Fig. 5.1: (a) Experimental stress-strain curve determined in torsion on the $0.79 \% \mathrm{C}$ steel deformed at $763^{\circ} \mathrm{C}$ (i.e. $\mathrm{Ae}_{3}+30^{\circ} \mathrm{C}$ ) at a strain rate of $4.0 \mathrm{~s}^{-1}$ to a strain of 4 . After the peak, the flow stress decreases due to the combined effect of DT and DRX. The yield stress $\sigma_{0}$ was defined using a total strain offset of 0.02 . The curve was fitted with a polynomial beginning at $\sigma_{0}$. (b) $\theta-\sigma$ plot derived from the fitted curve. Here the two $\sigma_{c}$ values are associated with two of the points of inflection. The '*' on the plot corresponds to the local maximum in the inset. 85

Fig. 5.2: Stress-strain curves determined in torsion on the (a) $0.06 \% \mathrm{C}$, (b) $0.09 \% \mathrm{C}$, (c) $0.21 \% \mathrm{C}$ and (d) $0.79 \% \mathrm{C}$ steels. The first two curves were determined at a strain rate of $0.4 \mathrm{~s}^{-1}$ and last two were at 4.5 and $4 \mathrm{~s}^{-1}$, respectively.

Fig. 5.3: $-(\partial \theta / \partial \sigma)$ vs. $\sigma$ plots at the various experimental temperatures of the (a) $0.06 \% \mathrm{C}$, (b) $0.09 \% \mathrm{C}$, (c) $0.21 \% \mathrm{C}$ and (d) $0.79 \% \mathrm{C}$ steels.

Fig. 5.4: Dependences of the critical strains for DT and DRX on $\Delta T$ (Experimental Temperature $-\mathrm{Ae}_{3}$ ) of the (a) $0.06 \% \mathrm{C}$, (b) $0.09 \% \mathrm{C}$, (c) $0.21 \% \mathrm{C}$ and (d) $0.79 \% \mathrm{C}$ steels. The fits to the DT points in these figures differ slightly from the versions of these diagrams published in Ref. 5.2.

Fig. 5.5: Effect of polynomial order on the second derivative/stress relationship according to the present (partial curve) method: (a) orders $2-6$; (b) orders 7 $15 ;$ (c) effect of order on the values of the critical strains.

Fig. 5.6: Effect of polynomial order on the second derivative/stress relationship according to the entire curve method: (a) orders $3-5$; (b) orders $6-11$; (c) orders $12-15$.

Fig. 5.7: Effect of order on the values of the critical strains.

Fig. 5.8: Dependences of the DT critical strain on $\Delta T$ in the three plain $C$ steels [2]. Note that the elevation of the nose above the conventional $\mathrm{Ae}_{3}$ increases with the alloy content and that the curve for the $0.20 \% \mathrm{C}$ steel is shown dashed, as more points are required to verify the tendency illustrated here.

101

Fig. 6.1: Mean flow stress as a function of $1000 / T$, where $T$ is the absolute pass temperature. Region 1 corresponds to the temperature range where 
recrystallization occurs after each pass; region II falls between the norecrystallization temperature $T_{n r}$ and $A_{r 3}{ }^{*}$, the upper critical temperature; region III is the intercritical temperature range; region IV lies below the $A_{r 1}{ }^{*}$, or lower critical temperature [4].

106

Fig. 6.2: Mean flow stress (MFS) values for the (a) $0.06 \% \mathrm{C}$, (b) $0.09 \% \mathrm{C}$, (c) $0.21 \% \mathrm{C}$ and (d) $0.79 \% \mathrm{C}$ steels displayed as a function of inverse absolute temperature $[6.8,6.11]$. The paraequilibrium and orthoequilibrium $\mathrm{Ae}_{3}$ temperatures are shown for comparison with the experimental suggested $A_{r 3} *$ temperatures. The broken lines in (a), (b) and (c) indicate the expected MFS behavior in the absence of dynamic transformation. The fits in these diagrams were drawn by fitting smooth curves to the experimental points.

108

Fig. 7.1: Experimental flow curve of austenite for Steel 4 at $743^{\circ} \mathrm{C}\left(\mathrm{Ae}_{3}+10^{\circ} \mathrm{C}\right)$ deformed to a strain of $\varepsilon=4.0$ at $4.0 \mathrm{~s}^{-1}$. The flow curve of the work hardened austenite was derived using the method of Jonas et al. [9]. The critical strain $\left(\varepsilon_{c}\right)$ for DT was determined using the method of Poliak and Jonas [10]. The ferrite flow curve is schematic.

120

Fig. 7.2: Dependence of the heterogeneity factor on strain at different values of $\Delta \mathrm{T}$ : (a) $0.06 \% \mathrm{C}$, (b) $0.09 \% \mathrm{C}$, (c) $0.21 \% \mathrm{C}$ and (d) $0.79 \% \mathrm{C}$ steels.

127

Fig. 7.3: Gibbs energy-composition diagrams for the $0.06 \% \mathrm{C}$ steel pertaining to (a) $897^{\circ} \mathrm{C}$ (i.e. $\mathrm{Ae}_{3}+20^{\circ} \mathrm{C}$ ) and (b) $917^{\circ} \mathrm{C}$ (i.e. $\mathrm{Ae}_{3}+40^{\circ} \mathrm{C}$ ) illustrating the Gibbs energy changes taking place during dynamic transformation.

129

Fig. 7.4: Gibbs energy-composition diagrams for the $0.09 \% \mathrm{C}$ steel pertaining to (a) $856^{\circ} \mathrm{C}$ (i.e. $\mathrm{Ae}_{3}+20^{\circ} \mathrm{C}$ ) and (b) $896^{\circ} \mathrm{C}$ (i.e. $\mathrm{Ae}_{3}+60^{\circ} \mathrm{C}$ ) illustrating the Gibbs energy changes taking place during dynamic transformation.

130

Fig. 7.5: Gibbs energy-composition diagrams for the $0.21 \% \mathrm{C}$ steel pertaining to (a) $862^{\circ} \mathrm{C}$ (i.e. $\mathrm{Ae}_{3}+40^{\circ} \mathrm{C}$ ) and (b) $892^{\circ} \mathrm{C}$ (i.e. $\mathrm{Ae}_{3}+70^{\circ} \mathrm{C}$ ) illustrating the Gibbs energy changes taking place during dynamic transformation.

132

Fig. 7.6: Gibbs energy-composition diagrams for the $0.79 \% \mathrm{C}$ steel pertaining to (a) $803^{\circ} \mathrm{C}$ (i.e. $\mathrm{Ae}_{3}+70^{\circ} \mathrm{C}$ ) and (b) $863^{\circ} \mathrm{C}$ (i.e. $\mathrm{Ae}_{3}+130^{\circ} \mathrm{C}$ ) illustrating the Gibbs energy changes taking place during dynamic transformation.

133

Fig. 7.7: Calculated quasi-binary paraequilibrium phase diagram for the $0.79 \% \mathrm{C}$ steel undergoing deformation compared with the conventional diagram for the undeformed material.

135

Fig. 7.8: Calculated quasi-binary paraequilibrium phase diagram for the $0.21 \% \mathrm{C}$ steel compared with that of the $0.79 \%$ C steel of Fig. 7.7.

Fig. 7.9: Calculated quasi-binary paraequilibrium phase diagram for the $0.06 \mathrm{C}$ $0.30 \mathrm{Mn}-0.50 \mathrm{Si}$ steel compared with that of the $0.79 \% \mathrm{C}$ steel of Fig. 7.7. 136 


\section{LIST OF TABLES}

Table 2.1. Comparison of hot rolling mills in terms of their ranges of strain rate and interpass time [3].

Table 3.1. Chemical compositions (mass \%) and $\mathrm{Ae}_{3}$ equilibrium transformation temperatures $\left({ }^{\circ} \mathrm{C}\right)$ of the steels investigated.

Table 4.1. Phase compositions (at\%) determined by APT based on the total number of atoms in the analyzed volume. The specimen was deformed in torsion to a strain of 4 at $4 \mathrm{~s}^{-1}$ at $763^{\circ} \mathrm{C}\left(\mathrm{Ae}_{3}+30^{\circ} \mathrm{C}\right)^{*}[8]$.

Table 4.2. The temperature ranges over which the various phases were observed in the four steels.

Table 7.1. Parameters employed in the calculations.

Table 7.2. Deformation stored energies of the $0.06 \% \mathrm{C}$ steel at selected experimental temperatures.

123

Table 7.3. Deformation stored energies of the $0.09 \% \mathrm{C}$ steel at selected experimental temperatures.

Table 7.4. Deformation stored energies of the $0.21 \% \mathrm{C}$ steel at selected experimental temperatures.

Table 7.5. Deformation stored energies of the $0.79 \% \mathrm{C}$ steel at selected experimental temperatures. 
Chapter 1

\section{Introduction}




\section{Introduction}

The dynamic transformation (DT) of austenite to ferrite has been receiving increasing attention ever since the classic work of Yada and co-workers in the late 1980's [1.1,1.2]. In addition to its practical importance, there is the challenge of accounting for the occurrence of the phase transformation at temperatures as much as $166^{\circ} \mathrm{C}$ above the normal equilibrium temperature as long as the austenite is being deformed [1.2]. They investigated the DT behavior of low C steels under both laboratory testing conditions and in pilot rolling mill trials. Another important feature they observed was the re-transformation of ferrite into austenite when it was held for increasing times after deformation above the $\mathrm{Ae}_{3}$. The rate of this reverse static transformation was much slower than that of the forward dynamic transformation [1.3]. In order to produce direct evidence for DT, Yada and co-workers deformed some steel samples in torsion in an x-ray diffraction apparatus [1.3]. In this way, they were able to confirm the occurrence of DT in real time.

This was followed over the next decade by a series of experiments [1.4-1.7] in which both the forward and reverse transformations were studied using laser dilatometry and other techniques and modeled using Monte Carlo simulation methods $[1.8,1.9]$. In the simulation work, authors allowed for the occurrence of dynamic recrystallization (DRX) as well as dynamic transformation (DT) during straining and their results indicate that both the mechanisms can take place concurrently. They found that DT is favored at the lower temperatures and higher strain rates and DRX under the opposite conditions.

The driving force for this kind of transformation has also been calculated by a number of authors $[1.10,1.11]$. Their calculations led to $\mathrm{Ae}_{3}$ increases of about $10^{\circ} \mathrm{C}$. Such small increases in the effective $\mathrm{Ae}_{3}$ are unable to account for the much larger temperature range over which the phenomenon of DT has been reported. 
Despite the appearance of these publications, many metallurgists are still skeptical about the idea that ferrite microstructures can be produced by deforming above the $\mathrm{Ae}_{3}$ temperature. The conventional view is that the ferrite is actually formed statically, below the $\mathrm{Ae}_{3}$, during quenching. This reaction is similar to that of the early critics of dynamic recrystallization (DRX), who maintained that the recrystallized structures allegedly produced during deformation were in fact formed statically during the quench to room temperature.

The reaction of the skeptics was the main motivation for the current work. In this investigation, the DT behavior of deformed austenite was studied systematically in four different steels of increasing carbon concentration. The experiments were conducted in torsion over the temperature range $743-917^{\circ} \mathrm{C}$ under an atmosphere of argon and $5 \% \mathrm{H}_{2}$. All the experimental temperatures were above the ortho- and para-equilibrium $\mathrm{Ae}_{3}$ temperatures of the steels. Strains of $0.15-$ 5 were applied at strain rates of $0.4-4.5 \mathrm{~s}^{-1}$.

A detailed literature review of this subject is presented in Chapter 2 . The compositions of the steels, the thermomechanical cycles to which they were subjected, and the various microstructural characterization techniques used in the current study are described in Chapter 3. The microstructural findings are described in Chapter 4, where it is concluded that the dynamically formed ferrite is nucleated in the form of Widmanstätten plates. This appears to take place displacively and the plates are gradually converted into approximately equiaxed grains during straining. In the next chapter (Chapter 5), the strains for the onset of both DT and DRX are determined analytically from the austenite flow curves using the double differentiation approach. Here it is shown that the occurrence of DT during the high temperature deformation of austenite is jointly responsible along with DRX for the shape of the familiar single peak flow curve and not just DRX alone. 
In Chapter 6, mean flow stresses (MFS's) are calculated from the experimental flow curves and plotted in the form of Boratto diagrams. Unexpectedly low values of MFS are detected above both the ortho- and para-equilibrium $\mathrm{Ae}_{3}$ temperatures of the steels, from which it is concluded that these drops can be ascribed to the DT of austenite to ferrite during deformation. The effect of deformation on the Gibbs energy of austenite is predicted in Chapter 7 by assuming that the austenite continues to work harden after the initiation of the transformation and that its flow stress and dislocation density can be estimated from the experimental flow curve for the two-phase material. The present calculations also indicate that the dislocation densities in the regions that experience transformation are 2 to 15 times higher than the average values. Finally, the conclusions stemming from the study as well as the contributions to original knowledge are stated in Chapters $\mathbf{8}$ and $\mathbf{9}$, respectively.

In summary, the previous workers have shown, by means of a thermodynamic analysis, that deformation can raise the $\mathrm{Ae}_{3}$ temperature by about $10^{\circ} \mathrm{C}$. However, in practice, increases of $100^{\circ} \mathrm{C}$ or even $150^{\circ} \mathrm{C}$ have been observed. It was therefore a principal aim of this work to try and find a theoretical justification for such increases. The secondary aim was to determine the characteristics of this type of dynamic transformation, i.e. the displacive vs. diffusional nature of the phase change. The third and final objective of the investigation was to consider how dynamic transformation can affect the operation and control of rolling mills.

\section{References}

$1.1 \mathrm{H}$. Yada, Y. Matsumura and T. Senuma; Proc. of the Int. Conf. on Martensitic Transformation, JIM (1986), p. 515.

1.2 H. Yada, Y. Matsumura and T. Senuma; Proc. 1st Conf. Physical Metallurgy of Thermomechanical Processing of Steels and Other Metals (THERMEC88), ed. by I. Tamura, ISIJ, Tokyo, (1988), p. 200.

1.3 H. Yada, C.M. Li and H. Yamagata; ISIJ Int., Vol. 40, (2000), p. 200. 
1.4 Y. Chen and Q. Chen; J. Iron Steel Res. Int., Vol. 10, (2003), p. 46.

1.5 Z. Liu, D. Li, S. Lu and G. Qiao; ISIJ Int., Vol. 47, (2007), p. 289.

1.6 H. Dong and X. Sun; Current Opinion in Solid State and Mater. Sci., Vol. 9, (2005), p. 269.

1.7 X. Sun, H. Luo, H. Dong, Q. Liu and Y. Weng; ISIJ Int., Vol. 48, (2008), p. 994.

1.8 M. Tong, D. Li, Y. Li, J. Ni and Y. Zhang; Metall. Mater. Trans. A, Vol. 35, (2004), p. 1565.

1.9 N. Xiao, M. Tong, Y. Lan, D. Li and Y. Li; Acta Mater., Vol. 54, (2006), p. 1265.

1.10 S.V. Parker; Ph.D. Thesis, Cambridge University, Cambridge, 1997.

1.11 D.N. Hanlon, J. Sietsma and S. van der Zwaag; ISIJ Int., Vol. 41, (2001), p. 1028. 
Chapter 2

\section{Literature Review}




\section{Literature Review}

Iron is one of the most abundantly available metals on the planet. Steel is the best known alloy of iron and the most important material produced in the world. The combination of low cost and high strength makes it suitable for the manufacture of a wide range of goods, from ships to cars, and for its use in the construction sector and household appliances. Although the basic constituents of steel are iron and carbon, depending on the use many alloying additions such as $\mathrm{Cr}, \mathrm{Co}, \mathrm{Mo}, \mathrm{Ni}, \mathrm{Ti}, \mathrm{Nb}$ etc. can be added to meet the application requirements. Apart from these, there are quite a few complex and interacting metallurgical requirements that must be taken into account while processing steel. A little change in composition, heat treatment or grain structure can have a significant influence on the final microstructure and thus properties. Therefore, it is necessary that these effects are fully understood before planning for a new steel grade or a process route.

\subsection{Hot Rolling Process}

The steel strip from which many products are manufactured is produced by hot rolling. A schematic of the hot rolling process is shown in Fig. 2.1 [2.1].

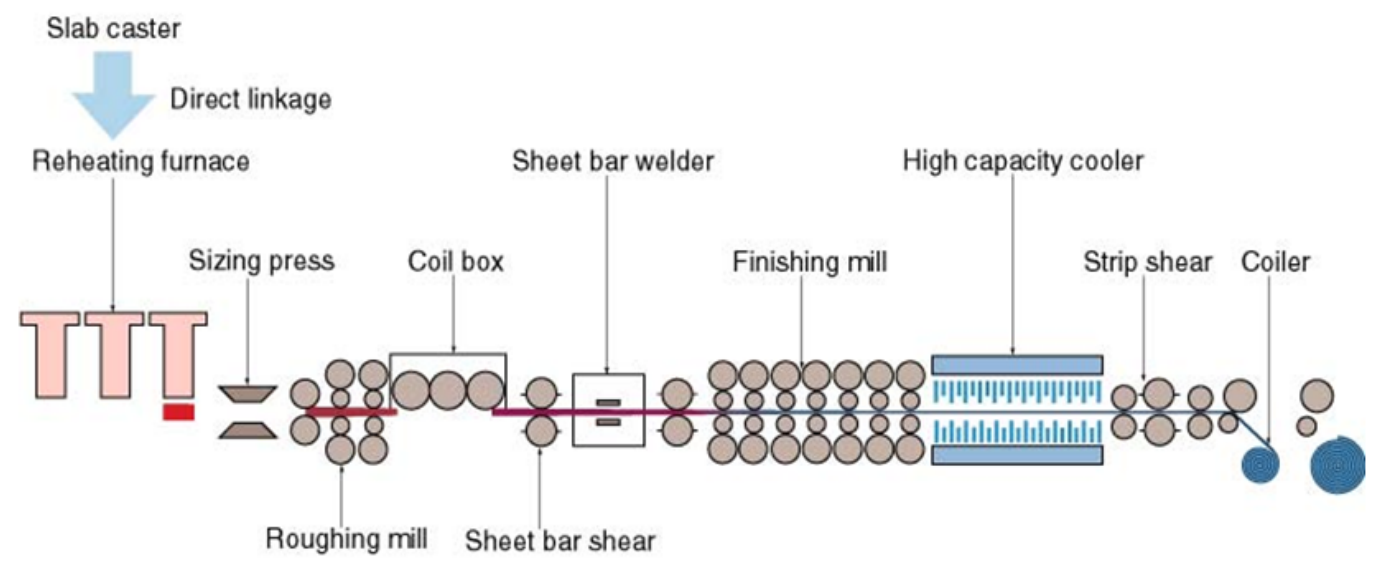

Fig. 2.1: Schematic layout of a hot rolling mill [2.1]. 
In this process, a cast steel billet or ingot is reheated in a reheating furnace to a temperature of around $1100-1250^{\circ} \mathrm{C}$, at which it is fully austenitic. The exact temperature of reheating varies with steel composition. It is then passed through a series of mill stands which reduce the billet to its final shape whilst still at high temperature in the austenitic state. In general, hot rolling process consists of rough rolling and finish rolling. The former is operated above the norecrystallization $\left(T_{n r}\right)$, while the latter is below the $T_{n r}$. As a result of this, during rough rolling, recrystallization proceeds rapidly. Controlling the strain and strain rate at this stage, repeated and completed recrystallization in austenite can take place which eventually lead to the refinement of austenite grains. However, there is a limit up to which grain refinement can occur by this repeated recrystallization. Further refinement is achieved during finish rolling, which is conducted between the $\mathrm{T}_{\mathrm{nr}}$ and the start of the austenite transformation temperature. Here, recrystallization is no longer complete and results in progressive elongation of the austenite grains. This is known as "austenite pancaking". It increases the grain surface area to grain volume which in turn increases the ferrite nucleation sites. Deformation also accelerates the nucleation rate. Formation of deformation bands and other substructures due to rolling provides additional nucleation sites, further enhancing the grain refinement process [2.2]. The steel sheet enters into the run-out table immediately after the finishing stands. Here it is cooled with water jets. The austenite microstructure and cooling rate determine the room temperature microstructure which in turn detects the final mechanical properties of the material. Therefore, depending on the final requirements of the steel, different kinds of cooling rates can be employed. Thus it is of utmost importance to carefully control the hot rolling process to ensure the correct combination of final properties.

Depending on strain rate and interpass time there are different kinds of hot rolling mill available; a list is given in Table 2.1 [2.3]. 
Table 2.1. Comparison of hot rolling mills in terms of their ranges of strain rate and interpass time [2.3].

\begin{tabular}{|c|c|c|}
\hline Mill Type & Strain Rate Range $\mathbf{s}^{\mathbf{- 1}}$ ) & Interpass Time (s) \\
\hline $\begin{array}{c}\text { Reversing Mills (plate, } \\
\text { roughing etc.) }\end{array}$ & $1-30$ & $8-20$ \\
\hline Hot Strip Mills & $10-200$ & $0.4-4$ \\
\hline Wire Rod Mills & $10-1000$ & $0.010-1$ \\
\hline
\end{tabular}

In rolling, softening and hardening occur alternately. In order to understand the process of rolling more clearly, it is important to know these in greater detail. Thus these are reviewed below.

\subsubsection{Recovery}

The strain energy of the matrix is released by the rearrangement of dislocations and defects during or after plastic deformation before the recrystallization process begins. This restoration phenomenon is termed as recovery. The recovery stage is primarily concerned with the rearrangement of these defects to reduce the lattice energy and does not involve the migration of high angle boundaries. The process is achieved by thermal activation i.e. with an increase in temperature, the rate of recovery increases. Depending on whether the process occurs during deformation or afterwards, it is divided into two categories, namely, dynamic and static. The recovery process leads to the formation of subgrains from the dislocations which become sharper as it progresses.

\subsubsection{Recrystallization}

Recrystallization is a process by which deformed grains are replaced by new strain-free, equiaxed grains. The new grains nucleate and grow until the original grains have been fully consumed. Again depending on the deformation conditions and temperature, recrystallization can be subdivided into three categories, namely, static, dynamic and metadynamic recrystallization. 


\subsubsection{Static Recrystallization}

Static recrystallization (SRX) is the most important of the softening mechanisms that occur after unloading. Despite the annihilation of dislocations by dynamic recovery, dislocations are accumulated during deformation. If the accumulated strain exceeds a certain critical value, static recrystallization can then take place by the nucleation and growth of dislocation-free grains. The nucleation process is thermally activated and requires an incubation time for nuclei to form. The recrystallization time decreases with increasing strain and deformation temperature. Increasing strain rate also introduces higher dislocation density and therefore higher driving force. However, this is marginal compared to the effect of strain [2.4].

\subsubsection{Dynamic Recrystallization}

Dynamic recrystallization (DRX) is a commonly observed softening mechanism that occurs concurrently with deformation. The typical characteristic flow curve of dynamic recrystallization is shown in Fig. 2.2 [2.5]. In this figure, it can be seen that the onset of DRX lies at a strain below the peak strain $\left(\varepsilon_{\mathrm{p}}\right)$ known as the critical strain $\left(\varepsilon_{c}\right)$. Once the applied strain exceeds $\varepsilon_{C}$, DRX softening takes place causing a peak at a strain $\varepsilon_{p}$, followed by a drop in stress. The critical strain ranges in most cases, between 0.65 to $0.8 \varepsilon_{\mathrm{p}}$. An increase in strain beyond $\varepsilon_{\mathrm{p}}$ results in an increase in the volume fraction of dynamically recrystallized grains, and a decrease in the stress occurs until a steady state is reached $\left(\sigma_{s s}\right)$. At this point, there is a balance between the generation of new strain-free grains and the work hardening of dynamically recrystallized grains.

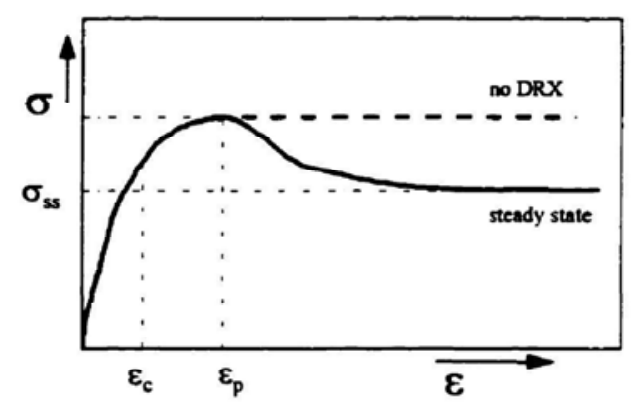

Fig. 2.2: Effect of DRX given by stressstrain curve during hot working [2.5]. 


\subsubsection{Metadynamic Recrystallization}

Metadynamic recrystallization (MDRX) results from the continued growth after unloading of the recrystallized austenite grain nuclei formed during deformation. MDRX is generally observed in hot deformation schedules when the peak strain level is achieved or exceeded. Once deformation is interrupted, the dynamically evolved nuclei can grow metadynamically. A transition strain $\varepsilon_{\mathrm{T}}$, can be introduced which lies between $\varepsilon_{\mathrm{P}}$ and $\varepsilon_{\mathrm{SS}}$. For strains $\varepsilon_{\mathrm{C}}<\varepsilon<\varepsilon_{\mathrm{T}}$, a mixture of static and metadynamic recrystallization occurs after deformation [2.6,2.7]. For $\mathrm{Nb}$ microalloyed steels with a coarse initial austenite grain size, $\varepsilon_{\mathrm{T}}$ has been estimated as $\varepsilon_{\mathrm{T}}=2.2 \varepsilon_{\mathrm{C}}$ [2.8]. This process does not involve an incubation time, since the nuclei are already present upon termination of the deformation. As mentioned before, SRX has a strong dependence on strain and temperature, less on strain rate. Conversely, MDRX is highly sensitive to strain rate, but not to strain [2.9]. At an identical strain rate, the grain size produced by MDRX is much finer than that produced by SRX, but larger than that of DRX by a factor of 1.5 or more [2.10].

\subsection{Iron-Carbon Phase Diagram}

The equilibrium phases present in the steel at each temperature as a function of composition can be represented by the phase diagram for the alloy. Fig. $\mathbf{2 . 3}$ represents the binary Fe-C phase diagram and displays the different phases that are stable in the different temperature ranges. In pure iron, at temperatures between $910^{\circ} \mathrm{C}$ and $1390^{\circ} \mathrm{C}$, the iron is fully austenitic. As it is alloyed with increasing amounts of carbon, the austenite is stabilized to lower temperatures. It reaches a minimum at the eutectoid composition, $0.8 \mathrm{wt} . \%$ carbon. This phase boundary is known as the $\mathrm{Ae}_{3}$ line. Below the $\mathrm{Ae}_{3}$ temperature, ferrite $(\alpha)$ starts to form from the austenite, and its volume fraction increases as the temperature decreases until all the austenite has transformed at the $\mathrm{Ae}_{1}$ temperature. This temperature is $723^{\circ} \mathrm{C}$ for the $\mathrm{Fe}-\mathrm{C}$ system. The maximum solubility of carbon in 


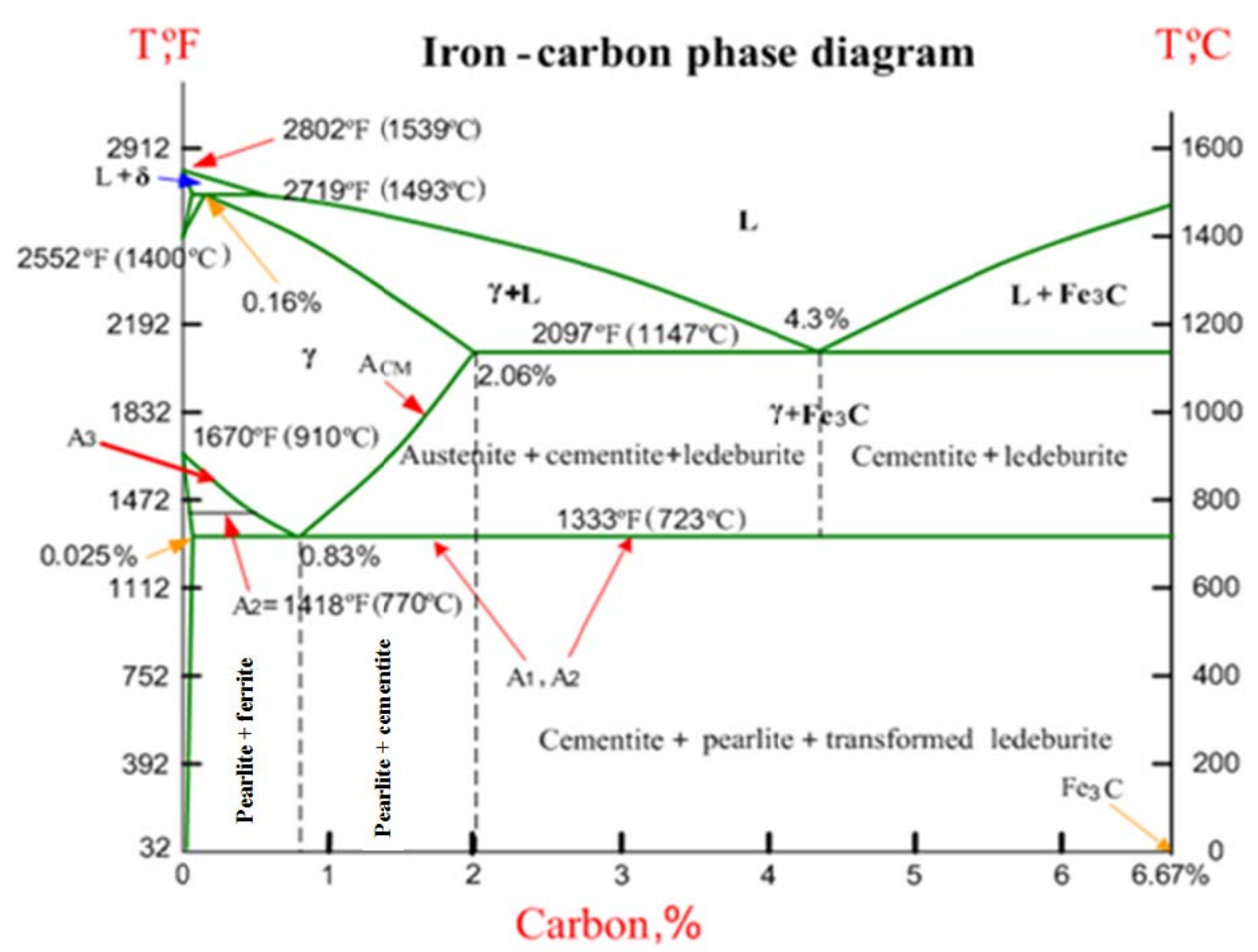

Fig. 2.3: Fe-C phase diagram, indicating the phases that are thermodynamically stable as a function of carbon concentration and temperature [2.11].

austenite is $2.14 \mathrm{wt} . \%$, while the same is very low, with a maximum of $0.02 \mathrm{wt} . \%$ at $723^{\circ} \mathrm{C}$ in ferrite. At higher carbon levels, the excess carbon is rejected from the ferrite into the austenite. Below $\mathrm{Ae}_{1}$ any remaining austenite transforms to pearlite, a lamellar mixture of ferrite and cementite $\left(\mathrm{Fe}_{3} \mathrm{C}\right)$. Thus, at room temperature the equilibrium microstructure of a hypo-eutectoid steel $\quad<0.8$ wt.\% carbon) consists of a mixture of ferrite and pearlite, the exact proportions dependent upon the carbon content of the steel. Steels are often alloyed with many elements other than carbon in order to achieve the wide range of properties demanded by different applications. All these additions, like carbon, also affect the free energies of the phases so that the multi-component phase diagram will differ appreciably from the basic $\mathrm{Fe}-\mathrm{C}$ phase diagram. The relative stabilities of austenite and ferrite are affected and the "ferrite stabilizers" are those that promote ferrite formation while the others are known as "austenite stabilizers" [2.12]. 


\subsection{Phase Transformation of Austenite}

The phase fields identified in the phase diagram are for equilibrium conditions only. However, the cooling rates employed during steel processing are usually too fast for actual equilibrium to be achieved. This leads to the formation of several non-equilibrium phases, which are often desirable in certain grades of steels. Two types of phase transformation are possible - reconstructive and displacive [2.12].

\subsubsection{Reconstructive Transformation}

Diffusion of all atoms takes place in this kind of transformation. The parent crystal lattice changes by an uncoordinated movement of atoms ("civilian") to form the product structure. It occurs at temperatures close to $\mathrm{Ae}_{3}$, where atomic mobility is sufficiently high for diffusion to occur readily. The diffusion of the solute atoms during the transformation is generally the rate controlling step of the whole process. Allotriomorphic ferrite and pearlite both form in this manner.

\subsubsection{Allotriomorphic Ferrite}

Allotriomorphic ferrite is an important phase in low alloy steels. It is the first phase to form from austenite at temperatures below the $\mathrm{Ae}_{3}$ and thus it determines the amount and composition of the austenite remaining for subsequent transformation to other phases. It is recognized by its well defined equiaxed shape and can be easily detected in the microscope [2.13]. Some authors also divide the ferrite into allotriomorphic and idiomorphic ferrite according to the place of location in the microstructure [2.14].

The most important nucleation sites are the prior austenite grain boundaries and the surfaces of inclusions as these are the higher energy sites. At small undercoolings below $\mathrm{Ae}_{3}$, allotriomorphic ferrite nucleates at the prior austenite grain boundaries, forming layers which follow the grain boundary contours (see

Fig. 2.4). By contrast, idiomorphs are embedded within the austenite grain and 


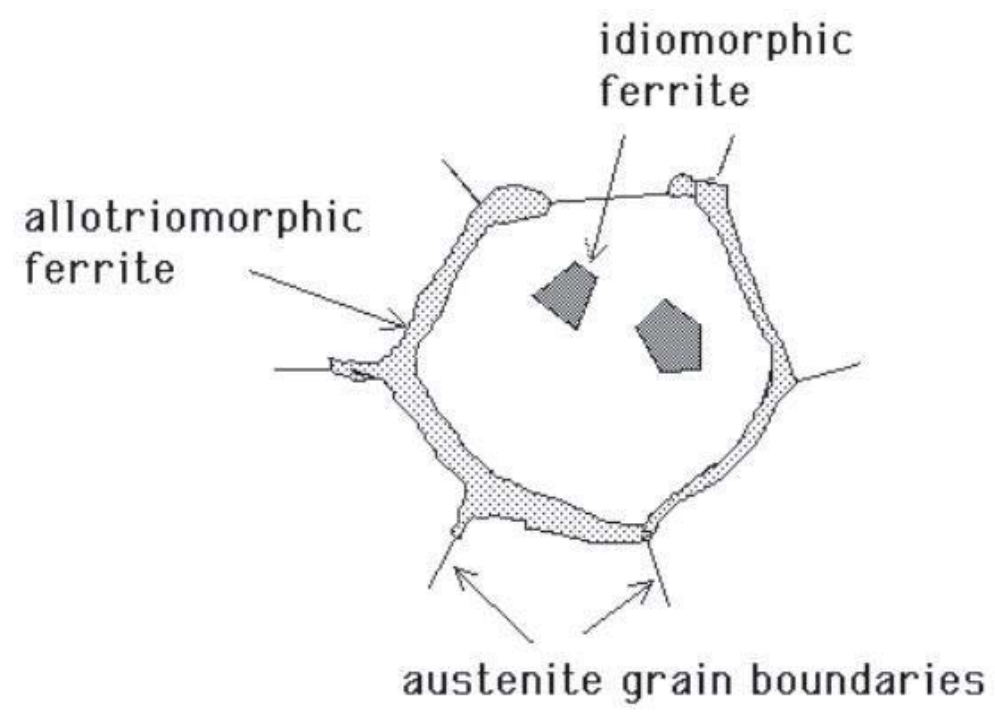

Fig. 2.4: Formation of allotriomorphic and idiomorphic ferrite [2.14].

they nucleate without any contact with the prior austenite grain boundaries. They tend to nucleate heterogeneously on the non-metallic inclusions that are inherently present in the steel [2.14].

\subsubsection{Pearlite}

Pearlite is the lamellar structure of ferrite and cementite $\left(\mathrm{Fe}_{3} \mathrm{C}\right)$ that forms below the eutectoid temperature $\left(723^{\circ} \mathrm{C}\right.$ in plain carbon steels). The initiation process for the development of a pearlitic microstructure entails the formation of neighboring nuclei of ferrite and cementite on an austenite grain boundary. The nucleation of pearlite occurs in two stages. First, a cementite plate nucleates at the grain boundary and grows inwards into one of the austenite grains. As the cementite plate thickens, the carbon content of the austenite on either side of the cementite plate decreases. When it falls to a critical value, two ferrite plates, one on either side of the cementite plate, nucleate. They grow by rejecting carbon in excess of $0.02 \%$ into the adjacent austenite, thereby enriching it. As the carbon content of the austenite increases to a critical value, two cementite plates nucleate on either side and grow. Thus the sidewise nucleation of pairs of lamellae continues in a pearlitic colony [2.15]. 
The edgewise growth of pearlite is illustrated in Fig. 2.5. In the austenite ahead of the growing plates, the carbon content opposite to a ferrite plate is higher than at a point opposite to the next cementite plate. Carbon diffuses down this concentration gradient, as indicated by arrows in the Fig. 2.5 [2.16].

Different pearlite colonies have different lamellae orientations as shown in Fig. 2.6. As the transformation progresses, neighboring colonies of lamellae join together and continue to advance into the austenite, such that when the transformation occurs at low degrees of undercooling the colony groups advance by a boundary that is roughly spheroidal in shape, leading to the formation of a pearlite nodule. Eventually, as the nodules continue to grow, they impinge on one another to complete the transformation [2.15].

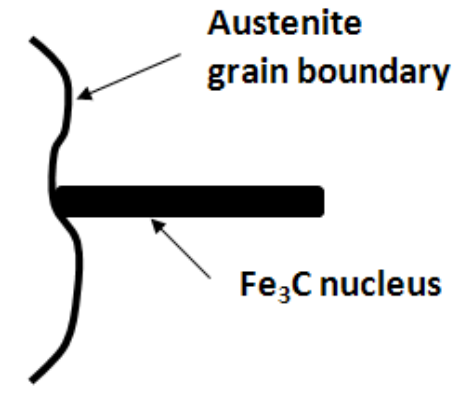

(a)

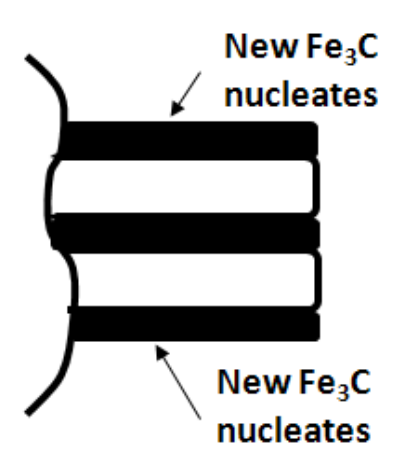

(c)

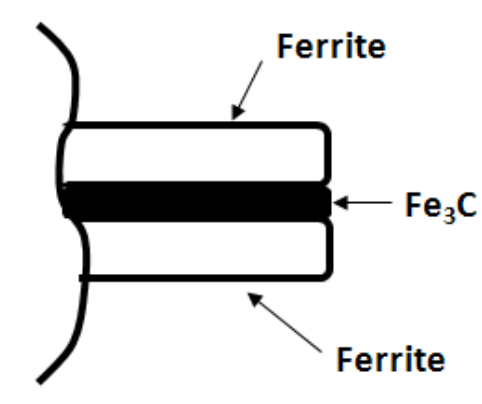

(b)

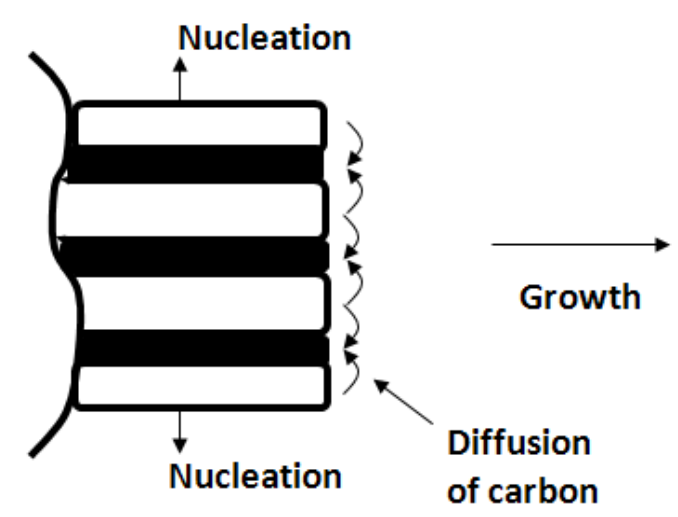

(d)

Fig. 2.5: Schematic representation of pearlite formation by nucleation and growth; (a) through (d) indicate successive steps in time sequence [2.16]. 


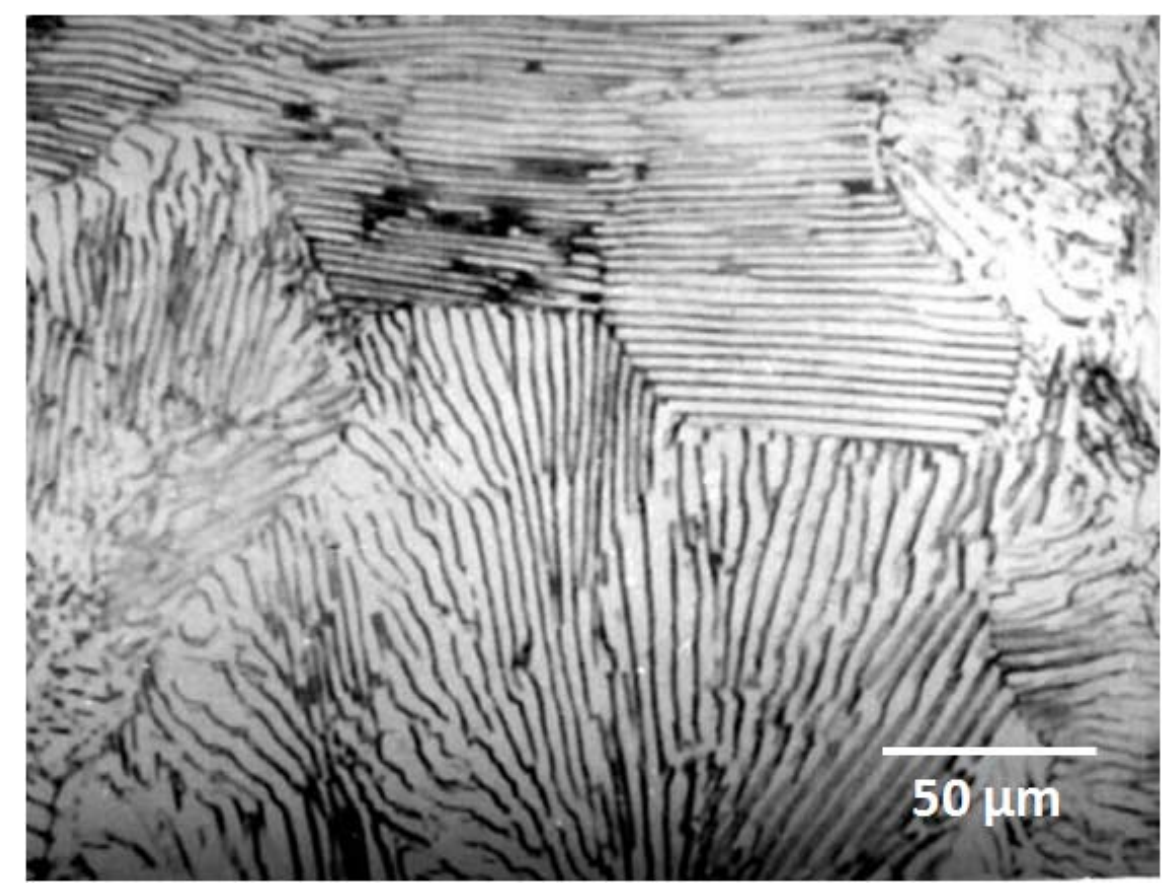

Fig. 2.6: Microstructure of pearlite.

\subsubsection{Displacive Transformation}

Displacive transformations involve a coordinated ("military") motion of atoms to generate the product phase crystal structure. They occur at temperatures where diffusion is sluggish and are favored during rapid cooling when there is insufficient time for atoms to diffuse. The transformation is actually a deformation, as no atomic bonds are broken. Thus there is a strain energy that must be overcome for growth of the phase to occur. Bainite and martensite are formed by this mechanism. Widmanstätten ferrite is also considered to nucleate displacively, but carbon diffusion is required for its growth.

\subsubsection{Widmanstätten Ferrite}

Widmanstätten ferrite $\left(\alpha_{w}\right)$ is a phase formed by the transformation of austenite below the $\mathrm{Ae}_{3}$ temperature. It often forms simultaneously and competitively with allotriomorphic ferrite and pearlite. However, it can also occur at temperatures where the reconstructive transformations are sluggish due to the very low mobility of atoms. It nucleates heterogeneously, either directly from 


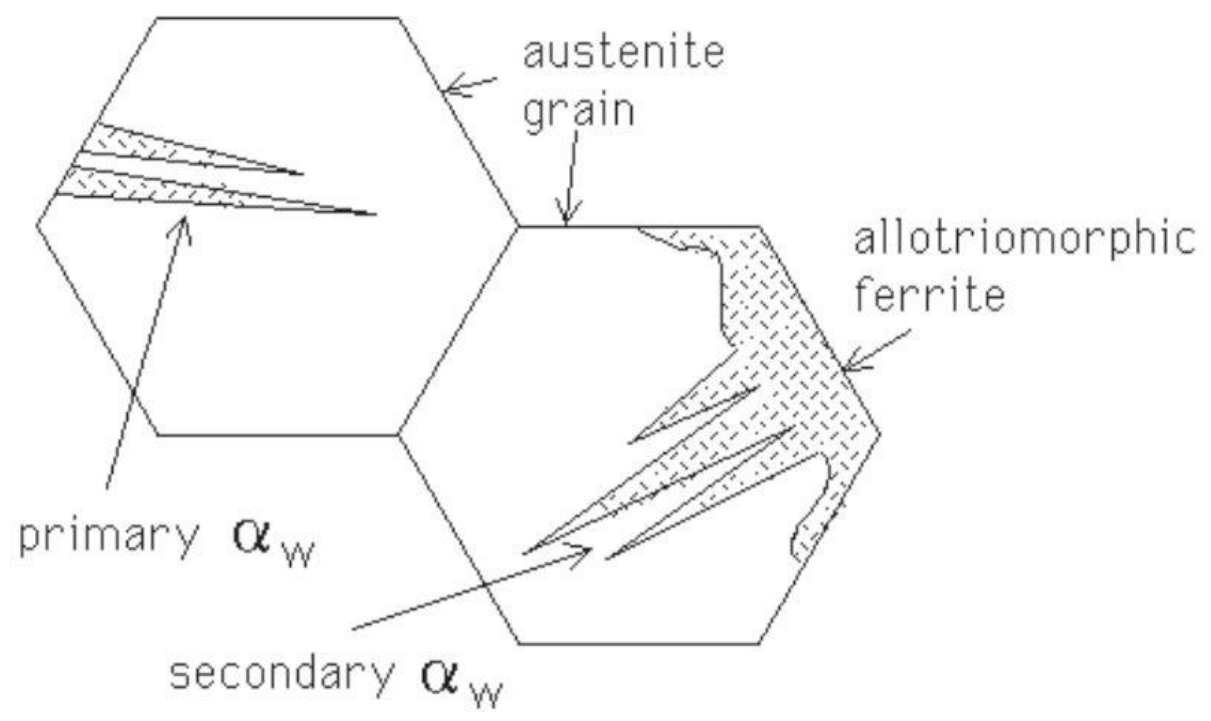

Fig. 2.7: Formation of Widmanstätten ferrite [2.17].

the austenite grain boundaries (primary Widmanstätten ferrite), or on the austenite/allotriomorphic ferrite interfaces (secondary Widmanstätten ferrite). This is clearly shown in Fig. 2.7. When examined optically, it takes the form of long, thin pointed plates, often emanating in parallel packets from the grain boundaries, or as plates growing from alternate sides of the boundary. The interstitial carbon atoms are able to diffuse during growth without affecting the shape change [2.17].

\subsubsection{Bainite}

Bainite consists of a non-lamellar aggregate of ferrite and carbides and generally forms at temperatures lower than Widmanstätten ferrite. It is usually classified into two categories. Upper bainite forms at relatively high temperatures and consists of fine, bainitic ferrite laths surrounded by carbide particles, the latter having formed from the carbon-enriched residual austenite surrounding the laths. At the higher temperature of formation upper bainite closely resembles finely spaced Widmanstätten side-plates. As the temperature decreases the bainitic laths become narrower so that individual laths may only be resolved by 
electron microscopy. At the highest temperatures where pearlite and bainite grow competitively in the same specimen, it becomes difficult to distinguish the two structures. Both appear as alternate layers of cementite in ferrite. The discontinuous nature of the bainitic carbides does not reveal the difference since pearlitic cementite can also appear as broken lamellae. However, the greatest difference between the two constituents lies in their crystallography. The ferrite and cementite in pearlite do not possess any specific orientation relationship with the parent austenite grain in which they are growing. This is not the case with bainite where the ferrite and cementite do have an orientation relationship with the parent grain [2.12].

At sufficiently low temperatures below $\sim 350^{\circ} \mathrm{C}$, the microstructure of bainite changes from laths into plates and the carbide dispersion becomes much finer. This is known as lower bainite. In this case, the cementite forms with an orientation relationship to the ferrite, which implies that the carbide precipitates within the ferrite plates at the advancing interface. At these low temperatures carbon diffusion is so slow that the ferrite plates thicken most rapidly by the repeated precipitation of cementite at the interface. This removes the excess carbon in the austenite allowing the interface to advance a small amount before the carbon concentration builds up again [2.12].

In bainite, each sheaf (which is essentially the ferrite plate) forms in a wedgeshaped plate on a macroscopic scale. Again each sheaf is an aggregate of parallel platelets called sub-units. This is shown in Fig. 2.8. The sheaves almost inevitably nucleate heterogeneously at the austenite grain boundaries and grow into the austenite grains. It is suggested that after nucleation the growth occurs rapidly without diffusion. As soon as the growth is arrested the excess carbon in the bainitic ferrite is partitioned into the residual austenite [2.18]. 


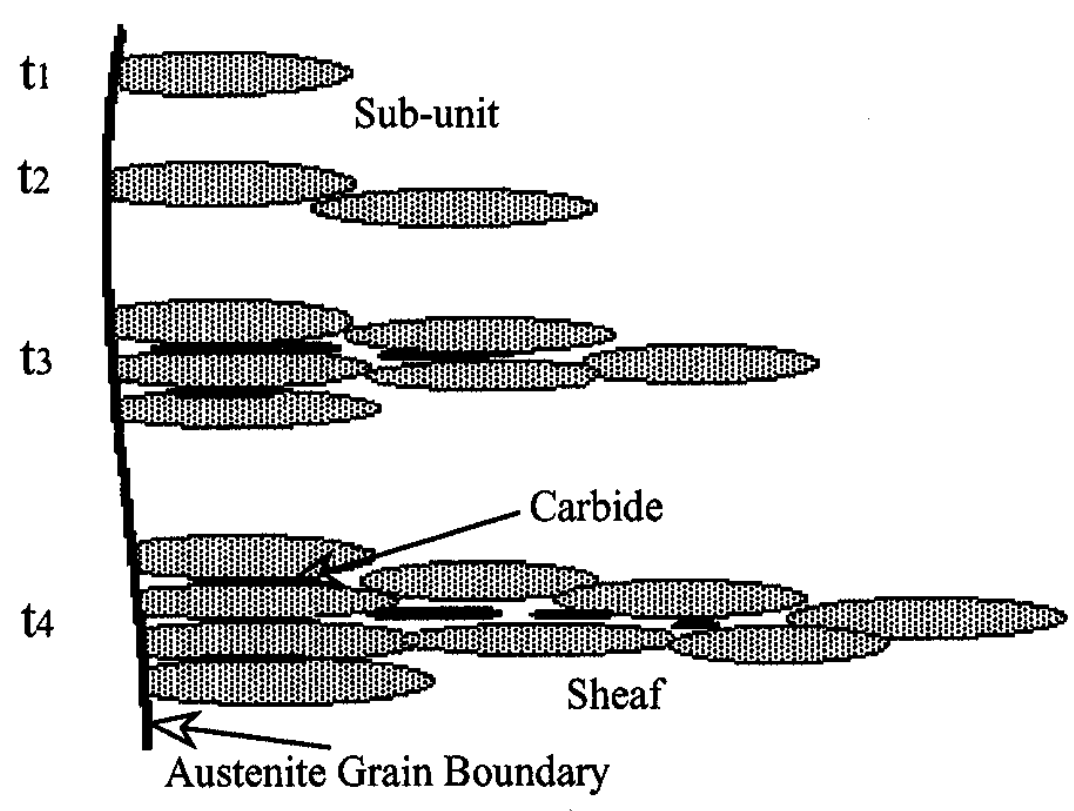

Fig. 2.8: Schematic representation of bainite formation [2.18].

\subsubsection{Martensite}

Martensite is a very hard phase usually formed by the rapid quenching of austenite to room temperature. It consists of a supersaturated solid solution of carbon in ferritic iron. The martensite forms with the same composition as the austenite by a diffusionless shear mechanism, with not even the carbon atoms able to partition. The carbon trapped within the interstices distorts the ferrite lattice, leading to strains that harden the material. Optically, martensite has a lath-like or lenticular morphology. Martensite starts to form at a well defined temperature (below the bainitic range) called $M_{s}$ (martensite start). The amount of martensite that forms is a function of the temperature to which the steel is cooled below $M_{s}$ and not of the time of holding at that temperature. The fraction of martensite formed increases slightly at first just below $M_{s}$ and then more rapidly with falling temperature. The transformation tails off again and is virtually complete at the $M_{f}$ (martensite finish) temperature. A single plate of martensite in steel grows in pico-seconds to its full size, at velocities approaching the speed of sound [2.12,2.19]. 


\subsection{Effect of Deformation on Austenite Phase Transformation}

The two basic means for solid state processing of steels are deformation and phase transformation. The former is characterized by strain, strain rate and temperature. Originally deformation and transformation were thought to be independent and thus were utilized separately to acquire the desired shape and properties, respectively. From the 1950's, the possible effect of deformation on subsequent phase transformations was realized. Subsequently, in the 1960's, the idea of Thermo Mechanical Controlled Processing (TMCP) was developed coupled with grain refinement, the only method that can improve both the strength and toughness of steels simultaneously. Since the 1980's, TMCP has become widely accepted as a popular industrial technology [2.20,2.21]. In 1981, Priestner et al. proposed that the $\gamma \rightarrow \alpha$ transformation taking place during deformation be termed "Strain Induced Transformation to Ferrite" [2.22]. In the next decade, researchers such as Hodgson [2.23], Lee [2.24], Choo [2.25] etc. used different terminologies such as "Deformation Induced Ferrite Transformation" (DIFT) [2.22,2.23].

This has also been referred as the dynamic transformation (DT) of austenite to ferrite, a topic that has been receiving increasing attention since the pioneering work of Yada and co-workers in the late 1980's [2.26,2.27]. In addition to its practical importance, there is the challenge of accounting for the occurrence of the phase transformation at temperatures as much as $166^{\circ} \mathrm{C}$ above the normal equilibrium temperature [2.27]. A second important issue concerns the possibility that the ferrite structures observed metallographically were produced below the $\mathrm{Ae}_{3}$ and during quenching or cooling to room temperature. These two aspects are considered in some detail below.

In their 1986 paper [2.26], Yada et al. showed that DT ferrite could be produced above the paraequilibrium $\mathrm{Ae}_{3}$ in three plain carbon $(0.003,0.11$ and $0.14 \% \mathrm{C})$ steels and that the diameters of the grains formed in this way ranged from 1 to 2 
$\mu \mathrm{m}$. Straining was done in plane strain compression and strain rates up to $250 \mathrm{~s}^{-1}$ were used together with quench times of $0.056 \mathrm{~s}$. Beyond a critical strain, the ferrite volume fraction increased with the applied strain, but decreased with the temperature of the experiment. Fig. 2.9 shows a transmission electron micrograph of the $0.11 \% \mathrm{C}$ steel which was quenched immediately after $75 \%$ deformation at $800^{\circ} \mathrm{C}$ (i.e. $13^{\circ} \mathrm{C}$ above the $A_{r 3}$ ) at a strain rate of $50 \mathrm{~s}^{-1}$ [2.26]. The fine grains in the structure were ascertained to be ferrite by selected area diffraction. The ferrite has a high dislocation density and contains fine cementite particles. Cementite films were also seen along the interfaces of the grains. During the formation of such DT ferrite, the sample flow stress decreased below the level expected for austenite deformation at the temperature of interest. They suggested that the driving force for this transformation was the energy stored in the deformed austenite. Because of the fine scale of the microstructure,

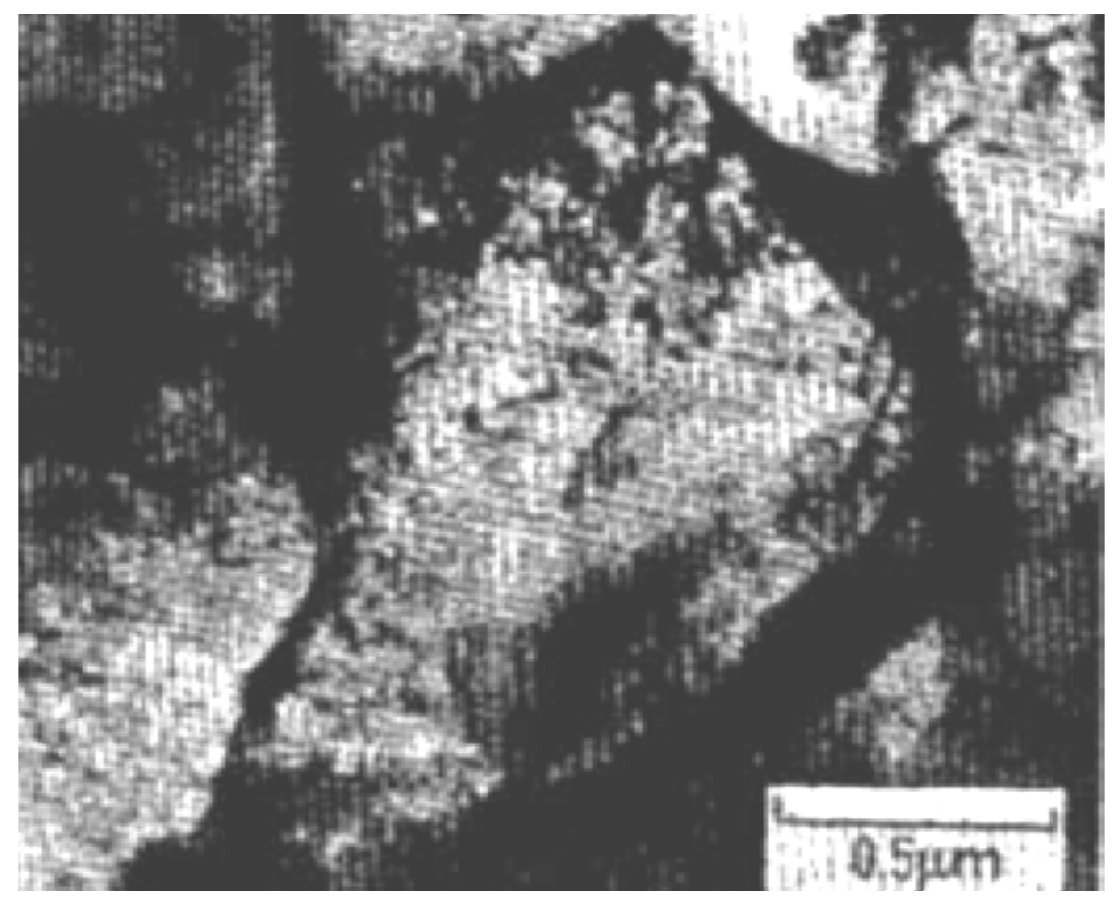

Fig. 2.9: Thin foil transmission electron micrograph of the $0.11 \% \mathrm{C}$ steel quenched immediately after $75 \%$ deformation at $800^{\circ} \mathrm{C}$ (i.e. $13^{\circ} \mathrm{C}$ above the $A_{r 3}$ ) at a strain rate of $50 \mathrm{~s}^{-1}$ [2.26]. 
the very short times involved in their formation, as well as the high densities of dislocations that were present in the ferrite, they concluded that their microstructures resulted from a massive transformation.

In their 1988 paper [2.27], Yada et al. described some strip mill simulations, in which interpass times of about $1 \mathrm{~s}$ were employed, together with strain rates above and below $100 \mathrm{~s}^{-1}$ and rolling was carried out above the paraequilibrium $\mathrm{Ae}_{3}$. These led to microstructures similar to those described above. They also performed isothermal holding experiments, in which samples were maintained for increasing times after deformation by axisymmetric compression above the $\mathrm{Ae}_{3}$. Fig. 2.10 is a quantitative representation of these experiments carried out at different temperatures. At both temperatures, the volume fraction of ferrite decreased with holding time. Using a dilatometer, they showed that the DT ferrite reverted to austenite, although the rate of reverse static transformation was much slower than that of the forward dynamic transformation. Thus a fairly long holding time led to the complete disappearance of the ferrite. There was

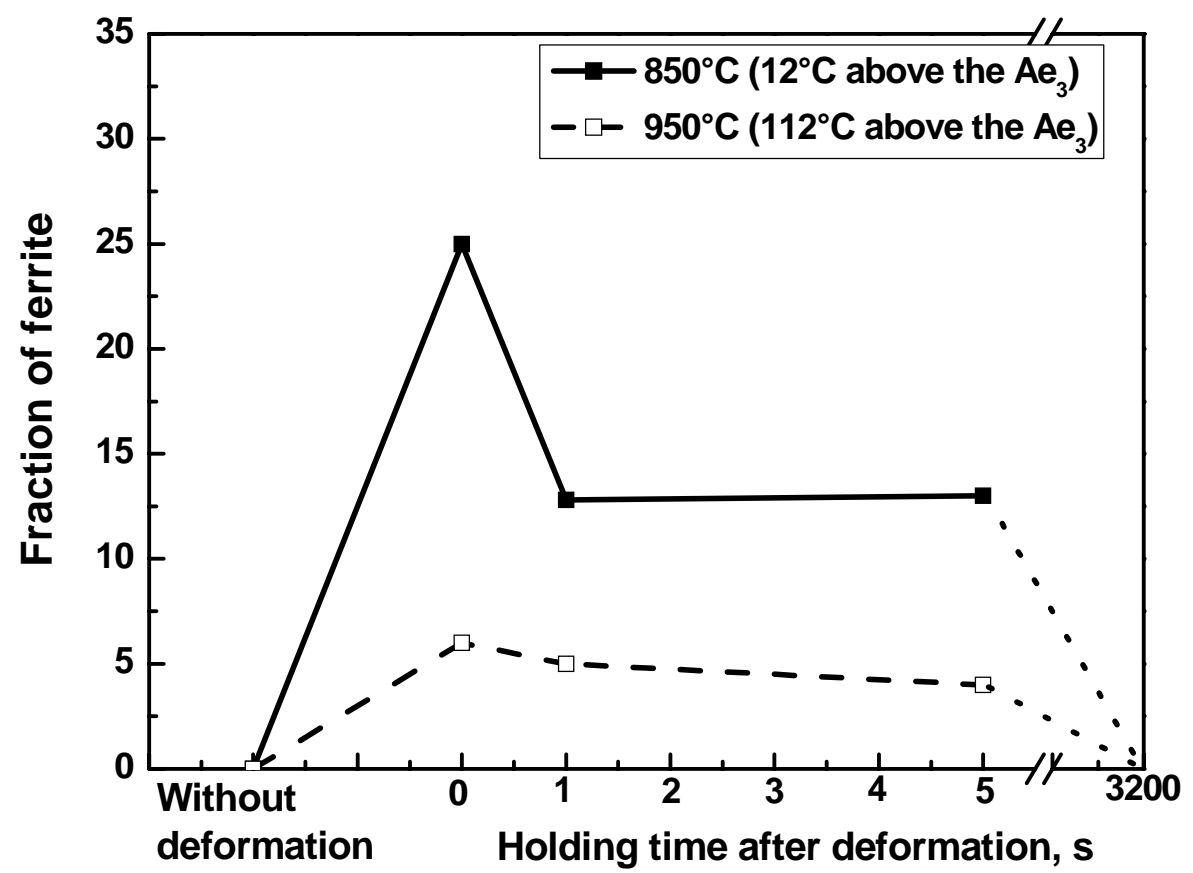

Fig. 2.10: Change in ferrite fraction produced by isothermal holding above the paraequilibrium $\mathrm{Ae}_{3}$ after hot deformation [2.27]. Dotted lines added by author. 
some indication that the critical strain for the formation of DT ferrite increased with the magnitude of the temperature interval above the $\mathrm{Ae}_{3}$. Another observation of interest was that the ultrafine "massive" ferrite was replaced by coarser polygonal ferrite during holding times of 2 to $5 \mathrm{~s}$.

Yada and co-workers returned to the topic of dynamic transformation in 2000 [2.28], when they deformed three Fe-C alloys containing different $C$ levels and about $6 \% \mathrm{Ni}$ in each case. The latter was added so as to reduce the paraequilibrium $\mathrm{Ae}_{3}$ temperatures to 697,680 and $654^{\circ} \mathrm{C}$. In this way, they were able to deform their samples in torsion above the $\mathrm{Ae}_{3}$ while carrying out in-situ xray experiments to determine the phases that were present or being formed in real time. By this means, they were able to verify that the ferrite observed microstructurally after quenching was being produced dynamically in a steel that was originally fully austenitic. The schematic setup of the in-situ X-ray diffraction experiment performed by them during torsional deformation is presented in Fig. 2.11. In that experiment they used $45 \mathrm{kV}$ of accelerating voltage coupled with $280 \mathrm{~mA}$ of current. These experiments were conducted at a strain rate of $0.09 \mathrm{~s}^{-1}$ and at temperatures as much as $40^{\circ} \mathrm{C}$ above the $\mathrm{Ae}_{3}$ [2.28]. Some typical in-situ X-ray diffraction patterns obtained by these researchers are reproduced in Fig. 2.12. This experiment was conducted at $720^{\circ} \mathrm{C}$, which was $40^{\circ} \mathrm{C}$ above the $\mathrm{Ae}_{3}$ temperature of the particular steel.

Fig. 2.12(a) shows the pattern of the specimen before heating where only a strong diffraction line corresponding to $(110)_{\alpha-F e}$ is observed. On the other hand, a line for $(111)_{Y-\mathrm{Fe}}$ in the pattern is visible in Fig. 2.12(b) when the sample was fully austenitized. When deformation was applied at this temperature, another line appeared, which corresponds to the $(110)_{\alpha-\mathrm{Fe}}$ line. This is exhibited in Fig. 2.12(c). In this work, higher temperatures of dynamic transformation were observed when the strain rate was increased. The flow stresses in these experiments were again lower than those associated with fully austenitic 
samples and ferritic microstructures similar to those described above were observed.

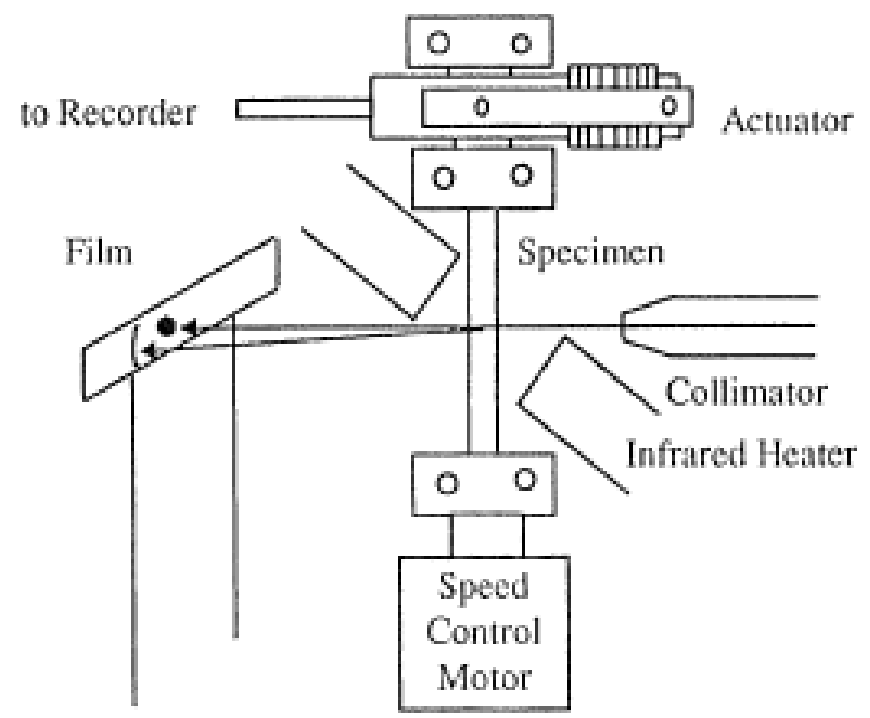

Fig. 2.11: A schematic diagram of the in-situ X-ray experimental setup [2.28].
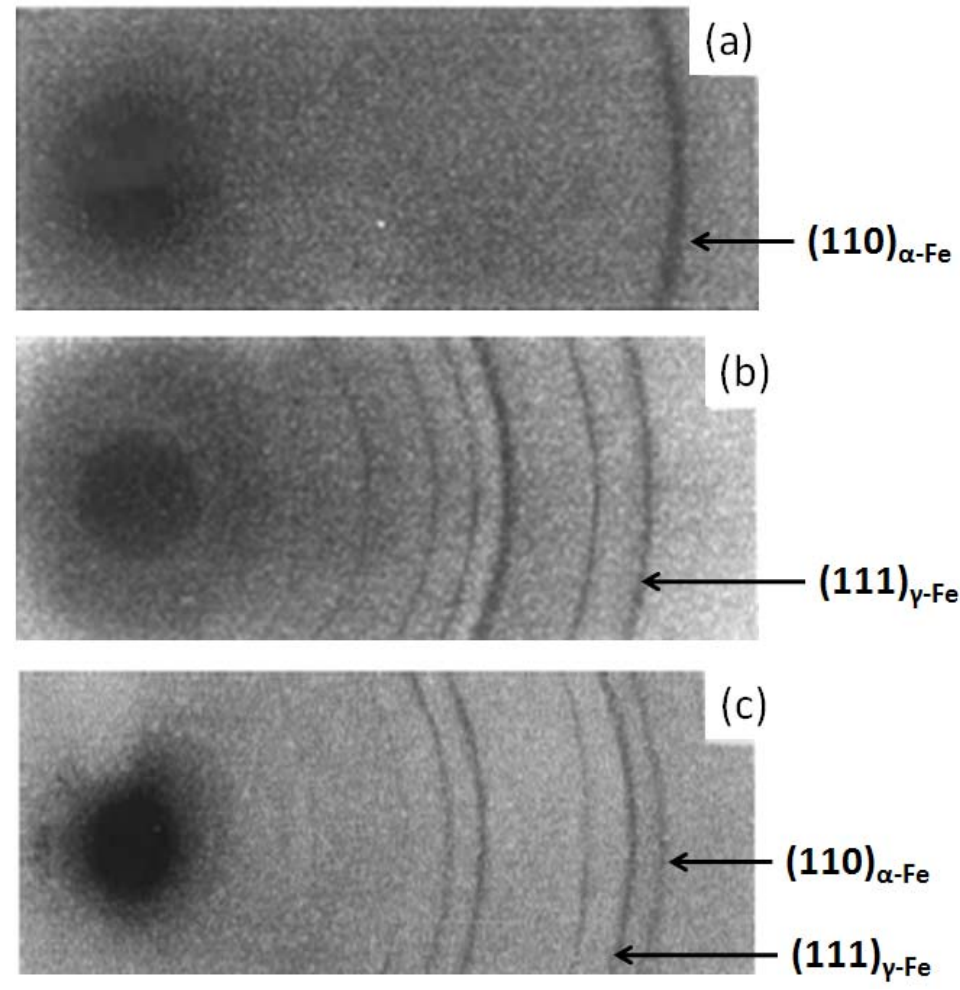

Fig. 2.12: Typical X-ray diffraction patterns (a) before heating, (b) at the austenitizing temperature, and (c) on the application of torsional deformation at the austenitizing temperature [2.28]. 


\subsubsection{Reversion of DT Ferrite to Austenite}

In 2003, Chen and Chen applied the technique of laser dilatometry to follow the reversion of DT ferrite to austenite following deformation above the $\mathrm{Ae}_{3}$ at $10 \mathrm{~s}^{-1}$ [2.29]. They showed that the retransformation took about $45 \mathrm{~s}$ at $860^{\circ} \mathrm{C}$, i.e. at about $30^{\circ} \mathrm{C}$ above the $\mathrm{Ae}_{3}$ temperature of their steel, whereas the forward transformation had been accomplished in a small fraction of a second.

The sequence of occurrence of these phenomena is depicted in Fig. 2.13 [2.30]. It can be seen from the figure that by applying deformation the Gibbs energy of the austenite is increased. Because of the higher stored energy, it becomes unstable and starts to transform to ferrite, even though the temperature is above the $\mathrm{Ae}_{3}$; i.e. the forward transformation takes place. This phenomenon has been described in detail in references [2.26-2.28] reviewed above. Meanwhile, the deformation is continuing and the ferrite newly formed above the $\mathrm{Ae}_{3}$ starts to deform as well and its energy also increases. During holding,

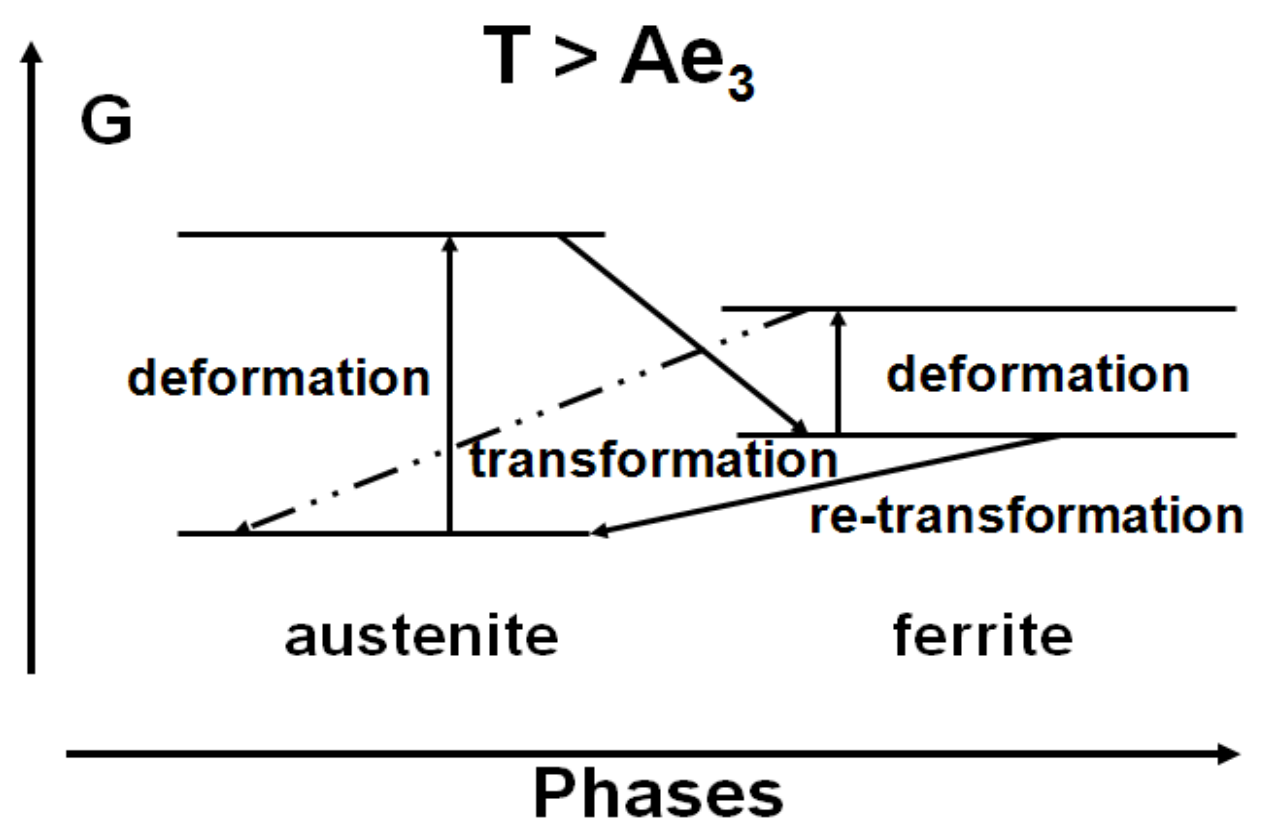

Fig. 2.13: Schematic of the Gibbs energy changes during dynamic phase transformation and the reverse transformation of ferrite to austenite above the $\mathrm{Ae}_{3}$ after the latter has undergone deformation [2.30]. 
after deformation the strain-induced ferrite as well as the deformed strain induced ferrite become unstable and re-transform back to (undeformed) austenite. This has been described in references [2.29-2.32].

The reversion of DT ferrite to austenite just above the $\mathrm{Ae}_{3}$ temperature has also been reported by Liu et al. [2.31]; their results, however, were limited to metallographic observations. Laser dilatometry experiments similar to those of Ref. 2.29 were carried out by Sun et al. in 2008 when they followed the reversion of ferrite to austenite following deformation above the orthoequilibrium $\mathrm{Ae}_{3}$ [2.32]. They deformed cylindrical specimens of a $0.17 \% \mathrm{C}$ steel in a Gleeble simulator at a strain rate of $1 \mathrm{~s}^{-1}$ and at temperatures up to $950^{\circ} \mathrm{C}$, i.e. up to $115^{\circ} \mathrm{C}$ above the $\mathrm{Ae}_{3}$ temperature of $835^{\circ} \mathrm{C}$. They failed to produce DT ferrite at $950^{\circ} \mathrm{C}$, but did at 840 and $860^{\circ} \mathrm{C}$, i.e. at 5 and $25^{\circ} \mathrm{C}$ above the $\mathrm{Ae}_{3}$. No tests were reported at temperatures between $860^{\circ} \mathrm{C}$ and $950^{\circ} \mathrm{C}$. The reversion to austenite took about $200 \mathrm{~s}$ at 840 and $860^{\circ} \mathrm{C}$.

Fig. 2.14 shows the dilatation curves of the specimens during isothermal holding after deformation at various temperatures above the $\mathrm{Ae}_{3}$. At $950^{\circ} \mathrm{C}$, no change in sample dimensions confirmed the absence of transformation. At the other two temperatures, the specimens clearly contracted after about $200 \mathrm{~s}$ of isothermal holding, indicating that the ferrite to austenite reverse transformation was taking place. These dilatometric results were consistent with metallographic observations of the presence or absence of ultrafine ferrite in samples quenched immediately after deformation or after periods of holding, as shown in Fig. 2.15. Significant amount of ferrite, mostly nucleated at austenite grain boundaries, can be observed in Fig. 2.15(a), which illustrates the microstructure present immediately after quenching following deformation at $850^{\circ} \mathrm{C}\left(\mathrm{Ae}_{3}+15^{\circ} \mathrm{C}\right)$ at a strain rate of $1 \mathrm{~s}^{-1}$. However, ferrite could not be observed after $1200 \mathrm{~s}$ of isothermal holding following deformation, as shown in Fig. 2.15(b). 


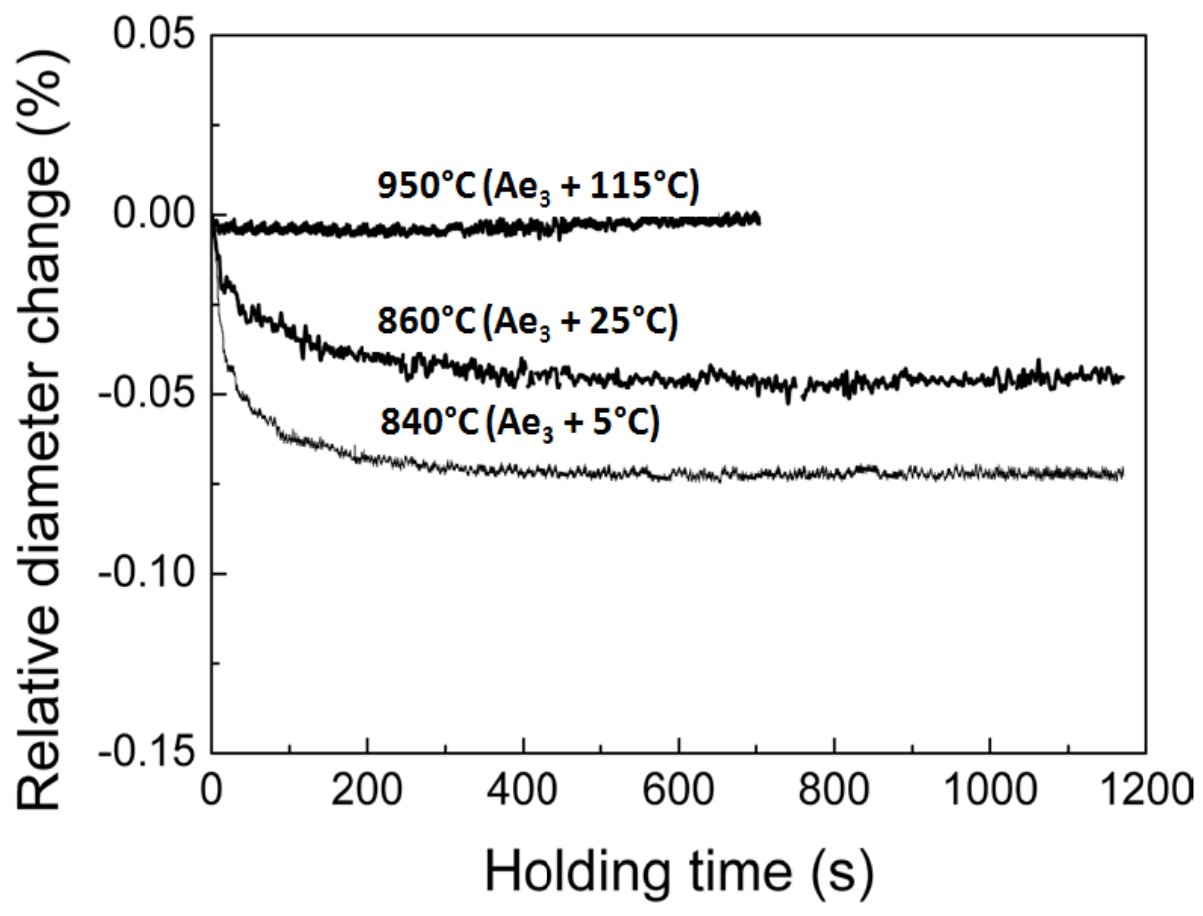

Fig. 2.14: Dilatation curves of specimens held isothermally after deformation at various temperatures above the $\mathrm{Ae}_{3}[2.32]$.
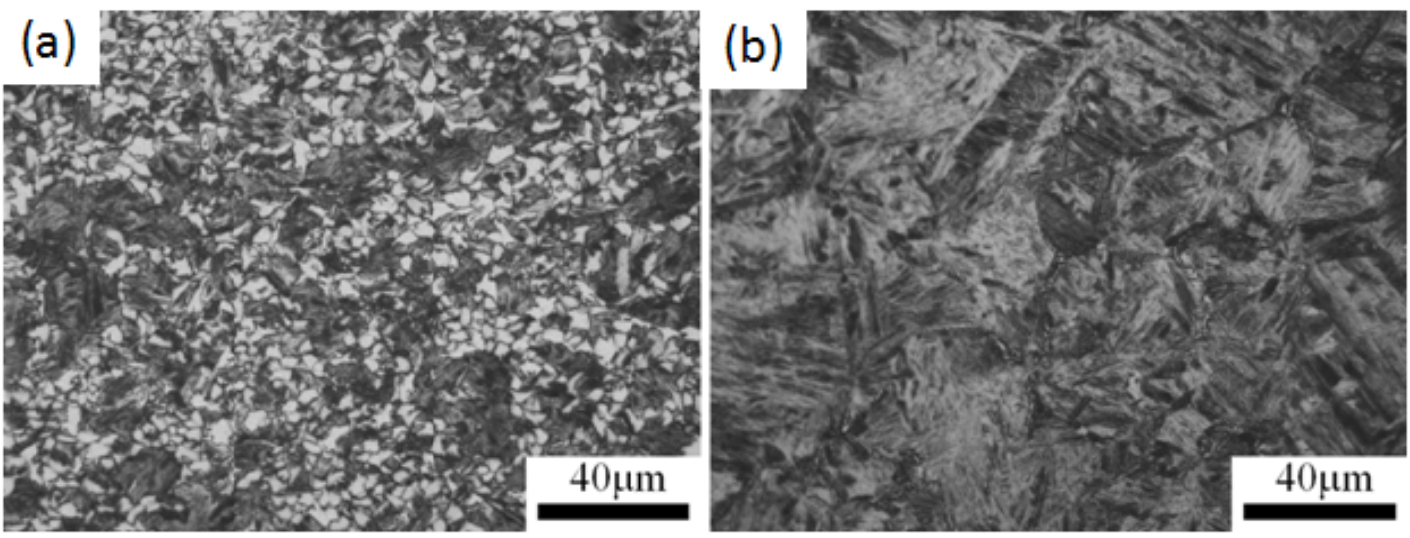

Fig. 2.15: Microstructures of a specimen (a) quenched immediately after deformation at $850^{\circ} \mathrm{C}\left(\mathrm{Ae}_{3}+15^{\circ} \mathrm{C}\right)$ and (b) subjected to $1200 \mathrm{~s}$ of holding following deformation and then quenched [2.32].

They also determined the critical strain for DT to occur by means of the double differentiation method [2.33] and observed that it increased with temperature from 840 to $860^{\circ} \mathrm{C}$. This is opposite to the trend displayed by the critical strain for 
dynamic recrystallization, a tendency that was taken as evidence that the initiation strain for DT increased with temperature. They determined the austenite stored energy required to produce an orthoequilibrium transformation at $860^{\circ} \mathrm{C}$ to be $35 \mathrm{~J} / \mathrm{mol}$ and compared this to the stored deformation energy of $22 \mathrm{~J} / \mathrm{mol}$. From this discrepancy, they concluded that the transformation was made possible by the inhomogeneous nature of the stored energy, which raised it locally to the required value.

In recent times, the most complete work on back transformation was that carried out by Basabe and Jonas [2.34]. In their case, the presence of Nb slowed the back transformation by comparison with the behavior of plain carbon steels. This can be attributed to dislocation pinning by $\mathrm{Nb}(\mathrm{C}, \mathrm{N})$ precipitates and solute drag due to the presence of $\mathrm{Nb}$ in solution. The back transformation in the $\mathrm{Nb}$ steel was characterized by two stages, as shown in Fig. 2.16. Stage I extended over the initial $200 \mathrm{~s}$ of isothermal holding, during which the deformationinduced ferrite remained fairly stable (Fig. 2.16(a) and (b)). As depicted by Fig. 2.16(c), stage II was observed after $200 \mathrm{~s}$ of holding; the reverse transformation took place and attained saturation after about $400 \mathrm{~s}$. The retardation of back transformation attributable to $\mathrm{Nb}$ addition indicates that the latter could play a useful role in preventing back transformation during steel processing.

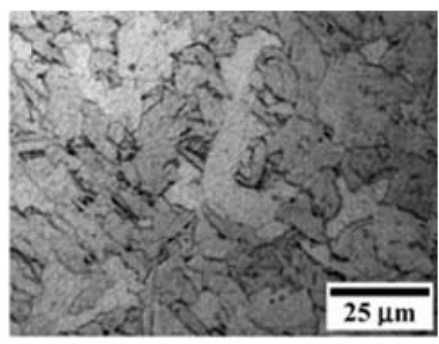

(a)

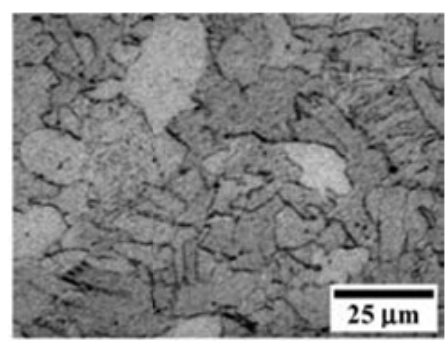

(b)

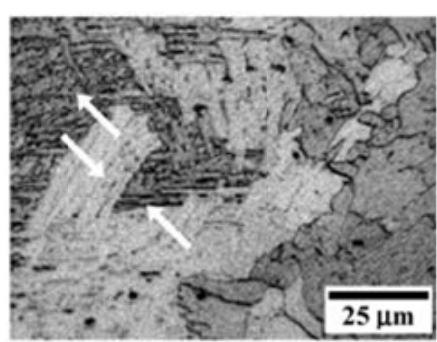

(c)

Fig. 2.16: Micrographs of specimens deformed at $856^{\circ} \mathrm{C}\left(\mathrm{Ae}_{3}+20^{\circ} \mathrm{C}\right)$ at $0.4 \mathrm{~s}^{-1}$ and held isothermally after deformation for (a) $0 \mathrm{~s}$, (b) $200 \mathrm{~s}$, (c) $400 \mathrm{~s}$. The reverse transformation began after $200 \mathrm{~s}$ of holding, as revealed by the presence of the martensite needles (arrows) [2.34]. 


\subsubsection{Modeling the Dynamic Transformation of Austenite}

Several authors have now modeled dynamic transformation as well as the retransformation to austenite. Tong et al. carried out a 2-D Monte Carlo simulation in which they took the energies of the three types of interfaces as well as the diffusion of $C$ in the binary Fe-C system into account [2.35]. They assumed that the stored strain energy was proportional to the square of the strain and that the work hardening rate in the austenite was about 6 times greater than in the ferrite. On application of a strain rate of $0.001 / \mathrm{MCS}$, their model reproduced the critical strain for the start of the transformation and led to an equilibrium volume fraction of ferrite of about $48 \%$. Under these conditions, the critical strain was about 0.1 and the stored energy required to induce the transformation was about $21 \mathrm{~J} / \mathrm{mol}$. The DT ferrite was much finer than the initial austenite, in keeping with the experimental observations. They also modeled the reverse transformation, which took place more 'slowly' than the forward process. The model was further modified so as to incorporate the occurrence of dynamic recrystallization (DRX). This led to an increase in the critical strain for DT but could not prevent its occurrence. The simulations showed that the 'faster' the kinetics of DRX, the lower the equilibrium volume fraction of ferrite.

More recently, Xiao et al. [2.36] elaborated on the above approach by coupling the Monte Carlo model to a crystal plasticity/finite element code. This enabled them to take grain orientation and the slip geometry into account. The calculation showed that the spatial distribution of ferrite grains is inhomogeneous because of the heterogeneous distribution of the stored energy. They had shown (by Monte Carlo simulation) that deformation at high temperatures accelerates the carbon diffusion kinetics in austenite. It can be observed from Fig. 2.17(a) that plastic deformation increases the equilibrium carbon concentration of austenite. 
This can be understood from the thermodynamic principles shown schematically in Fig. 2.17(b). The free energy of austenite increases with deformation. This

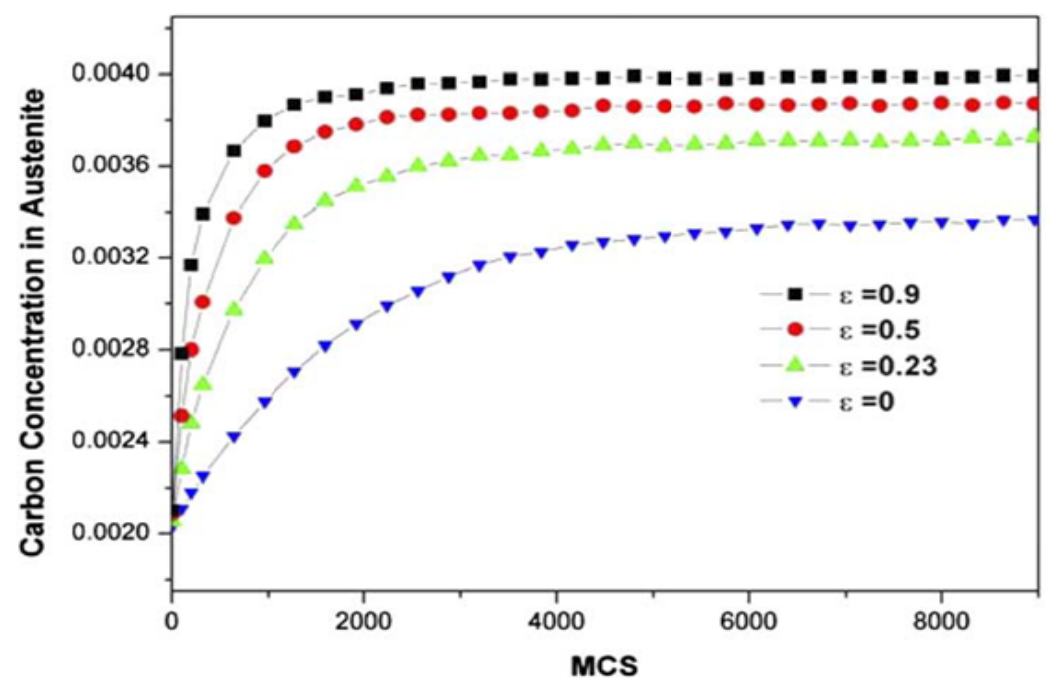

(a)

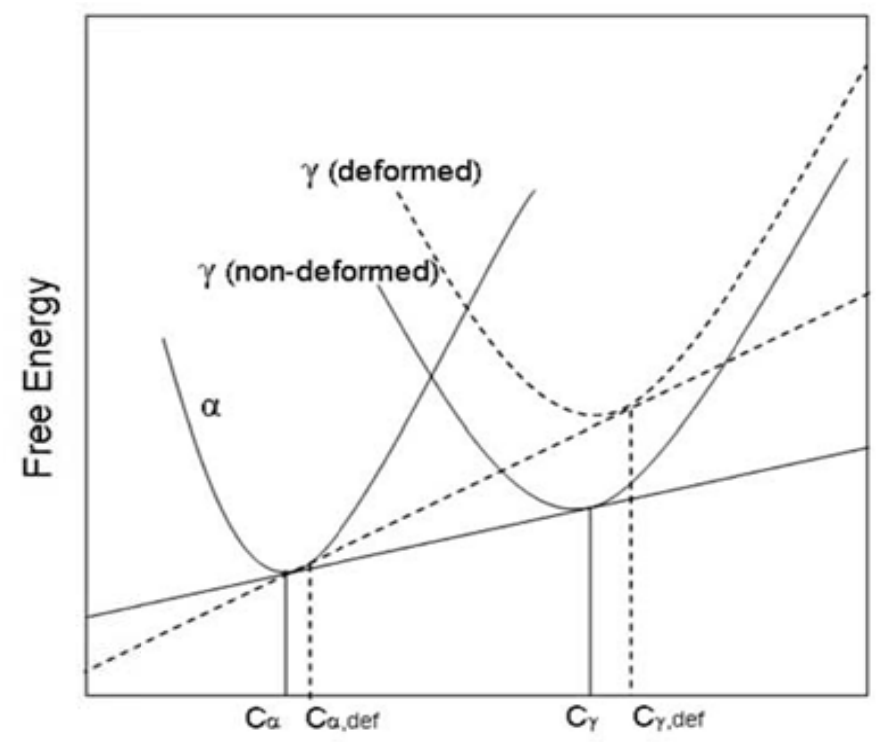

Carbon Concentration

(b)

Fig. 2.17: (a) Carbon diffusion kinetics in austenite at different logarithmic strains; (b) schematic curves of the free energy vs. carbon concentration showing the effect of austenite deformation on the equilibrium carbon concentration in ferrite and austenite [2.36]. 
then results in higher equilibrium carbon concentrations in both austenite and ferrite. The second important observation from Fig. 2.17(a) is that the plastic deformation accelerates the carbon diffusion kinetics in austenite. The time elapsed before the carbon concentration in austenite reaches the saturation values decreases with increasing strain. In general, the diffusivity of carbon in austenite is governed by its activation energy. During deformation, a great number of dislocations and other defects are introduced into the material. Crystal lattices with defects possess higher energies compared to perfect lattices. This in turn results in decreasing the diffusion activation energy of carbon atoms and therefore increases the carbon diffusivity in austenite [2.36].

\subsubsection{Change in Equilibrium $\mathrm{Ae}_{3}$ Temperature}

In her 1997 Ph.D. thesis [2.37], S.V. Parker estimated the influence of various amounts of stored energy on increasing the driving force for transformation in a $0.1 \% \mathrm{C}$ steel. For example, dislocation densities of $1.2 \times 10^{15} / \mathrm{m}^{2}$ and $3.5 \times$ $10^{15} / \mathrm{m}^{2}$, corresponded to stored energies of $21.6 \mathrm{~J} / \mathrm{mol}$ and $63.4 \mathrm{~J} / \mathrm{mol}$, respectively. These values were obtained by assuming that $10 \%$ of the work done was stored in the form of dislocations. The latter, in turn, led to driving force increases of the same amounts. Although her calculations dealt with temperatures below the $\mathrm{Ae}_{3}$, if these values are extrapolated to higher temperatures, increases in the paraequilibrium $\mathrm{Ae}_{3}$ of approximately 7 and $17.5^{\circ} \mathrm{C}$, respectively, are obtained. The increases in free energy require modification of the conventional phase diagram. A schematic representation of the effect of deformation on the phase diagram is presented in Fig. 2.18 [2.38].

Others have also attempted to explain the phenomena associated with the transformation of ferrite from deformed austenite above the equilibrium transformation temperature. Hanlon et al. [2.39] and Umemoto et al. [2.40] took into account the dislocation density, deformation substructure [2.41], stored energy distribution, and compositional effects to develop analytical models to 


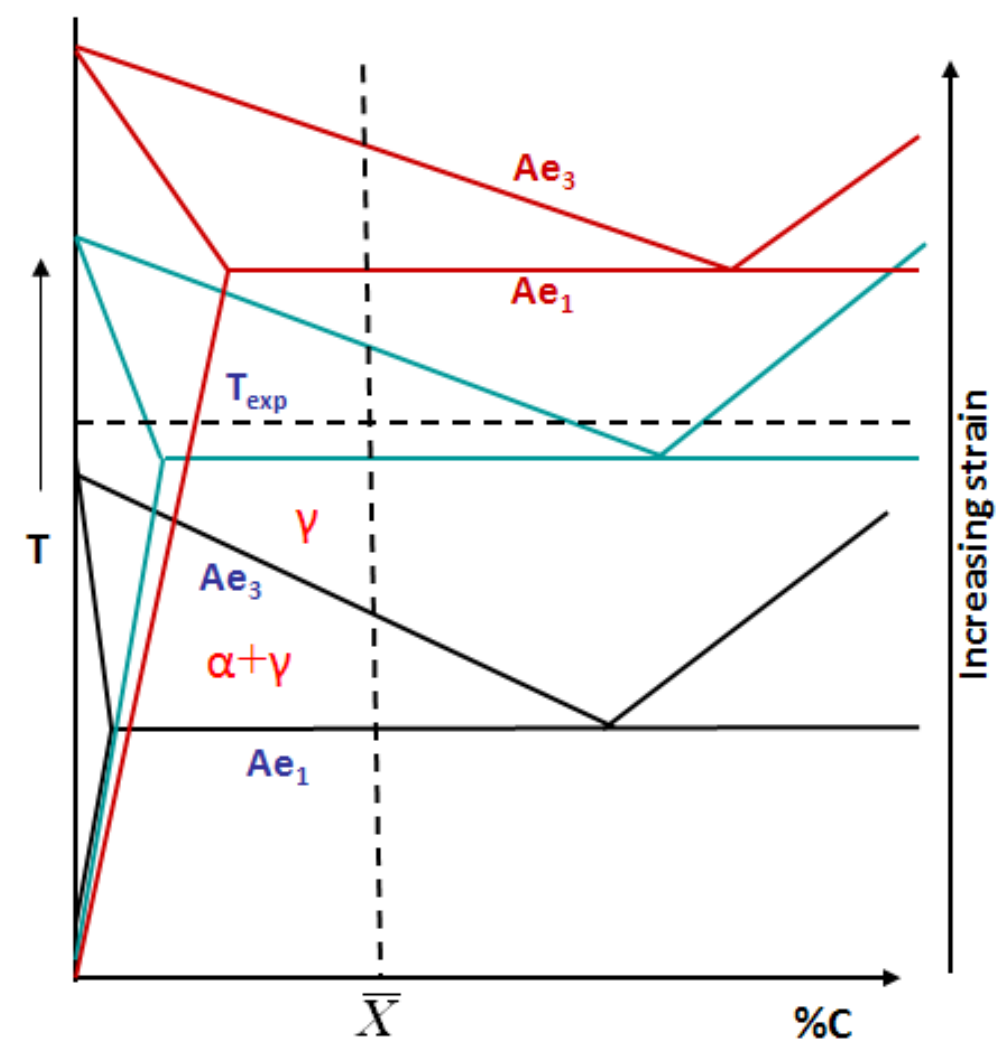

Fig. 2.18: Schematic representation of the effect of deformation on the Fe-C phase diagram. $\bar{X}$ represents the mean $C$ concentration of a particular steel. The lowest plot is the conventional orthoequilibrium diagram. An increase in strain raises the effective diagram (blue lines) sufficiently that the experimental temperature $\mathrm{T}_{\exp }$ is now below the effective $\mathrm{Ae}_{3}$. Additional deformation raises it still further (red lines) so that the experimental temperature is now below the $\mathrm{Ae}_{1}[2.38]$.

investigate this kind of transformation.

Umemoto et al. [2.40] in their pioneering work derived the basic kinetic equations for transformation from work hardened austenite to polygonal ferrite under isothermal conditions. The increase in the ferrite nucleation rate from deformed austenite was attributed to three factors:

1. The increase in the austenite grain surface area $\left(S_{v}\right)$ by elongation of the grains;

2. The increase in the nucleation rate per unit area $\left(I_{s}\right)$ of grain surface; 
3. The formation of additional nucleation sites such as annealing twin boundaries, shear bands, etc.

The mechanism of enhanced nucleation is shown schematically in Fig. 2.19, where the deformed austenite grain boundaries exhibit ledges. Ferrite nucleation at these ledges decreases the activation energy by about $\theta / \pi$ times compared with nucleation on a planar grain boundary. Also dislocations favor nucleation through their stress fields [2.42].

The strain energy associated with work hardened austenite was approximated by Umemoto et al. [2.40] as $E=V^{m} \rho \frac{\mu b^{2}}{4 \pi K} \ln \left(\frac{R_{d}}{b}\right)$, where $\mathrm{V}^{\mathrm{m}}$ is the molar volume, $\rho$ the dislocation density, $\mu$ the shear modulus, $b$ the Burgers vector, $R_{d}$ the interdislocation distance, and $\mathrm{K}$ a constant. As an extension of this, Hanlon et al. [2.39] presented a transformation model validated for plain carbon steels by using both the diffusivity and interface mobility concepts [2.43-2.45]. In their model, the effect of plastic deformation was added as a term $\left(\Delta G_{\text {def }}\right)$ additional to the chemical driving force and was evaluated by assuming that the deformation substructure can be described as proposed by Adachi et al. [2.46].

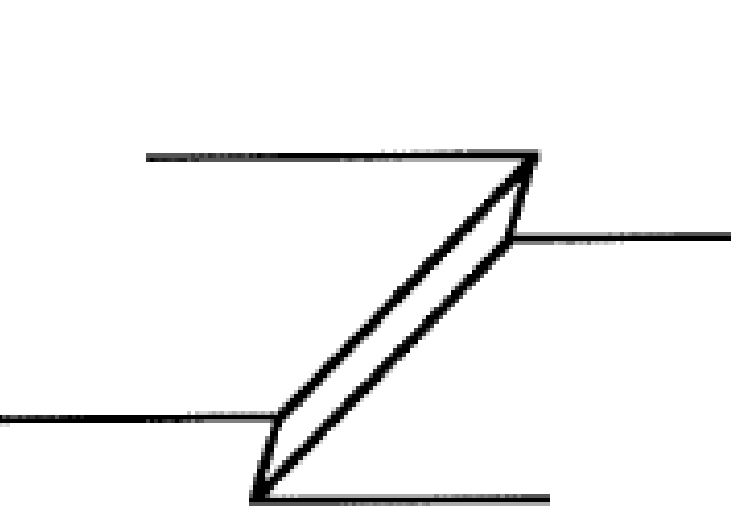

(a)

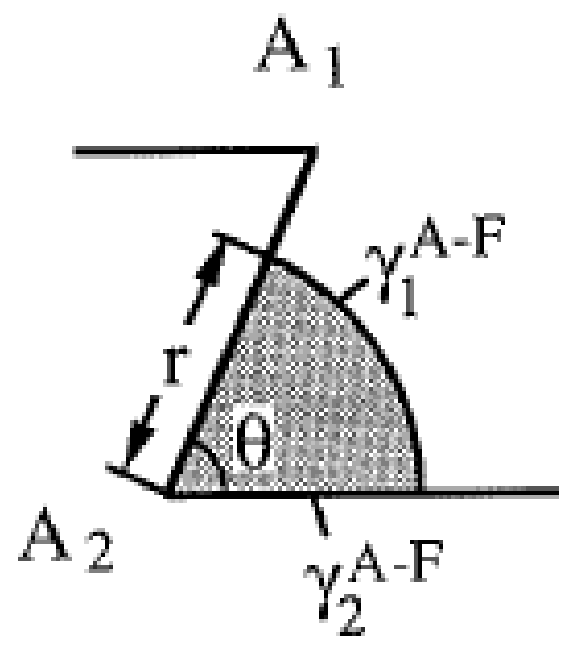

(b)

Fig. 2.19: Schematic of ferrite nucleation at a ledge on deformed austenite grain boundaries. (a) a ledge on a grain boundary; (b) ferrite nucleation at a ledge [2.42]. 
Accordingly, $\Delta G_{\text {def }}$ was evaluated as $\Delta G_{d e f}=\frac{1}{2} \mu b^{2} \rho_{i}+\frac{3 \sigma}{\delta}$, where $\mu$ is the shear modulus, $b$ the Burgers vector, $\rho_{\mathrm{i}}$ the free dislocation density, $\sigma$ the subboundary interfacial energy and $\delta$ the cell/subgrain diameter. They estimated the effects of: i) a dislocation density of $10^{15} / \mathrm{m}^{2}$, and ii) of a recovered substructure of cell size $0.2 \mu \mathrm{m}$. The stored energies associated with these two types of microstructures each led to $\mathrm{Ae}_{3}$ increases of about $10^{\circ} \mathrm{C}$. These grossly underestimate the influence of deformation, as the reported $\mathrm{Ae}_{3}$ increment is well over $100^{\circ} \mathrm{C}[2.27]$.

\section{References}

2.1 http://www.jfe-21st-cf.or.jp/chapter_6/6i_1_img.html.

2.2 M. Cohen and S.S. Hansen; HSLA Steels: Metallurgy and Applications, ASM International, 1986, p. 67.

2.3 J.J. Jonas; Mater. Sci. Forum, Vol. 284-286, (1998), p. 3.

2.4 W.B. Morrison; J Iron and Steel Inst., Vol. 210, (1972), p. 618.

2.5 F. Siciliano; PhD Thesis, McGill University, Montreal, Canada, 1999.

2.6 B. Pereda, I. Fernandez and J.M. Rodriguez-Ibabe; ISIJ Int., Vol. 47, (2007), p. 860.

2.7 M.R. Cartmill, M.R. Barnett, S.H. Zahiri and P.D. Hodgson; ISIJ Int., Vol. 45, (2005), p. 1903.

2.8 P. Uranga, I. Fernandez, B. Lopez and J.M. Rodriguez-lbabe; Mater. Sci. Eng. A, Vol. 345, (2003), p. 319.

2.9 C. Roucoules, S. Yue and J.J. Jonas; Metall. Mater. Trans. A, Vol. 26, (1995), p. 181.

2.10 J.J. Jonas; Mater. Sci. Eng. A, Vol. 184, (1994), p. 155.

2.11 W.A. Johnson and R.F. Mehl; Trans. AIME, Vol. 135, (1939), p. 416.

2.12 D.A. Porter and K.E. Easterling; Phase Transformations in Metals and Alloys $-2^{\text {nd }}$ Edition, Taylor-Francis Group, 2004.

2.13 H.K.D.H. Bhadeshia; Bainite in Steels-2 ${ }^{\text {nd }}$ Edition, University of Cambridge, Institute of Materials, 2001.

2.14 H.K.D.H. Bhadeshia; Ferrite Undergraduate Lecture Notes, University of Cambridge, http://www.msm.cam.ac.uk/phase-trans/index.html, 2010.

2.15 V. Raghavan; Physical Metallurgy: Principles and Practice, $2^{\text {nd }}$ Edition, Prentice-Hall of India Pvt. Ltd. 1998.

2.16 A. Elwazri; PhD Thesis, McGill University, Montreal, Canada, 2004. 
2.17 H.K.D.H. Bhadeshia; Widmanstätten Ferrite Undergraduate Lecture Notes, University of Cambridge, http://www.msm.cam.ac.uk/phasetrans/index.html, 2010.

2.18 H.K.D.H. Bhadeshia; Bainite in Steels, The Institute of Materials, London, 1992.

2.19 R.F. Bunshah and R.F. Mehl; Trans AIME, Vol. 193, (1953), p. 1251.

$2.20 \mathrm{H}$. Dong and X. Sun; Current Opinion in Solid State and Mater. Sci., Vol. 9, (2005), p. 269.

2.21 I. Tamura, C. Ouchi, T. Tanaka and H. Sekine; Thermomechanical processing of high strength low carbon steels. Butterworth \& Co. Ltd; 1988.

2.22 R. Priestner; Metallurgical Society of AIME, (1981), p. 455.

2.23 J.H. Beynon, R. Gloss and P.D. Hodgson; Mater. Forum, Vol. 16, (1992), p. 37.

2.24 S. Lee, D. Kwon, Y.K. Lee and O. Kwon; Metall. Mater. Trans. A, Vol. 26, (1995), p. 1093.

2.25 W.Y. Choo, J.S. Lee and C.S. Lee; CAMP ISIJ, Vol. 13, (2000), p. 1144.

$2.26 \mathrm{H}$. Yada, Y. Matsumura and T. Senuma; Proc. of the Int. Conf. on Martensitic Transformation, JIM (1986), p. 515.

$2.27 \mathrm{H}$. Yada, Y. Matsumura and T. Senuma; Proc. 1st Conf. Physical Metallurgy of Thermomechanical Processing of Steels and Other Metals (THERMEC-88), ed. by I. Tamura, ISIJ, Tokyo, (1988), p. 200.

2.28 H. Yada, C.M. Li and H. Yamagata; ISIJ Int., Vol. 40, (2000), p. 200.

2.29 Y. Chen and Q. Chen; J. Iron Steel Res. Int., Vol. 10, (2003), p. 46.

$2.30 \mathrm{H}$. Mahjoubi ; M.S Thesis, Ecole Polytechnique Fédérale de Lausanne (EPFL), Lausanne, Switzerland, 2010.

2.31 Z. Liu, D. Li, S. Lu and G. Qiao; ISIJ Int., Vol. 47, (2007), p. 289.

2.32 X. Sun, H. Luo, H. Dong, Q. Liu and Y. Weng; ISIJ Int., Vol. 48, (2008), p. 994.

2.33 E. Poliak and J.J. Jonas; Acta Mater., Vol. 44, (1996), p. 127.

2.34 V.V. Basabe and J.J. Jonas; ISIJ Int., Vol. 50, (2010), p. 1185.

2.35 M. Tong, D. Li, Y. Li, J. Ni and Y. Zhang; Metall. Mater. Trans. A, Vol. 35, (2004), p. 1565.

2.36 N. Xiao, M. Tong, Y. Lan, D. Li and Y. Li; Acta Mater., Vol. 54, (2006), p. 1265.

2.37 S.V. Parker; Ph.D. Thesis, Cambridge University, Cambridge, 1997.

2.38 J.J. Jonas, V. Basabe and C. Ghosh; Mater. Sci. Forum, Vols. 706-709, (2012), p. 49.

2.39 D.N. Hanlon, J. Sietsma and S. van der Zwaag; ISIJ Int., Vol. 41, (2001), p. 1028.

2.40 M. Umemoto, A. Hiramatsu, A. Moriya, T. Watanabe, S. Nanba, N.

Nakajima, G. Anan and Y. Higo; ISIJ Int., Vol. 32, (1992), p. 306.

2.41 M. Tong, D. Li and Y. Li; Acta Mater., Vol. 53, (2005), p. 1485. 
2.42 M. Umemoto, H. Ohtsuka and I. Tamura; THERMEC-88, Vol.2, ISIJ, Tokyo, (1988), p. 769.

2.43 J.W. Christian; The theory of transformations in metals and alloys, $2^{\text {nd }}$ Edition, Oxford: Pergamon Press, 1981.

2.44 G.P. Krielaart, J. Sietsma and S. van der Zwaag; Mater. Sci. Eng. A, Vol. 237, (1997), p. 216.

2.45 G. Krielaart and S. van der Zwaag; Mater. Sci. Tech., Vol. 14, (1998), p. 10.

2.46 Y. Adachi, T. Tomida and S. Hinatoni; ISIJ Int., Vol. 40, (2000), p. S194. 
Chapter 3

Experimental Procedure 


\section{Experimental Procedure}

\subsection{Experimental Materials}

The steels under investigation in the current study were supplied as hot rolled plates $12.5 \mathrm{~mm}$ thick. Their chemical compositions and $\mathrm{Ae}_{3}$ temperatures are given in Table 3.1. These temperatures were predicted using the Thermocalc [3.1] thermodynamic software with the FactSage FSStel database [3.2]. It was Hultgren [3.3] who first introduced the term "orthoequilibrium" and "paraequilibrium" in the study of the transformation of austenite to ferrite and cementite. Orthoequilibrium is generally used to mean full equilibrium of all the elements at a migrating interface. On the other hand paraequilibrium describes a constrained mode of equilibrium in which the interstitials are able to partition between the parent and product phases to an extent that allows their chemical potentials to become identical in both phases. However, slower diffusing substitutional elements are unable to partition. Therefore, it is a metastable mode of transformation and a carbon (and nitrogen) diffusion controlled process. It is to be noted that the paraequilibrium $\mathrm{Ae}_{3}$ temperatures are always below the orthoequilibrium ones.

Table 3.1. Chemical compositions (mass \%) and $\mathrm{Ae}_{3}$ equilibrium transformation temperatures $\left({ }^{\circ} \mathrm{C}\right)$ of the steels investigated.

\begin{tabular}{|c|c||c|c|c|c|c|}
\hline Steel & $\mathbf{C}$ & $\mathbf{M n}$ & $\mathbf{S i}$ & $\mathbf{N b}$ & $\begin{array}{c}\mathbf{A e}_{3}\left({ }^{\circ} \mathbf{C}\right) \\
\text { Orthoequilibrium }\end{array}$ & $\begin{array}{c}\mathbf{A e}_{3}\left({ }^{\circ} \mathbf{C}\right) \\
\text { Paraequilibrium }\end{array}$ \\
\hline 1 & 0.06 & 0.30 & 0.01 & - & 877 & 870 \\
\hline 2 & 0.09 & 1.30 & 0.02 & 0.036 & 836 & 820 \\
\hline 3 & 0.21 & 1.30 & 0.24 & - & 822 & 808 \\
\hline 4 & 0.79 & 0.65 & 0.24 & - & 733 & 709 \\
\hline
\end{tabular}




\subsection{Torsion Testing}

Torsion machines are widely used for conducting research related to steel rolling. The torsion test has two distinct advantages. Primarily, the torsion test is readily capable of conducting tests at constant and relatively high strain rates (up to $10 \mathrm{~s}^{-1}$ ) by twisting at a constant rate. In addition, large values of true strain (up to 5 or even more) can be reached without complications such as necking in tension or barreling in compression. The simulation of multipass hot rolling can be conveniently carried out using hot torsion equipment due to the following advantages:

- $\quad$ ease of use and low cost;

- easy control of strain, strain rate, interpass time and temperature;

- possibility to achieve high shear strains;

- easy and fast quenching of specimens to room temperature.

The two disadvantages of torsion testing are that: i) the strain is not uniformly distributed along the radius of a specimen (it is maximum at the surface and zero along the axis); and ii) the flow stress at the outer radius cannot be derived precisely from the measured torque.

\subsubsection{Theory}

In the torsion test, the strain in a solid cylindrical specimen varies linearly from zero along the axis to a maximum at the surface. As calculated by Nadai [3.4], the shear stress, $\tau$, at the surface of a rate-insensitive material is given by:

$$
\tau=\left(1 / 2 \pi r^{3}\right)(3 T+\theta d T / d \theta)
$$

where $T$ is the torque, $d T / d \theta$ the slope of the torque-twist curve, $r$ the radius of the specimen and $\theta$ the amount of twist in the specimen (radians).

Later, Fields and Backofen [3.5] pointed out that, in a rate-sensitive material, $d T / d \theta=(T / \theta)(n+m)$. Here $n$ is the twist sensitivity coefficient and $m$ the twist rate 
sensitivity coefficient. These are defined by the slopes of plots of $\log T$ vs. $\log \theta$ at a constant $\dot{\theta}$ and of $\log$ T vs. $\log \dot{\theta}$ at a constant $\theta$, respectively. This leads to:

$\tau=\left(1 / 2 \pi r^{3}\right) T(3+n+m) \quad$-...(3.2)

Now at temperatures above $500^{\circ} \mathrm{C}, \mathrm{n}$ is negligible and $\mathrm{m}$ can be taken as approximately 0.3 . These lead to:

$\tau=3.3 T / 2 \pi r^{3}$

Again $\tau=\sigma / \sqrt{ } 3$ where $\sigma$ is the von Mises equivalent stress.

Therefore, $\sigma=3.3 \sqrt{ } 3 \mathrm{~T} / 2 \pi r^{3}$

The equivalent strain $\varepsilon=r \theta / v 3 \mathrm{~L}$

where $L$ is the length of the specimen. Despite claims to the contrary [3.6], the von Mises description is the one best suited to the description of torsion experiments [3.7-3.9]. It is evident from Eq. 3.5, that the strain is maximum at the surface of the specimen, while it is zero along the axis.

\subsubsection{Hot Torsion Machine}

The present work was conducted on a servo-hydraulic, computer controlled MTS torsion machine mounted on a lathe bed, with the motor-furnace-torque cell system set longitudinally. A schematic diagram of the torsion machine is illustrated in Fig. 3.1 [3.10]. The machine is capable of providing strain rates up to $10 \mathrm{~s}^{-1}$. Specimens were held securely at one end while the other end was attached to the freely rotating shaft of the machine. A servo-controlled software (MTS TESTAR ${ }^{\text {TM }}$ ) controls the amount of twist applied to the specimen. During a test, the developed load was measured by the torque cell, while the displacement, the angle of twist of the specimen, was logged by a rotary transducer. A computer was used to log the applied forces as twist-torque data at a rate of up to 1000 points per second. 


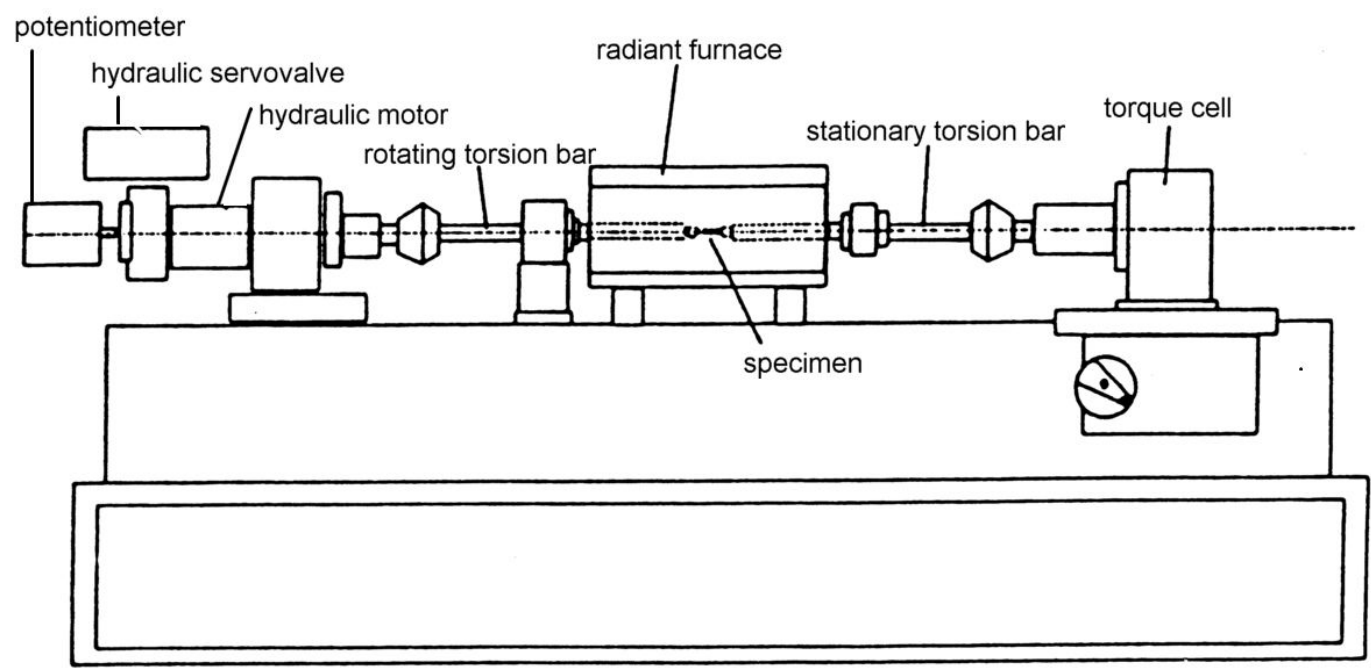

Fig. 3.1: Schematic diagram of the torsion machine [3.10].

Model 793.10 MultiPurpose TestWare (MPT) was used to create test design files for running the testing system. The TestStar control system consists of three essential parts, namely, a digital controller, a load control panel and the system software. The load control panel is employed to operate the hydraulic system. The overall control is conducted using the system Station Manager. Through the MPT application software, test procedures are created, edited and run. Test procedures contain specifications for test programs, and may include position control, data acquisition, event detection and external control instructions. These can be designed step by step in terms of the procedure specifications. Once the procedure is ready, the deformation parameters, such as strain, strain rate are entered into the template. The present experiments were carried out under twist control.

Specimens were heated using a water-cooled radiant furnace containing an array of four quartz lamps, in which a maximum temperature of $1300^{\circ} \mathrm{C}$ could be reached. The specimen, held by two loading bars, was located in the central part of the furnace. To prevent oxidation, the specimen and parts of the loading bars were enclosed in a quartz tube sealed with O-rings, through which a constant 


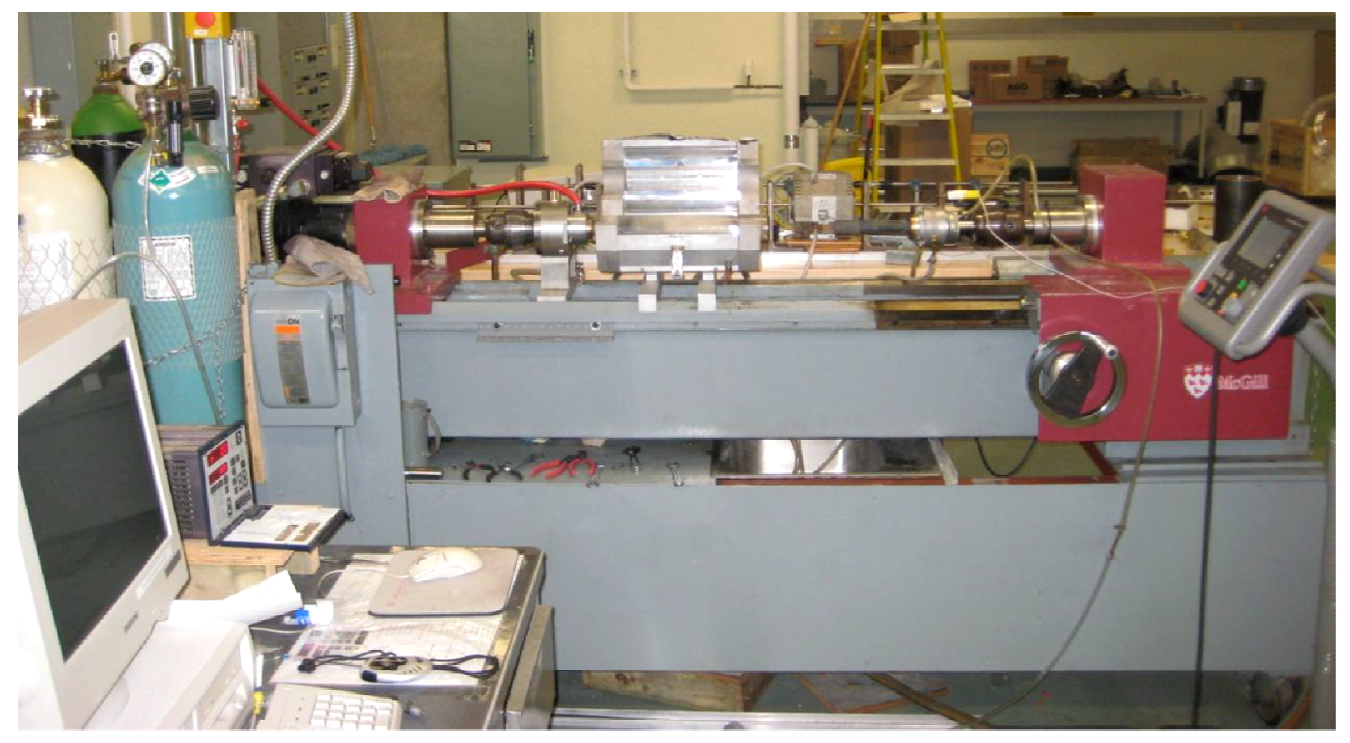

Fig. 3.2: The torsion machine at McGill University.

flow of $\mathrm{Ar}-5 \% \mathrm{H}_{2}$ was maintained. To enable rapid quenching of the specimens, they were manually withdrawn from the furnace by a wheeled manipulator. The furnace, argon and hydrogen cylinders and control system are shown in Fig. 3.2.

\subsection{Sample Preparation}

Cylindrical torsion specimens $3.15 \mathrm{~mm}$ in radius and $22.2 \mathrm{~mm}$ in length were machined from the hot rolled plates, the cylinder axes being parallel to the rolling direction. Fig. 3.3 depicts a schematic diagram of the specimen.

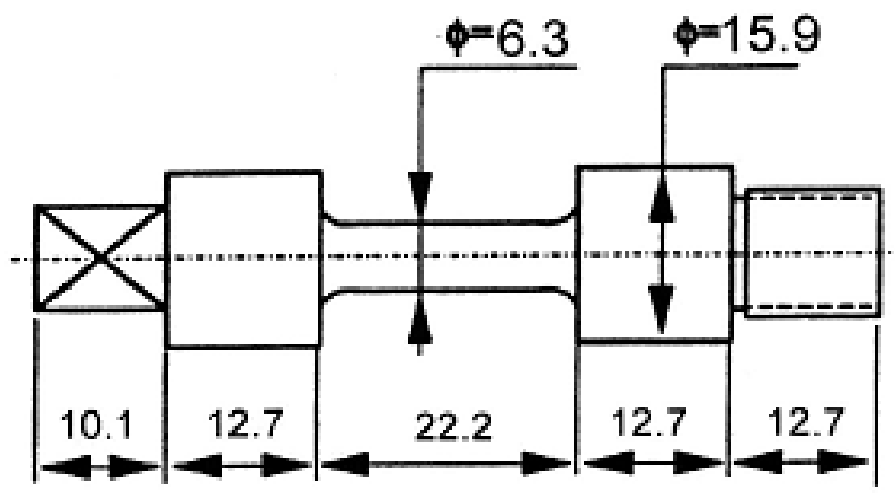

Fig. 3.3: Schematic diagram of a cylindrical torsion specimen. 


\subsection{Thermomechanical Schedule}

The thermomechanical schedule used for the $0.06 \% \mathrm{C}[3.11]$ and $0.09 \% \mathrm{C}$ steels [3.12] in the torsion tests is depicted in Fig. 3.4(a). To condition the austenite, the first deformation was applied at $1200^{\circ} \mathrm{C}$ and the second at temperatures above the $\mathrm{Ae}_{3}$. These were selected so as to explore the phenomenon of austenite transformation above the orthoequilibrium $\mathrm{Ae}_{3}$. In the second deformation, the specimens were strained to $\varepsilon=0.2-5.0$ at strain rates of $\dot{\varepsilon}=0.4$ $\mathrm{s}^{-1}$. These tests were carried out by Dr. V.V. Basabe.

The thermomechanical schedule used for the $0.21 \% \mathrm{C}$ and $0.79 \% \mathrm{C}$ steels is presented in Fig. 3.4(b) $[3.13,3.14]$. These specimens were heated at $1^{\circ} \mathrm{C} / \mathrm{s}$ to $1200^{\circ} \mathrm{C}$ for $0.21 \% \mathrm{C}$ steel and to $1150^{\circ} \mathrm{C}$ for $0.79 \% \mathrm{C}$ steel, austenitized for 20 mins, and then cooled at $1^{\circ} \mathrm{C} / \mathrm{s}$ to $1050^{\circ} \mathrm{C}$. After holding for $20 \mathrm{~s}$ at this temperature, the specimens were strained to $\varepsilon=1.0$ at a strain rate of $2.0 \mathrm{~s}^{-1}$ to simulate roughing. After the first deformation, the specimens were held at this temperature for $100 \mathrm{~s}$ to permit recrystallization and then cooled to the various test temperatures at $1^{\circ} \mathrm{C} / \mathrm{s}$. Here also the temperatures were chosen so as to explore the phenomenon of austenite transformation above the orthoequilibrium $\mathrm{Ae}_{3}$.

Prior to the second deformation, the torsion specimens were held for $1 \mathrm{~min}$ at the test temperature. They were then deformed to strains in the range $\varepsilon=0.15-$ 3.0 and $0.25-4.0$ for the $0.21 \% \mathrm{C}$ and $0.79 \% \mathrm{C}$ steels, respectively, at strain rates of $4.5 \mathrm{~s}^{-1}$ (for the $0.21 \% \mathrm{C}$ steel) and $4.0 \mathrm{~s}^{-1}$ (for the $0.79 \% \mathrm{C}$ steel). After the second deformation, the specimens were water quenched in about $1.5 \mathrm{~s}$ to arrest the progress of static and post-dynamic recrystallization and to prevent the static decomposition of austenite into cementite and ferrite during cooling. A tubular horizontal radiation furnace with an atmosphere composed of argon and $5 \% \mathrm{H}_{2}$ was used during heating and torsion testing to minimize decarburization and oxidation of the specimens. An Omega Super XL type K thermocouple was 


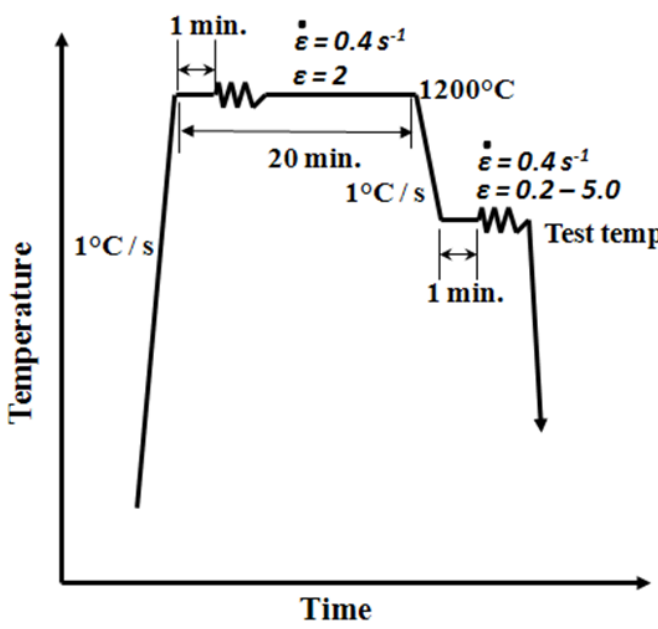

(a)

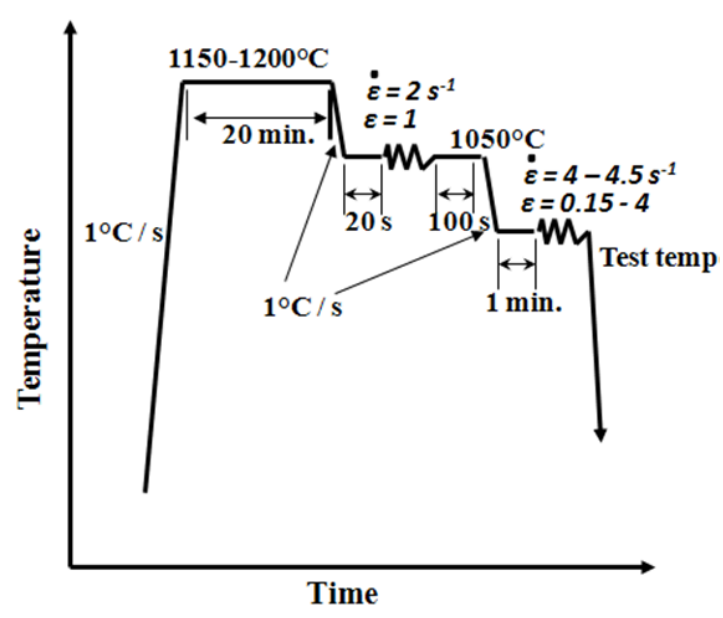

(b)

Fig. 3.4: Thermomechanical schedules for the torsion tests of (a) Steels 1 and 2 [3.11,3.12] and (b) Steels 3 and 4 [3.13,3.14].

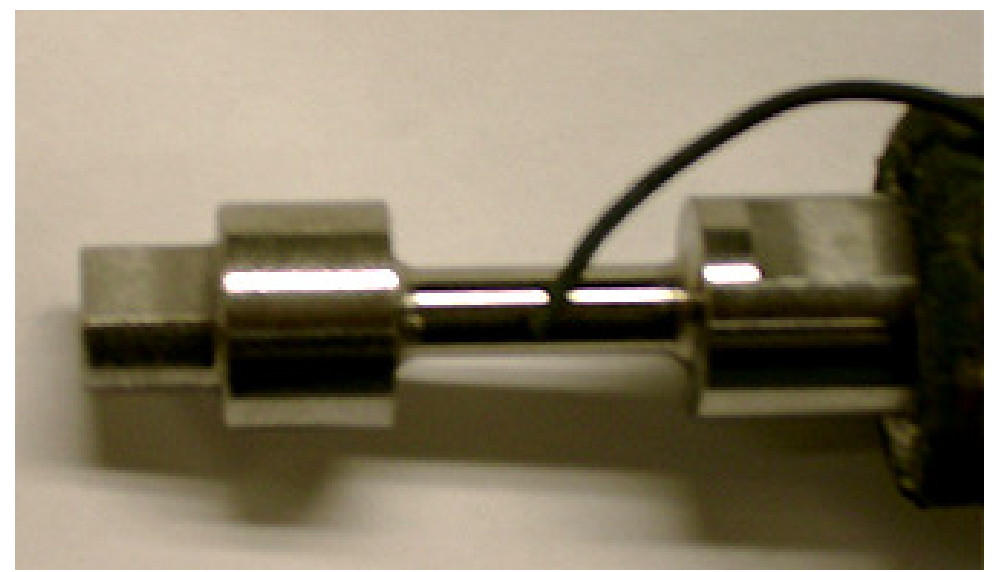

Fig. 3.5: Position of the thermocouple with respect to the torsion sample.

placed in contact with the external surface of the mid-length of the torsion specimen for temperature measurement and control. These thermocouples are specified to have a maximum error of $1^{\circ} \mathrm{C}$ over the present temperature range [3.15]. 


\subsection{Microstructural Characterization}

It is evident from Eq. 3.5, that the strain is maximum at the surface of the torsion specimen, while it is zero along the axis. The amount of dynamic transformation is therefore expected to be at a maximum at the outer surface and to decrease to zero along the radius. For this reason, microscopic observations were carried out along the radius to observe the effect of strain on the microstructure.

In the current study, microstructural characterizations were carried out using scanning electron microscopy (SEM), electron back scattered diffraction (EBSD), transmission electron microscopy (TEM) and atom probe tomography (APT) techniques*. In order to reveal the microstructure, cross-sections perpendicular to the longitudinal axis were cut from the deformed specimens. Fig. 3.6 clearly shows the area of interest for the microstructural observations. The samples were mounted for scanning electron microscopy and EBSD on a Philips XL30 FEGSEM, operated at $15 \mathrm{kV}$. The surface preparation of the mounted samples was carried out in three successive stages, namely, grinding, polishing and etching.

Grinding was done with 400-600-800-1200 grit silicon-carbide sand papers soaked with water. Small grit-number sand papers provide rough grinding, which is useful for removal of the deformed layer caused by sectioning. Increasing number sand papers remove the scratches caused by the previous paper. At the end of grinding, the samples were flushed with alcohol and dried with a hair dryer. After this, they were polished on a rotating wheel using 3 and $1 \mu \mathrm{m}$ diamond pastes. Again the samples were flushed with alcohol and dried. Polishing was continued until the specimen surface became scratch-free and mirror-like. Colloidal $0.05 \mu \mathrm{m}$ silica was employed to polish the samples for EBSD analysis. The polished samples were preheated slightly using a hot air blower and then etched for times that varied from 5 to $10 \mathrm{~s}$. The objective of etching was to

\footnotetext{
*The author is indebted to Dr. V.V. Basabe for carrying out most of the EBSD examinations and Dr Xiang Y. Xiong, Dr.
} Ilana Thimokhina and Professor Elena Pereloma for performing the TEM and APT examinations. 

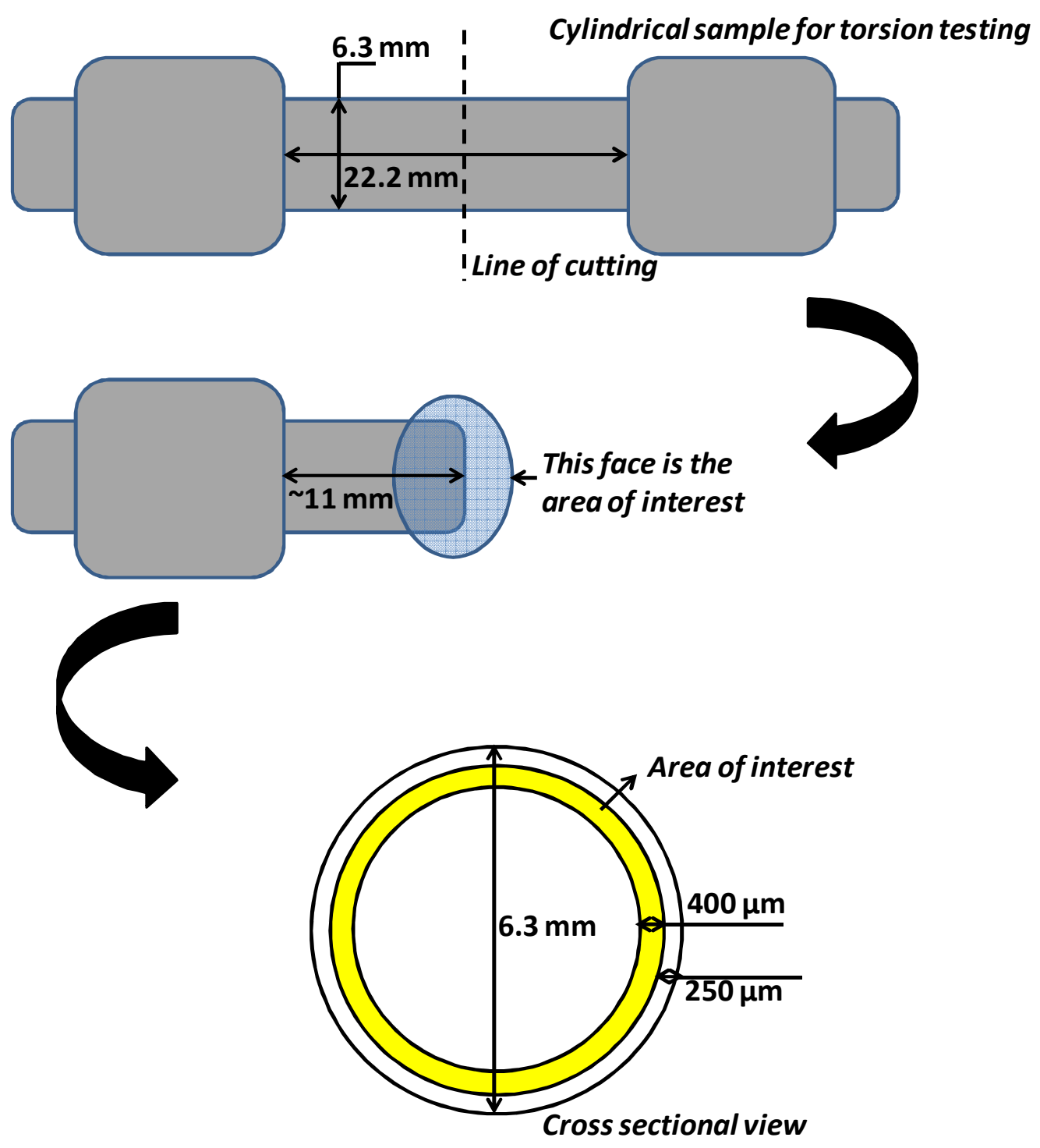

Fig. 3.6: Sample cutting for microstructural characterization.

create image contrast on the surfaces of the polished specimens. In the current work, $2 \%$ nital was always used as the etchant. Etchant solutions were prepared and applied in accordance with Ref. 3.16. The polished and etched samples were always stored in desiccators under vacuum in order to protect them from atmospheric corrosion.

Thin foils for TEM were prepared by twin jet electro-polishing using a solution of $5 \%$ perchloric acid in methanol at $253 \mathrm{~K}\left(-20^{\circ} \mathrm{C}\right)$ and an operating voltage of $50 \mathrm{~V}$. 
Bright-field and dark-field images and selected area electron diffraction patterns were obtained on a Philips CM 20, operated at 200 kV*.

A standard two-stage electropolishing procedure [3.17] was used to prepare the needle-shaped atom probe samples using 33\% nitric acid in methanol for the first stage, followed by $2 \%$ perchloric acid in butoxyethanol at $16 \mathrm{~V}$. APT of the specimen was conducted using the Oxford nanoScience 3DAP (Oxford nanoScience Ltd., Milton Keynes, UK) at the Monash Centre for Electron Microscopy. The pulse repetition rate was $20 \mathrm{kHz}$, the pulse fraction was 0.2 and the sample temperature was maintained at $60 \mathrm{~K}\left(-213^{\circ} \mathrm{C}\right)$. The compositions of the various phases were obtained from volumes of interest, free from any visible element segregation (e.g., clusters, precipitates, Cottrell atmospheres and boundaries) based on the number of atoms present after background noise was subtracted*.

\subsection{Hardness Measurements}

Apart from microstructural characterizations, phase identification was also carried out using microhardness measurements on a Vickers hardness $\left(H_{V}\right)$ tester. A load of $1 \mathrm{~kg}$ was used in the present study. The Vickers hardness uses the square-base diamond pyramid indenter as depicted in Fig. 3.7(a). Here, the load is applied smoothly, without any impact and held in contact for 10 to $15 \mathrm{~s}$. Then it is removed and the impression diagonals are measured, as illustrated in Fig. 3.7(b). The average of these measurements is used to calculate $\mathrm{H}_{V}$ according to the following empirical relationship:

$$
H_{V}=[(2000) P \sin (\alpha / 2)] / d^{2}=(1854.4) P / d^{2}
$$

*The author is indebted to Dr Xiang Y. Xiong, Dr. Ilana Thimokhina and Professor Elena Pereloma for performing the TEM and APT examinations. 


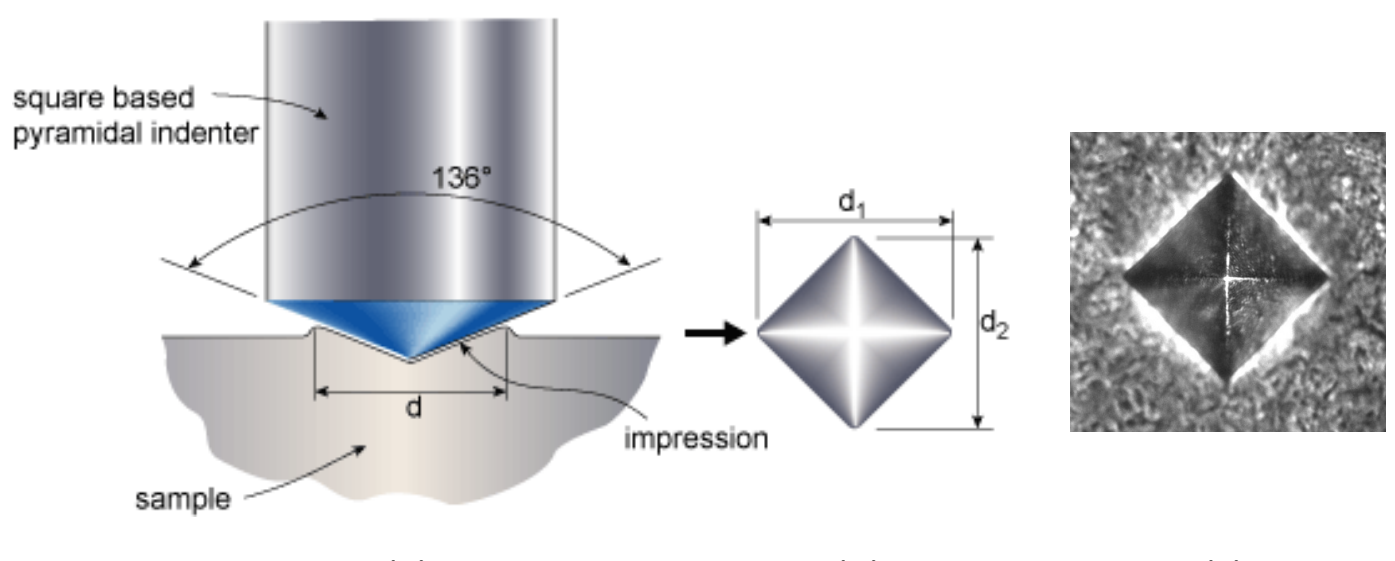

(a)

(b)

(c)

Fig. 3.7: Schematic diagram of the Vickers hardness test (a) Vickers indentation; (b) measurement of the impression diagonals [3.18]; (c) an example of the indentation it produces.

where $P$ is the applied load in grams, $\alpha$ the face angle $\left(136^{\circ}\right)$ and $d$ the mean diagonal in $\mu \mathrm{m}$. Fig. 3.7(c) depicts an example of the indention it creates on the specimen surface. The final hardness values were calculated from the average of 6 separate measurements taken at randomly selected points.

\subsection{Quantification of the Phase Measurements}

To quantify the amount of deformation-induced ferrite and cementite present in the microstructure under different conditions, the Clemex Captiva image analyzer software was used. A representative area of the microstructure where the measurements were carried out is illustrated in Fig. 3.8. The areas where deformation-induced ferrite and cementite are present were measured. In order to calculate the percentages of the phases present in the structure, they were subtracted from the total area. The final values were calculated from the average of 3 separate measurements taken at randomly selected places. 


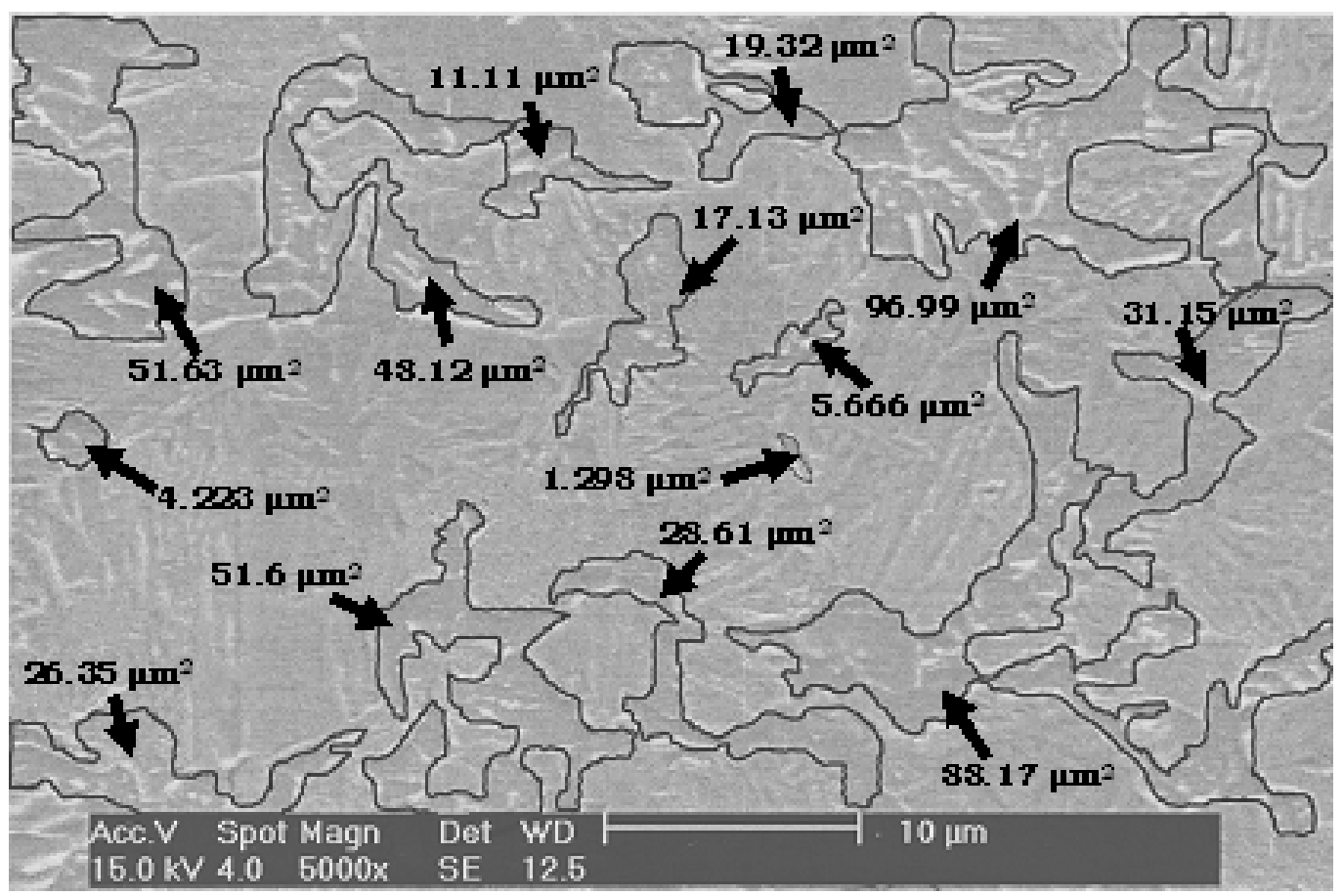

Fig. 3.8: Quantification of the ferrite grain areas.

\subsection{Thermodynamic Calculations}

In order to estimate the increase in the austenite (FCC) - to - ferrite (BCC) transition temperature $\left(\mathrm{Ae}_{3}\right)$ due to hot deformation, paraequilibrium calculations were performed to take into account the effect of deformation on the free energy of the austenite phase and the influence of alloy composition on the transformation. The approach employed is briefly described below.

\subsubsection{Thermodynamics of the Fe-Mn-Si-C System}

The Gibbs energy of FCC and BCC solutions can be expressed by the following equations using the Compound Energy Formalism [3.19,3.20].

$$
\begin{aligned}
& G_{\text {soln }}=\sum_{i} \sum_{j} Y_{i}^{\prime} Y_{j}^{\prime \prime} G_{i j}^{0}+R T\left(n_{1} \sum_{i} Y_{i}^{\prime} \ln Y_{i}^{\prime}+n_{2} \sum_{j} Y_{j}^{\prime \prime} \ln Y_{j}^{\prime \prime}\right)+g^{e x} \\
& g^{e x}=\sum_{i} \sum_{j} \sum_{k} Y_{i}^{\prime} Y_{j}^{\prime} Y_{k}^{\prime \prime} L_{i j: k}+\sum_{i} \sum_{j} \sum_{k} Y_{i}^{\prime} Y_{j}^{\prime \prime} Y_{k}^{\prime \prime} L_{i: j k}
\end{aligned}
$$


Here $Y_{i}^{\prime}$ and $Y_{j}^{\prime \prime}$ represent the site fractions of solute $i$ in substitutional sites and $j$ in interstitial sites, $G_{i j}^{0}$ is the Gibbs energy of an end-member $i j$ of the solution in which the substitutional and interstitial sites are occupied only by $i$ and $j$, and $n_{1}$ and $n_{2}$ are the numbers of sites on the substitutional and interstitial sites per formula unit of the solution. The parameters $L_{i j: k}$ are related to the interactions between atoms $i$ and $j$ on the substitutional sites when the interstitial sites are only occupied by $k$ atoms, and the parameters $L_{i: j k}$ represent the interactions between atoms $j$ and $k$ on the interstitial sites when the substitutional sites are only occupied by $i$ atoms.

Following the normal expressions for a steel thermodynamic database [3.1,3.2], the substitutional elements in the present case are $\mathrm{Fe}, \mathrm{Mn}$ and $\mathrm{Si}$; $\mathrm{C}$ and $\mathrm{Va}$ (vacancy) are considered as interstitial sites; and $n_{1}$ and $n_{2}$ are the numbers of the substitutional and interstitial sites per formula unit of the solution. In the case of the present FCC solid solution, both $n_{1}$ and $n_{2}$ are equal to 1 , whereas $n_{2}$ becomes 3 in the case of the BCC solid solution. The Gibbs energy of the cementite solution can be similarly expressed using the Compound Energy Formalism.

The thermodynamic data and model parameters for all the sub-binary and ternary systems of the Fe-Mn-Si-C system have been reported in previous studies and have been combined in a commercial database for software packages such as ThermoCalc [3.1] and FactSage [3.2]. These model parameters were used in the present study without any modification to calculate the bulk Gibbs energies of the FCC, BCC and cementite solid solutions. For example, the Gibbs energy of the FCC solution for the Fe-C system [3.21,3.22] was expressed as follows:

$$
\begin{aligned}
& G_{F C C}=y_{F e} y_{V a} G_{F e: V a}^{0}+y_{F e} y_{C} G_{F e: C}^{0}+R T\left[\left(y_{F e} \ln y_{F e}\right)+\left(y_{C} \ln y_{C}+\right.\right. \\
& \left.\left.y_{V a} \ln y_{V a}\right)\right]+y_{F e} y_{C} y_{V a} L_{F e: C, V a} \\
& G_{F e: V a}^{0}=G_{F e}^{0 f c c}
\end{aligned}
$$




$$
\begin{aligned}
& =-236.7+132.416 T-24.6643 T \ln T-0.00375752 T^{2}-5.8927 \times 10^{-8} T^{3}+77358.5 T^{-1} \\
& (\mathrm{~J} / \mathrm{mol})(298.15 \mathrm{~K}<\mathrm{T}<1811.00 \mathrm{~K}) \\
& =-27097.396+300.25256 T-46.0 T \ln T+2.78854 \times 10^{31} T^{-9}(\mathrm{~J} / \mathrm{mol})(1811.00 \mathrm{~K}< \\
& \mathrm{T}<6000.00 \mathrm{~K}) \\
& G_{C}^{0 \text { graphite }}=-17368.441+170.73 T-24.3 T \ln T-4.723 \times 10^{-4} T^{2}+2562600 T^{-1}- \\
& 2.643 \times 10^{8} T^{-2}+1.2 \times 10^{10} T^{-3}(\mathrm{~J} / \mathrm{mol})(298.15 \mathrm{~K}<\mathrm{T}<6000.00 \mathrm{~K}) \\
& G_{F e: C}^{0}=G_{F e}^{0 f c c}+G_{C}^{0 \text { graphite }}+77207-15.877 T(\mathrm{~J} / \mathrm{mol}) \\
& L_{F e: C, V a}=-34671(\mathrm{~J} / \mathrm{mol})
\end{aligned}
$$

\subsection{Paraequilibrium}

As carbon is an interstitial element in the Fe FCC and BCC phases, its diffusivity is very much faster than that of the substitutional elements $\mathrm{Fe}, \mathrm{Mn}$ and Si. Given the time constraints discussed below, the steels can be considered to have attained a paraequilibrium state during transformation rather than full equilibrium (orthoequilibrium). In the paraequilibrium condition, therefore, carbon can be exchanged between the FCC and BCC phases to reach equilibrium, but the substitutional elements are not redistributed between the phases. According to such calculations, the $\mathrm{Ae}_{3}$ paraequilibrium temperatures are lower than the $\mathrm{Ae}_{3}$ orthoequilibrium temperatures by about 5 to $25^{\circ} \mathrm{C}$, depending on the carbon concentration.

\subsubsection{Addition of Deformation Energy to Bulk Gibbs Energy in FCC}

In order to take the deformation energy into account in the bulk Gibbs energy of the FCC phase, the Gibbs energies of the end-members of the FCC solid solution in Eq. 3.8 were changed as follows:

$G_{F e: V a}^{0(\text { deformed })}=G_{F e: V a}^{0}+\Delta G_{F e: V a}=G_{F e: V a}^{0}+652.66-0.4184 T(\mathrm{~J} / \mathrm{mol})$ 
$G_{F e: C}^{0(\text { deformed })}=G_{F e: C}^{0}+\Delta G_{F e: C}=G_{F e: C}^{0}+2928(\mathrm{~J} / \mathrm{mol})$

In the present calculation, $\Delta G_{F e: V a}$ was employed mainly to model the deformation-induced $\mathrm{FCC}$ to $\mathrm{BCC}$ transformation temperature and $\Delta G_{F e: C}$ was employed mainly to model the transformation of FCC to cementite. The influence of deformation on the Gibbs energies of the other end-members, $G_{M n: V a}^{0}, G_{M n: C}^{0}, G_{S i: V a}^{0}$ and $G_{S i: C}^{0}$ were not considered in the present study because the concentrations of $\mathrm{Mn}$ and $\mathrm{Si}$ in the FCC solution were considered to be 'dilute'. Strictly speaking, these Gibbs energies should also be influenced by the deformation, but the contributions of these altered energies were taken to be negligible in the present case. The values of the deformation Gibbs energy, $\Delta G_{F e: V a}^{0(\text { deformed })}$ and $\Delta G_{F e: C}^{0(\text { deformed })}$ obtained in this way are reasonable considering the inhomogeneity of the stored energy, a topic that is discussed in detail in Chapter 7.

\section{References}

3.1 B. Sundman, B. Jansson and J.O. Anderson; Calphad, Vol. 9, (1985), p. 153.

3.2 C.W. Bale, E. Bélisle, P. Chartrand, S.A. Decterov, G. Eriksson, K. Hack, I.H. Jung, Y.B. Kang, J. Melançon, A.D. Pelton, C. Robelin and S. Petersen; Calphad, Vol. 33, (2009), p. 295.

3.3 A. Hultgren; Trans ASM, (1947), p. 915.

3.4 A. Nadai; Theory of Flow and Fracture of Solids, McGraw-Hill Book Co., Inc., New York, N. Y., (1950), p. 349.

3.5 D.S. Fields and W.A. Backofen; Proc. ASTM, Vol. 57, (1957), p. 1259.

3.6 S. Onaka; Phil. Mag. Lett., Vol. 90, (2010), p. 633.

3.7 J.J. Jonas, C. Ghosh and S. Shrivastava; Mater. Trans., Vol. 52, (2011), p. 1748.

3.8 S. Shrivastava, C. Ghosh and J.J. Jonas; Phil. Mag., Vol. 92, (2012), p. 779.

3.9 J.J. Jonas, C. Ghosh, V.V. Basabe and S. Shrivastava; Phil. Mag., Vol. 92, (2012), p. 2313.

3.10 H. Mahjoubi; M.S. Thesis, Ecole Polytechnique Fédérale de Lausanne (EPFL), Lausanne, Switzerland, 2010.

3.11 V.V. Basabe, J.J. Jonas and H. Mahjoubi; ISIJ Int., Vol. 51, (2011), p. 612.

3.12 V.V. Basabe and J.J. Jonas; ISIJ Int., Vol. 50, (2010), p. 1185. 
3.13 V.V. Basabe, J.J. Jonas and C. Ghosh; Adv. Mater. Res., Vol. 409, (2012), p. 829.

3.14 C. Ghosh, V.V. Basabe, J.J. Jonas, S. Yue and X.Y. Xiong; ISIJ Int., Vol. 53, (2013), p. 900.

3.15 www.omega.com/pptst/NBCAXL_NNXL.html.

3.16 Metallography and Microstructures; ASM Handbook, ASM International, Vol. 9, 2004.

3.17 M.K. Miller; Atom Probe Tomography, Kluwer, Academic/Plenum Press, New York, NY, (2000); p. 28.

3.18 http://www.twi.co.uk/technical-knowledge/job-knowledge/jobknowledge-74-hardness-testing-part-1/.

3.19 M. Hillert, B. Jansson and B. Sundman; Z. Metallkd., Vol. 79, (1988), p. 81.

3.20 M. Hillert and L.I. Staffansson; Acta Chem. Scand., Vol. 24, (1970), p. 3618.

3.21 A.T. Dinsdale; Calphad, Vol. 15, (1991), p. 317.

3.22 P. Gustafson; Scand. J Metall., Vol. 14, (1985), p. 259. 
Chapter 4

\section{Microstructural Characterization}




\section{Microstructural Characterization*}

The microstructural characteristics of the two phases, ferrite and cementite, that form dynamically from deformed austenite will be described in this chapter. All four steels investigated in the current study were strained at temperatures above the $\mathrm{Ae}_{3}$. The characterizations were carried out using scanning electron microscopy (SEM), electron back scattered diffraction (EBSD), transmission electron microscopy (TEM) and atom probe tomography (APT). By these means, the Widmanstätten nature of the ferrite formed was confirmed. The dependences of the ferrite volume fraction on strain and temperature were also determined and are presented here.

In the Discussion section, the diffusion distances over which the interstitial and substitutional atoms can travel over the experimental temperature range are derived. These are shown to be consistent with the view that DT ferrite nucleates displacively and that the supersaturated carbon is rejected into the austenite or precipitates in the ferrite during subsequent growth. Since there is insufficient time for substitutional diffusion, it is concluded that, while nucleation is displacive, growth occurs under paraequilibrium conditions.

\section{1 $0.06 \% \mathrm{C}$ and $0.09 \% \mathrm{C}$ Steels}

The microstructural characterization of the $0.06 \% \mathrm{C}$ and $0.09 \% \mathrm{C}$ steels was carried out by Dr. V.V. Basabe [4.1-4.2]. Two sets of micrographs from this investigation are reproduced here as Figs. 4.1 and $\mathbf{4 . 2}$ [4.3]. As will be seen in more detail below, the Widmanstätten ferrite plates evident in these micrographs are of considerable interest and the mechanism of their formation will be examined more closely later.

\footnotetext{
*Some of the material in this chapter has been published in Refs. 4.3 and 4.6.
} 


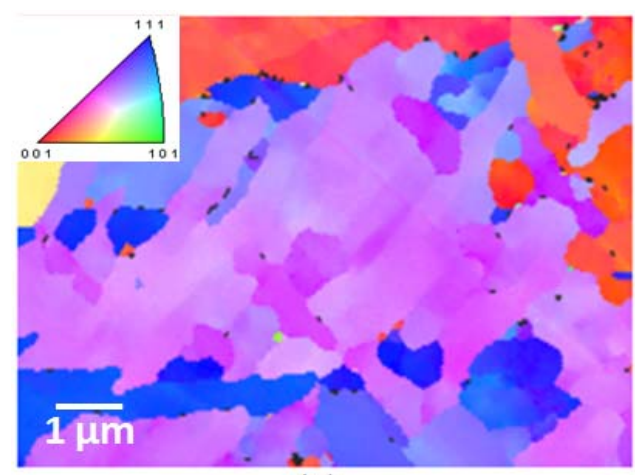

(a)

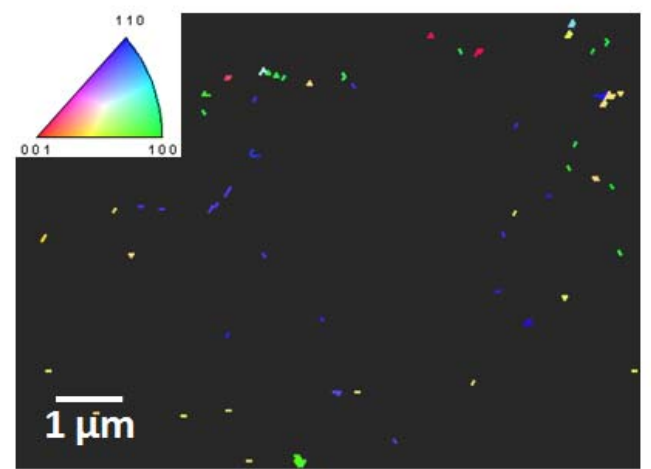

(c)

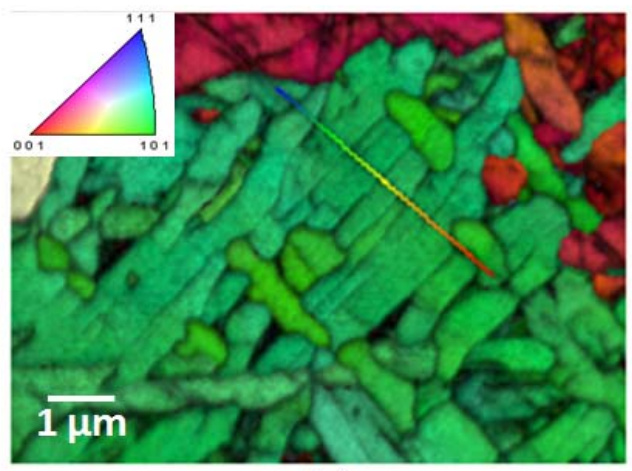

(b)

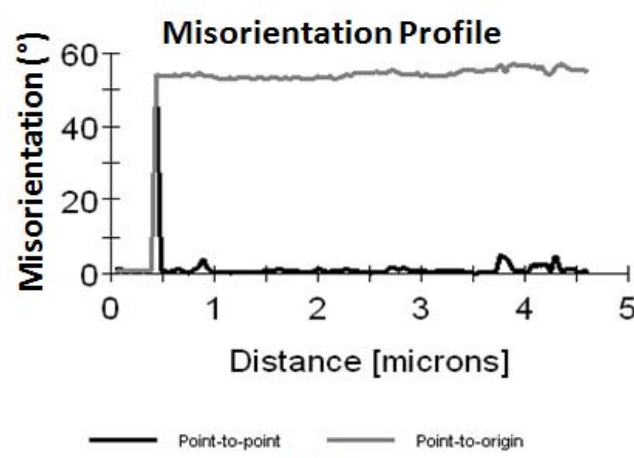

(d)

Fig. 4.1: EBSD micrographs of a transverse cross-section of the $0.06 \% \mathrm{C}$ steel strained to $\varepsilon=0.25$ at $887^{\circ} \mathrm{C}\left(\mathrm{Ae}_{3}+10^{\circ} \mathrm{C}\right)$ : (a) orientation image map of the ferrite phase (radial direction), black regions are martensite, (b) IPF and IQ map of the ferrite phase (circumferential direction), (c) orientation image map of the martensite phase, black regions are ferrite (circumferential direction), (d) misorientations measured along the line in (b). The $60^{\circ}$ misorientation indicates the presence of a twinned region in the prior austenite [4.3]. 


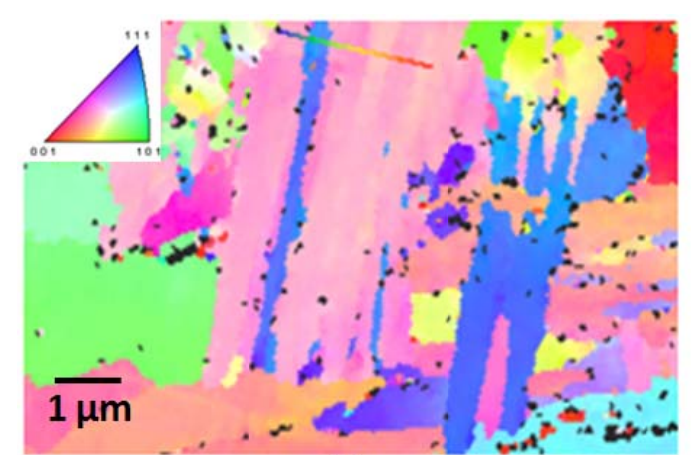

(a)

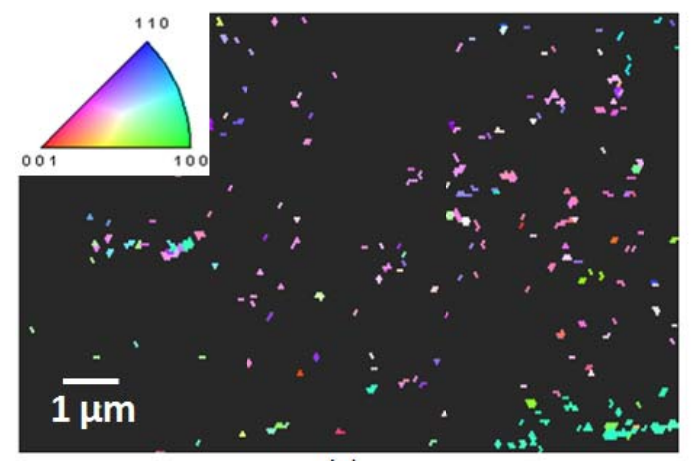

(c)

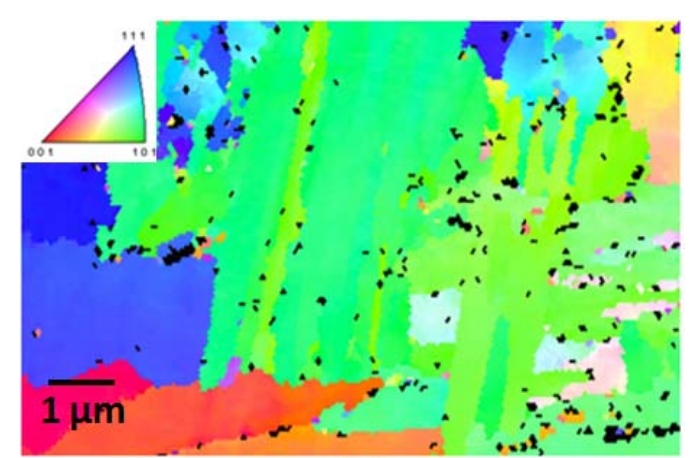

(b)

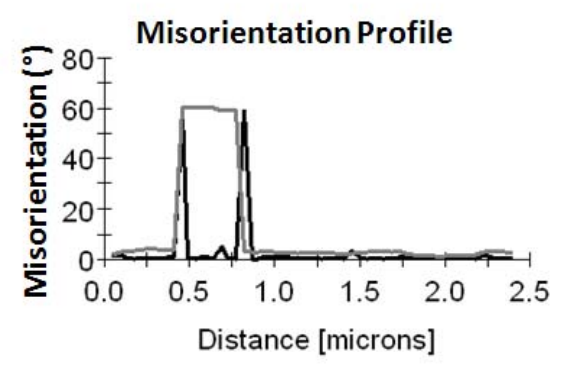

(d)

Fig. 4.2: EBSD micrographs of a transverse cross-section of the $0.09 \% \mathrm{C}$ steel strained to $\varepsilon=0.5$ at $856^{\circ} \mathrm{C}\left(\mathrm{Ae}_{3}+20^{\circ} \mathrm{C}\right)$ : (a) orientation image map of the ferrite phase (radial direction), black regions are martensite, (b) orientation image map of the ferrite phase (longitudinal direction), (c) orientation image map of the martensite phase, black regions are ferrite (radial direction), (d) misorientations measured along the line in (a). The $60^{\circ}$ misorientation indicates the presence of a twinned region in the prior austenite [4.3].

\subsection{21\%C Steel}

\subsubsection{SEM Results}

In this steel, the critical strain for the formation of DT ferrite was found to be about 0.15 . The detailed calculations carried out to evaluate the critical strains are discussed in Chapter 5 [4.4]. Under the present conditions, the freshly formed ferrite is predominantly plate-like in shape. This is displayed in Fig. 4.3(a). Some of the plates contain cementite particles. These are just visible at higher magnification in Fig. 4.3(c). Some typical straight interfaces characteristic of the displacive transformation are evident in Fig. 4.3(a) and (c). The features of 
these plates have led them to be characterized as being formed by a Widmanstätten type process [4.3]. The untransformed austenite matrix was converted to martensite on quenching, as confirmed by EBSD measurements.

(a)

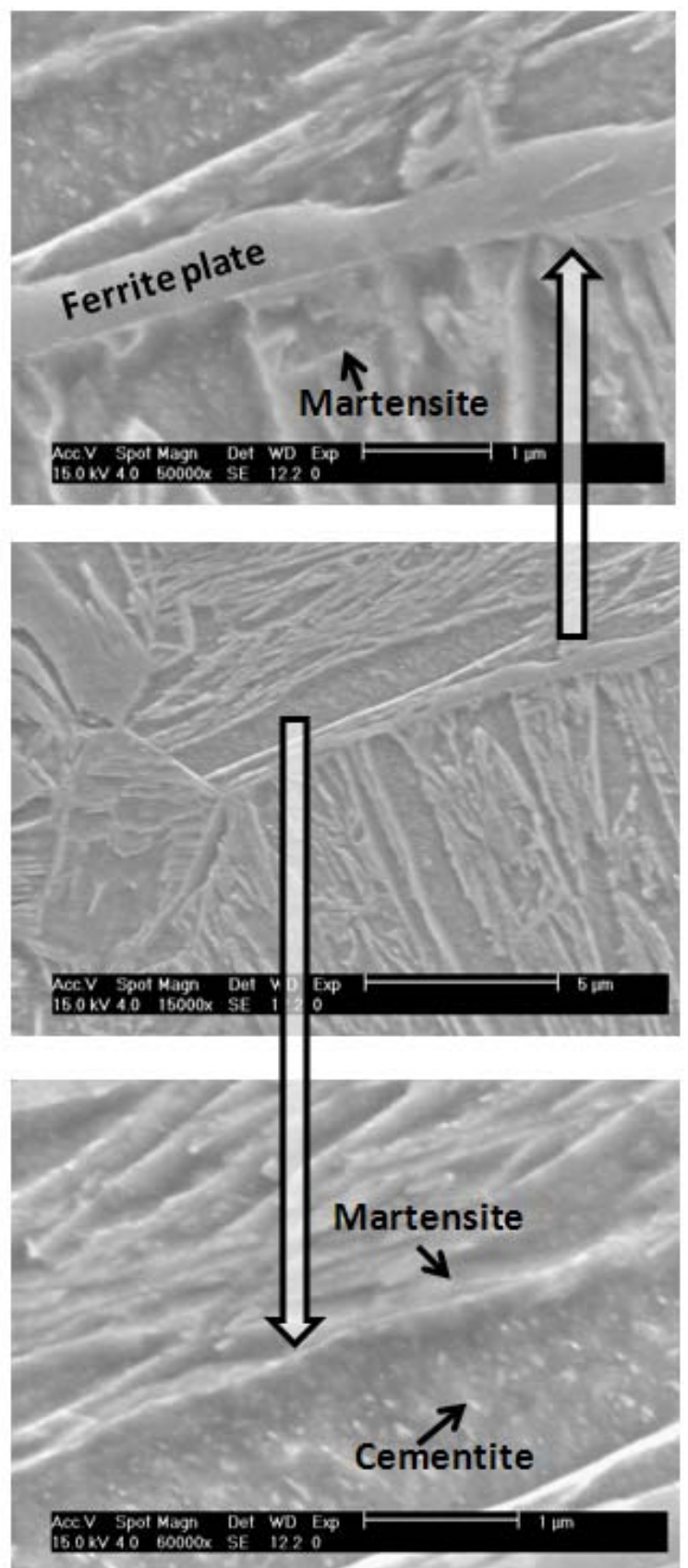

Fig. 4.3: Scanning electron micrographs illustrating the formation of: (a) plate ferrite and (c) cementite particles. The specimen was deformed in torsion at $862^{\circ} \mathrm{C}\left(\mathrm{Ae}_{3}+40^{\circ} \mathrm{C}\right)$ to a strain of $\varepsilon=0.15$ in $33 \mathrm{~ms}$ and then quenched. The austenite present after straining was converted to martensite. 
When the strain is increased beyond 0.15 , the initial plate-like structure is gradually converted into fairly equiaxed grains. This process leads to a deformation microstructure that is a complex mixture of both grains and plates of ferrite located in a martensite matrix. This is shown in Fig. 4.4. The presence of cementite particles should be noted in some of the ferrite plates as well as in some of the ferrite grains. The straight boundaries of the ferrite plates indicate that they formed by a displacive transformation and are Widmanstätten in nature. This generalization is supported by the short times involved in their formation, e.g., about 5 ms per $1 \%$ strain [4.3].

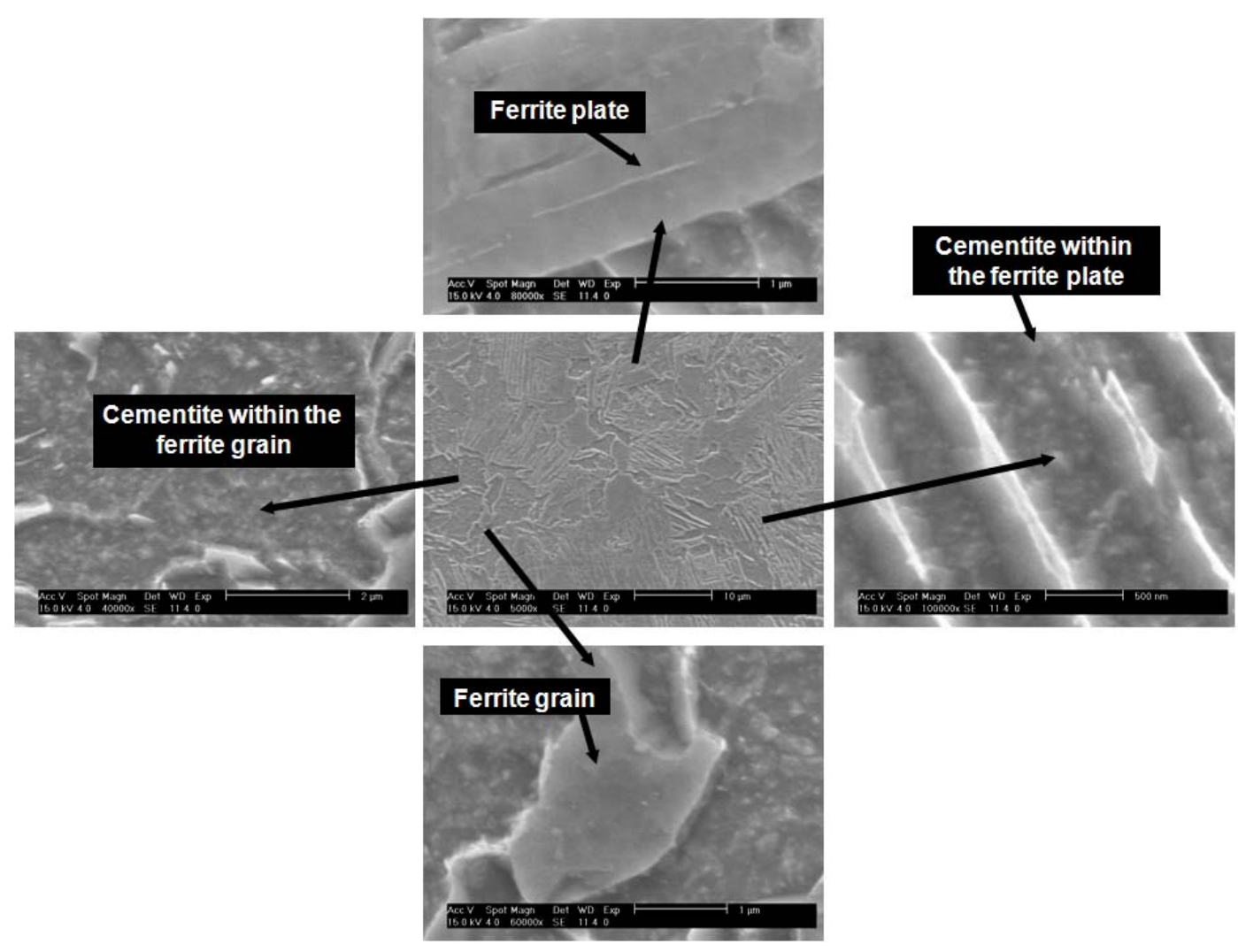

Fig. 4.4: Scanning electron micrograph of a specimen deformed to a strain of 0.25 at $4.5 \mathrm{~s}^{-1}$ at $862^{\circ} \mathrm{C}\left(\mathrm{Ae}_{3}+40^{\circ} \mathrm{C}\right)$. The deformed and quenched specimen contains ferrite, cementite and martensite. 
It is significant that the basic constituents of the microstructure do not change as the temperature is increased above the $\mathrm{Ae}_{3}$. Three phases (ferrite, cementite and martensite) are present up to $892^{\circ} \mathrm{C}$ (i.e. $\mathrm{Ae}_{3}+70^{\circ} \mathrm{C}$ ). This is clearly demonstrated in Figs. 4.5(a) and (b), where the samples were deformed to a strain of 3 at $4.5 \mathrm{~s}^{-}$

${ }^{1}$ at the temperatures shown (Fig. $4.5(\mathrm{a})-842^{\circ} \mathrm{C}\left(\mathrm{Ae}_{3}+20^{\circ} \mathrm{C}\right)$ and (b) $-892^{\circ} \mathrm{C}\left(\mathrm{Ae}_{3}\right.$ $\left.+70^{\circ} \mathrm{C}\right)$ ). The presence of martensite after large strains indicates that some areas of the material had not yet reached the critical strain for dynamic transformation (DT) and that the dislocation density (driving force for DT) was not high enough in these particular regions of the specimens to provoke the transformation.

(a)

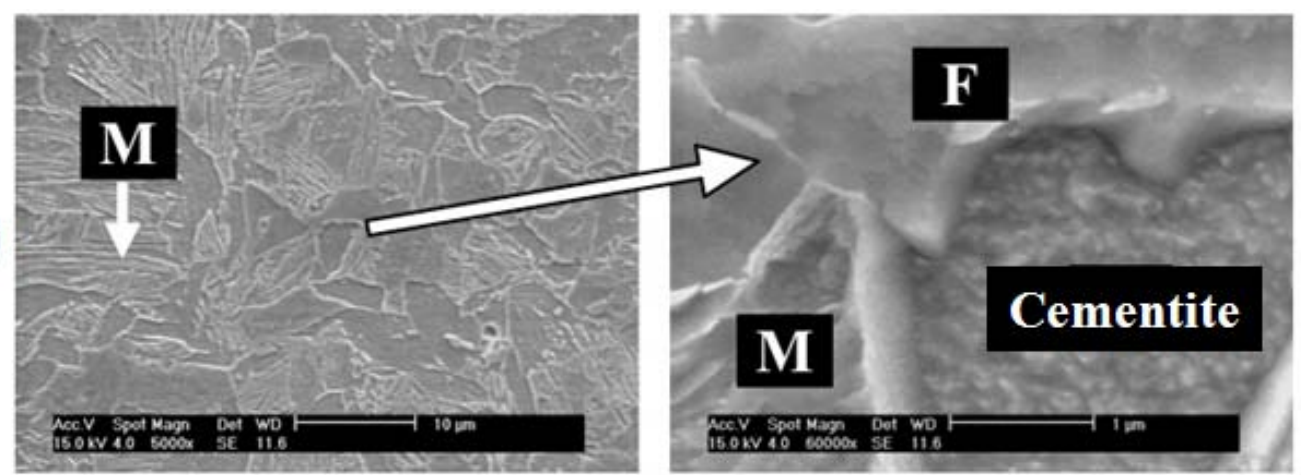

(b)

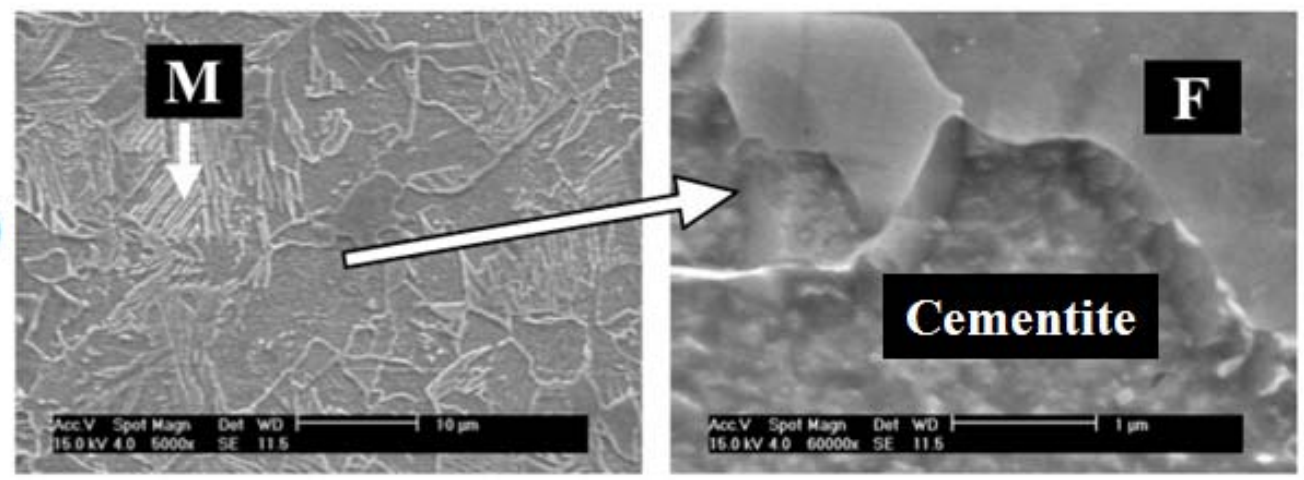

Fig. 4.5: Presence of ferrite and cementite particles in the microstructure after deformation to a strain of 3 at $4.5 \mathrm{~s}^{-1}$ at the following temperatures: (a) $842^{\circ} \mathrm{C}$ $\left(\mathrm{Ae}_{3}+20^{\circ} \mathrm{C}\right)$, (b) $892^{\circ} \mathrm{C}\left(\mathrm{Ae}_{3}+70^{\circ} \mathrm{C}\right)$. Here the $\mathrm{Ae}_{3}$ is the orthoequilibrium temperature; the paraequilibrium temperatures are $14^{\circ} \mathrm{C}$ lower. 


\subsubsection{EBSD Results}

An EBSD investigation of the $0.21 \%$ C steel was carried out by Dr. V.V. Basabe. Some examples of the micrographs of this steel deformed to a strain of $\varepsilon=0.25$ at $862^{\circ} \mathrm{C}$ (i.e. $\mathrm{Ae}_{3}+40^{\circ} \mathrm{C}$ ) he obtained are presented in Fig. 4.6. Here the presence of the dynamically formed Widmanstätten ferrite plates is clearly evident as well as the martensite that formed from the prior austenite. It should be noted that the Widmanstätten ferrite plates in Fig. 4.6(a) and (b) are a few hundred nanometers wide and that some of the martensite in Fig. 4.6(c) is also of plate (rather than equiaxed) morphology. Another interesting feature is that the martensite (i.e. prior austenite) phase is frequently absent in the interiors of the plate colonies. Here it is important to note that the Widmanstätten ferrite does not nucleate on allotriomorphic ferrite, which is absent above the $\mathrm{Ae}_{3}$. This behavior is in contrast to that of conventional Widmanstätten ferrite and is an aspect of the current type of microstructure. The scattered locations of the retained austenite indicate that the strain distribution in the matrix is inhomogeneous and that the critical strain for DT was not attained in these regions [4.3].

An important characteristic of this microstructure is the small value of the misorientations between the ferrite plates, see Fig. 4.6(d). This is one of the reasons why the plates are able to coalesce so readily into grains. Another is the absence of "spines" between pairs of plates, a common characteristic of subequilibrium Widmanstätten ferrite [4.5]. Under the latter conditions, pairs of variants of compensating shears grow in tandem so as to reduce the total accommodation required. Here it can be seen that the additional driving force provided in the deformed austenite eliminates the need for self-accommodating growth. 


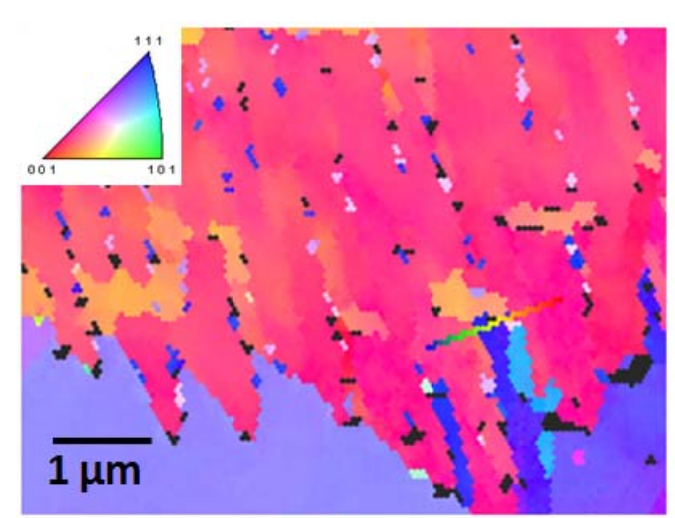

(a)

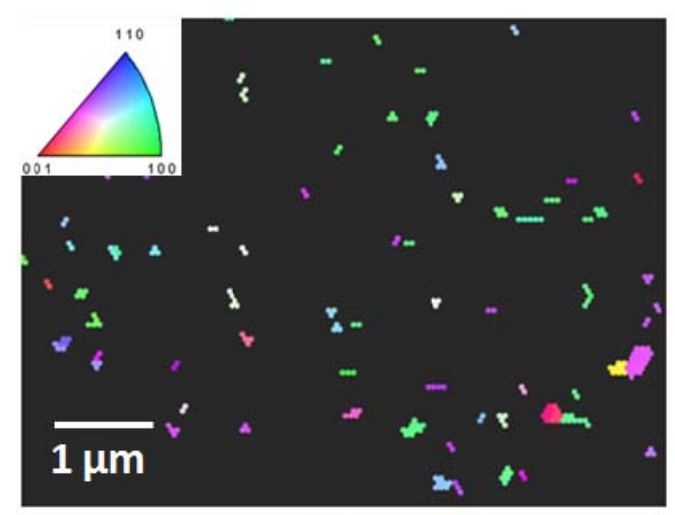

(c)

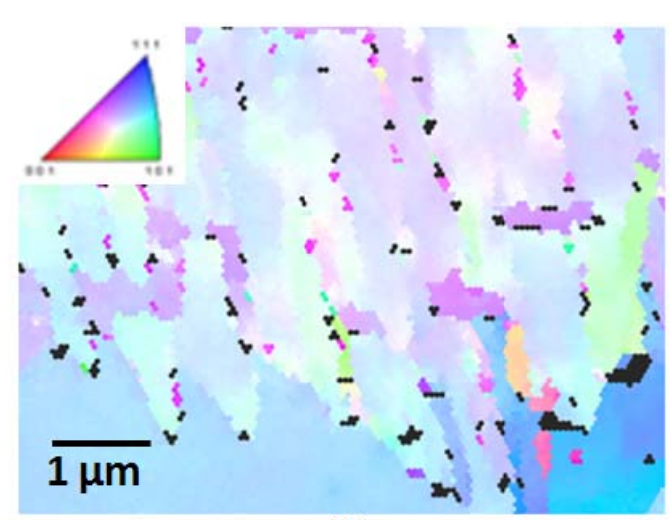

(b)

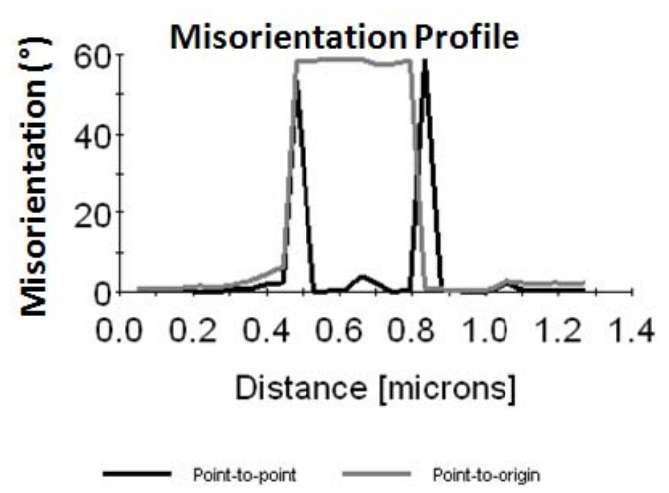

(d)

Fig. 4.6: EBSD micrographs of a transverse cross-section of the $0.21 \% \mathrm{C}$ steel strained to $\varepsilon=0.25$ at $862^{\circ} \mathrm{C}\left(\mathrm{Ae}_{3}+40^{\circ} \mathrm{C}\right)$ : (a) orientation image map of the ferrite phase (radial direction), black regions are martensite, (b) orientation image map of the ferrite phase (longitudinal direction), (c) orientation image map of the martensite phase, black regions are ferrite (radial direction), (d) misorientations measured along the line in (a). The $60^{\circ}$ misorientation indicates the presence of a twinned region in the prior austenite [4.3].

\subsubsection{Effect of Strain on Phase Proportions}

The dependence of the DT ferrite volume fraction on strain at $862^{\circ} \mathrm{C}$ (i.e. $\mathrm{Ae}_{3}+$ $40^{\circ} \mathrm{C}$ ) is illustrated in Fig. 4.7, where the specimens were deformed at a strain rate of $4.5 \mathrm{~s}^{-1}$. From this figure, it appears that the critical strain for DT in this particular steel is very approximately 0.15 . More precise values will be presented later in Chapter 5. It is also to be noted that, in the strain interval $0.3-0.6$, the 


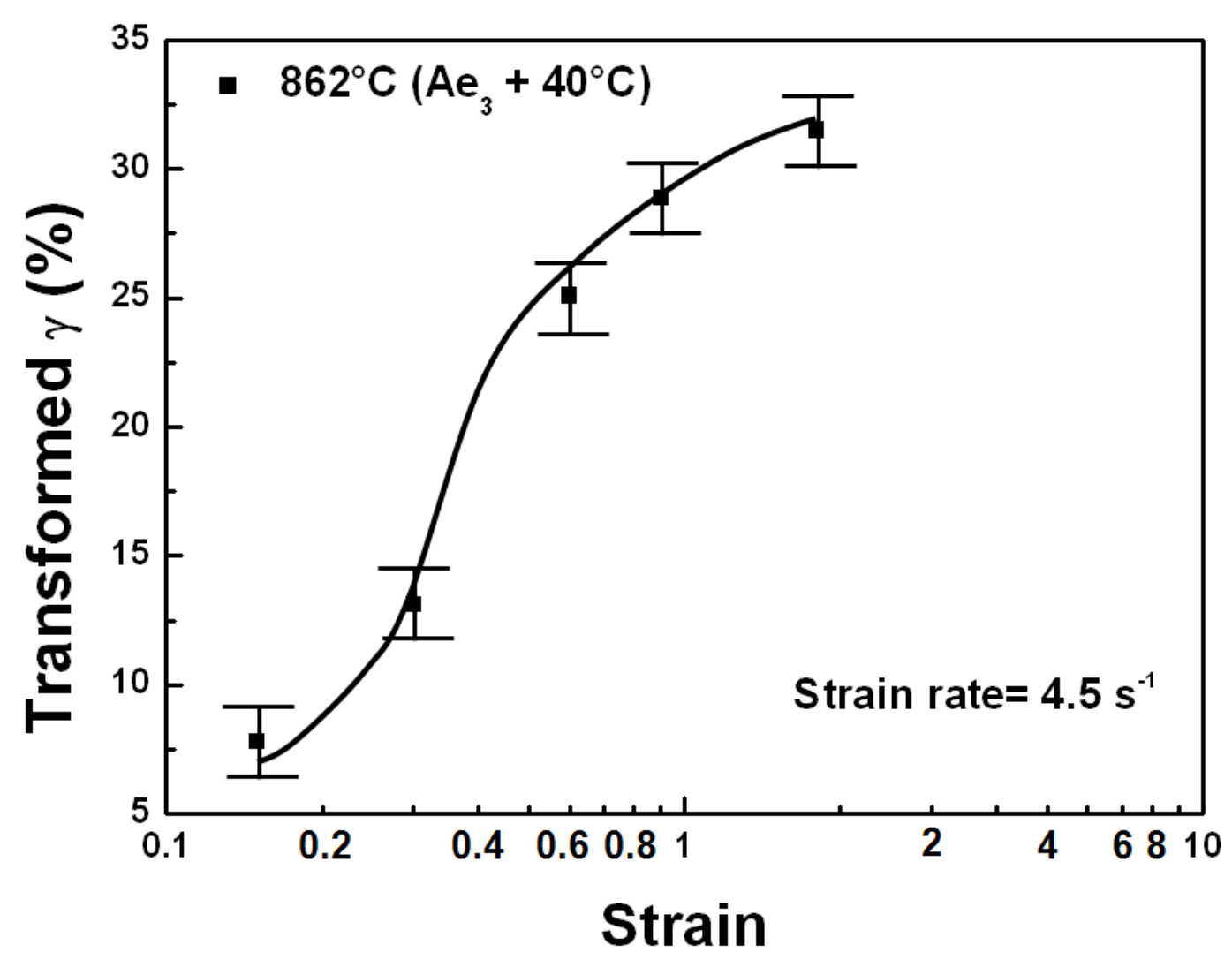

Fig. 4.7: Effect of strain on the percentage of austenite that transforms dynamically into ferrite and cementite at $862^{\circ} \mathrm{C}\left(\mathrm{Ae}_{3}+40^{\circ} \mathrm{C}\right)$ at $4.5 \mathrm{~s}^{-1}$.

rate of transformation increases sharply. Beyond a strain of about 0.6 , the rate of transformation per unit strain decreases significantly.

\subsection{79\%C Steel}

\subsubsection{SEM Results}

The critical strain for the initiation of dynamic transformation of this steel was found to be about 0.25 . Detailed calculations for evaluating the value of the critical strain are discussed in Chapter 5 [4.4]. A scanning electron micrograph of the steel at $753^{\circ} \mathrm{C}$ (i.e. $\mathrm{Ae}_{3}+20^{\circ} \mathrm{C}$ ) is illustrated in Fig. 4.8 after straining to $\varepsilon=$ 0.25 at a strain rate of $\dot{\varepsilon}=4.0 \mathrm{~s}^{-1}$. The microstructure reveals the concurrent presence of three phases, namely, ferrite, cementite and martensite. The freshly formed DT ferrite in the present case is predominantly plate-like in form; see Fig. 
4.8, top right side. Some typical straight interfaces characteristic of these microstructures are highlighted with white arrows. These interfaces are indicative of plate formation by a displacive mode [4.6]. This is consistent with the short times involved in their formation, i.e. about $2 \mathrm{~ms}$ per $1 \%$ strain [4.3]. The Widmanstätten nature of these plates is discussed in more detail later.

Given the relatively high carbon content, appreciable amounts of cementite $\left(\mathrm{Fe}_{3} \mathrm{C}\right)$ were formed, in addition to the ferrite. The finely dispersed cementite particles can be seen to better effect at higher magnification in the lower right hand figure. These are less than $100 \mathrm{~nm}$ in diameter and can be much more clearly identified using TEM techniques, see Fig. 4.13(b). Due to the inhomogeneous strain distribution in the parent austenite, some of the areas have not yet attained the critical strain for DT. These regions eventually transform into martensite on quenching. The three phases in the microstructure are readily identified by their morphological characteristics.

Similar microstructures were obtained from the steel deformed at $783^{\circ} \mathrm{C}$ (i.e. $\mathrm{Ae}_{3}$ $+50^{\circ} \mathrm{C}$ ) to a strain of 0.25 at a strain rate of $\dot{\varepsilon}=4.0 \mathrm{~s}^{-1}$. These are depicted in Fig.

\section{9.}

In a few places, at higher applied strains, the initial plate-like structures were transformed into equiaxed grains decorating the prior austenite grain boundaries. An example is provided in Fig. 4.10, where a scanning electron micrograph of a specimen deformed to a strain of 0.5 at $4 \mathrm{~s}^{-1}$ at $753^{\circ} \mathrm{C}$ (i.e. $\mathrm{Ae}_{3}+$ $20^{\circ} \mathrm{C}$ ) is shown [4.6]. Both Widmanstätten ferrite plates and ferrite grains can be seen. Particles are present in some of the ferrite plates as well as in some of the ferrite grains. Conversely, some of the plates and grains are devoid of particles. Some cementite plates are located next to the spheroid-free ferrite plates. Thus the microstructure of the deformed and quenched material is quite complex in nature. 


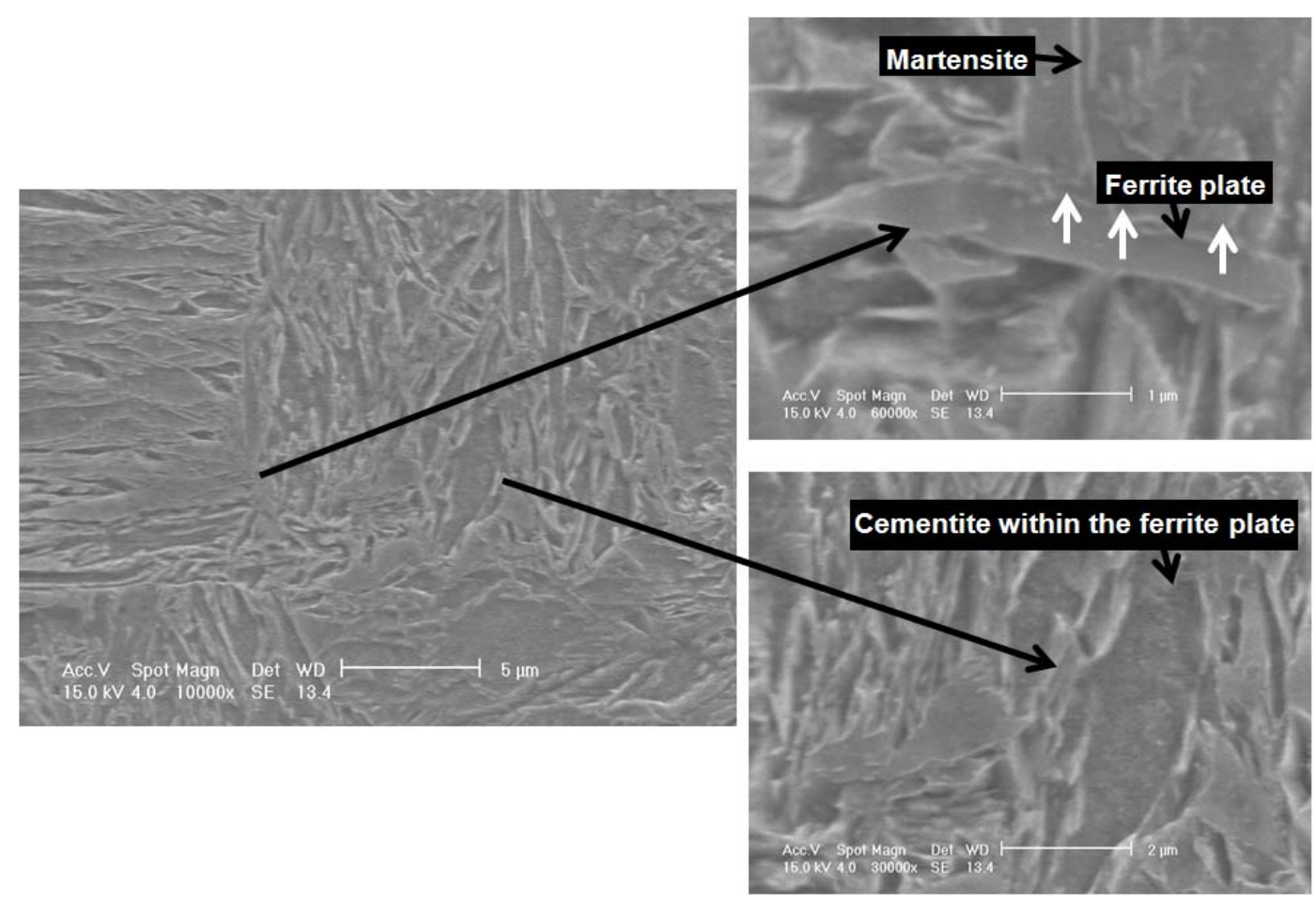

Fig. 4.8: Scanning electron micrographs showing the presence of Widmanstätten ferrite plates and cementite precipitates. The specimen was deformed at $753^{\circ} \mathrm{C}$ $\left(\mathrm{Ae}_{3}+20^{\circ} \mathrm{C}\right)$ to a strain of 0.25 in $62 \mathrm{~ms}$ and then quenched. The austenite present after straining was converted into martensite. Some characteristic straight interfaces are highlighted with white arrows [4.6].

It is of interest that the principal constituents of the microstructure do not change as the temperature is increased above the $\mathrm{Ae}_{3}$. Three phases, namely, ferrite, cementite and martensite, are present over the entire temperature range from $743^{\circ} \mathrm{C}$ (i.e. $\mathrm{Ae}_{3}+10^{\circ} \mathrm{C}$ ) to $863^{\circ} \mathrm{C}$ (i.e. $\mathrm{Ae}_{3}+130^{\circ} \mathrm{C}$ ), the highest temperature investigated. This is clearly demonstrated in Figs. 4.11(a) to (i), where the samples were deformed to a strain of 4 at a strain rate of $4 \mathrm{~s}^{-1}$ at the temperatures shown (Fig. 4.11(a) $-743^{\circ} \mathrm{C}\left(\mathrm{Ae}_{3}+10^{\circ} \mathrm{C}\right)$, Fig. $4.11(b)-753^{\circ} \mathrm{C}\left(\mathrm{Ae}_{3}+\right.$ $\left.20^{\circ} \mathrm{C}\right)$, Fig. $4.11(\mathrm{c})-763^{\circ} \mathrm{C}\left(\mathrm{Ae}_{3}+30^{\circ} \mathrm{C}\right)$, Fig. 4.11(d) $-773^{\circ} \mathrm{C}\left(\mathrm{Ae}_{3}+40^{\circ} \mathrm{C}\right)$, Fig. 4.11(e) $-783^{\circ} \mathrm{C}\left(\mathrm{Ae}_{3}+50^{\circ} \mathrm{C}\right)$, Fig. 4.11(f) $-793^{\circ} \mathrm{C}\left(\mathrm{Ae}_{3}+60^{\circ} \mathrm{C}\right)$, Fig. 4.11(g) $-803^{\circ} \mathrm{C}$ $\left(\mathrm{Ae}_{3}+70^{\circ} \mathrm{C}\right)$, Fig. 4.11(h) $-823^{\circ} \mathrm{C}\left(\mathrm{Ae}_{3}+90^{\circ} \mathrm{C}\right)$ and Fig. 4.11(i) $-863^{\circ} \mathrm{C}\left(\mathrm{Ae}_{3}+\right.$ $\left.130^{\circ} \mathrm{C}\right)$ ). The presence of martensite even after such large strains indicates that 


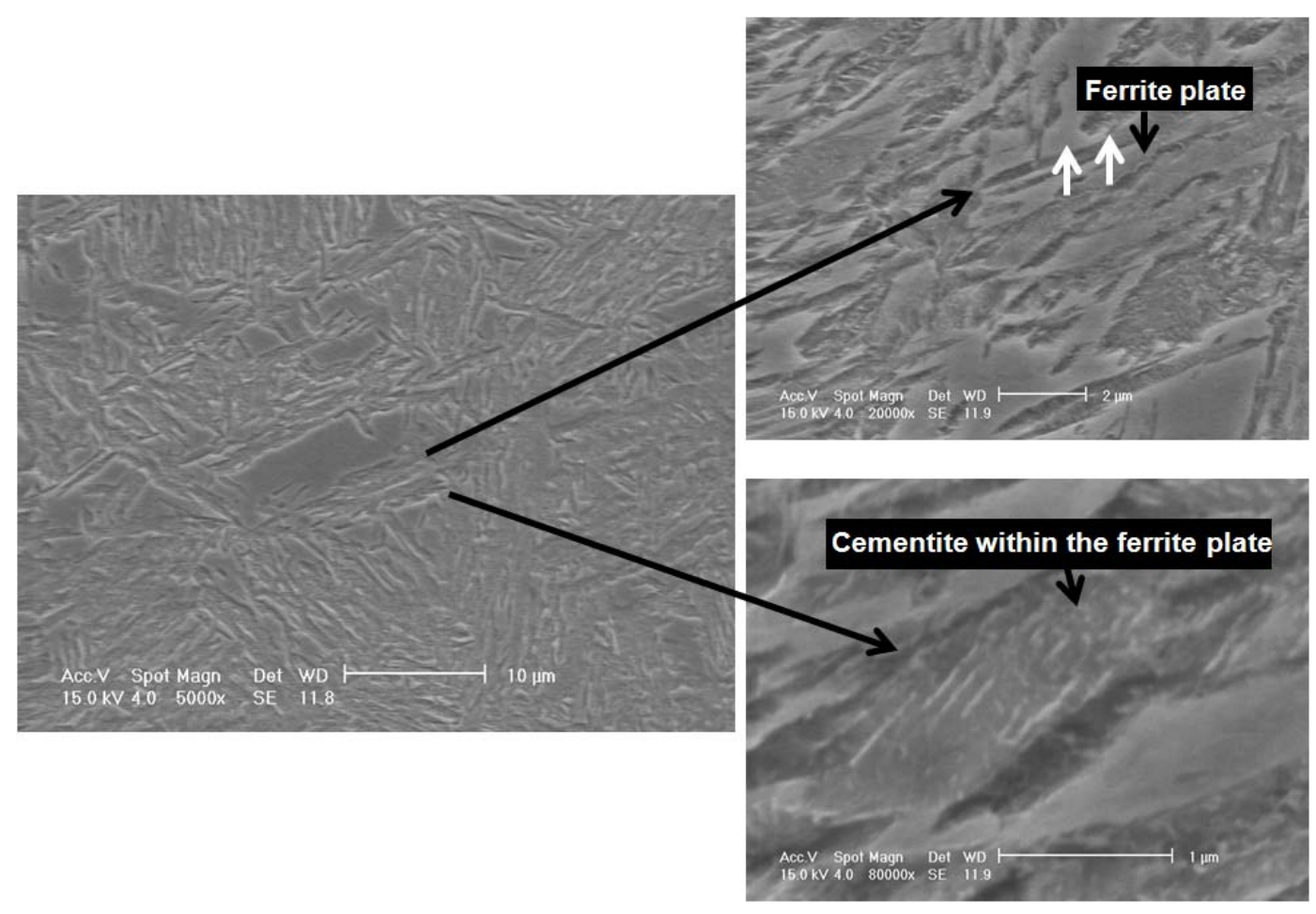

Fig. 4.9: Scanning electron micrographs showing the presence of Widmanstätten ferrite plates and cementite precipitates. The specimen was deformed at $783^{\circ} \mathrm{C}$ $\left(\mathrm{Ae}_{3}+50^{\circ} \mathrm{C}\right)$ to a strain of 0.25 in $62 \mathrm{~ms}$ and then quenched. The austenite present after straining was converted into martensite. Some characteristic straight interfaces are highlighted with white arrows.

the local dislocation density is not high enough in these regions to provide a sufficient driving force for DT. That is, the austenite in these locations did not attain the critical strain for dynamic transformation. As in the case of Fig. 4.11, the density of the cementite particles is not uniform across the microstructure [4.6]. 


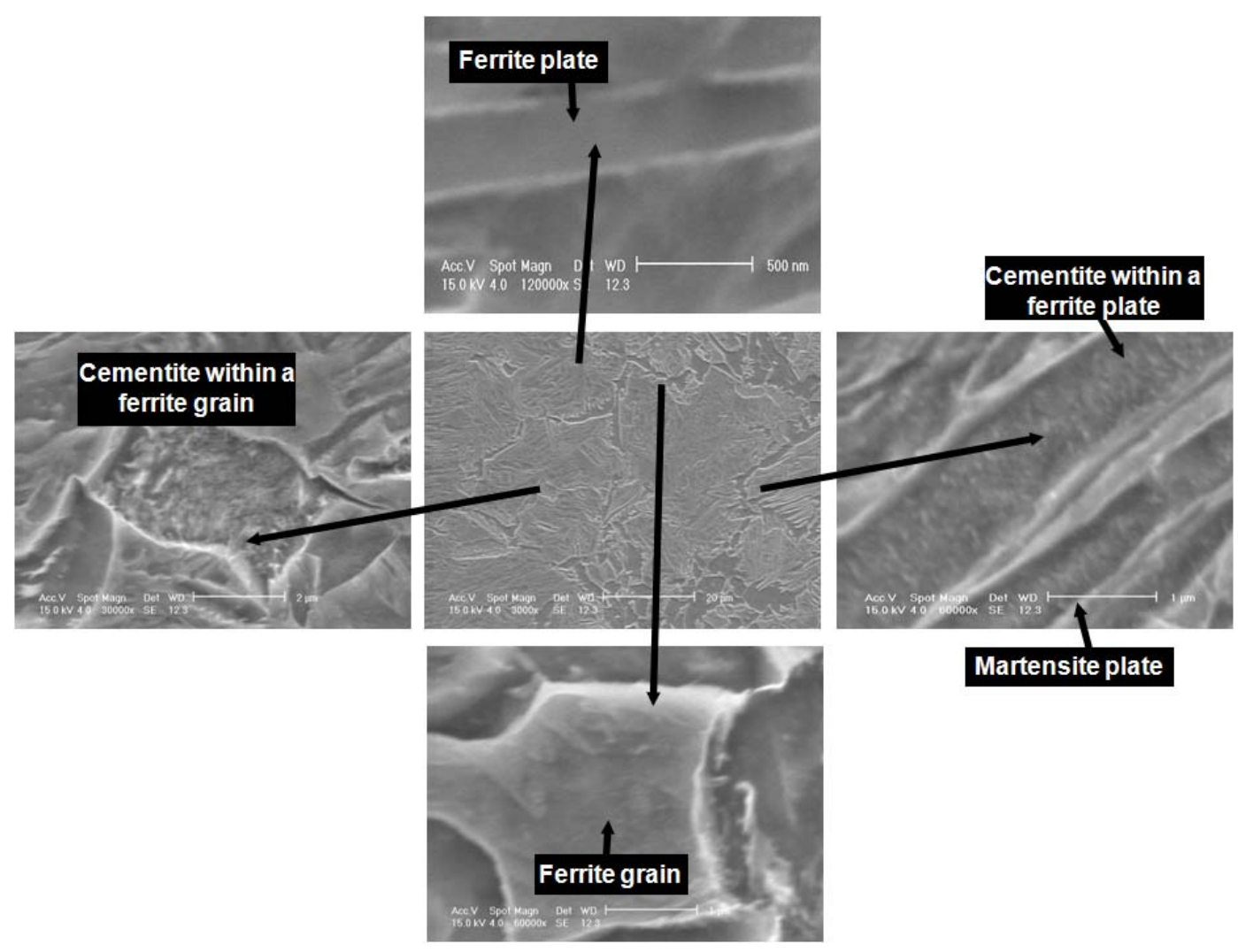

Fig. 4.10: Scanning electron micrograph of a specimen deformed to a strain of 0.5 at $4 \mathrm{~s}^{-1}$ at $753^{\circ} \mathrm{C}\left(\mathrm{Ae}_{3}+20^{\circ} \mathrm{C}\right)$. The deformed and quenched specimen contains Widmanstätten ferrite, cementite and martensite [4.6].

(a)

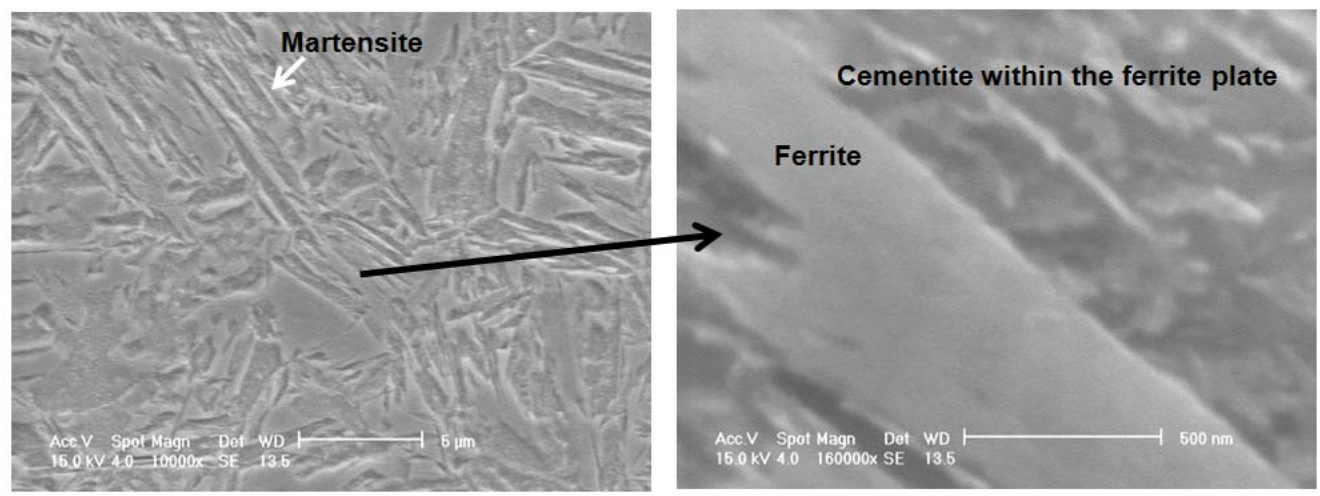


(b)

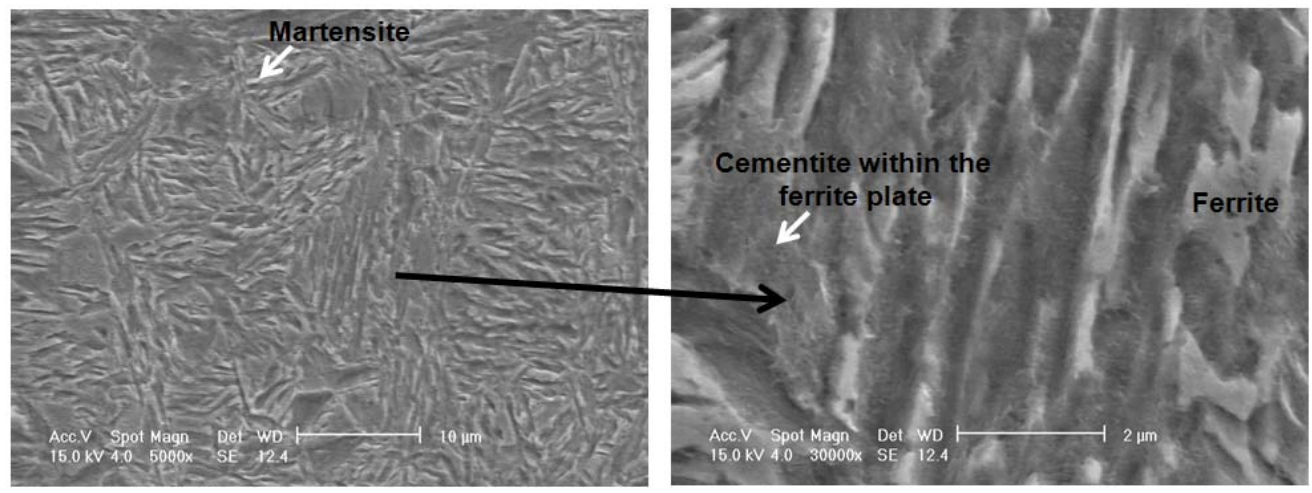

(c)

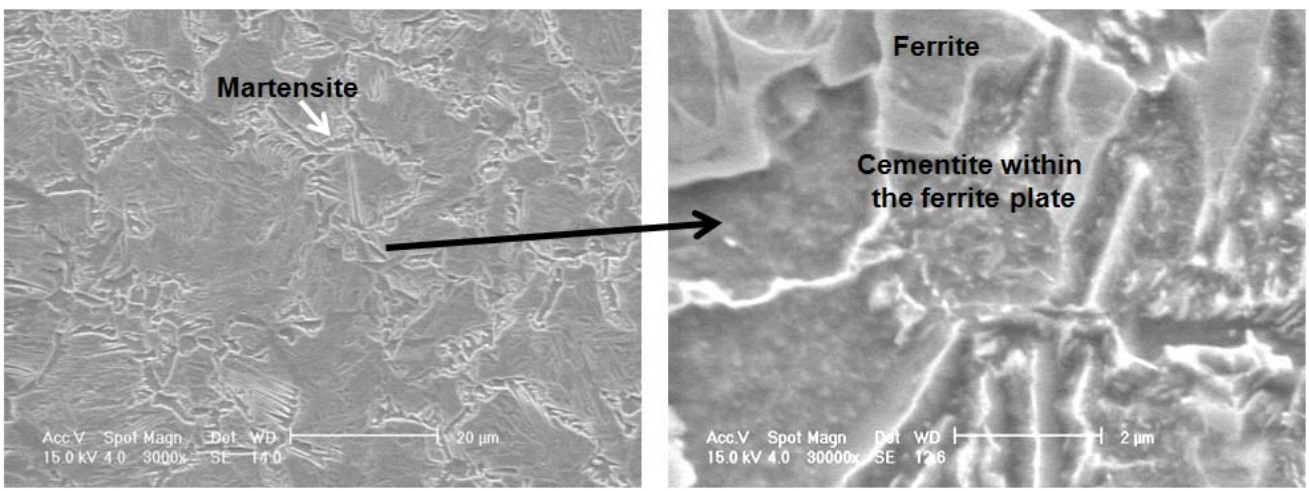

(d)

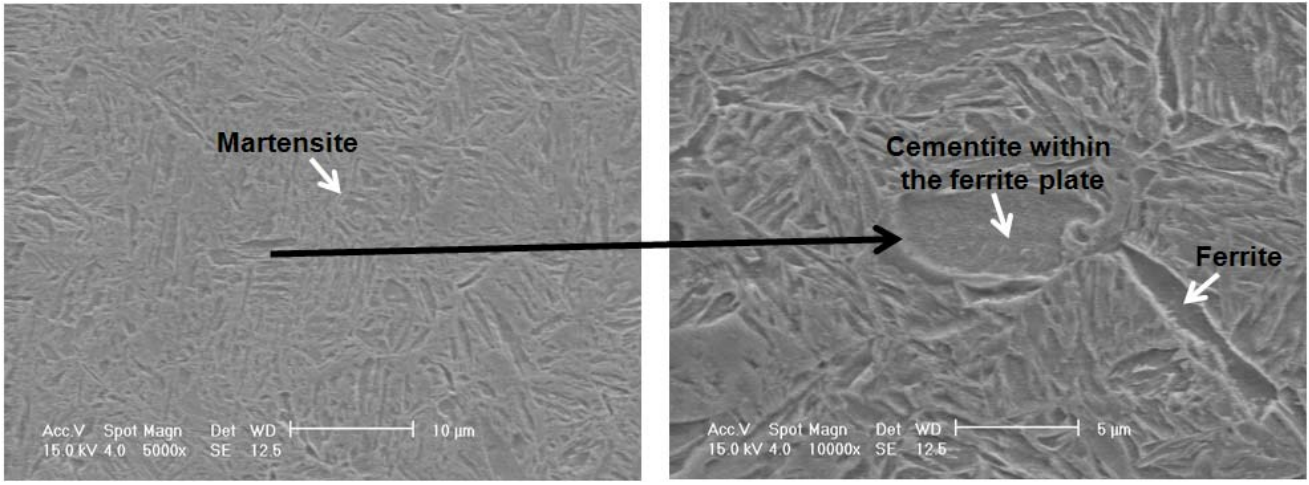


(e)

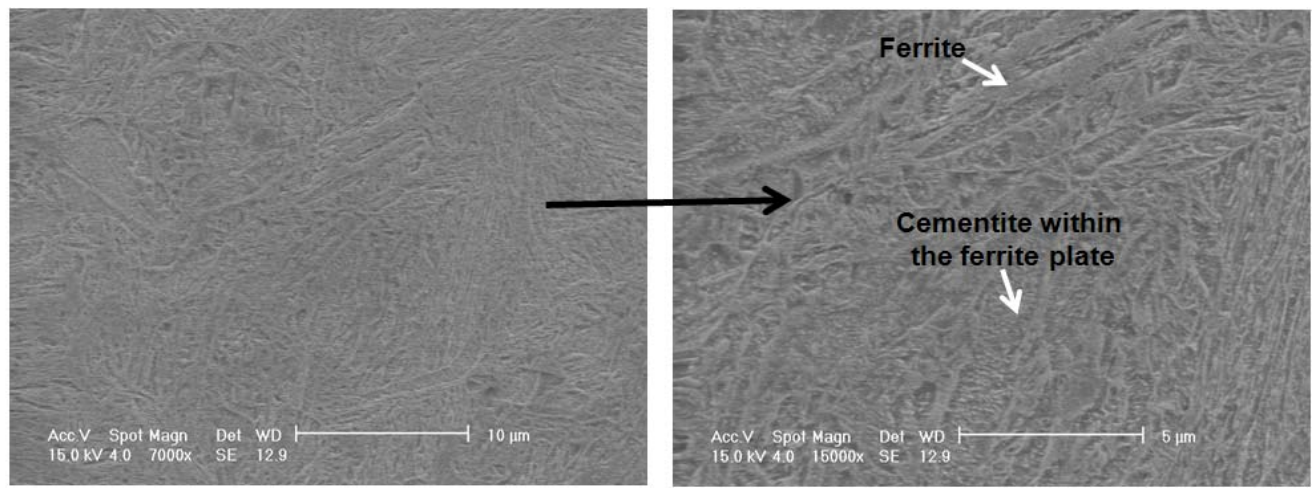

(f)

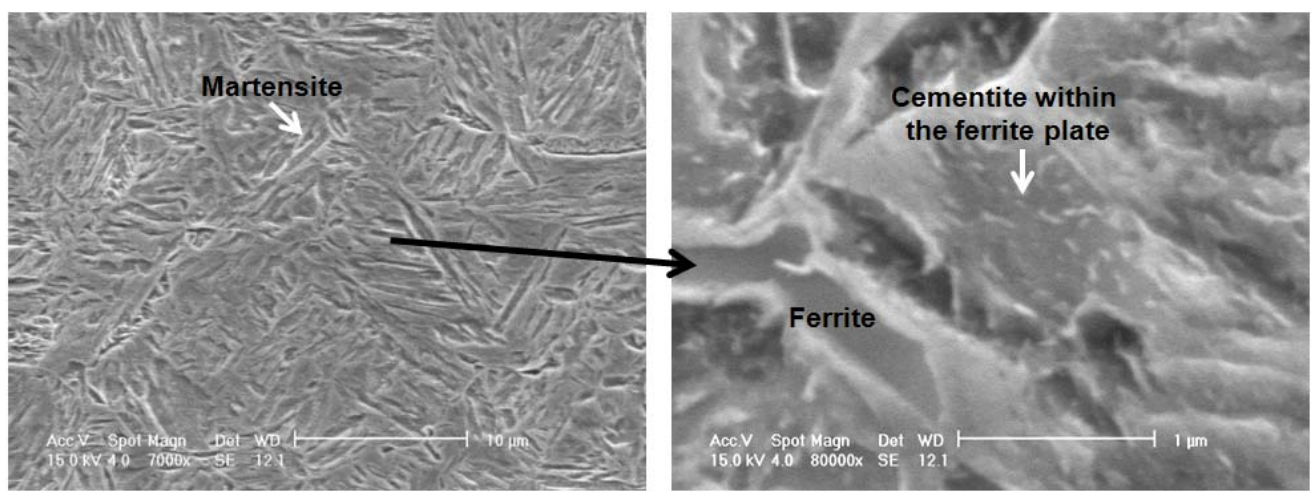

(g)

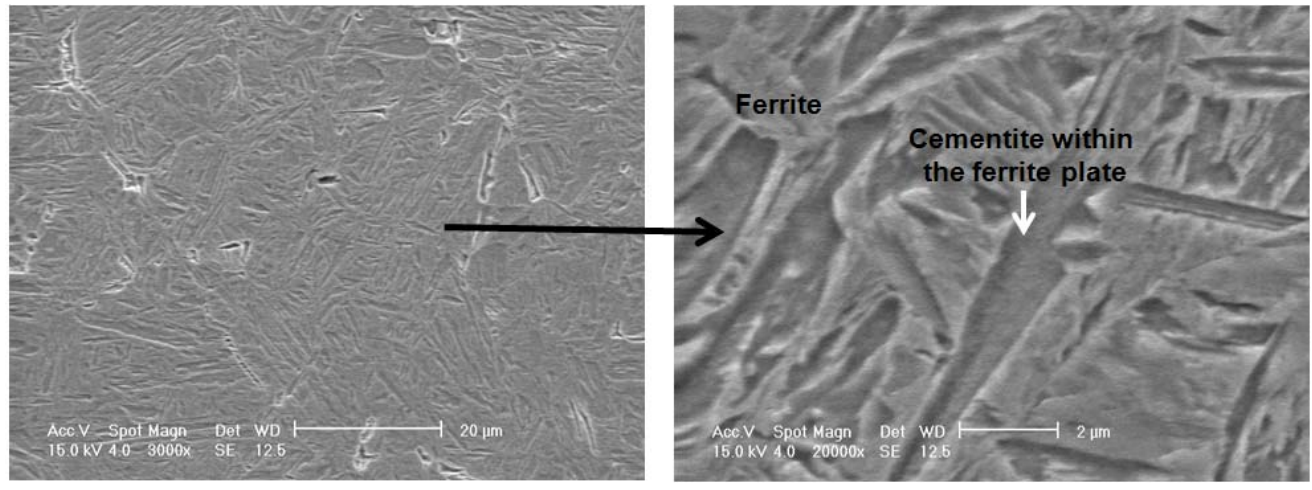


(h)

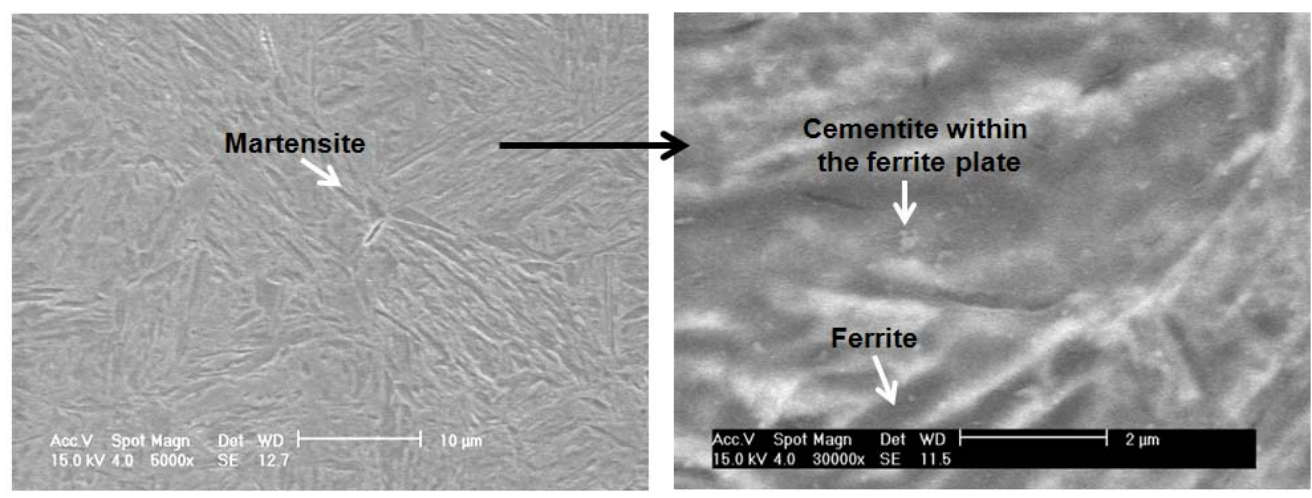

(i)

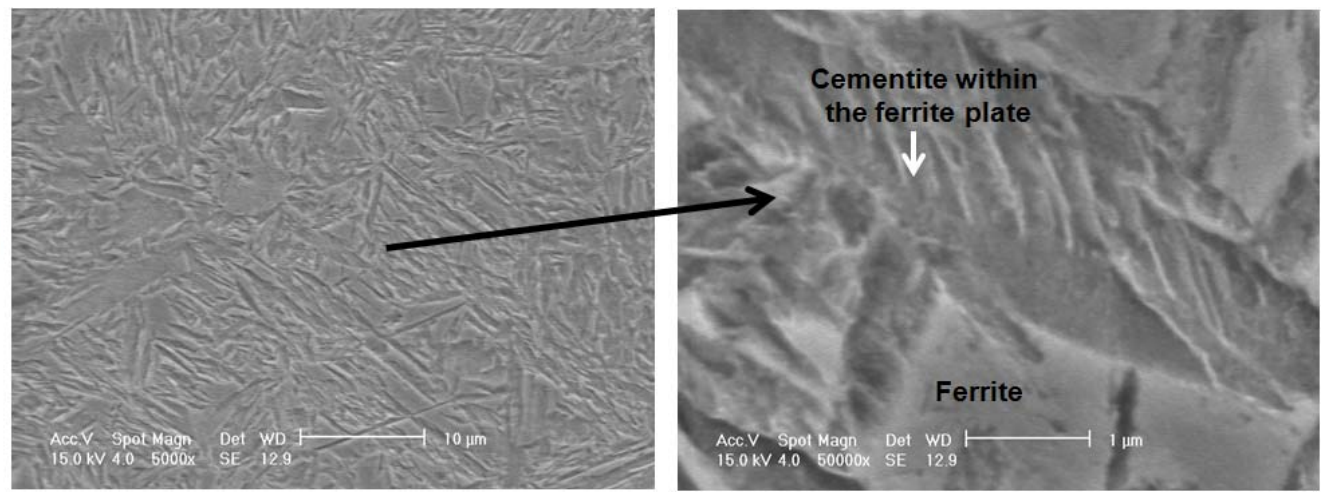

Fig. 4.11: Presence of ferrite and cementite in the microstructure after deformation to a strain of 4 at $4 \mathrm{~s}^{-1}$ at the following temperatures: (a) $743^{\circ} \mathrm{C}\left(\mathrm{Ae}_{3}\right.$ $\left.+10^{\circ} \mathrm{C}\right)$, (b) $753^{\circ} \mathrm{C}\left(\mathrm{Ae}_{3}+20^{\circ} \mathrm{C}\right)$, (c) $763^{\circ} \mathrm{C}\left(\mathrm{Ae}_{3}+30^{\circ} \mathrm{C}\right)$, (d) $773^{\circ} \mathrm{C}\left(\mathrm{Ae}_{3}+40^{\circ} \mathrm{C}\right)$, (e) $783^{\circ} \mathrm{C}\left(\mathrm{Ae}_{3}+50^{\circ} \mathrm{C}\right)$, (f) $793^{\circ} \mathrm{C}\left(\mathrm{Ae}_{3}+60^{\circ} \mathrm{C}\right)$, (g) $803^{\circ} \mathrm{C}\left(\mathrm{Ae}_{3}+70^{\circ} \mathrm{C}\right)$, (h) $823^{\circ} \mathrm{C}\left(\mathrm{Ae}_{3}+\right.$ $90^{\circ} \mathrm{C}$ ) and (i) $863^{\circ} \mathrm{C}\left(\mathrm{Ae}_{3}+130^{\circ} \mathrm{C}\right)$. Here the $\mathrm{Ae}_{3}$ is the orthoequilibrium temperature; the paraequilibrium intervals are $24^{\circ} \mathrm{C}$ greater [4.6].

\subsubsection{TEM Results}

The concurrent presence of ferrite, cementite and martensite in the microstructure was also verified using TEM techniques*. The presence of ferrite (F) and martensite (M) (i.e. prior austenite) in the microstructure of a sample deformed to a strain of 4 at $4 \mathrm{~s}^{-1}$ at $763^{\circ} \mathrm{C}\left(\mathrm{Ae}_{3}+30^{\circ} \mathrm{C}\right)$ is illustrated in Fig. 4.12. In

*The author is greatly indebted to Dr Xiang Y. Xiong, Dr. Ilana Thimokhina and Professor Elena Pereloma for providing the micrographs in Figs. 4.12 to 4.14 as well as for their assistance in the interpretation of the micrographs. 
the same sample, the morphology of the DT ferrite and its associated diffraction pattern are displayed in Fig. 4.13(a). The cementite precipitates inside the ferrite grains and their diffraction pattern are shown in Fig. 4.13(b). In the latter figure, three cementite precipitates are highlighted by white arrows. The martensite present in the microstructure had two different morphologies, namely, lath and plate shaped. These are illustrated in Fig. 4.14(a) and (b), respectively [4.6].

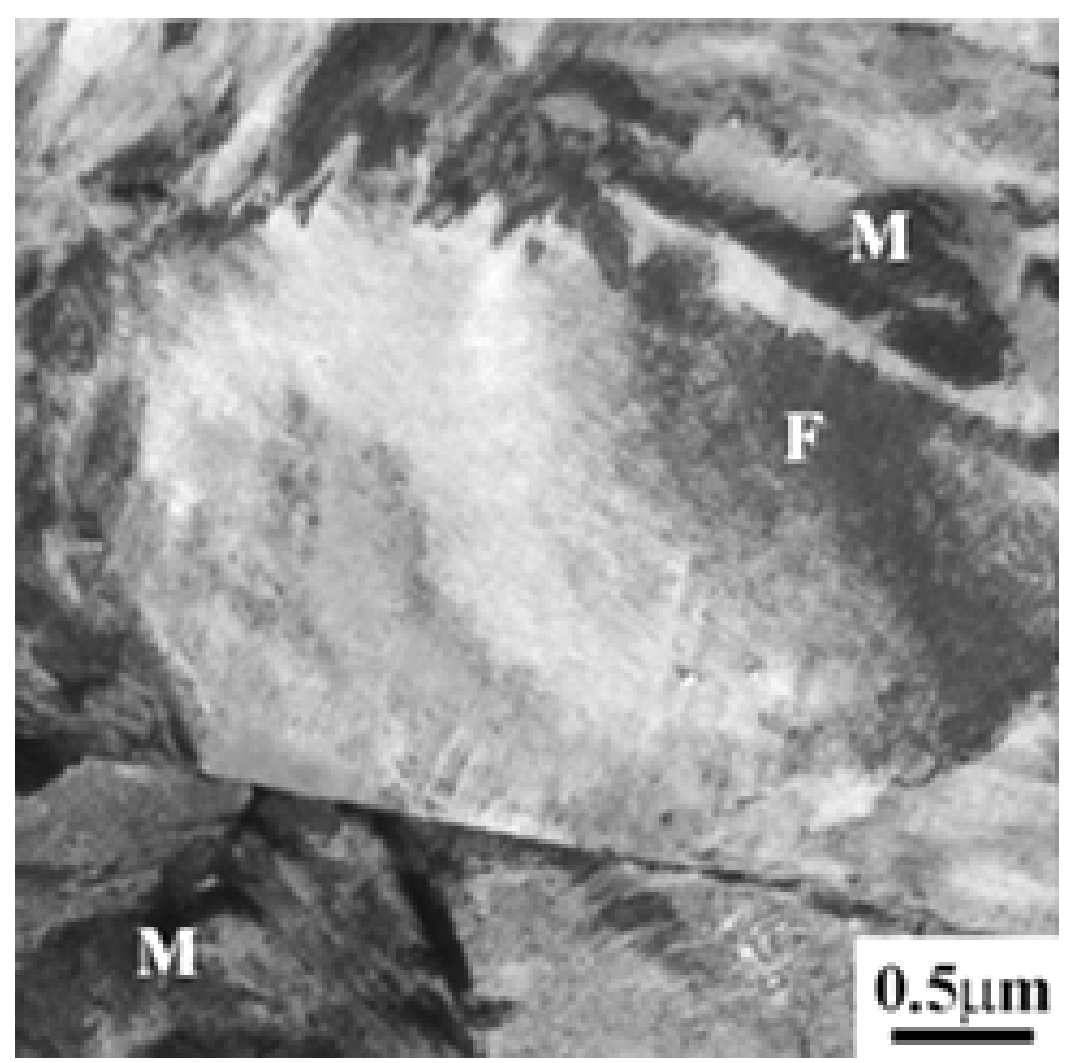

Fig. 4.12: Transmission electron micrograph illustrating the simultaneous presence of a ferrite plate $(F)$ and martensite $(M)$, i.e. austenite, in the microstructure. The sample was deformed to a strain of 4 at $4 \mathrm{~s}^{-1}$ at $763^{\circ} \mathrm{C}\left(\mathrm{Ae}_{3}+\right.$ $\left.30^{\circ} \mathrm{C}\right)$ [4.6]. 


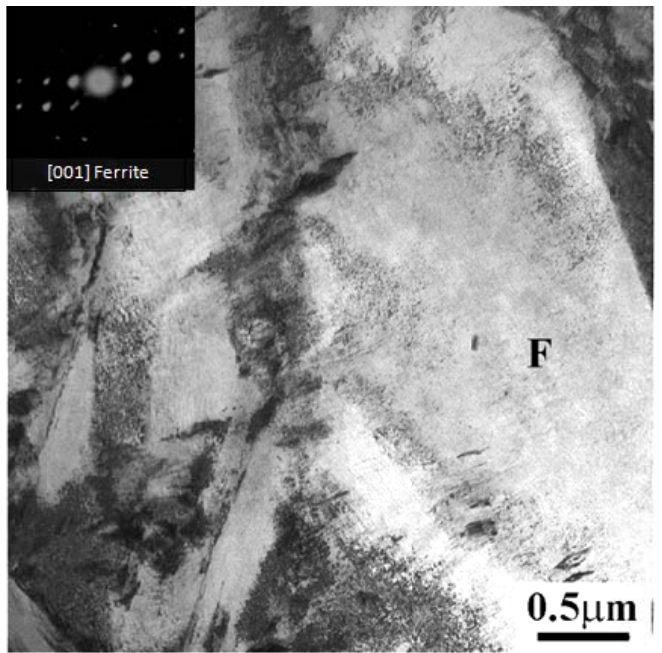

(a)

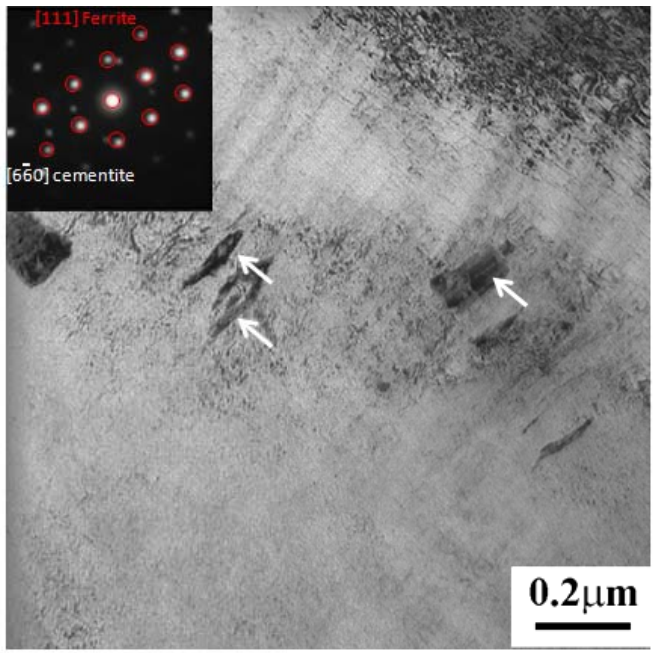

(b)

Fig. 4.13: Transmission electron micrographs displaying (a) the ferrite plate (F) morphology (diffraction pattern inset); (b) three cementite precipitates indicated by arrows and their corresponding diffraction pattern (inset). The sample was deformed in torsion to a strain of 4 at $4 \mathrm{~s}^{-1}$ at $763^{\circ} \mathrm{C}\left(\mathrm{Ae}_{3}+30^{\circ} \mathrm{C}\right)$ and quenched immediately afterwards [4.6].

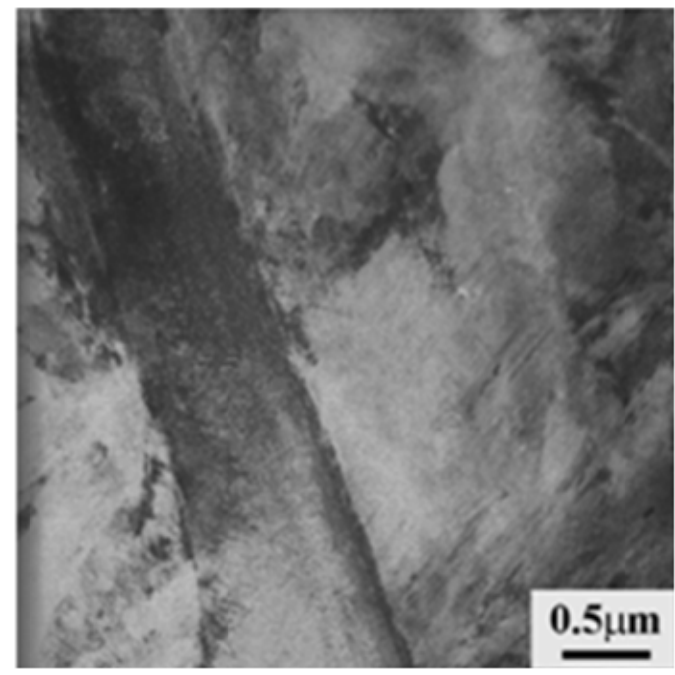

(a)

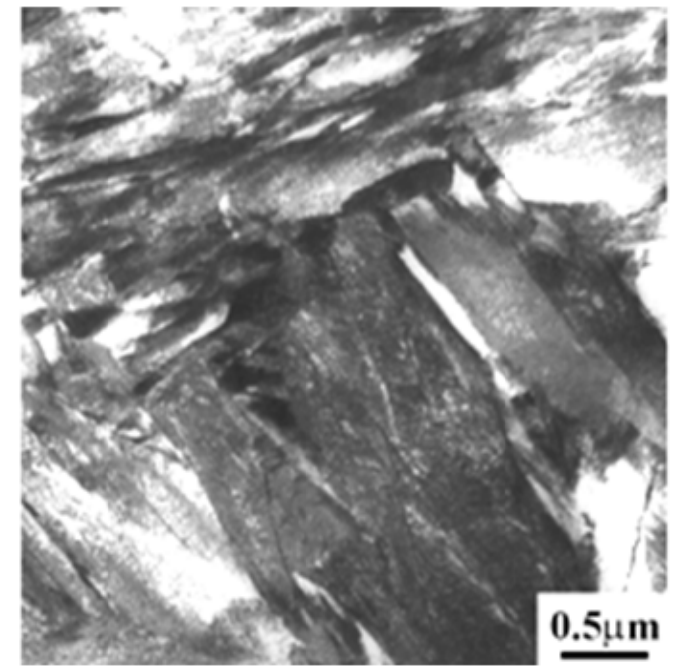

(b)

Fig. 4.14: Transmission electron micrographs of the martensite showing the two different morphologies observed: (a) lath-like and (b) plate-like. The sample was deformed in torsion to a strain of 4 at $4 \mathrm{~s}^{-1}$ at $763^{\circ} \mathrm{C}\left(\mathrm{Ae}_{3}+30^{\circ} \mathrm{C}\right)[4.6]$. 


\subsubsection{Atom Probe Analysis}

The compositions of the various phases were averaged over several volumes and are listed in Table 4.1. Here martensite (prior austenite) can be seen to contain more than 2 at\%C, polygonal ferrite as having about 0.02 at\%C, and carbide-free plate ferrite as containing less than 0.5 at\%C. Although the martensite $\mathrm{C}$ concentration is less than the nominal composition of the steel (3.6 at \%), this is consistent with the precipitation of $\mathrm{C}$ in the numerous cementite regions that were observed, both as dispersed particles and as thin films between the ferrite plates. The $\mathrm{Mn}$ and Si concentrations in the polygonal ferrite are in agreement with the paraequilibrium phase diagram and the carbide-free plate ferrite concentration with the results of previous APT studies of bainite formation $[4.7,4.8]$. The latter result is thus consistent with the interpretation of the plate ferrite being formed by a displacive mechanism. This conclusion is supported by the lack of partitioning of the substitutional elements $\mathrm{Mn}$ and $\mathrm{Si}$, not illustrated in detail here. In the plate ferrite that contained carbides, the $\mathrm{C}$ concentration is almost double that in the carbide free plates, Table 4.1. (The overestimation of the Si level in the present results can be attributed to certain deficiencies of the APT method [4.9].)

A representative $C$ atom map of the martensite referred to above is presented in Fig. 4.15(a) and of the plate ferrite in Fig. 4.15(b). A C concentration profile across the Fig. 4.15(b) sub-boundary is depicted in Fig. 4.15(c), where the segregation to dislocations can be readily seen. Detailed examination of the torsion sample deformed at $763^{\circ} \mathrm{C}$ also revealed considerable $\mathrm{C}$ segregation to shear bands, see Fig. 4.16(a). The enrichment at these bands attained levels as high as 4-9 at\%, Fig. 4.16(b). In the plate ferrite, carbides formed in these regions of C enrichment [4.6]. 
Table 4.1. Phase compositions (at\%) determined by APT based on the total number of atoms in the analyzed volume. The specimen was deformed in torsion to a strain of 4 at $4 \mathrm{~s}^{-1}$ at $763^{\circ} \mathrm{C}\left(\mathrm{Ae}_{3}+30^{\circ} \mathrm{C}\right) *[4.6]$.

\begin{tabular}{|c|c|c|c|c|c|c|}
\hline \multicolumn{2}{|c|}{ Steel composition } & Martensite & $\begin{array}{c}\text { Polygonal } \\
\text { ferrite }\end{array}$ & $\begin{array}{c}\text { Plate ferrite } \\
\text { free of visible } \\
\text { carbides }\end{array}$ & $\begin{array}{c}\text { Plate ferrite } \\
\text { containing } \\
\text { carbides }\end{array}$ \\
\hline & wt\% & at\% & at\% & at\% & at\% & at\% \\
\hline C & 0.79 & 3.60 & $2.56 \pm 0.02$ & $0.02 \pm 0.004$ & $0.45 \pm 0.008$ & $0.80 \pm 0.005$ \\
\hline Mn & 0.65 & 0.64 & $0.79 \pm 0.01$ & $0.78 \pm 0.02$ & $0.76 \pm 0.01$ & $0.74 \pm 0.004$ \\
\hline Si & 0.24 & 0.49 & $0.84 \pm 0.01$ & $0.77 \pm 0.02$ & $0.76 \pm 0.01$ & $0.75 \pm 0.005$ \\
\hline
\end{tabular}

(a)
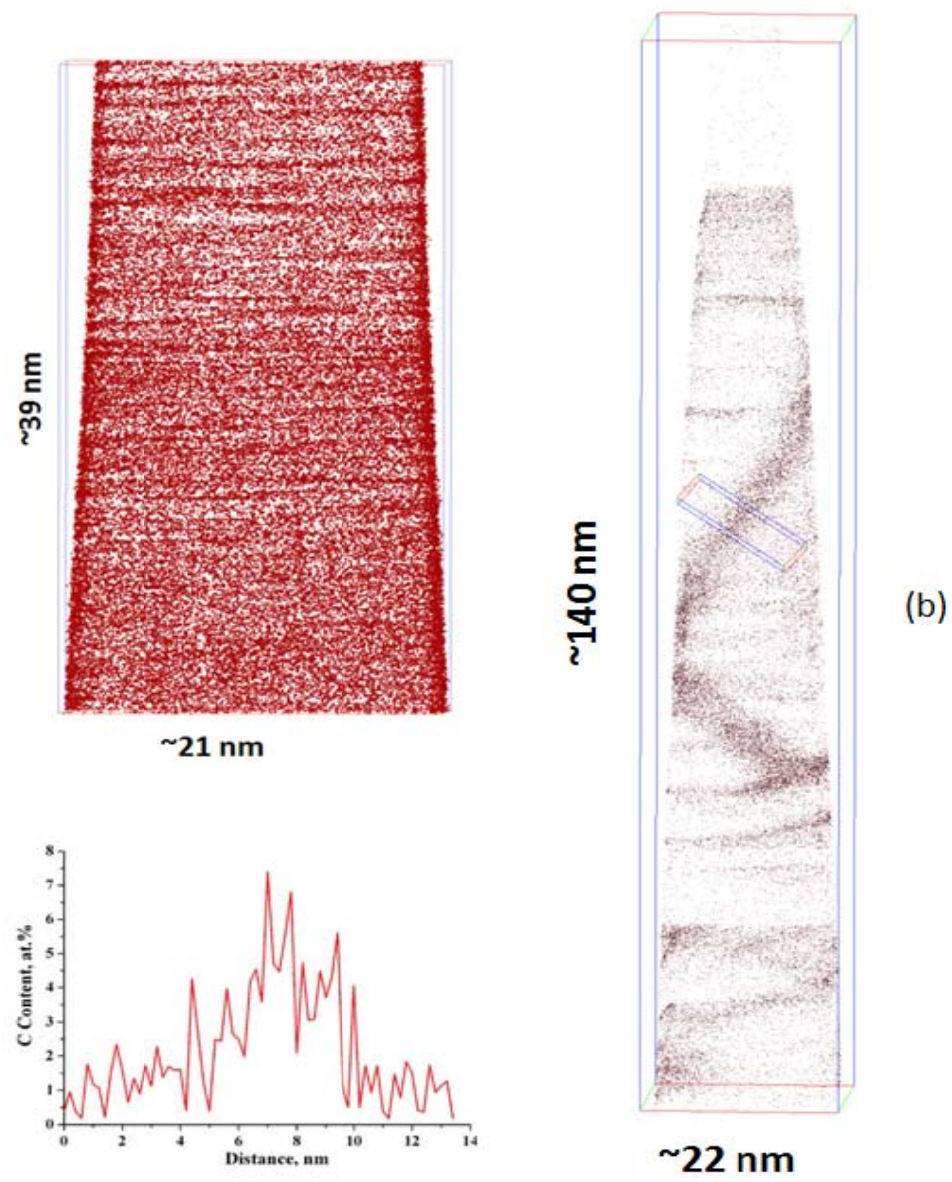

(c)

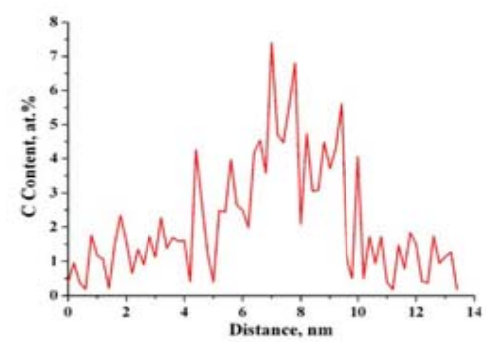

(b)

Fig. 4.15: $C$ atom maps from representative (a) martensitic; (b) plate ferritic regions. (c) $\mathrm{C}$ concentration profile across a sub-boundary in the plate ferrite. The specimen was deformed to a strain of $\varepsilon=4.0$ at $4.0 \mathrm{~s}^{-1}$ at $763^{\circ} \mathrm{C}\left(\mathrm{Ae}_{3}+30^{\circ} \mathrm{C}\right)$ [4.6].

\footnotetext{
*The author is indebted to Dr Xiang Y. Xiong, Dr. Ilana Thimokhina and Professor Elena Pereloma for performing the TEM and APT examinations.
} 


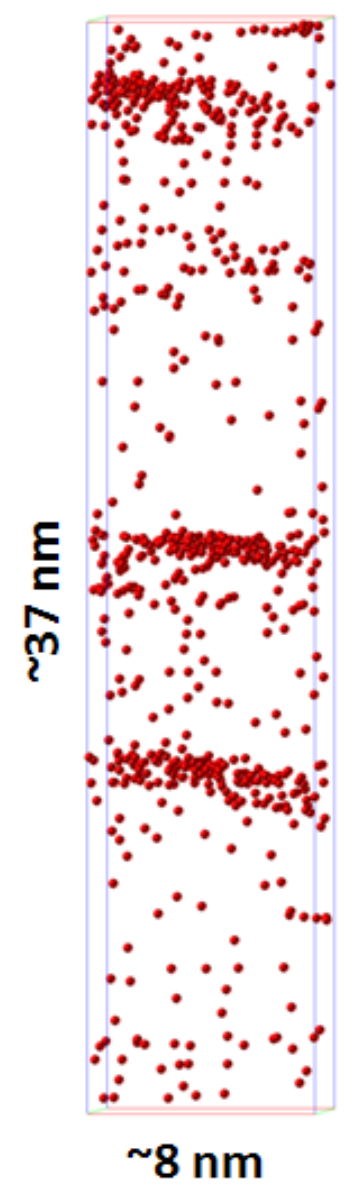

(a)

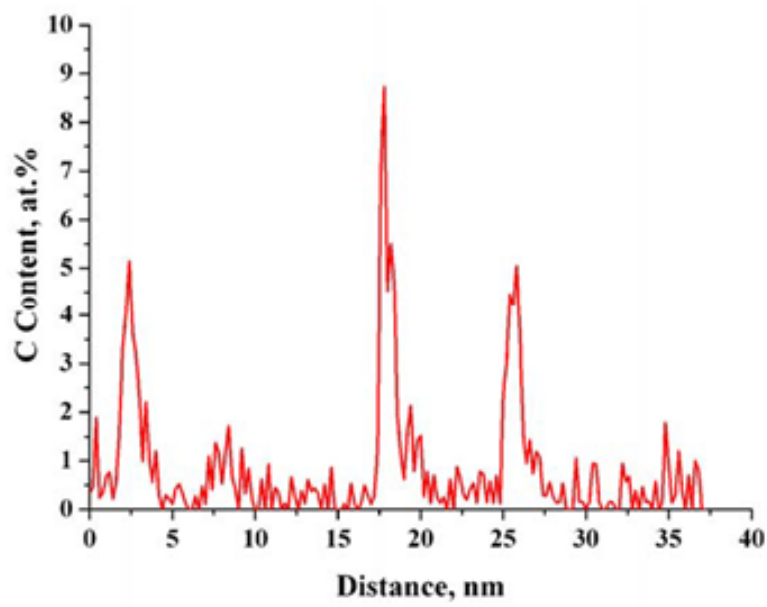

(b)

Fig. 4.16: (a) C atom map of plate ferrite; (b) concentration profile measured in the sample shown in (a). The specimen was deformed to a strain of $\varepsilon=4.0$ at 4.0 $\mathrm{s}^{-1}$ at $763^{\circ} \mathrm{C}\left(\mathrm{Ae}_{3}+30^{\circ} \mathrm{C}\right)[4.6]$.

\subsubsection{Effect of Strain on Phase Proportions}

The volume fraction of DT ferrite that forms depends on the applied strain and temperature. The fractions determined by the method of Fig. 3.8 are depicted in Fig. 4.17 for specimens deformed at $4 \mathrm{~s}^{-1}$ at $753^{\circ} \mathrm{C}$ (i.e. $\mathrm{Ae}_{3}+20^{\circ} \mathrm{C}$ ) and $783^{\circ} \mathrm{C}$ (i.e. $\mathrm{Ae}_{3}+50^{\circ} \mathrm{C}$ ). From Fig. 4.17 it appears roughly that the critical strain for DT to occur in this particular steel is about 0.25 , which is consistent with the results of the critical strain analysis, see Chapter 5 [4.4]. Below the strain, no phase transformation can be detected. The rate of transformation is highest in the 
strain interval from 0.6 to 2.0 and decreases with temperature. Beyond this strain, the fraction transformed approaches saturation, as called for by the deformation-modified phase diagram [4.3].

It is important to note that the volume fractions of the transformed phases are highest at the sample surface, where the quench rate is also the highest, while the volume fractions of the martensite (i.e. austenite not subject to DT) are highest near the axis of the specimens, where conversely the quench rate is the slowest.

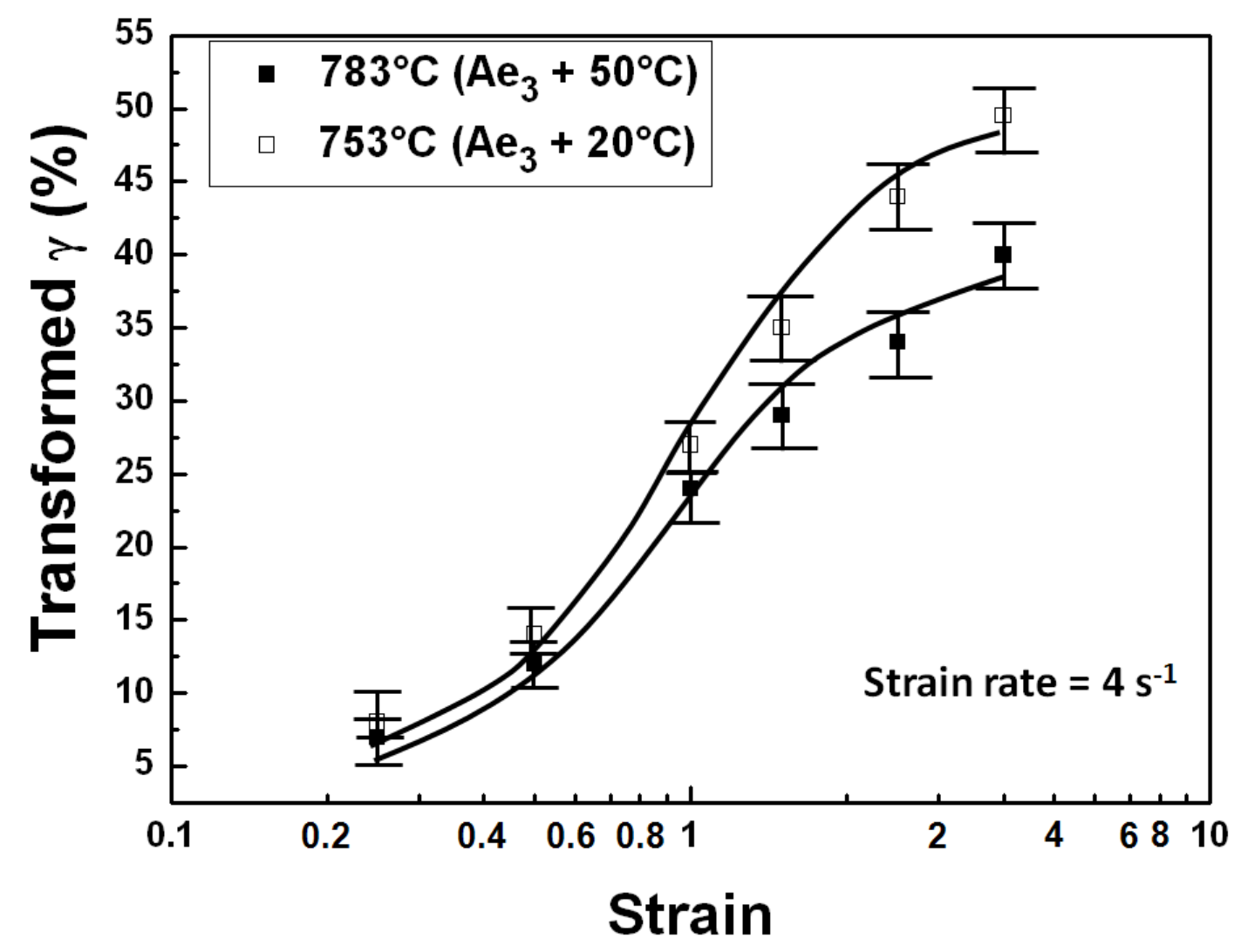

Fig. 4.17: Effect of strain on the percentage of austenite that transforms dynamically into ferrite and cementite at $753^{\circ} \mathrm{C}\left(\mathrm{Ae}_{3}+20^{\circ} \mathrm{C}\right)$ and $783^{\circ} \mathrm{C}\left(\mathrm{Ae}_{3}+\right.$ $50^{\circ} \mathrm{C}$ ) during deformation at $4 \mathrm{~s}^{-1}[4.6]$. 


\subsubsection{Effect of Temperature on Phase Proportions and Microhardness Values}

The effect of temperature on dynamic transformation is illustrated in Fig. 4.18, where the specimens were deformed to a strain of 4 at $4 \mathrm{~s}^{-1}$. Here it is evident that the amounts of deformation-induced ferrite and cementite decrease as the temperature is increased. This is because the driving force for the $\gamma$-to- $\alpha$ transformation decreases as the temperature is increased, resulting in lower amounts of ferrite and cementite at the higher temperatures. This trend was observed up to $863^{\circ} \mathrm{C}$ (i.e. $\mathrm{Ae}_{3}+130^{\circ} \mathrm{C}$ ), the highest experimental temperature employed in the present investigation. As these quantities are inversely proportional to the amount of martensite, the hardness of the quenched samples increases with deformation temperature [4.6].

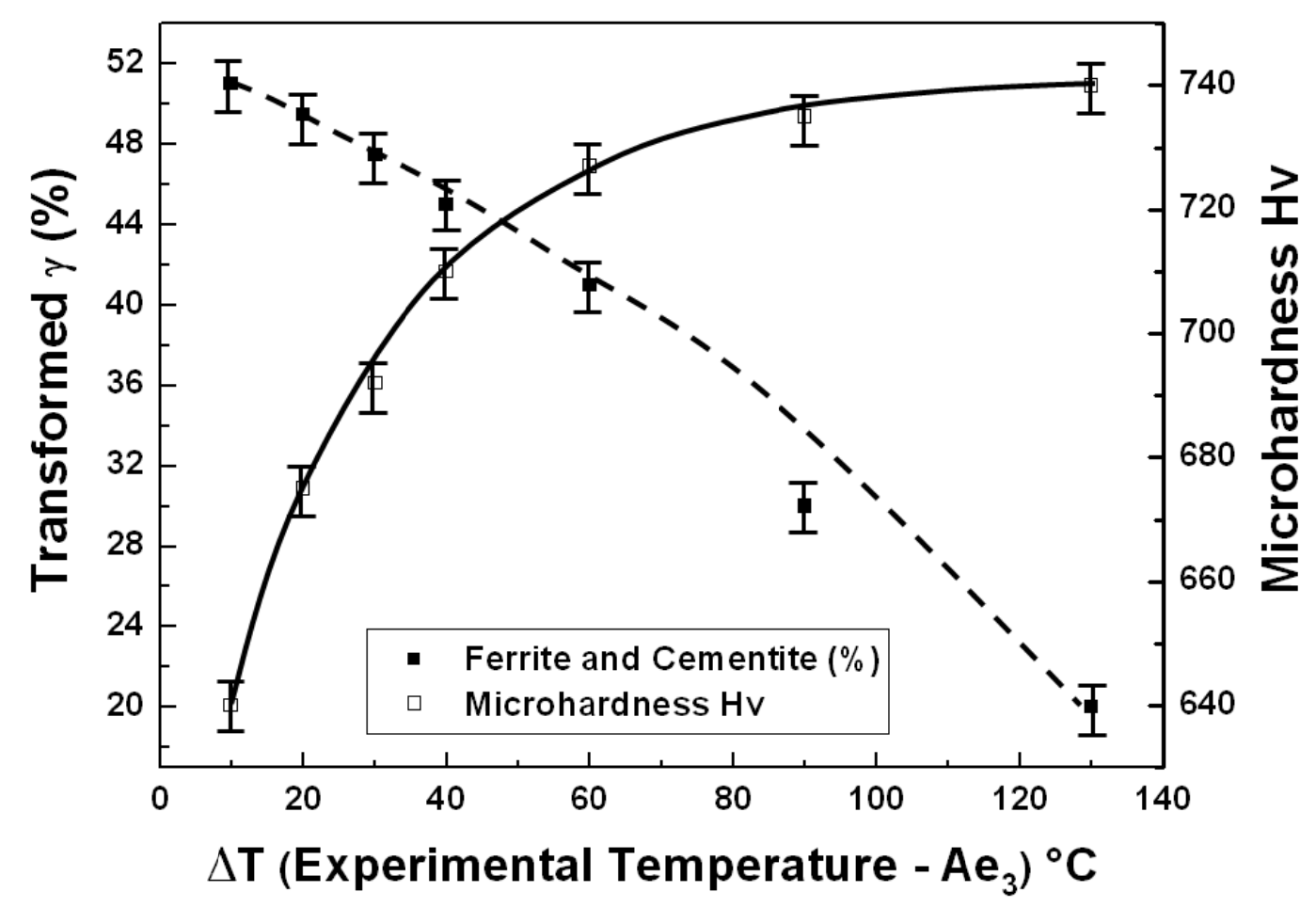

Fig. 4.18: Dependences of the ferrite plus cementite volume fraction and microhardness on $\Delta T$ (Experimental Temperature - $\mathrm{Ae}_{3}$ ). The specimens were deformed to strains of $\varepsilon=4.0$ at $4.0 \mathrm{~s}^{-1}$ and then quenched [4.6]. 


\subsection{Summary of the Microstructural Observations}

The temperature ranges over which the various phases appeared in the four different steels are summarized in Table 4.2 ( $3^{\text {rd }}$ column). The maximum temperatures up to which dynamic transformation is expected to take place can be determined from the data in Chapter 5 and are shown in this table $\left(4^{\text {th }}\right.$ column). In all 4 steels, the ferrite phase appearing at the start of DT was mostly of Widmanstätten form; these structures were gradually converted into polygonal form with increasing strain and time, as already observed by Yada [4.10]. The formation of Widmanstätten ferrite under DT conditions is discussed in greater detail below.

Table 4.2. The temperature ranges over which the various phases were observed in the four steels.

\begin{tabular}{|c|c|c|c|}
\hline Steel & Phases present & $\begin{array}{c}\text { Temperature } \\
\text { range observed }\end{array}$ & $\begin{array}{c}\text { Temperature range predicted } \\
\text { from the critical strains }\end{array}$ \\
\hline 1 & $\mathrm{~F}+\mathrm{M} / \mathrm{A}$ & $\mathrm{Ae}_{3}+40^{\circ} \mathrm{C}$ & $\mathrm{Ae}_{3}+70^{\circ} \mathrm{C}$ \\
\hline 2 & $\mathrm{~F}+\mathrm{M} / \mathrm{A}$ & $\mathrm{Ae}_{3}+60^{\circ} \mathrm{C}$ & $\mathrm{Ae}_{3}+100^{\circ} \mathrm{C}$ \\
\hline 3 & $\mathrm{~F}+$ Cementite $+\mathrm{M} / \mathrm{A}$ & $\mathrm{Ae}_{3}+70^{\circ} \mathrm{C}$ & $\mathrm{Ae}_{3}+120^{\circ} \mathrm{C}$ \\
\hline 4 & $\mathrm{~F}+$ Cementite $+\mathrm{M} / \mathrm{A}$ & $\mathrm{Ae}_{3}+130^{\circ} \mathrm{C}$ & $\mathrm{Ae}_{3}+150^{\circ} \mathrm{C}$ \\
\hline
\end{tabular}

F: Ferrite; M: Martensite; A: Austenite

\subsection{Discussion}

\subsubsection{Likely Mechanisms of DT}

In the early work of Yada et al. [4.11], DT was considered to be a kind of 'massive' transformation during which there is no long range diffusion. Other researchers [4.12-4.14], on the other hand, have proposed that DT is a long range diffusion controlled process, somewhat like that of the formation of proeutectoid ferrite. Here the view is taken that DT is essentially a type of displacive transformation, but one that allows for carbon diffusion on a local scale. This view is supported by the microstructure shown in Fig. 4.19, where the $0.79 \% \mathrm{C}$ 


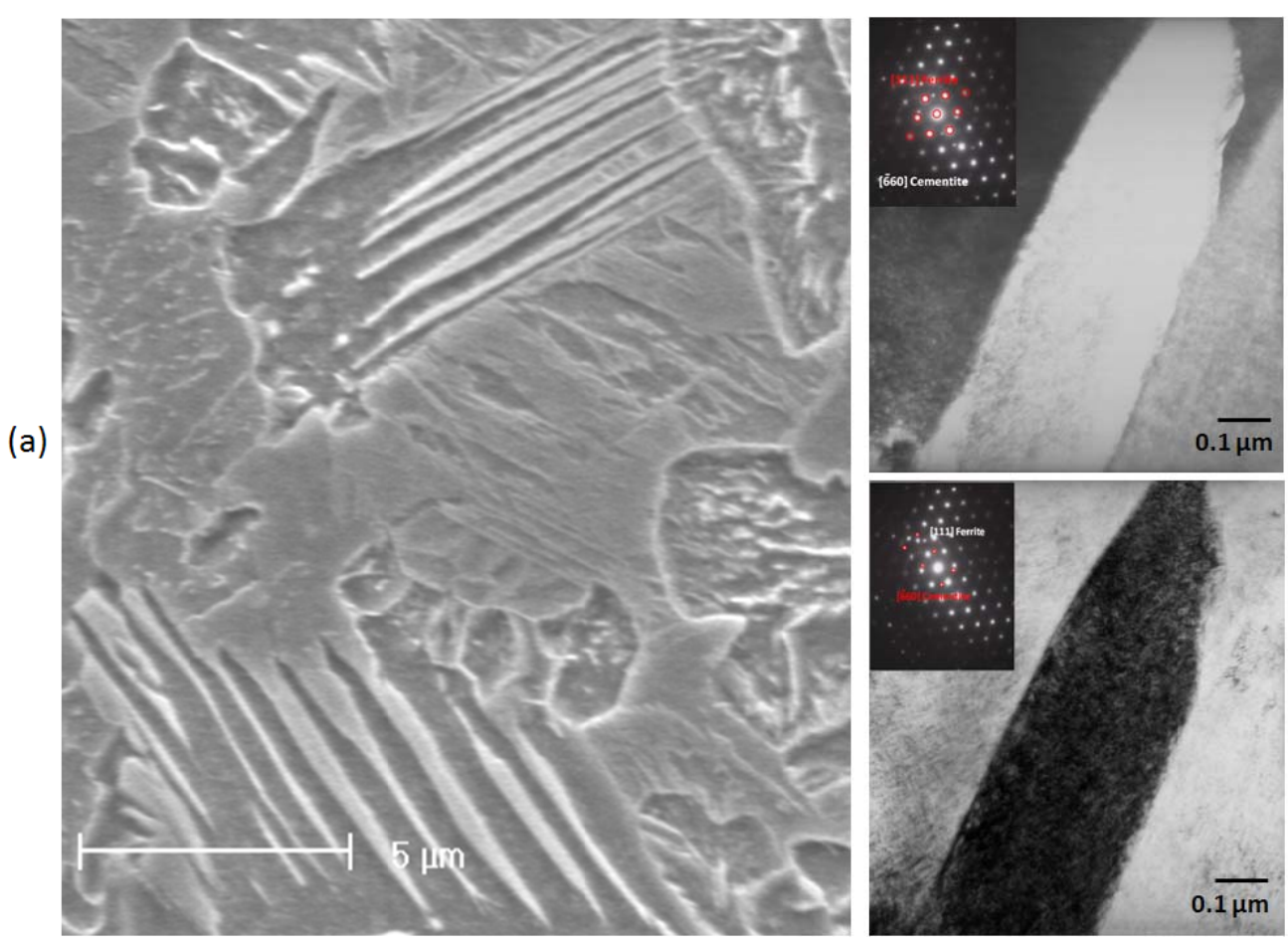

(b)

Fig. 4.19: (a) Scanning electron micrographs of $0.79 \% \mathrm{C}$ steel strained to $\varepsilon=4.0$ at $4 \mathrm{~s}^{-1}$ at $763^{\circ} \mathrm{C}\left(\mathrm{Ae}_{3}+30^{\circ} \mathrm{C}\right)$, (b) and (c) TEM micrographs showing the presence of ferrite and cementite (diffraction patterns inset) [4.3].

steel was deformed at $763^{\circ} \mathrm{C}\left(\mathrm{Ae}_{3}+30^{\circ} \mathrm{C}\right)$ to a strain of $\varepsilon=4.0$. The mixed microstructure, containing Widmanstätten ferrite, cementite and martensite (former austenite) is depicted in Fig. 4.19(a). The Widmanstätten ferrite is shown at higher magnification in Figs. 4.19(b) and (c). The diffraction patterns of Figs. 4.19(b) and (c) provide positive identification of the ferrite and also of the fine cementite particles visible within the ferrite plates. Here the cementite particles have diameters of about $30 \mathrm{~nm}$ and the plate thickness is about $200 \mathrm{~nm}$.

This interpretation will now be examined more closely. Displacive transformations can take place at velocities close to the speed of sound. This involves a lattice change from FCC to BCC in the present case and the absence of any substitutional or interstitial diffusion. Typical velocities of about one-third the speed of sound have been suggested [4.15], which lead to elapsed times of 
the order of picoseconds for nucleation of the microstructural units illustrated above. At this juncture, it is important to estimate how far $\mathrm{C}$ as well as $\mathrm{Mn}$ and $\mathrm{Si}$ can diffuse during torsion or rolling or laboratory experiments.

An example of the time available for DT during hot rolling is provided in Fig. 4.20. Here a bar is being subjected to a reduction of $35 \%(\varepsilon=0.5)$ while being rolled at a typical strip mill strain rate of $100 \mathrm{~s}^{-1}$. The total time of the austenite in the deformation zone under these conditions is $5 \mathrm{~ms}$, so that the time that elapses during a strain increment of $1 \%$ is about $100 \mu \mathrm{s}$. (During torsion testing at $10 \mathrm{~s}^{-1}$ or $1 \mathrm{~s}^{-1}$, this time is increased to $1 \mathrm{~ms}$ and $10 \mathrm{~ms}$, respectively.)

The question thus arises as to how far $\mathrm{C}$ and $\mathrm{Mn}$ can diffuse during time intervals of $100 \mu \mathrm{s}$, more or less. The following relationship can be used to calculate the diffusion distances of $\mathrm{C}$ and $\mathrm{Mn}$ in ferrite.

$\bar{X}=\vee(D t)$

where $\bar{X}$ is the mean diffusion distance, $\mathrm{t}$ the time and $\mathrm{D}$ the diffusivity. The diffusivity depends in turn on temperature according to

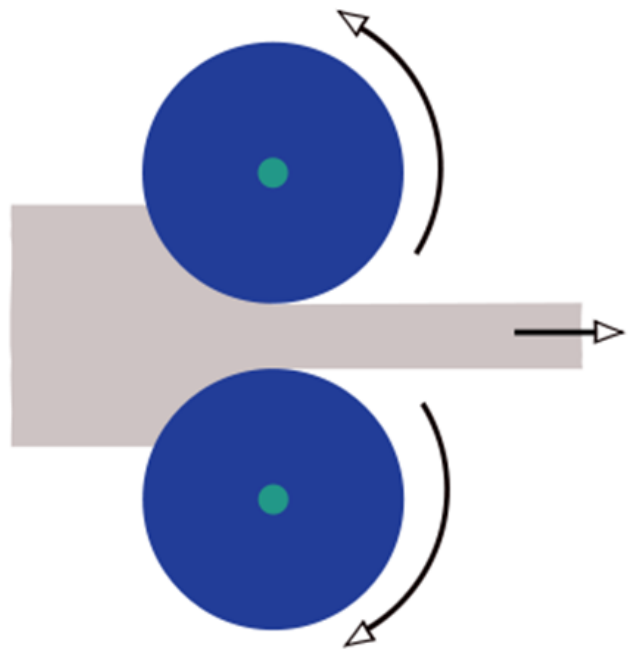

$\varepsilon=0.5(35 \%$ reduction $)$

$\varepsilon=100 \mathrm{~s}^{-1}$

Time in the deformation

zone $=5 \mathrm{~ms}$

Incremental transformation

time $=100 \mu$ s (for $1 \%$ strain)

Fig. 4.20: Schematic of a hot rolling mill illustrating the time available for DT to take place. Here a true strain of $\varepsilon=0.5$ (i.e. $35 \%$ reduction) is being applied at a strain rate of $100 \mathrm{~s}^{-1}$. Under these conditions, the time in the deformation zone is $5 \mathrm{~ms}$ and the elapsed time during a strain increment of $1 \%$ is about $100 \mu \mathrm{s}$ [4.3]. 
$\mathrm{D}=\mathrm{D}_{0} \exp (-\mathrm{Q} / \mathrm{RT})$

Here $D_{0}$ is the pre-exponential term, $Q$ the activation energy for diffusion and $T$ the temperature in $\mathrm{K}$. The diffusion distances of $\mathrm{C}$ and $\mathrm{Mn}$ in ferrite within the experimental temperature range, i.e. $743-823^{\circ} \mathrm{C}$, were calculated by setting the pre-exponential factors equal to $7.9 \times 10^{-3} \mathrm{~cm}^{2} \mathrm{~s}^{-1}$ (for $\mathrm{C}$ in ferrite) [4.16] and 1.49 $\mathrm{cm}^{2} \mathrm{~s}^{-1}$ (for $\mathrm{Mn}$ in ferrite) [4.17]. The values of $\mathrm{Q}$ for $\mathrm{C}$ and $\mathrm{Mn}$ were taken as 75.6 $\mathrm{kJ} \mathrm{mol}^{-1}$ [4.16] and $233.6 \mathrm{~kJ} \mathrm{~mol}^{-1}$ [4.17], respectively.

The estimated diffusion distances are shown in Fig. 4.21, from which it can be seen that, at these temperatures, carbon takes about $100 \mu$ s to diffuse a distance of $100 \mathrm{~nm}$ in ferrite, Fig. 4.21(a). (These plots do not take into account the effect of deformation on the diffusion rate, which will be somewhat faster than indicated in the diagram). This is the approximate time required for carbon to diffuse out of the ferrite plates during their formation. The cementite particles present in the microstructure can form in even shorter times. In this case the required diffusion distance was reduced to about $30-50 \mathrm{~nm}$, so that only $50 \mu \mathrm{s}$ are required for the formation of the fine particles.

By contrast, as shown in Fig. 4.21(b), Mn can only diffuse a small fraction of a nanometer, i.e. less than one atomic diameter within this time frame. Here too, the effect of prior deformation is not shown, as appropriate information was not available to the author. Nevertheless, it is unlikely to call for displacements of more than a few atomic diameters.

Thus the dynamic transformation that takes place during a strain increment of $1 \%$ must be accomplished in times that are clearly too short for substitutional diffusion, but long enough to permit interstitial diffusion according to Fig. 4.21. This conclusion would seem to apply, not only to industrial rolling, but to laboratory testing as well. 


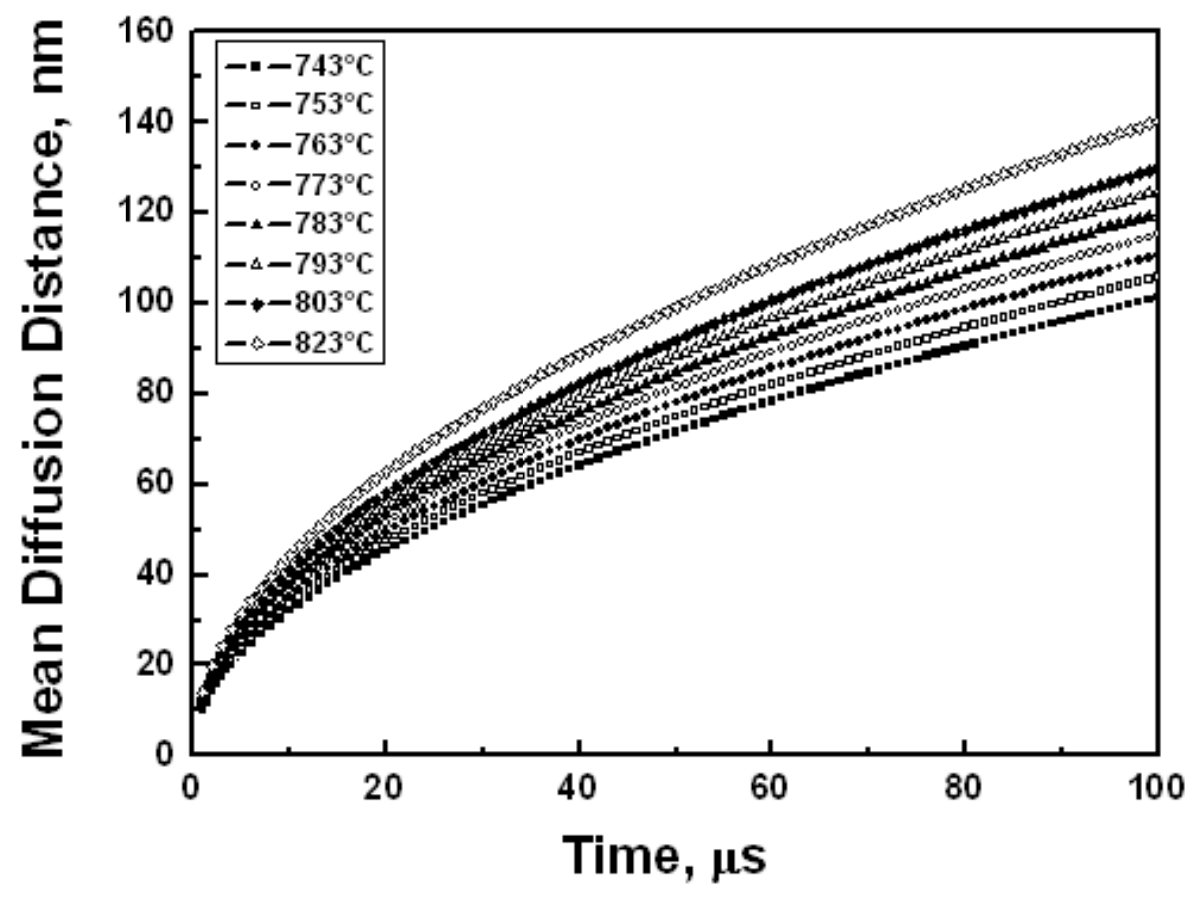

(a)

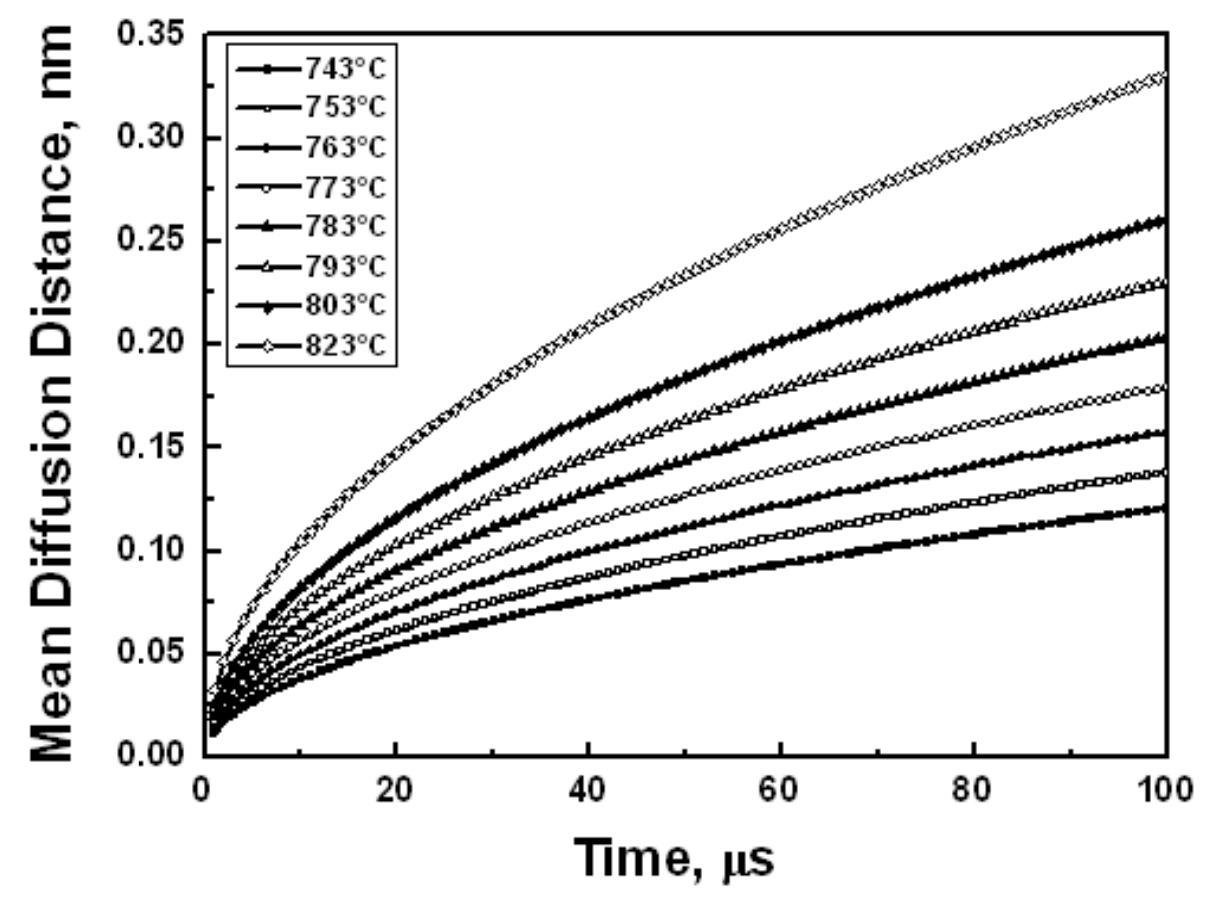

(b)

Fig. 4.21: Estimated mean diffusion distances of (a) $\mathrm{C}$ and (b) $\mathrm{Mn}$ in ferrite over the experimental temperature range [4.6]. 
The available time increments are also consistent with the view that nucleation of the Widmanstätten ferrite takes place displacively and that such plates will be supersaturated in carbon on formation. During growth of the Widmanstätten ferrite plates, however, the carbon is expected to be rejected from the ferrite and to partition into the austenite phase [4.2]. The carbon remaining in the ferrite can also precipitate to form the cementite particles shown above (Fig. 4.19). Although nucleation is displacive, growth therefore occurs under paraequilibrium conditions, as there is insufficient time for substitutional (Mn or Si) diffusion. On the other hand, as shown in Fig. 4.21(a), such carbon diffusion only requires times in the range of microseconds and can readily take place. The time scales of the three kinds of mechanisms referred to here are compared in Fig. 4.22.

\begin{tabular}{|ccc|}
\hline FCC $\rightarrow$ BCC & C diffusion & Substitutional diffusion \\
$\begin{array}{c}\text { Displacive } \\
\text { picoseconds }\end{array}$ & $\begin{array}{c}\text { Paraequilibrium } \\
\text { microseconds }\end{array}$ & $\begin{array}{c}\text { Orthoequilibrium } \\
\text { seconds }\end{array}$ \\
\hline
\end{tabular}

Fig. 4.22: Time scales for the three kinds of transformations [4.3].

In order to verify that diffusional transformation products were not being produced during quenching, the quench rates were measured. These showed that quenching took about $1 \mathrm{~s}$ at the surface, and about $4 \mathrm{~s}$ along the axis. These cooling rates were superimposed on calculated deformed CCT diagrams of the steel, as reported in Ref. 4.6. Noting that the pearlite nose is at about $30 \mathrm{~s}$, it is clear that the pearlite transformation is completely avoided during quenching.

It is important to note that a simple Fe-C eutectoid steel can transform to pearlite in $1 \mathrm{~s}$ because only interstitial diffusion is involved. However, as the present materials contain $\mathrm{Mn}$ and $\mathrm{Si}$, substitutional diffusion is required to 
permit partitioning and pearlite formation. It is thus the presence of $\mathrm{Mn}$ and $\mathrm{Si}$ that prevents the formation of pearlite during $1 \mathrm{~s}$ quenches.

\subsubsection{Application to Industrial Processing}

The present results as well as those reported earlier [4.1,4.2,4.18-4.21] indicate that DT ferrite probably forms during the finishing stages of hot rolling, when pancaking accompanied by strain accumulation takes place at temperatures below the $T_{n r}$ (but above the $A_{3}$ ). However, it cannot be detected because of the fine scale of this type of microstructure and also because the plates are likely to coalescence into grains during passage along the run-out table. A further factor that limits the observability of this phenomenon is the limited amount of DT ferrite that forms during each increment of straining. This has been estimated as $0.5-1 \%$ volume fraction per $1 \%$ of strain [4.22]. Since the parameters that control this mechanism are not well understood at the moment, it has not yet been possible to devise controlled rolling schedules that exploit this type of transformation. Perhaps it could be employed in planetary hot rolling, where large reductions can be applied in a single pass just above the $\mathrm{Ae}_{3}$. It probably also has applications in strip rolling, where the interpass times are short, leading to strain accumulation in the austenite. The formation of DT ferrite (a softer phase) from austenite under these conditions will reduce the roll separation force, thus influencing the rolling load.

\subsection{Conclusions}

The following conclusions can be drawn from the present results.

1. The critical strain for the formation of strain-induced ferrite and cementite above the $\mathrm{Ae}_{3}$ in the $0.79 \% \mathrm{C}$ steel is about 0.25 and the same for the $0.21 \% \mathrm{C}$ steel is about 0.15 . 
2. The volume fractions of the DT ferrite and cementite increase with applied strain and decrease as the temperature is increased above the $\mathrm{Ae}_{3}$.

3. DT ferrite is first nucleated in the form of Widmanstätten plates $200 \mathrm{~nm}$ thick by a displacive mechanism.

4. As the applied strain is increased, some of the plates are gradually converted into approximately equiaxed grains.

5. The carbon diffusion distances associated with the formation of ferrite plates and cementite particles are consistent with elapsed times of less than a millisecond over the experimental temperature range. Thus there is sufficient time for interstitial diffusion to take place during DT. However, the times available do not allow for any substitutional diffusion.

\section{References}

4.1 V.V. Basabe, J.J. Jonas and H. Mahjoubi; ISIJ Int., Vol. 51, (2011), p. 612.

4.2 V.V. Basabe and J.J. Jonas; ISIJ Int., Vol. 50, (2010), p. 1185.

4.3 C. Ghosh, V.V. Basabe, J.J. Jonas, Y.M. Kim, I.H. Jung and S. Yue; Acta Mater., Vol. 61, (2013), p. 2348.

4.4 C. Ghosh, V.V. Basabe and J.J. Jonas; Steel Res. Int., in press (DOI: 10.1002/srin.201200188).

4.5 J.R. Yang and L.C. Chang; Mater. Sci. Eng. A, Vol. 223, (1997), p. 158.

4.6 C. Ghosh, V.V. Basabe, J.J. Jonas, S. Yue and X.Y. Xiong; ISIJ Int., Vol. 53, (2013), p. 900.

4.7 F.G. Caballero, M.K. Miller, S.S. Babu and C. Garcia-Mateo; Acta Mater., Vol. 55, (2007), p. 381.

4.8 E.V. Pereloma, I.B. Timokhina, J.J. Jonas and M.K. Miller; Acta Mater., Vol. 54, (2006), p. 4539.

4.9 M.K. Miller; Atom Probe Tomography, Kluwer, Academic/Plenum Press, New York, NY, (2000); p. 28.

$4.10 \mathrm{H}$. Yada, Y. Matsumura and T. Senuma; Proc. 1st Conf. Physical Metallurgy of Thermomechanical Processing of Steels and Other Metals (THERMEC-88), ed. by I. Tamura, ISIJ, Tokyo, (1988), p. 200.

4.11 H. Yada, C.M. Li and H. Yamagata; ISIJ Int., Vol. 40, (2000), p. 200.

4.12 W.Y. Yang, J.J. Qi and Z.Q. Sun; Acta Metall. Sin., Vol. 40, (2004), p. 135.

4.13 W.Y. Choo, J.S. Lee and C.S. Lee; CAMP-ISIJ, Vol. 13, (2000), p. 1144.

4.14 P.J. Hurley and P.D. Hodgson; Mater. Sci. Eng. A, Vol. 302, (2001), p. 206. 
4.15 R.F. Bunshah and R.F. Mehl; Trans. AIME, Vol. 193, (1953), p. 1251.

4.16 J.K. Stanley; Trans. AIME, Vol. 185, (1949), p. 752.

4.17 J. Kučera and K. Stránský; Mater. Sci. Engg., Vol. 52, (1982), p. 1.

4.18 X. Sun, H. Luo, H. Dong, Q. Liu and Y. Weng; ISIJ Int., Vol. 48, (2008), p. 994.

4.19 V.V. Basabe, J.J. Jonas and C. Ghosh; Adv. Mater. Res., Vol. 409, (2012), p. 829.

4.20 J.J. Jonas and V.V. Basabe; Solid State Phenomena, Vol. 172-174, (2011), p. 372.

4.21 H. Dong and X. Sun; Current Opinion in Solid State and Mater. Sci., Vol. 9, (2005), p. 269.

4.22 J.J. Jonas, C. Ghosh and V.V. Basabe; Steel Res. Int., Vol. 84, (2013), p. 253. 
Chapter 5

\section{Critical Strain Determinations}




\section{Critical Strain Determinations ${ }^{*}$}

\subsection{Background}

The strains at which dynamic transformation (DT) and dynamic recrystallization (DRX) are initiated are of considerable industrial importance. These strains are often referred to as the critical strains $\left(\varepsilon_{c}\right)$ for DT and DRX. As both of these are flow softening mechanisms, DT and DRX lead to decreases in the net workhardening rate (and therefore in the rolling load) compared to the values expected when only dynamic recovery is taking place. However, such decreases are relatively minor in the immediate aftermaths of the critical strains because only small volume fractions of ferrite and recrystallized austenite appear at this stage of straining. The flow stress therefore continues to increase beyond these critical points until the total softening due to DT and DRX balances the strain hardening taking place in the untransformed material [5.1]. This balance occurs at the peak stress and its corresponding strain. Eventually, a strain independent steady state is achieved, which reflects the final balance between the rates of hardening and restoration.

Although the peak in the flow curve is a good indication that softening is well underway, it does not provide any information about the exact onsets of DT or DRX. Such critical strains can in principle be determined metallographically by quenching specimens deformed to strains above and below the $\varepsilon_{c}$. However, this technique is not particularly useful for the precise determination of the critical strains [5.2].

In fact, the early critics of DRX considered that the recrystallized structures produced in such experiments were formed statically during the quench to room temperature. Further developments led to a method for determining the critical strain associated with the initiation of recrystallization. This strain is attained

\footnotetext{
*Some of the material in this chapter has been published in Refs. 5.2 and 5.20.
} 
well before the maximum or peak stress and can be accurately identified using the double differentiation or second derivative method developed by Poliak and Jonas [5.3]. This has been used successfully to detect the precise onset of DRX. Here the critical stress (and its corresponding strain) are determined from the point of inflection in a plot of the strain hardening rate as a function of the stress. Following the nucleation of DRX, its progress can be modeled in numerous ways, such as the Monte Carlo, cellular automata and other methods [5.4-5.7]. The kinetics of DRX can in turn be described empirically using approaches such as the Avrami formalism [5.8-5.10]. Originally the double derivative method was restricted to determining the onset of DRX, although it can identify the initiation of other softening mechanisms as well. For example, it can detect the occurrence of twinning when this leads to softening and has been employed to distinguish the strain associated with the initiation of DT $[5.11,5.12]$. In the present work, the second derivative method is applied to the flow stress data of the four investigated steels and it is shown that the individual onsets of DT and DRX can both be detected and with reasonable accuracy.

It has also been established that DT can be nucleated at temperatures as high as $100^{\circ} \mathrm{C}$ above the $\mathrm{Ae}_{3}$ and that the critical strain for DT is significantly less than that for DRX [5.1, 5.13-5.17]. That is, that DT is nucleated well before DRX. The extent to which the order of the polynomial affects the precise value of the critical strain will also be considered below.

\subsection{Method of Analysis}

The flow curves were first obtained in electronic (Excel ${ }^{\mathrm{TM}}$ ) form, which enabled relatively straightforward data treatment. The curves were then analyzed by the method described below [5.2]. In each case, a "yield stress" was first identified as a $2 \%$ offset in the total strain. This was considered to represent the beginning of macroscopic work hardening in torsion. After removal of the initial loading transient, each curve up to and then just beyond the peak was fitted and 
smoothed with a seventh-order polynomial using the MATLAB ${ }^{\text {TM }}$ software. In some difficult cases, a higher-order polynomial was used. The smoothing eliminated the noise and fluctuations present in the experimental curves and in this way permitted the differentiation operations [5.2].

An example of an experimental curve is given in Fig. 5.1(a), together with its fitted curve. In order to determine the values of the critical stresses $\left(\sigma_{c}\right)$ for the onset of DT and DRX, $\theta$ vs. $\sigma$ curves were prepared. Here $\theta$ is the conventional strain hardening rate and is defined as $\theta=(\partial \sigma / \partial \varepsilon)_{\dot{\varepsilon}}$ [5.3]. An example is presented here as Fig. 5.1(b) for the data of Fig. 5.1(a). The method of Ref. 5.3 was employed to define the critical stresses, $\sigma_{c}$ i.e. the stresses associated with the initiation of DT and DRX. These are the points that correspond to the following condition:

$(\partial / \partial \sigma)(-(\partial \theta / \partial \sigma))=0$

Therefore, according to Eq. 5.1, the onsets of DT and DRX are associated with inflection points in a $\theta-\sigma$ plot and with minima in a $-(\partial \theta / \partial \sigma)$ vs. $\sigma$ curve. The $\sigma_{c}$ points are also indicated in Fig. 5.1(b). Here it is important to note that in general the uncertainties associated with these values are about $\pm 6 \%$ [5.18].

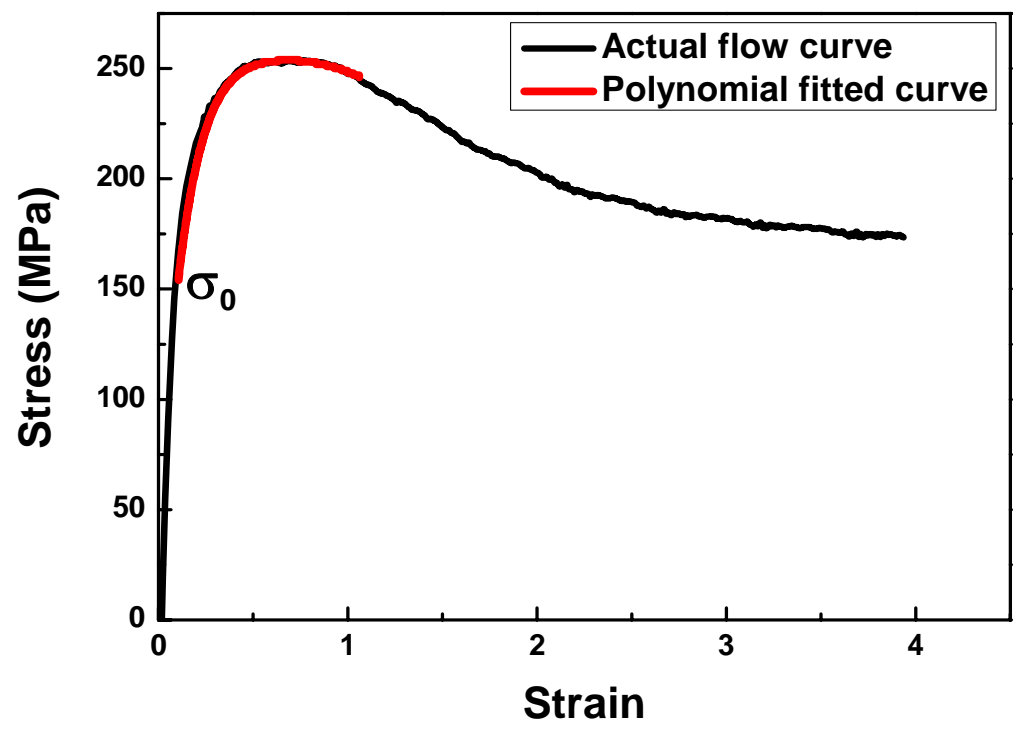

(a) 


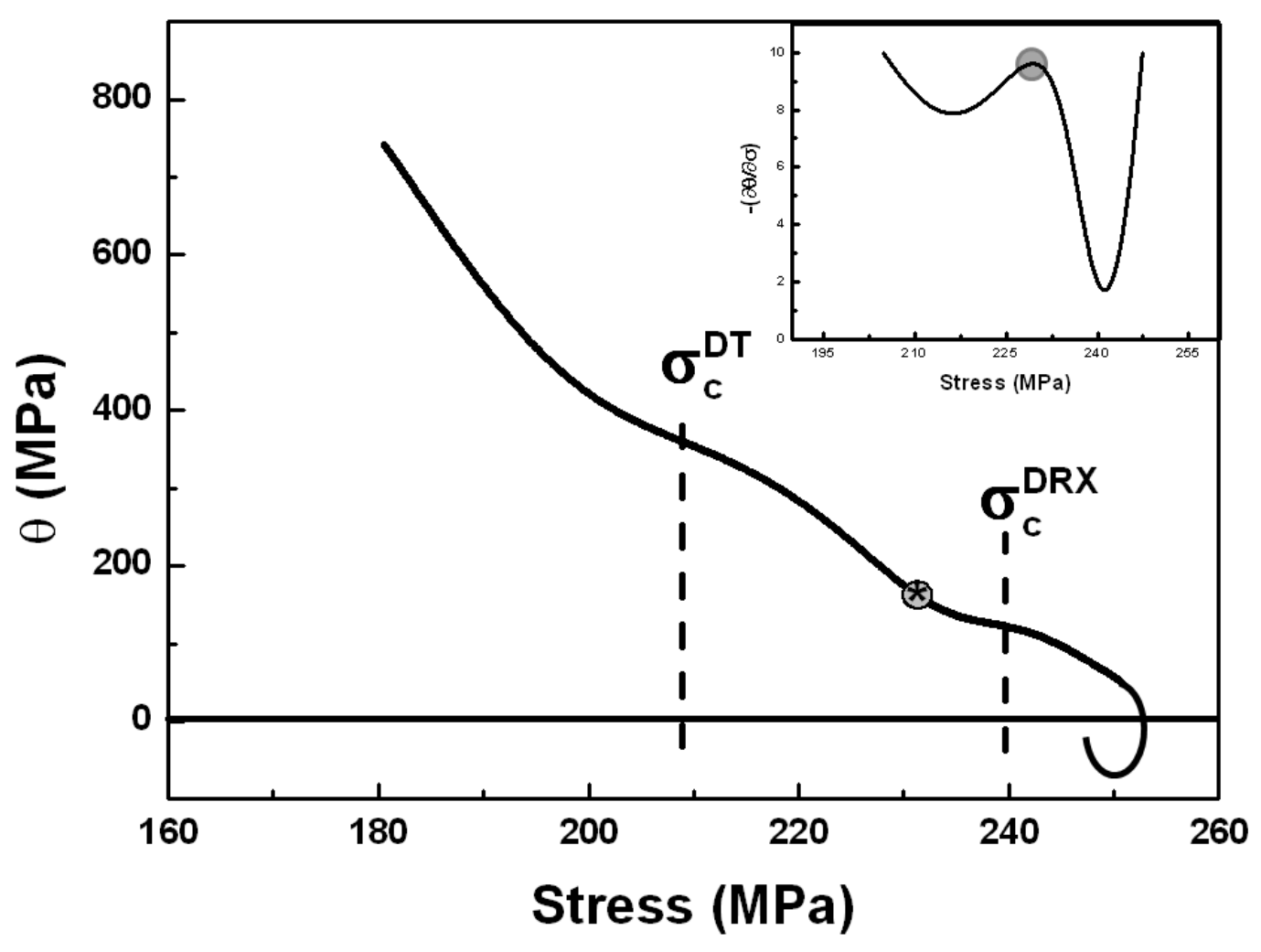

(b)

Fig. 5.1: (a) Experimental stress-strain curve determined in torsion on the $0.79 \% \mathrm{C}$ steel deformed at $763^{\circ} \mathrm{C}$ (i.e. $\mathrm{Ae}_{3}+30^{\circ} \mathrm{C}$ ) at a strain rate of $4.0 \mathrm{~s}^{-1}$ to a strain of 4. After the peak, the flow stress decreases due to the combined effect of DT and DRX. The yield stress $\sigma_{0}$ was defined using a total strain offset of 0.02 . The curve was fitted with a polynomial beginning at $\sigma_{0}$. (b) $\theta-\sigma$ plot derived from the fitted curve. Here the two $\sigma_{c}$ values are associated with two of the points of inflection. The ${ }^{(*)}$ on the plot corresponds to the local maximum in the inset.

\subsection{Results}

The flow curves determined in torsion on the four investigated steels (namely, the $0.06 \% \mathrm{C}, 0.09 \% \mathrm{C}, 0.21 \% \mathrm{C}$ and $0.79 \% \mathrm{C}$ steel grades) are collected and presented in Fig. 5.2. The data for the $0.06 \% \mathrm{C}$ and $0.09 \% \mathrm{C}$ steels are summarized in Figs. 5.2(a) and (b), while those for the $0.21 \% \mathrm{C}$ and $0.79 \% \mathrm{C}$ grades are illustrated in Figs. 5.2(c) and (d). These curves were analyzed by the method described above. 


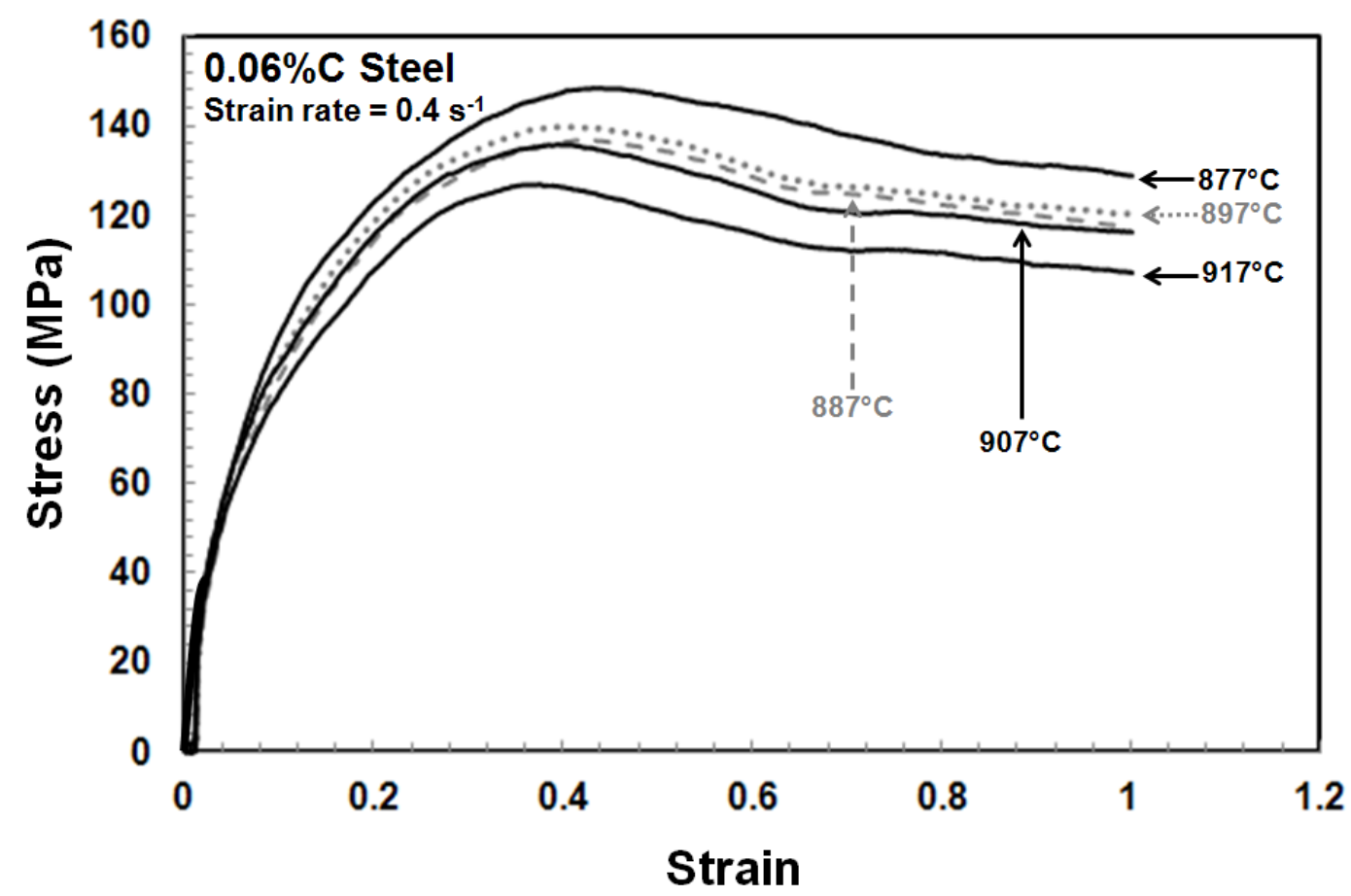

(a)

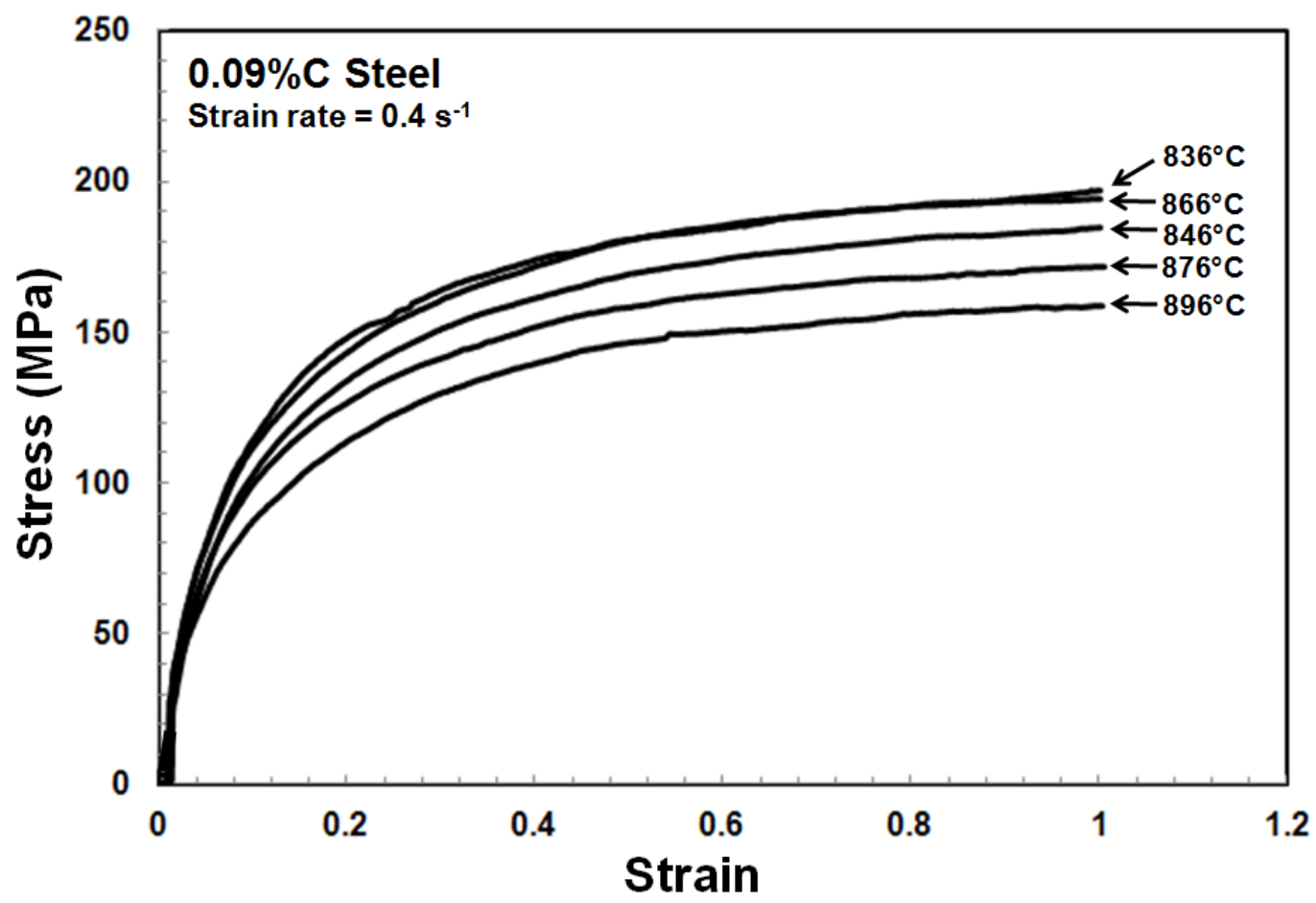

(b) 


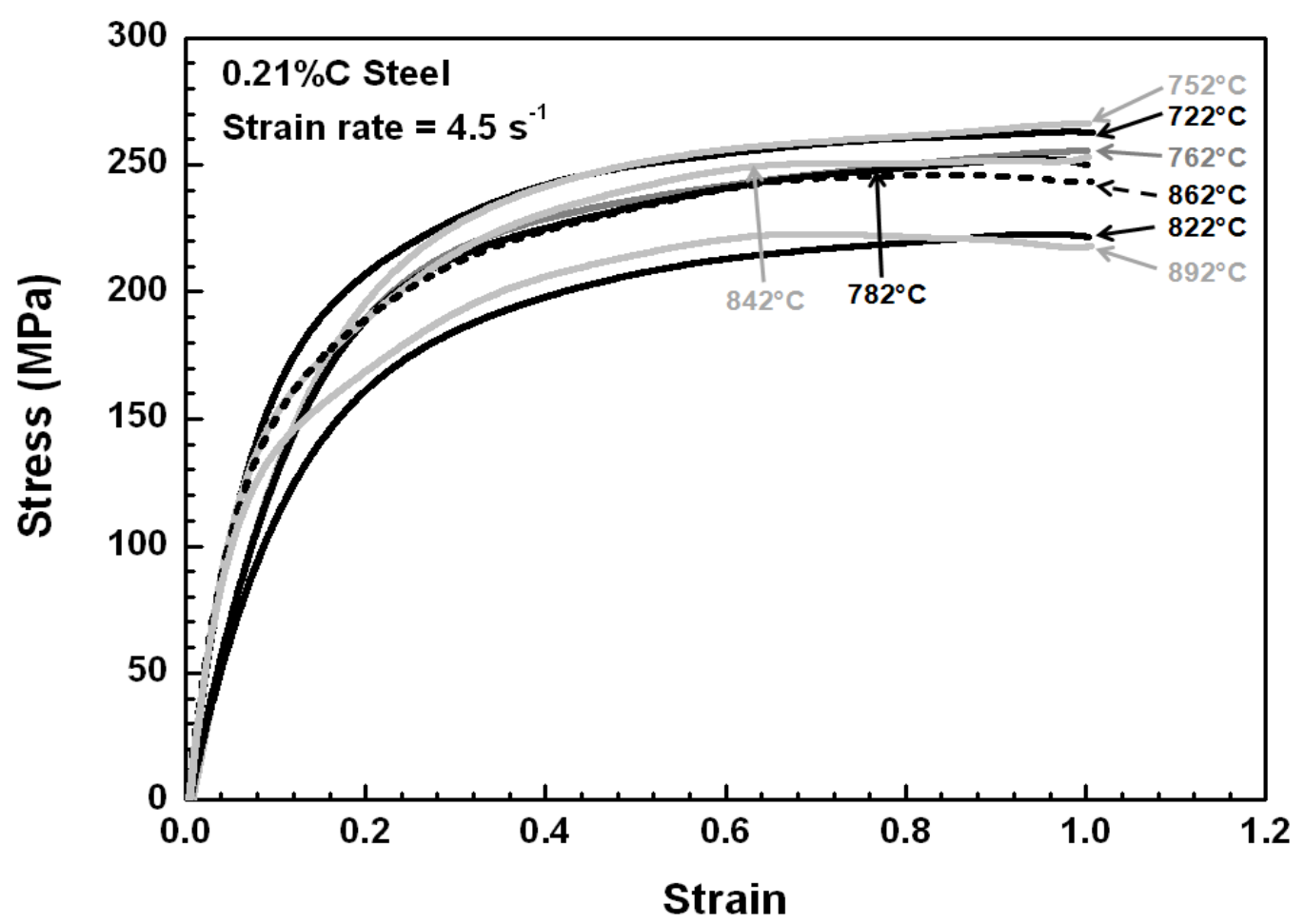

(c)

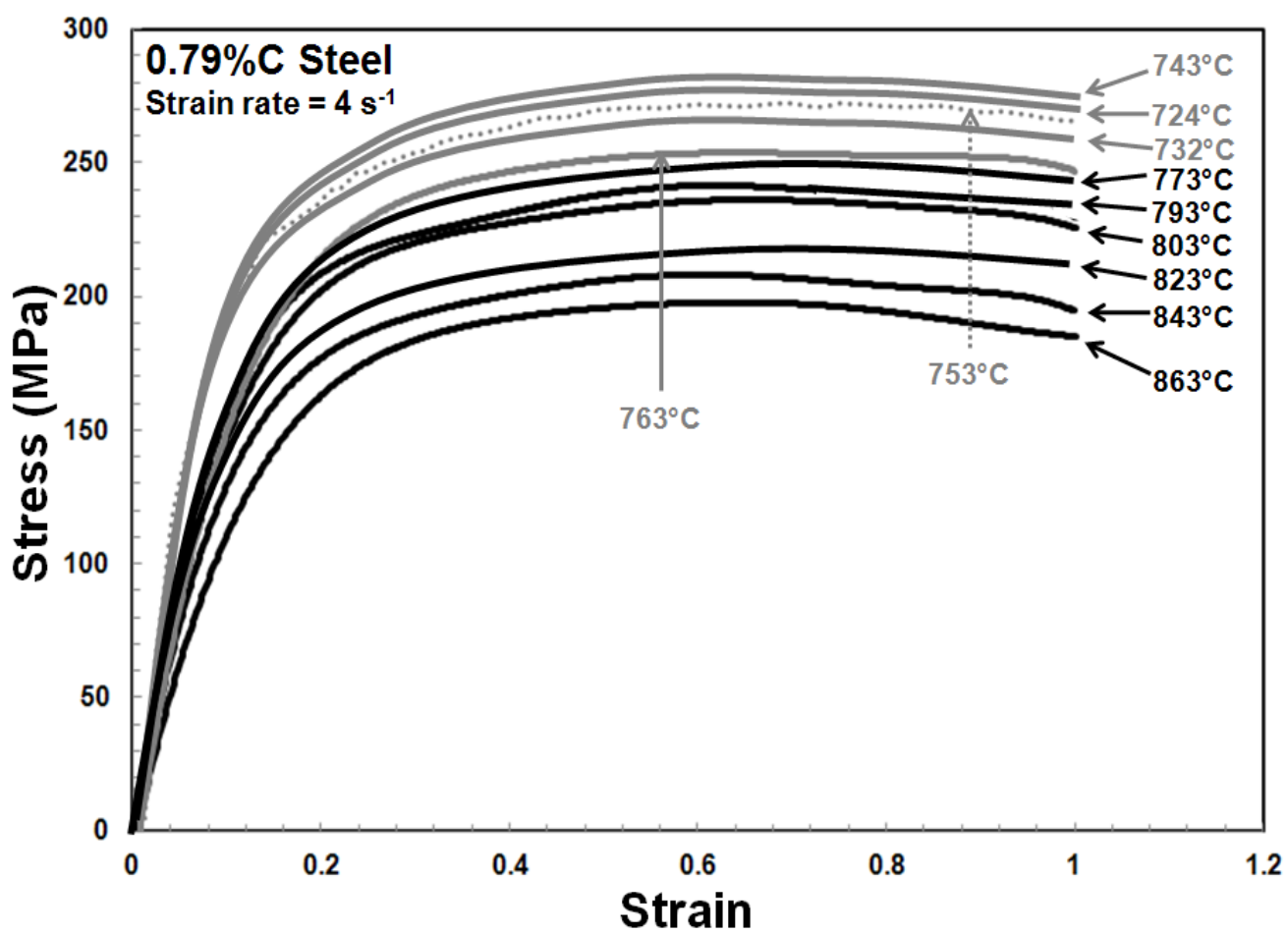

(d)

Fig. 5.2: Stress-strain curves determined in torsion on the (a) $0.06 \% \mathrm{C}$, (b) $0.09 \% \mathrm{C}$, (c) $0.21 \% \mathrm{C}$ and (d) $0.79 \% \mathrm{C}$ steels. The first two curves were determined at a strain rate of $0.4 \mathrm{~s}^{-1}$ and last two were at 4.5 and $4 \mathrm{~s}^{-1}$, respectively. 
The $-(\partial \theta / \partial \sigma)$ vs. $\sigma$ curves for the $0.06 \% \mathrm{C}, 0.09 \% \mathrm{C}, 0.21 \% \mathrm{C}$ and $0.79 \% \mathrm{C}$ steels at various experimental temperatures are depicted in Figs. 5.3(a) - (d), respectively. The important point to note in these figures is that in every case there are three inflection points. The first of these indicates the onset of DT and the third the initiation of DRX, as illustrated in Fig. 5.3(a) considered in more detail below. The critical strains that correspond to these critical stresses were in turn evaluated from the flow curves. The second inflection point is associated with the local maxima in the second derivative plots of Figs. 5.3(a), (b), (c) and (d). The maxima, in turn, indicate that the rate of dynamic transformation has decreased below a particular level [5.2].

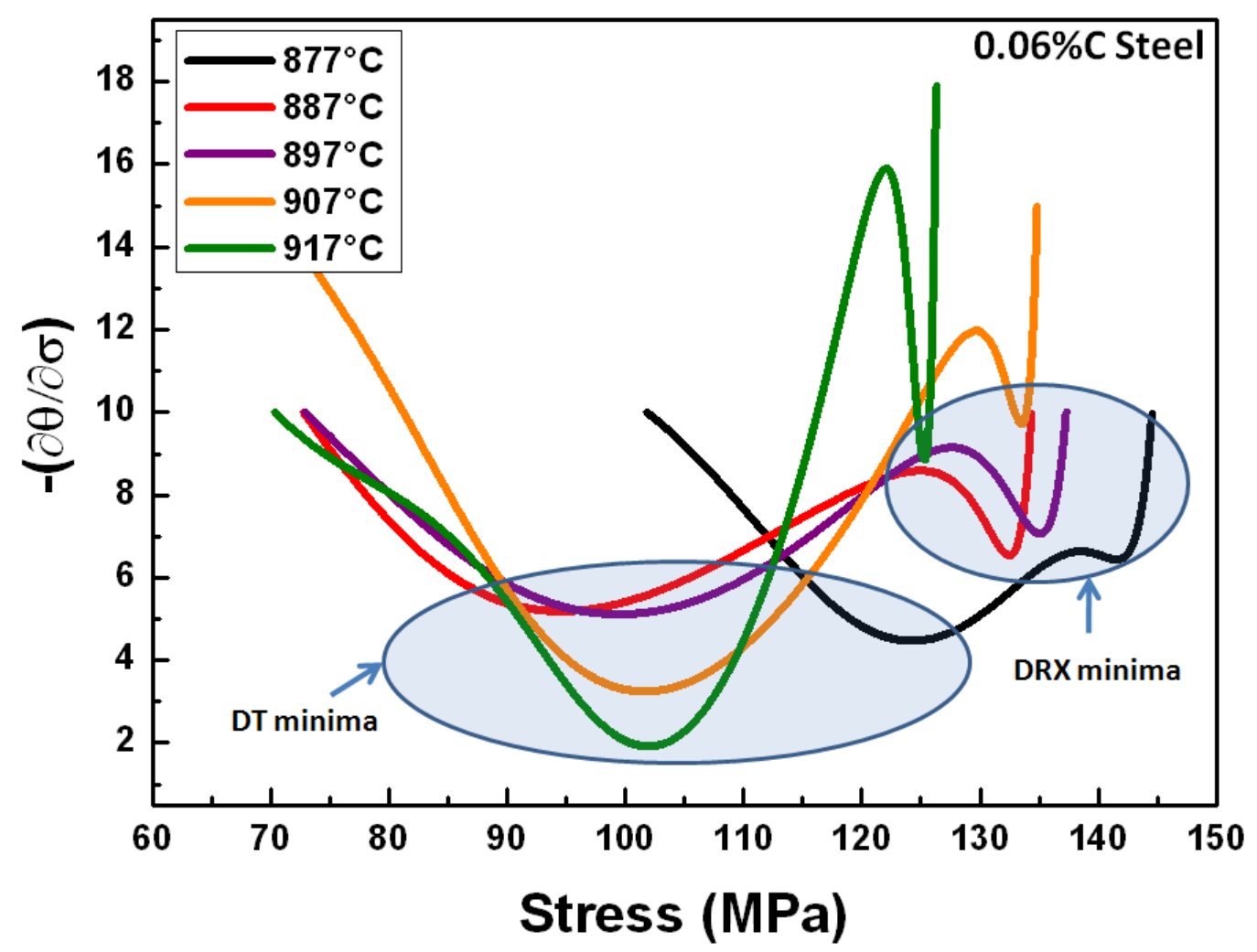

(a) 


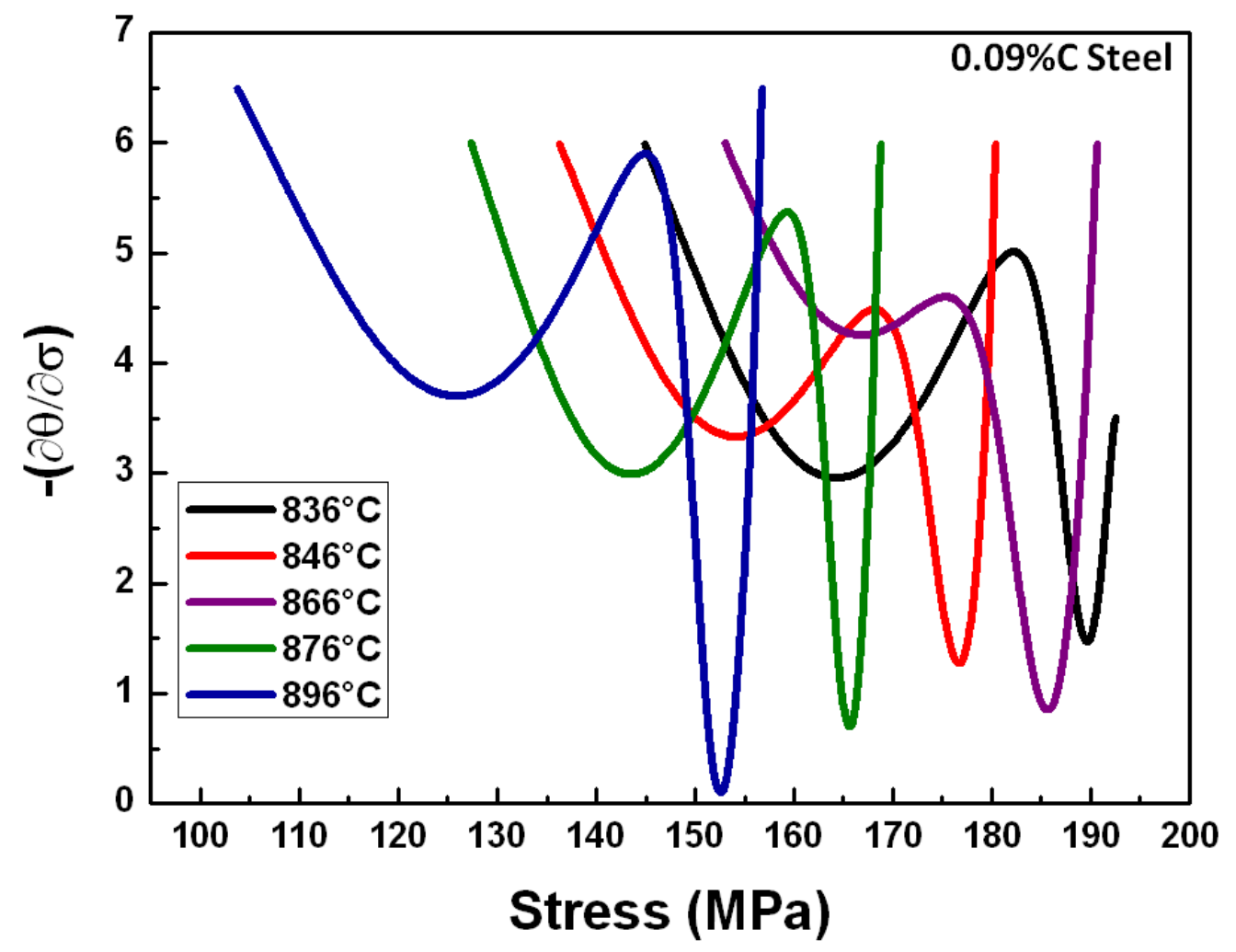

(b)

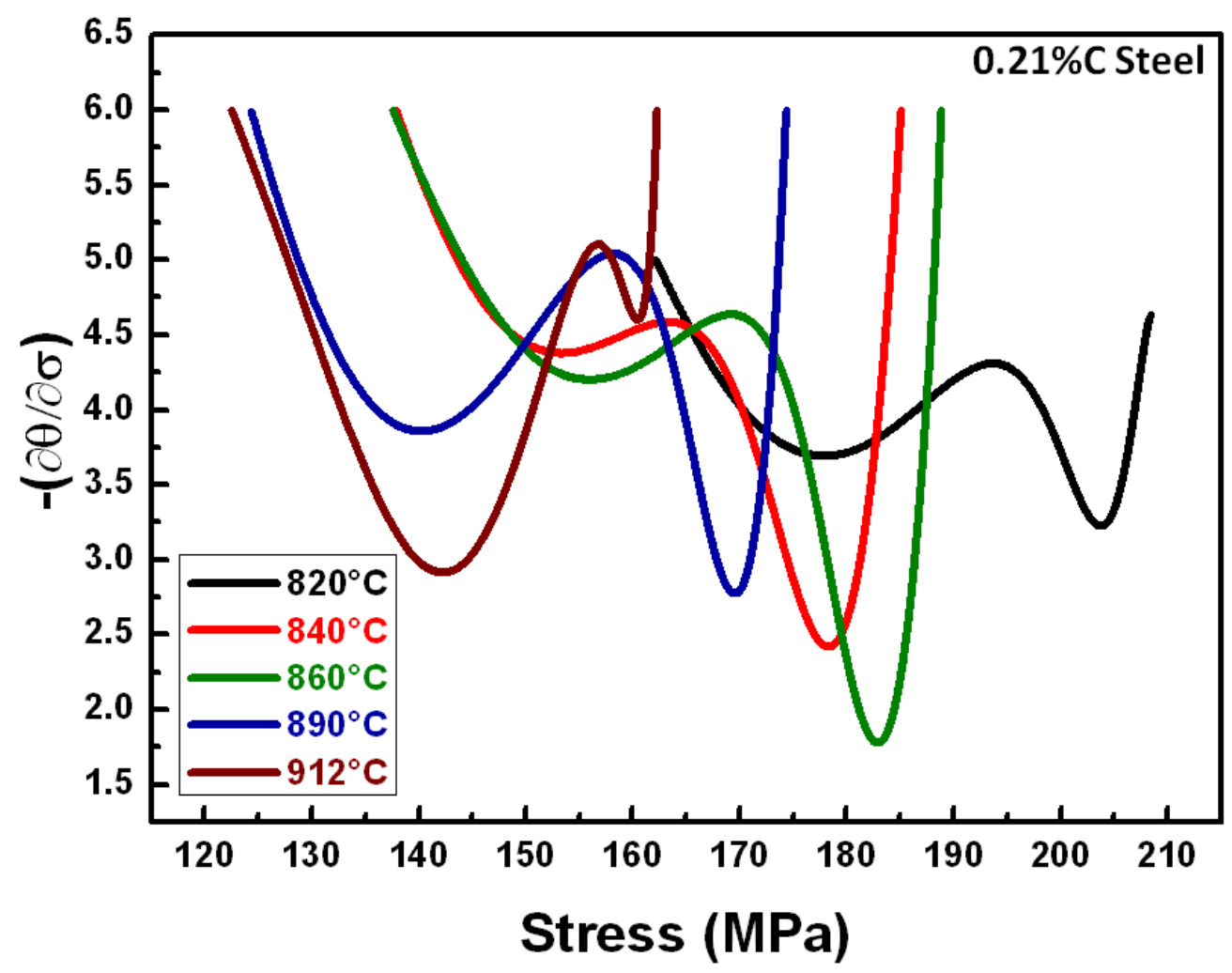

(c) 


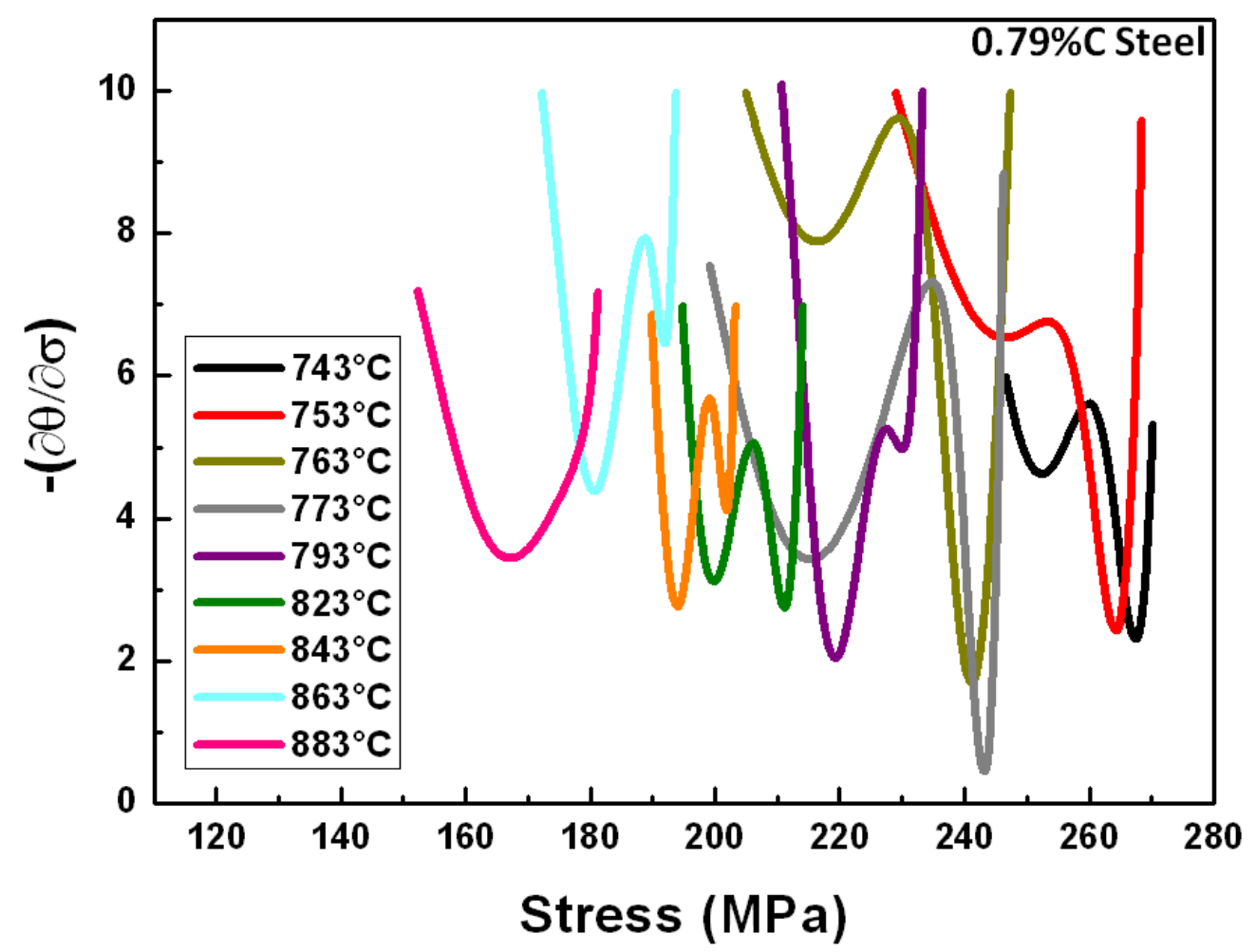

(d)

Fig. 5.3: $-(\partial \theta / \partial \sigma)$ vs. $\sigma$ plots at the various experimental temperatures of the (a) $0.06 \% \mathrm{C}$, (b) $0.09 \% \mathrm{C}$, (c) $0.21 \% \mathrm{C}$ and (d) $0.79 \% \mathrm{C}$ steels.

The dependences of the critical strains on $\Delta T$ (defined as Experimental Temperature $\left.-\mathrm{Ae}_{3}\right)$ for the $0.06 \% \mathrm{C}, 0.09 \% \mathrm{C}, 0.21 \% \mathrm{C}$ and $0.79 \% \mathrm{C}$ steels are displayed in Figs. 5.4(a) - (d), respectively. Beyond a $\Delta \mathrm{T}$ of about 10 to $20^{\circ} \mathrm{C}$, the critical strain for DT appears to increase with temperature, as called for thermodynamically, see below. It is important to note that these critical strains are consistent with the microstructural observations regarding the first appearance of ferrite in deformed and quenched samples, as discussed in Chapter 4. The magnitude of the critical strain appears to increase with the Mn (solute) content in the various steels, a tendency that requires further investigation. 


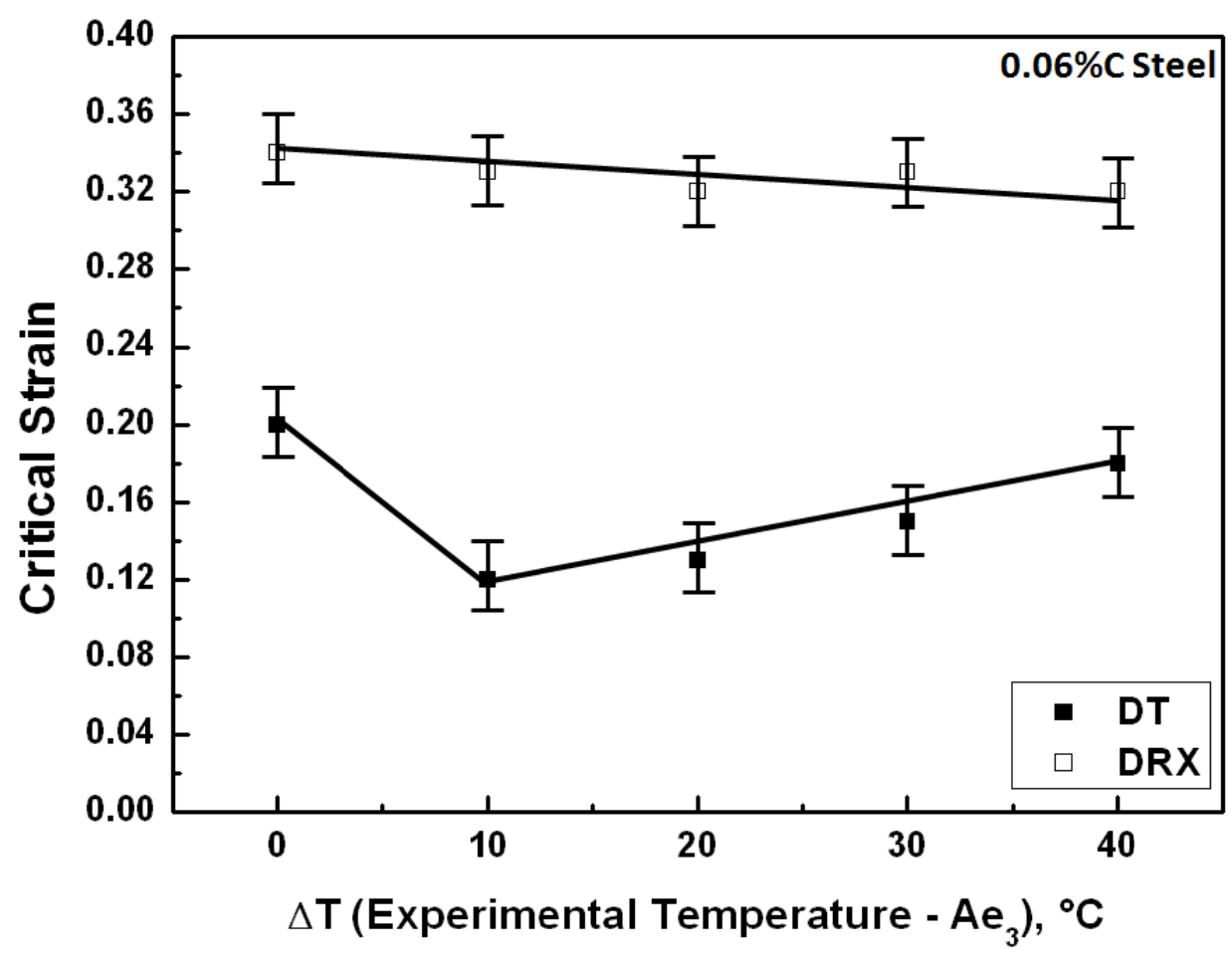

(a)

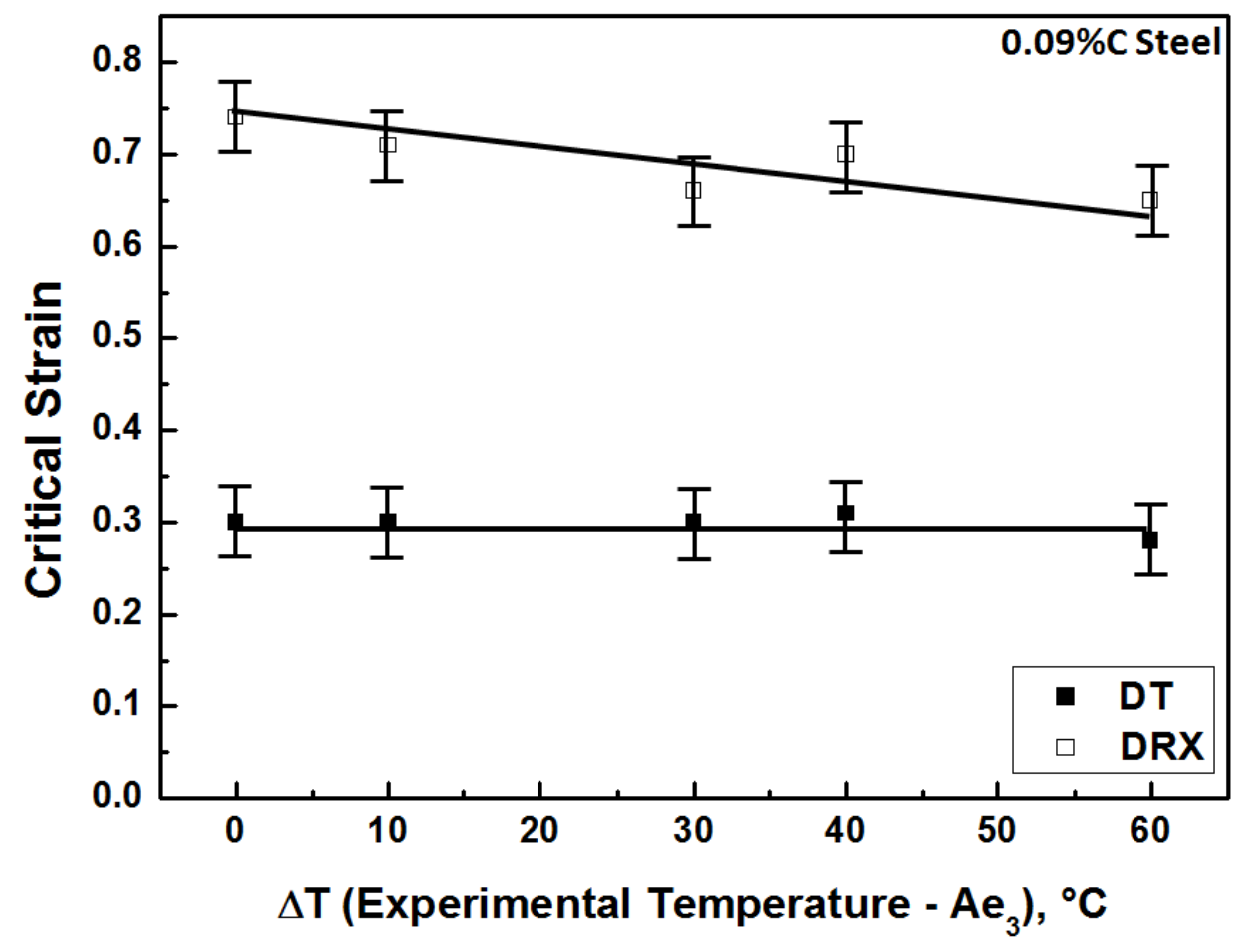

(b) 


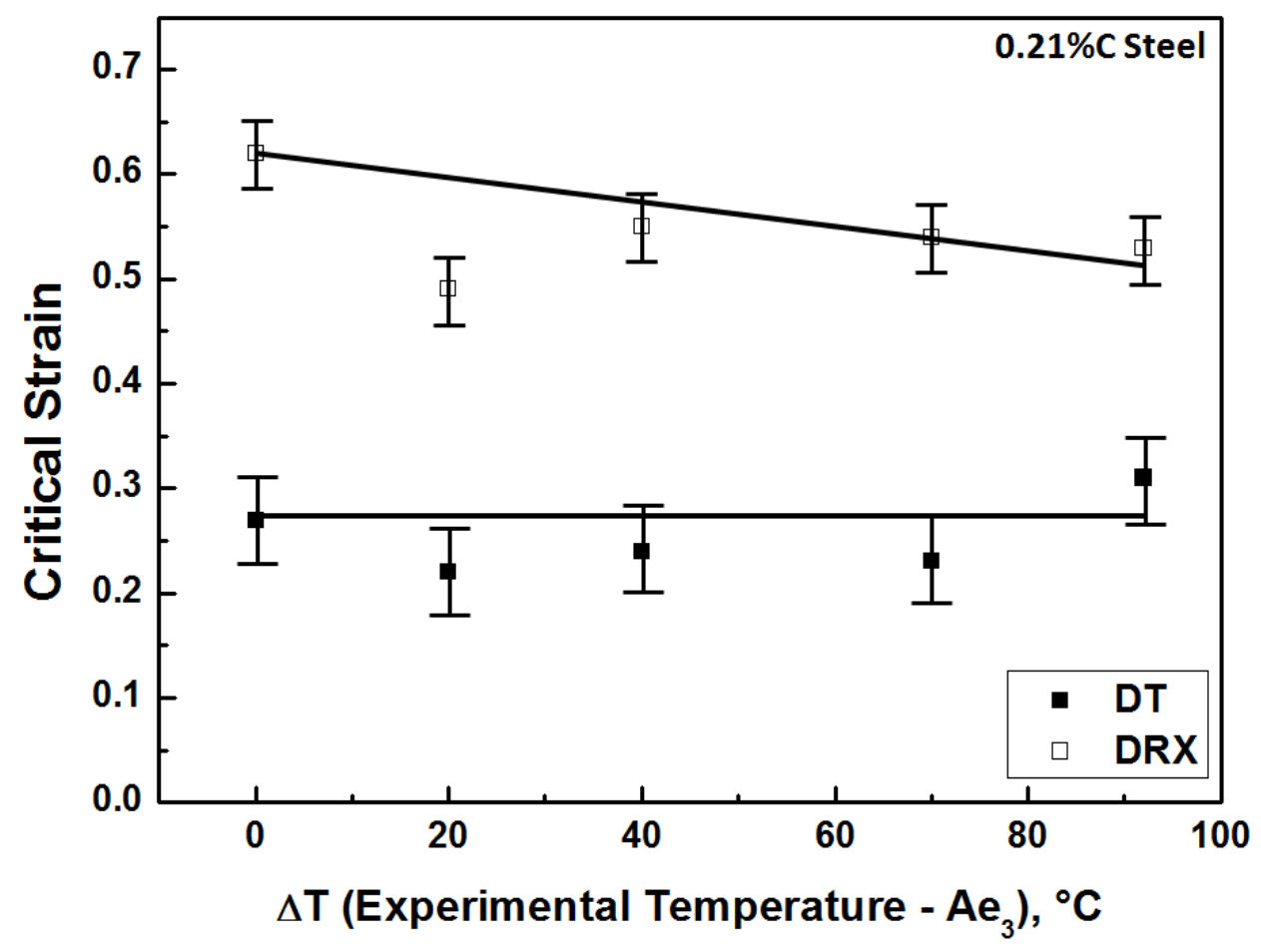

(c)

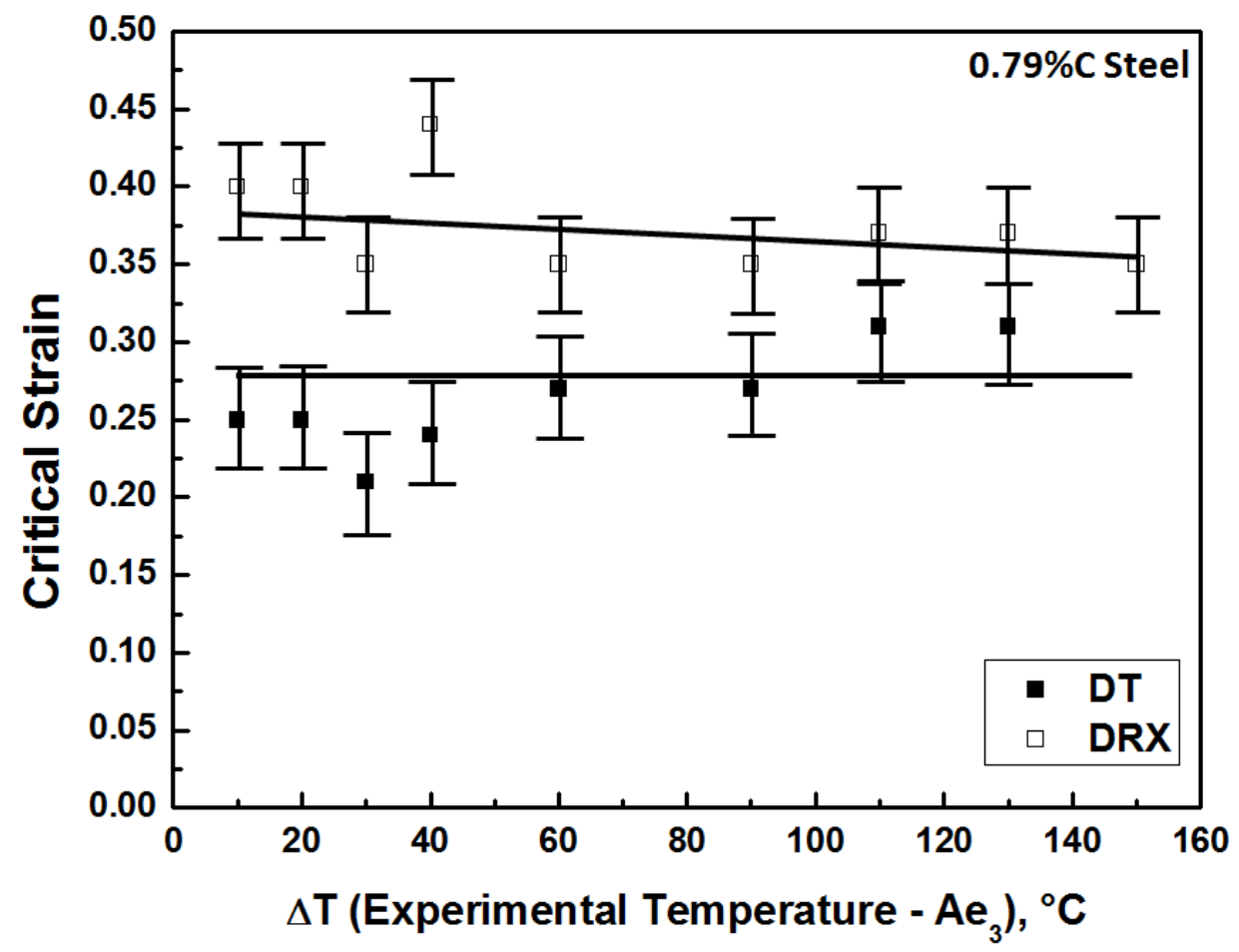

(d)

Fig. 5.4: Dependences of the critical strains for DT and DRX on $\triangle T$ (Experimental Temperature $-\mathrm{Ae}_{3}$ ) of the (a) $0.06 \% \mathrm{C}$, (b) $0.09 \% \mathrm{C}$, (c) $0.21 \% \mathrm{C}$ and (d) $0.79 \% \mathrm{C}$ steels. The fits to the DT points in these figures differ slightly from the versions of these diagrams published in Ref. 5.2. 
By contrast, the critical strains for DRX exhibit the reverse tendency; i.e. they decrease with temperature in the usual way [5.19]. It should be noted that over most of the experimental temperature range covered here, the critical strain for DT is less than for DRX i.e. the initiation of DT is likely to precede that of DRX. Beyond the intersection of the two relationships, at about 150 degrees above the $\mathrm{Ae}_{3}$, the extrapolated DRX critical strain is lower than the extrapolated DT critical strain. However, it appears that in this high temperature range, only single minima are observed. This indicates that, once DRX is nucleated and begins to remove dislocations, it is no longer possible for DT to be initiated at all, see Fig. 5.4(a). Therefore, it appears that the prior initiation of DRX prevents the later nucleation of DT so that only a single softening mechanism operates in this temperature range. It should be added in passing that, as only about 0.5 to 1 volume percent ferrite forms per one percent strain and as this only results in a small reduction in the dynamic recovery work hardening rate, the effect of the production of DT ferrite can easily be overlooked. Also as mentioned earlier, this is compounded by the fact that the ferrite is in the form of Widmanstätten plates only about $200 \mathrm{~nm}$ in width and therefore not resolvable using optical microscopy $[5 \cdot 1,5.2,5.20]$

\subsubsection{Effect of Polynomial Order}

The double differentiation method generally requires the use of polynomials of at least order 7 [5.2]. When lower orders are employed, the shape of the experimental flow curve is not reproduced accurately enough for the departure from conventional dynamic recovery behavior to be detectable. It is therefore of interest to consider the effect of polynomial order on the sensitivity of the double differentiation method as well as on the actual value of the critical strain determined in this way. For this purpose, the early part of the flow curve (to just after the peak) determined on the $0.79 \% \mathrm{C}$ steel at $753^{\circ} \mathrm{C}$ at $4 \mathrm{~s}^{-1}$ was analyzed using orders of $n=2-15$. The second derivative results obtained in this way are presented in Figs. 5.5(a) and 5.5(b). From Fig. 5.5(a), it can be seen that 
polynomials of order 2, 3 and 4 are unable to detect any minima at all. Curves of order 5 and 6, on the other hand, can be used to detect the DRX minima, but are unable to identify the DT minima. In Fig. 5.5(b), it can be seen that, as long as the order is 7 or higher, both minima are readily distinguished.

The dependences of the critical strains for DT and DRX on polynomial order are shown in Fig. 5.5(c). Of particular importance is the influence of order on the precise values of the critical strains determined in this way. It can be seen that, although there is a distinct dependence of the stresses associated with the minima on order, the effect on the actual value of the strain is fairly small. This is related to the high slope of the flow curve after yielding. It appears that, as long as the order is 7 or higher, the DT strains can be determined to accuracies of about $\pm 1 \%$ in strain, which thus appears to be the limit of precision of the present procedure. On the other hand, in the metallographic method, at least 5 volume $\%$ of the new phase must be present for the transition to be detectable and thus the actual point of initiation is in fact indeterminate [5.20].

It is important to note from Fig. 5.5(c) that, as long as the polynomial order is at least 4 , the DRX critical strains remain fairly constant over the polynomial order range from 4 to 15 . Thus the minimum does not seem to be an artefact of the order of the polynomial. This is consistent with the observations of numerous previous researchers [e.g. 5.21-5.25], who have employed differing orders in their work. Similar remarks apply to the DT critical strains, which do not vary over the polynomial order range 7 to 15 . The double derivative method has previously been employed successfully to determine the DT critical strains by Sun et al. [5.11] and Choi et al. [5.12]. In summary, the DRX and DT minima are shown here to be relatively independent of polynomial order and can thus be taken to represent the points of initiation of softening mechanisms, as has been demonstrated by numerous previous investigators [e.g. 5.11,5.12,5.21-5.25]. 
With respect to the DRX critical strains, the uncertainty is slightly greater, but the maximum and minimum strain values still fall in a range of about $\pm 2 \%$. The increment in uncertainty is due to the fact that, at the larger strains, the flow curve slopes are somewhat lower. This leads to larger strain differences for a given stress interval [5.20].

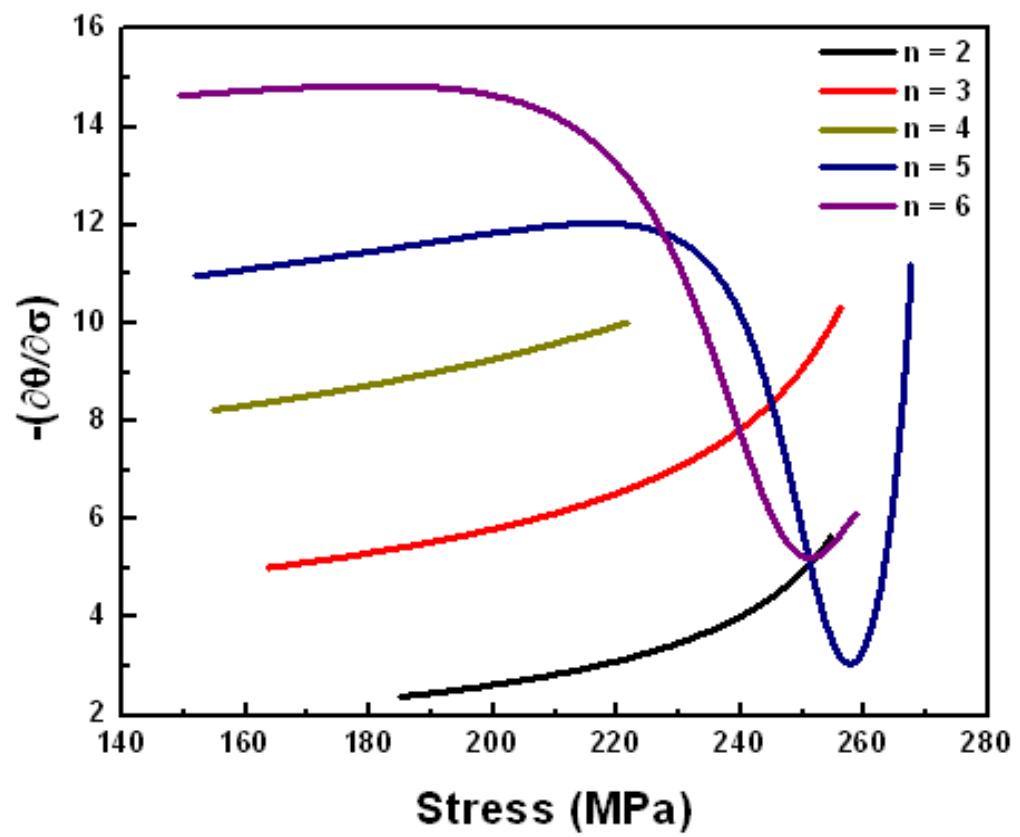

(a)

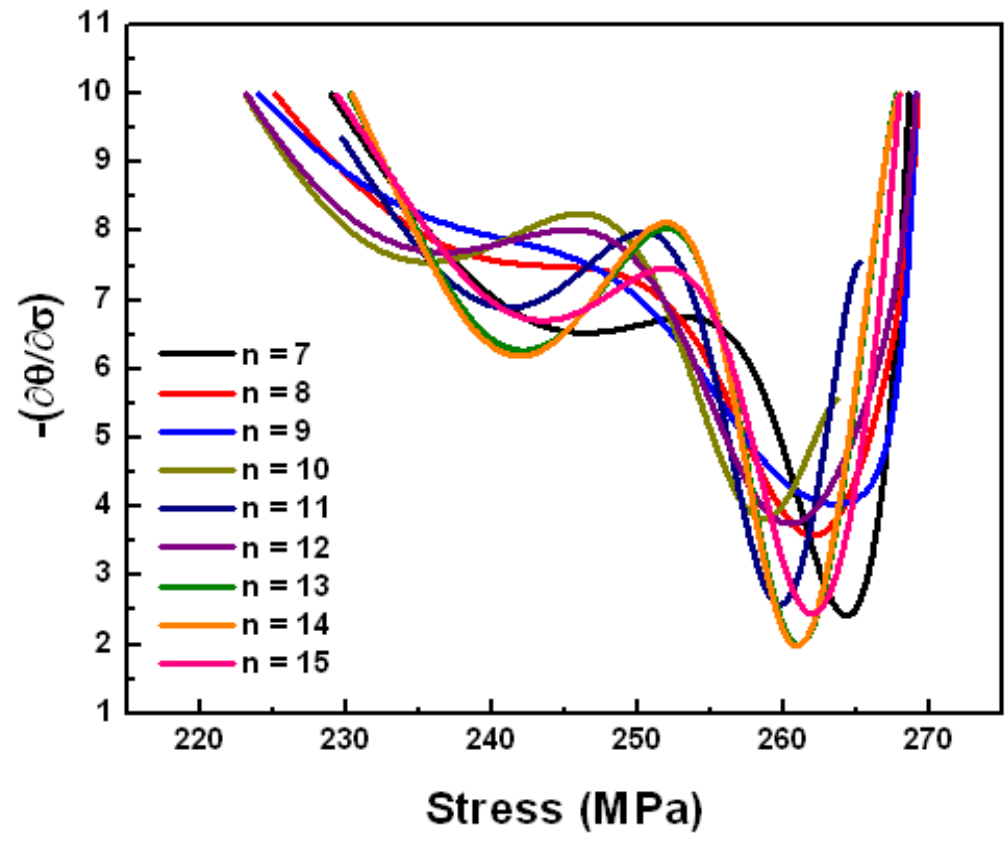

(b) 


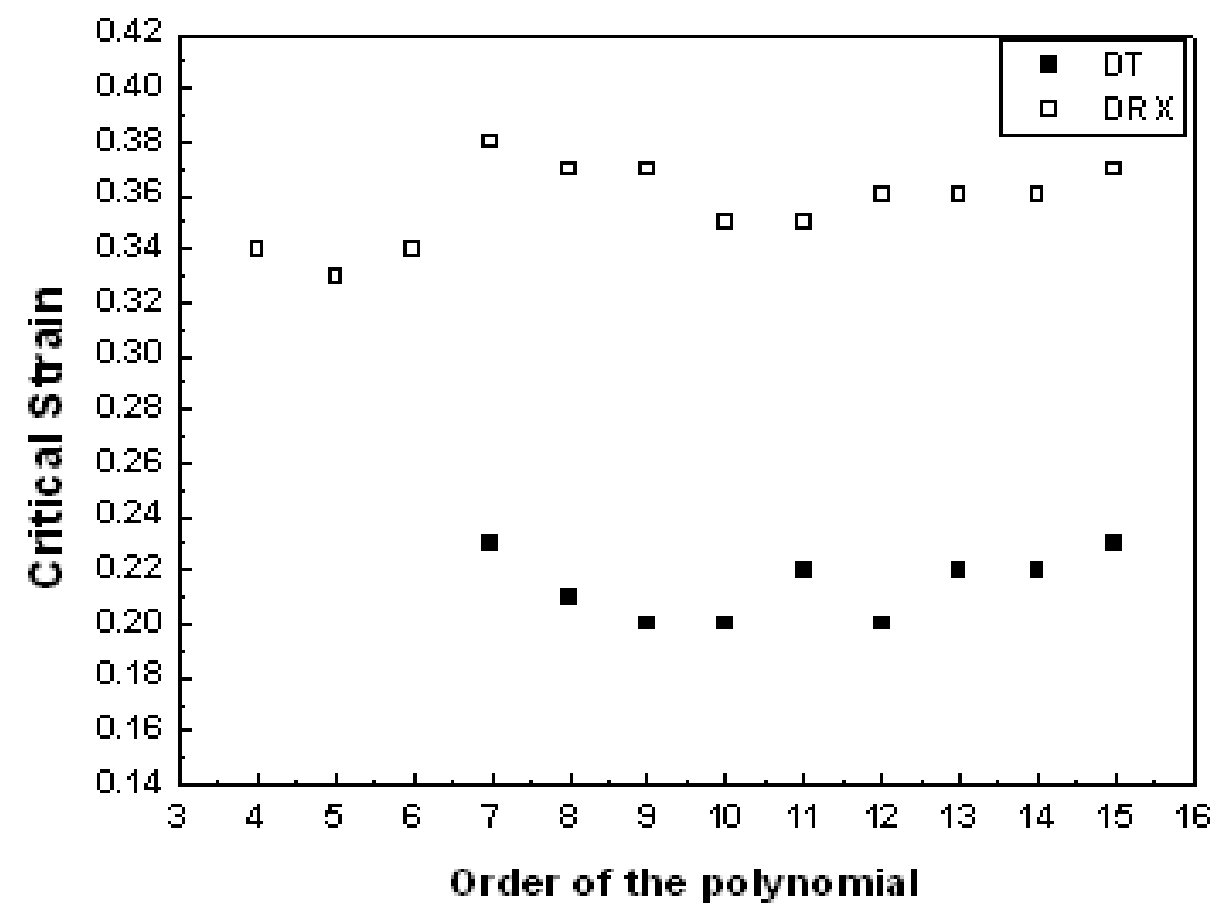

(c)

Fig. 5.5: Effect of polynomial order on the second derivative/stress relationship according to the present (partial curve) method: (a) orders $2-6$; (b) orders 7 15; (c) effect of order on the values of the critical strains.

\subsection{Discussion}

Many authors have derived only a single set of minima using the double derivative method [5.20]. This is generally associated with the initiation of DRX. Therefore, the question arises as to how it is possible to arrive at either two sets of critical strains or alternatively at a single set from a particular set of flow curves and moreover using the same basic analytical technique. A resolution of this dilemma is essential since the double derivative method is in wide use currently.

In order to resolve this issue, the flow curve considered in Fig. 5.5 was reanalyzed using the approach of Ref. 5.26. The first important difference between the present calculations and those of the earlier treatment is that, in the previous fitting, the polynomial was required to reproduce the entire flow curve. However, in the present study, the major objective of the polynomial was only to 
reproduce the features of the initial portion (to just beyond the peak) of the curve. In the prior work, the fitted curve was employed to calculate the fractional softening taking place during straining and so a fit of the entire curve was required. Here, only the critical strains are important. Thus the rest of the flow curve is not relevant for the present purpose. The important point to note is that it is more difficult to reproduce the detailed features of extended flow curves using polynomials (particularly when flow softening is taking place) than those of short flow curves, where the increase in stress is nearly monotonic [5.20].

The second derivative values obtained from the polynomials fitted to the entire flow curve are depicted in Figs. 5.6(a), 5.6(b) and 5.6(c). From Fig. 5.6(a), it can be seen that, as before, no minima can be detected at all if the order is relatively low, $3-5$ in the present case. When the order is increased into the $6-11$ range, the DRX minima are detectable, but the DT ones are not. From Fig. 5.6(c), it is evident that, when the order is increased into the $12-15$ range, both sets of minima can easily be detected. Therefore, polynomials of order 11 and lower will only produce single minima when the entire flow curve is being fitted. In this case, the higher orders of polynomials are essential inorder to reveal the double minima, the higher orders being required due to the additional constraints imposed on the fitting in this case.

The critical strains associated with these minima are shown in Fig. 5.7. Here it can be seen that the DT critical strains vary only marginally, although they only appear if the order is 12 or higher. Similarly, the values of the DRX critical strains do not differ in any important way from those illustrated earlier.

In the absence of straining, ferrite is thermodynamically unstable at temperatures above the $\mathrm{Ae}_{3}$. However, deformation provides the driving force for DT and more strain is required to produce the transformation at higher temperatures where the ferrite is more unstable. This is why the critical strain for the initiation of DT increases with temperature. By contrast, the critical strain 


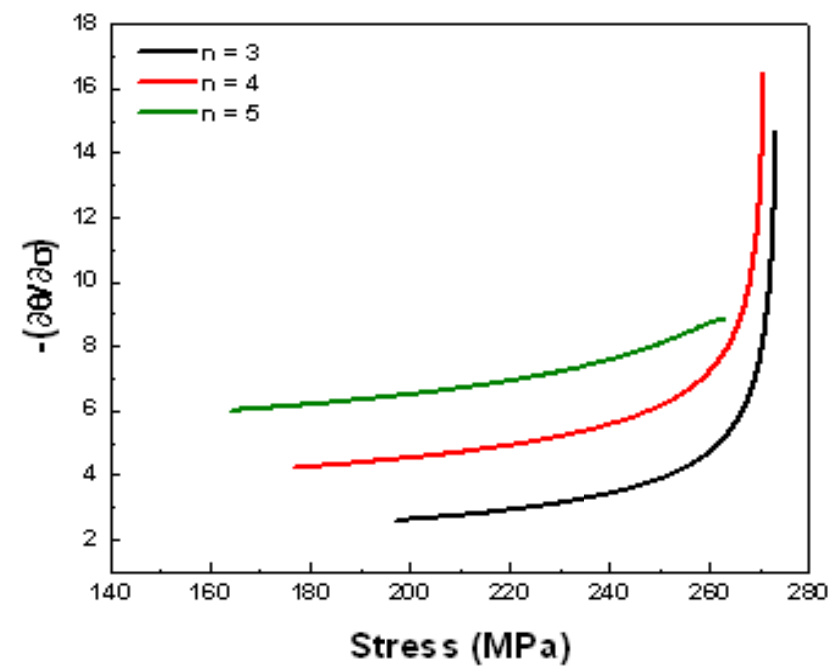

(a)

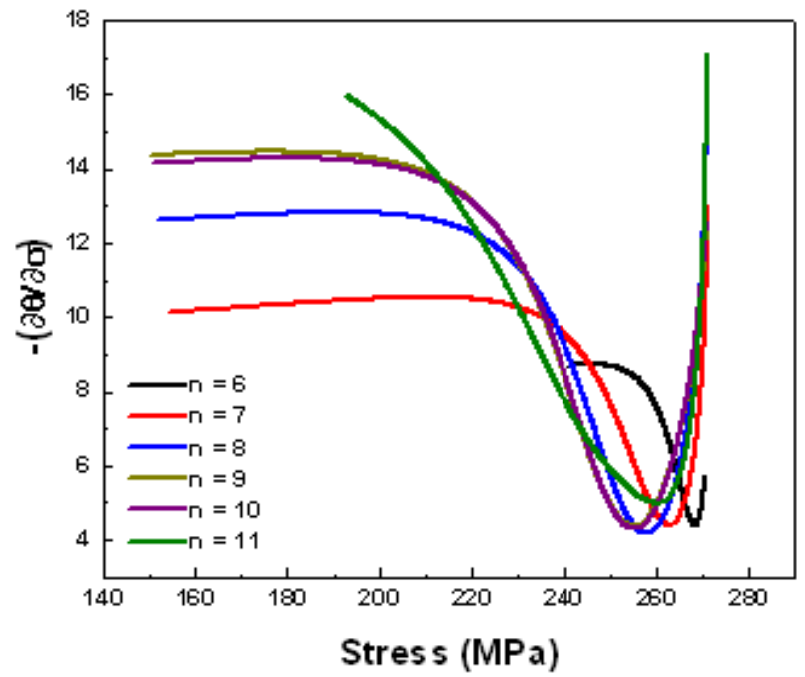

(b)

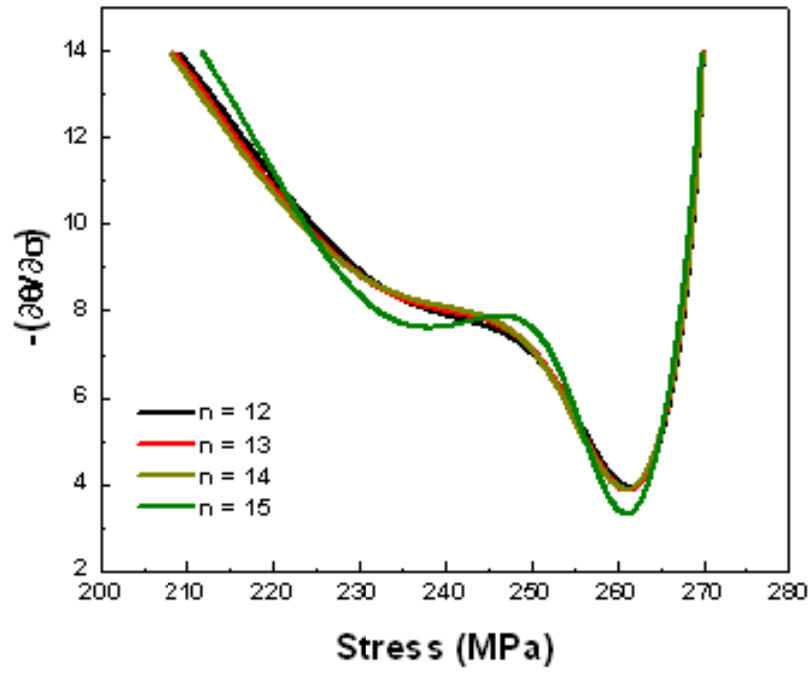

(c)

Fig. 5.6: Effect of polynomial order on the second derivative/stress relationship according to the entire curve method: (a) orders $3-5$; (b) orders $6-11$; (c) orders $12-15$. 


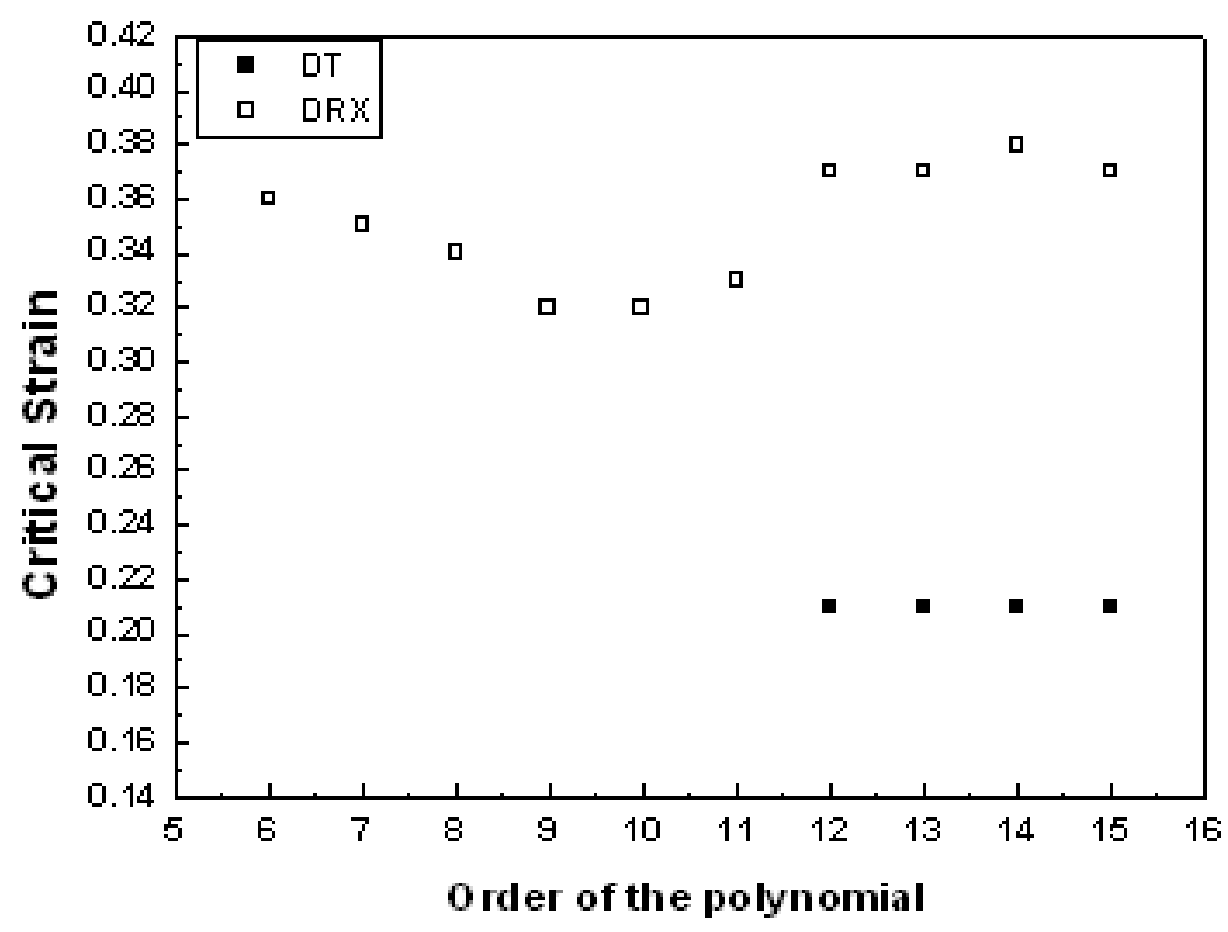

Fig. 5.7: Effect of order on the values of the critical strains.

for DRX decreases with temperature [5.27]. The second highest experimental temperature investigated in the current work was about $130^{\circ} \mathrm{C}$ above the $\mathrm{Ae}_{3}$ in an experiment carried out on the $0.79 \% \mathrm{C}$ steel. Even at this temperature, the presence of two minima (Fig. 5.3(a)) signifies that both softening mechanisms, i.e. DT and DRX, operate concurrently in the material. The relevant microstructures were shown above in Chapter 4 (Fig. 4.4(i)). This conflicts with the computer simulations of Sun et al. [5.11] and Choi et al. [5.12], who reported that DT was the operative softening mechanism up to $860^{\circ} \mathrm{C}$ and that DRX alone took place above that temperature [5.2]. (In these calculations, DT only occurred up to $25^{\circ} \mathrm{C}$ above the $\mathrm{Ae}_{3}$, suggesting that the driving forces they employed for DT in their model were too low. )

An interesting feature of the present observations concerns the possible presence of a "nose" in the DT kinetics. In static transformations, this nose represents the point at which the dependences on temperature of the driving force for the reaction and the diffusion rate combine to produce the highest 
reaction rate. Under DT conditions, the time is replaced by the strain as the relevant variable, but the same considerations apply. The critical strains for the onset of DT are illustrated in Fig. $\mathbf{5 . 8}$ for the three plain C steels (the $\mathbf{N b}$ steel did not display this tendency). Here it can be seen that the 'noses' for two of the steels are located above the conventional $\mathrm{Ae}_{3}$ 's because deformation has raised the effective 'equilibrium' transformation temperatures to higher levels. (The position of the nose for the third plain $C$ steel was not located precisely, but appears to be about 30 to $40^{\circ} \mathrm{C}$ above the $A e_{3}$ ). The presence of such a nose signifies that the formation of DT ferrite is accelerated in the vicinity of the nose temperature [5.2]. This conjecture has the potential to explain the abnormally low rolling loads frequently observed in industrial mills above the $\mathrm{Ae}_{3}$ [5.28] and is a topic that is addressed in the next chapter.

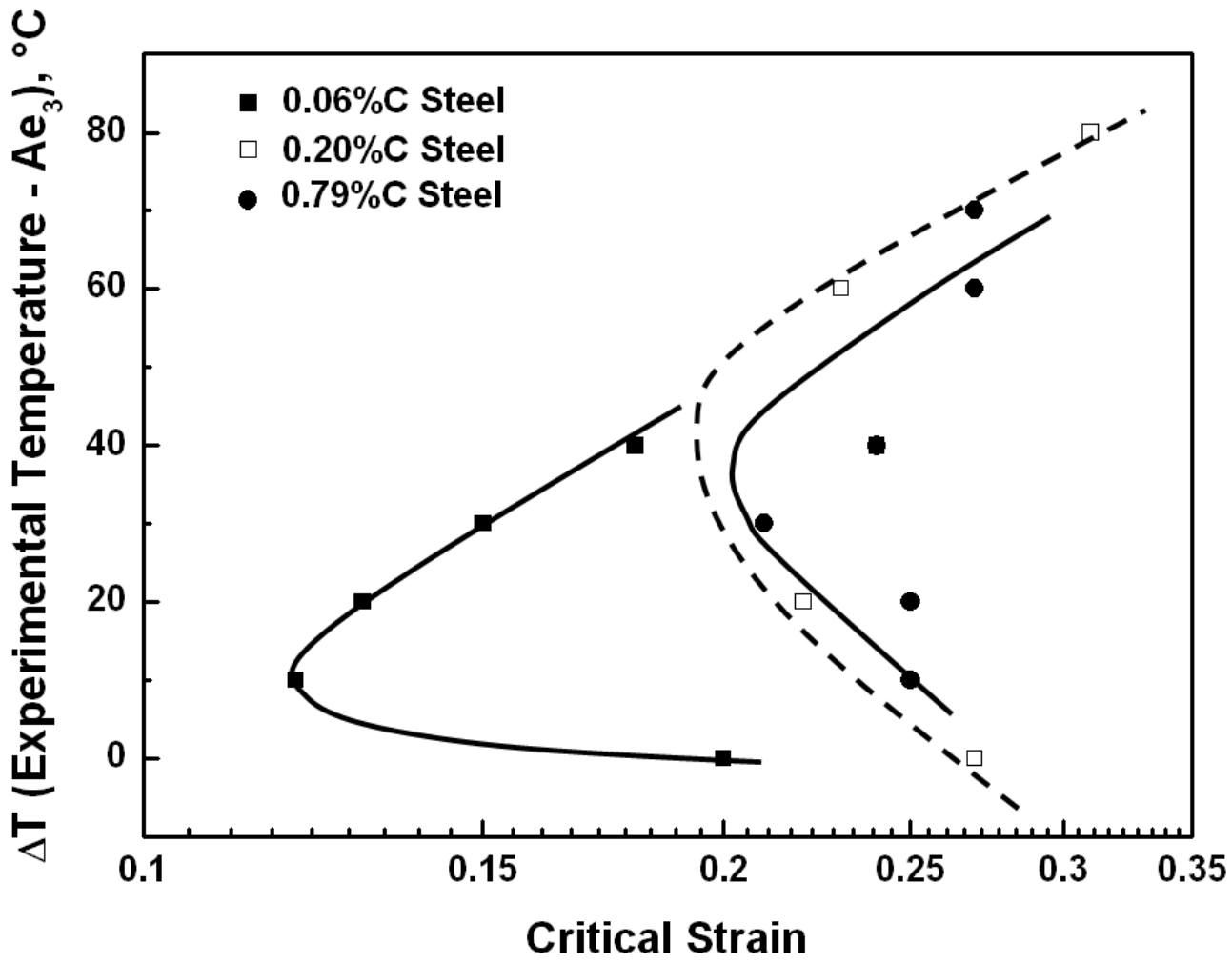

Fig. 5.8: Dependences of the DT critical strain on $\Delta T$ in the three plain $C$ steels [5.2]. Note that the elevation of the nose above the conventional $\mathrm{Ae}_{3}$ increases with the alloy content and that the curve for the $0.20 \% \mathrm{C}$ steel is shown dashed, as more points are required to verify the tendency illustrated here. 


\subsection{Conclusions}

The flow curves determined in the hot torsion tests on the four steels were fitted with polynomial expressions using the MATLAB software. These were then analyzed by the double derivative method. Analysis of the data led to the following conclusions.

1. As long as the polynomial order is sufficiently high, two minima in the $(\partial \theta / \partial \sigma)$ vs. $\sigma$ plots associated with the flow curves are consistently observed over most of the experimental temperature range investigated.

2. The first minimum corresponds to the initiation of dynamic transformation and the second to that of dynamic recrystallization.

3. When the fitting procedure is limited to the initial part of the flow curve, detection of the first set of minima requires the use of polynomial orders of at least seven. Thus the initiation of DT (and even of DRX) may fail to be detected if the polynomial order employed is too low.

4. Although the order has a detectable effect on the flow stress associated with the minimum, it only leads to small differences in the derived critical strains. In the present case, all the DT critical strains were within about $\pm 1 \%$ of the average value and the DRX critical strains within about $\pm 2 \%$.

5. The critical strain for DT was lower than for DRX in this range and increased slightly with temperature. Conversely, the critical strain for DRX decreased with temperature in the usual way. At the highest temperatures, only single minima were observed, indicating that solely DRX was initiated.

6. The occurrence of dynamic transformation during the high temperature deformation of austenite signifies that two softening mechanisms (DT and DRX) are jointly responsible for the shape of the familiar single peak flow curve and not just dynamic recrystallization alone. 


\section{References}

5.1 J.J. Jonas, C. Ghosh and V.V. Basabe; Steel Res. Int., Vol. 84, (2013), p. 253.

5.2 C. Ghosh, V.V. Basabe and J.J. Jonas; Steel Res. Int., in press (DOI: 10.1002/srin.201200188).

5.3 E. Poliak and J.J. Jonas; Acta Mater., Vol. 44, (1996), p. 127.

5.4 N. Xiao, M. Tong Y. Lan, D. Li and Y. Li; Acta Mater., Vol. 54, (2006), p. 1265.

5.5 R. Ding and Z.X. Guo; Mater. Sci. Eng. A, Vol. 365, (2004), p. 172.

5.6 T. Takaki, A. Yamanaka and Y. Tomita; ISIJ Int., Vol. 51, (2011), p. 1717.

5.7 D.G. Gram, H.S. Zurob, Y.J.M. Brechet and C.R. Hutchinson; Acta Mater., Vol. 57, (2009), p. 5218.

5.8 A.I. Fernandez, P. Uranga, B. Lopez and J.M. Rodriguez-Ibabe; Mater. Sci. Eng. A, Vol. 361, (2003), p. 367.

5.9 L. Ma, Z. Liu, S. Jiao, X. Yuan and D. Wu; J. Iron Steel Res. Int., Vol. 15, (2008), p. 31.

5.10 J. Wang, J. Chen, Z. Zhao and X. Ruan; J. Iron Steel Res. Int., Vol. 15, (2008), p. 78.

5.11 X. Sun, H. Luo, H. Dong, Q. Liu and Y. Weng; ISIJ Int., Vol. 48, (2008), p. 994.

5.12 J.K. Choi, D.H. Seo, J.S. Lee, K.K. Um and W.Y. Choo; ISIJ Int., Vol. 43, (2003), p. 746.

5.13 V.V. Basabe, J.J. Jonas and H. Mahjoubi; ISIJ Int., Vol. 51, (2011), p. 612.

5.14 V.V. Basabe and J.J. Jonas; ISIJ Int., Vol. 50, (2010), p. 1185.

5.15 V.V. Basabe, J.J. Jonas and C. Ghosh; Adv. Mater. Res., Vol. 409, (2012), p. 829.

5.16 J.J. Jonas and V.V. Basabe; Solid State Phenomena, Vol. 172-174, (2011), p. 372.

5.17 C. Ghosh, V.V. Basabe, J.J. Jonas, S. Yue and X.Y. Xiong; ISIJ Int., Vol. 53, (2013), p. 900.

5.18 J.J. Jonas, X. Quelennec, L. Jiang and E. Martin; Acta Mater., Vol. 57, (2009), p. 2748.

5.19 T. Sakai and J.J. Jonas; Acta Metall., Vol. 32, (1984), p. 189.

5.20 J.J. Jonas, C. Ghosh, X. Quelennec and V.V. Basabe; ISIJ Int., Vol. 53, (2013), p. 145.

$5.21 \mathrm{H}$. Mirzadeh and A. Najafizadeh; Mater. Design, Vol. 31, (2010), p. 1174.

5.22 G.R. Ebrahimi, H. Keshmiri, A.R. Maldad and A. Momeni; J. Mater. Sci.

Tech., Vol. 28, (2012), p. 467.

5.23 G. Gottstein, M. Frommert, M. Goerdeler and N. Schäfer; Mater. Sci.

Eng. A, Vol. 387-389, p. 604.

5.24 X.K. Liang, X.J. Sun, Q.Y. Liu and H. Dong; Acta Mat. Sin., Vol. 19, (2006), p. 265. 
5.25 X. Zhao, K. Zhang, X. Li, Y. Li, Q. He and J. Sun; J. Rare Earths, Vol. 26, (2008), p. 846.

5.26 X. Quelennec and J.J. Jonas; ISIJ Int., Vol. 52, (2012), p. 1145.

5.27 G. Zhu, J. Gao, S.V. Subramanian and L.E. Collins; Thermomechanical Processing of Steels, TIM, London, (2000), p. 466.

5.28 E. Poliak; Arcelor-Mittal Global Research \& Development Center, East Chicago, IL, private communication. 
Chapter 6

\section{Effect of Dynamic Transformation on the Mean Flow Stress}




\section{Effect of Dynamic Transformation on the Mean Flow Stress ${ }^{*}$}

\subsection{Background}

In general the rolling load is estimated from the mean flow stress (MFS). This is defined as the area under each $\sigma-\varepsilon$ curve, normalized by the strain. It is calculated by summing, over the entire deformation, the product of strain increment for each data reading, $\Delta \varepsilon$, and the average stress in that increment $\sigma_{\mathrm{av}}$ $[6.1,6.2]:$

$\mathrm{MFS}=\frac{1}{\varepsilon_{\mathrm{b}}-\varepsilon_{\mathrm{a}}} \sum_{\mathrm{a}}^{\mathrm{b}} \sigma_{\mathrm{av}} \Delta \varepsilon$

where $\varepsilon_{\mathrm{a}}$ and $\varepsilon_{\mathrm{b}}$ denote the beginning and end of the strain interval, respectively.

The dependence of the MFS on temperature is of considerable interest, as the upper and lower critical temperatures, $A_{r 3} *$ and $A_{r 1} *$, related to rolling can be determined from a Boratto diagram [6.3], as shown in Fig. 6.1 [6.4]. The beginning of the austenite-to-ferrite $(\gamma$-to- $\alpha)$ transformation in deformed austenite is referred to as the upper critical temperature $\left(A_{r 3}{ }^{*}\right)$. On the other hand, the lower critical $\left(A_{r 1}{ }^{*}\right)$ refers to the temperature at which this transformation is complete during cooling. In general, the MFS increases as the hot rolling schedule progresses, which essentially corresponds to continually decreasing pass temperatures.

As shown in Fig. 6.1, when the MFS is plotted against $1000 / T$, where $T$ is the pass temperature in Kelvin, four regions are clearly revealed. In the high temperature region I, there is a low rate of increase of MFS. Because recrystallization is essentially complete between passes, this is mainly due to the decrease in temperature. On further lowering of the temperature, there is a transition to a higher rate of flow stress increase, which results from the transition from recrystallization to no-recrystallization behaviour. The higher

\footnotetext{
*Some of the material in this chapter has been published in Refs. 6.8 and 6.11.
} 
stress levels are due to accumulated austenite work hardening. Region III is characterized by a decrease in MFS, reflecting the presence of the ferrite that has transformed from the austenite [6.5]. Since at a given temperature ferrite is softer than austenite, MFS's in the intercritical $(\alpha+\gamma)$ temperature range are lower than in the adjacent temperature austenite range. This leads to a decrease in separation force during rolling in this lower temperature interval. During the planning of rolling schedules, the upper critical temperature is of particular importance as it determines the maximum 'pancaking' strain that can be applied to the austenite in a given schedule. This is an essential requirement of the controlled rolling process in microalloyed steels [6.6]. Once the austenite-toferrite transformation is completed at the beginning of region IV, ferrite work hardening along with the decreasing temperature combine to account for the further increases in MFS in this region [6.5].

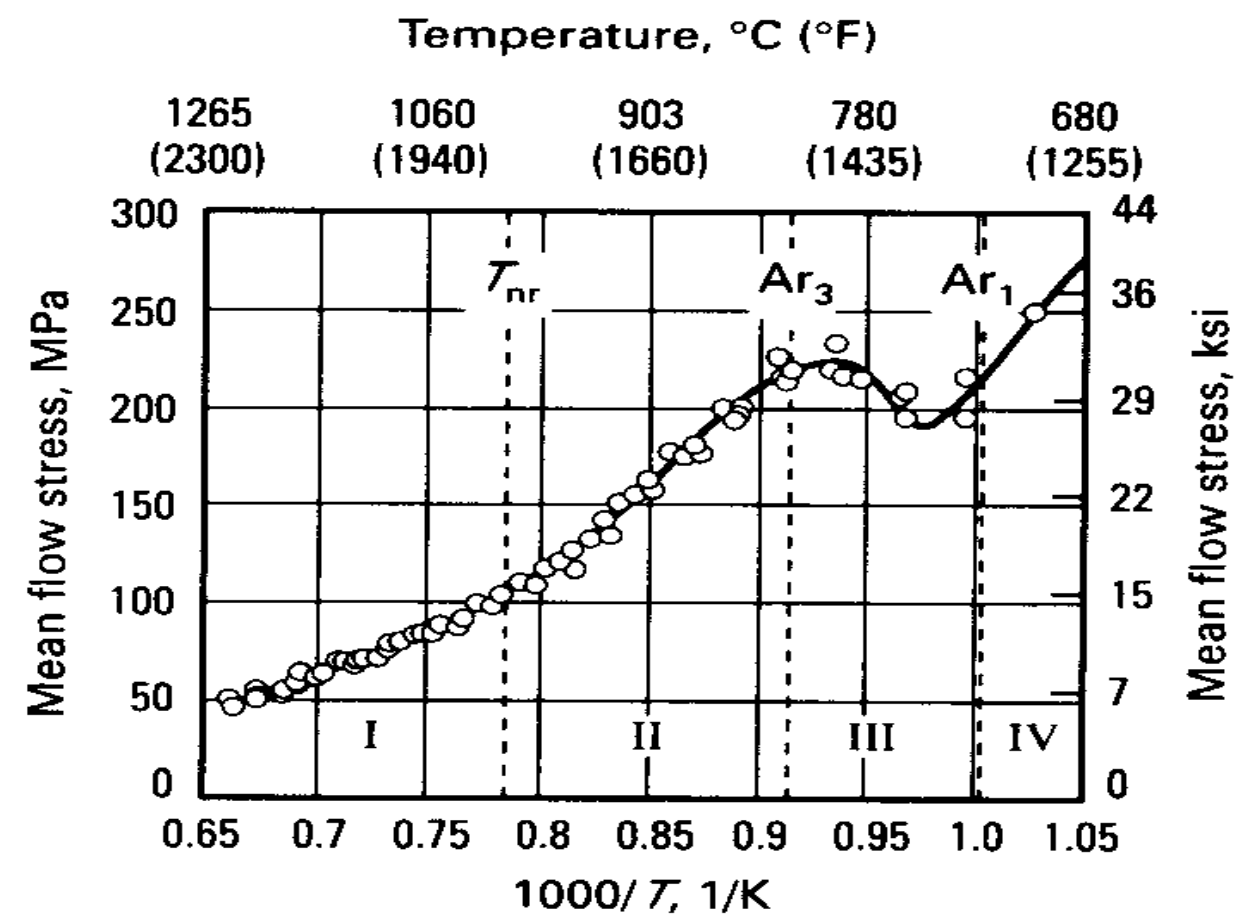

Fig. 6.1: Mean flow stress as a function of $1000 / T$, where $T$ is the absolute pass temperature. Region 1 corresponds to the temperature range where recrystallization occurs after each pass; region II falls between the norecrystallization temperature $T_{n r}$ and $A_{r 3} *$, the upper critical temperature; region III is the intercritical temperature range; region IV lies below the $A_{r 1}{ }^{*}$, or lower critical temperature [6.4]. 
It is important to note that the upper $\left(A_{r 3}\right)$ and lower $\left(A_{r 1}\right)$ critical temperatures in undeformed austenite, which are determined during cooling in a conventional dilatometer are not equal to the upper $\left(A_{r 3}{ }^{*}\right)$ and lower $\left(A_{r 1}{ }^{*}\right)$ critical temperatures in deformed austenite. The deformed austenite possesses higher free energy than the undeformed austenite [6.7]. Thus the $A_{r 3} *$ and $A_{r 1}$ * temperatures are generally higher than the $A_{r 3}$ and $A_{r 1}$ temperatures. They are usually assumed to be close to (and just below) the $\mathrm{Ae}_{3}$ and $\mathrm{Ae}_{1}$ temperatures, respectively. Now it is shown in this work that the $A_{r 3} *$ temperature can actually be higher than the $\mathrm{Ae}_{3}$ temperature in a given steel [6.8]. In this chapter, the observations relating to the present steels are reviewed and it will be shown that the mechanism responsible for the elevation in this temperature is dynamic transformation (DT).

\subsection{Method of Analysis}

The mean flow stresses (MFS values) were determined from the flow curves shown in Fig. $\mathbf{5 . 2}$ by simple integration. These calculations were carried out using the Excel ${ }^{T M}$ and Origin ${ }^{T M}$ software programs. The results obtained were then plotted against inverse absolute temperature following the Boratto [6.3] procedure.

\subsection{Results}

It can be seen from Fig. $\mathbf{5 . 2}$ that the stress levels of the flow curves do not decrease smoothly with increasing temperature. This is in line with the behavior of the steel shown in Fig. 6.1. The ferrite microstructures produced by DT in these four steels at various temperatures and strain levels are described in detail in Chapter $\mathbf{4}$ and are not reproduced here. Also the critical strains at which DT was initiated in these materials were derived by the double-differentiation method [6.9] and were reported in Chapter 5. They are shown to be consistent with the microstructural observations [6.10]. Generally, DT is initiated at a strain of about 0.10 to 0.20 . This value increases slightly with temperature. After 
initiation, the volume fraction of the dynamically formed ferrite increases more rapidly at first and then more slowly on further increases in strain [6.8]. The integration referred to above was carried out on each of the flow curves at various strain levels starting at 0.25 and ranging up to 1.5. The MFS data at various strain levels for the $0.06 \% \mathrm{C}, 0.09 \% \mathrm{C}, 0.21 \% \mathrm{C}$ and $0.79 \% \mathrm{C}$ steels are plotted against $10000 / \mathrm{T}\left(\mathrm{K}^{-1}\right)$ in the form of Boratto diagrams and are illustrated in Fig. 6.2. Finally, the $\mathrm{Ae}_{3}$ temperatures that correspond to these steels (listed in Table 3.1) are also plotted in Fig. 6.2 for comparison with the derived suggested values of $A_{r 3} *$.

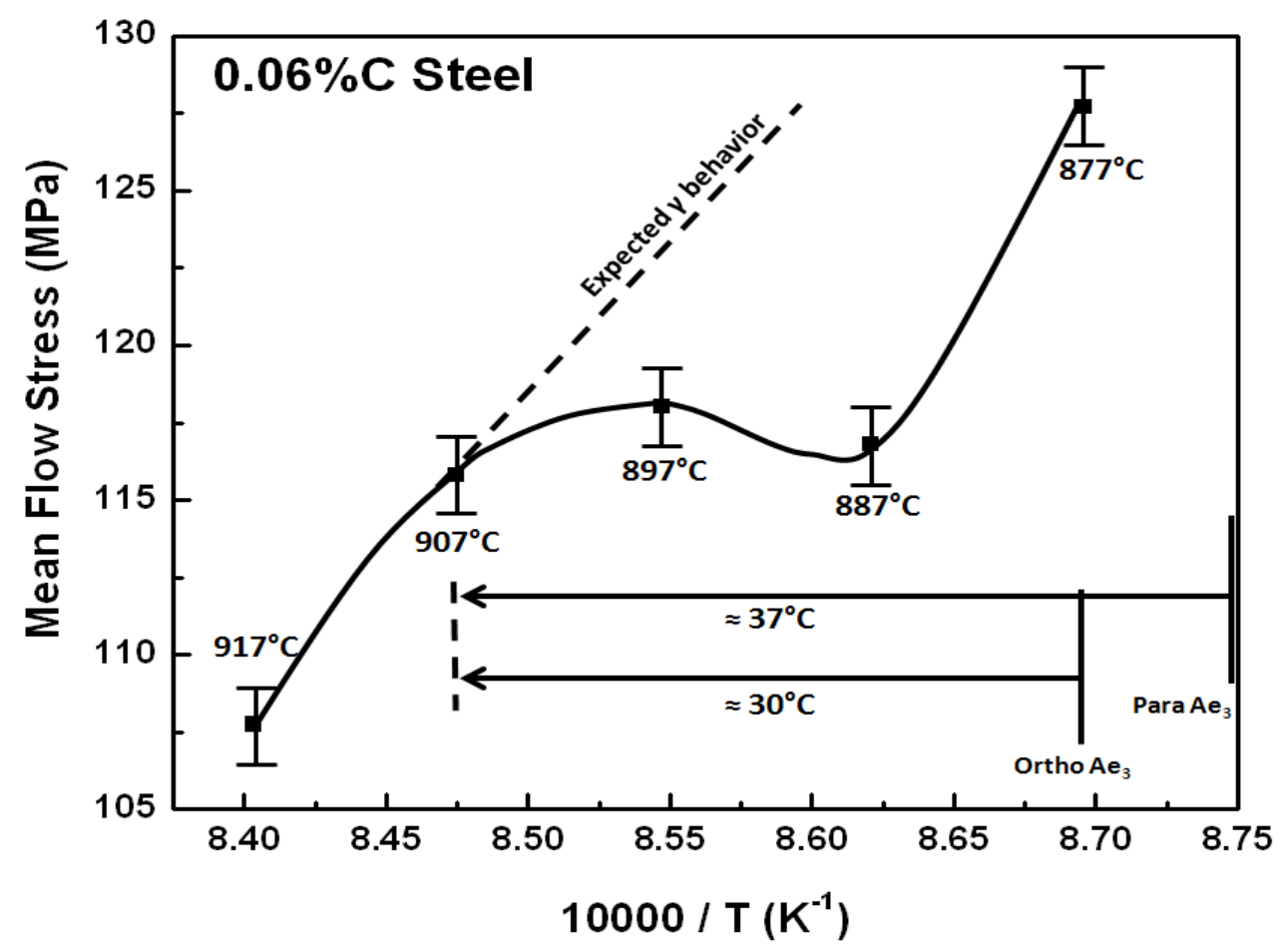

(a) 


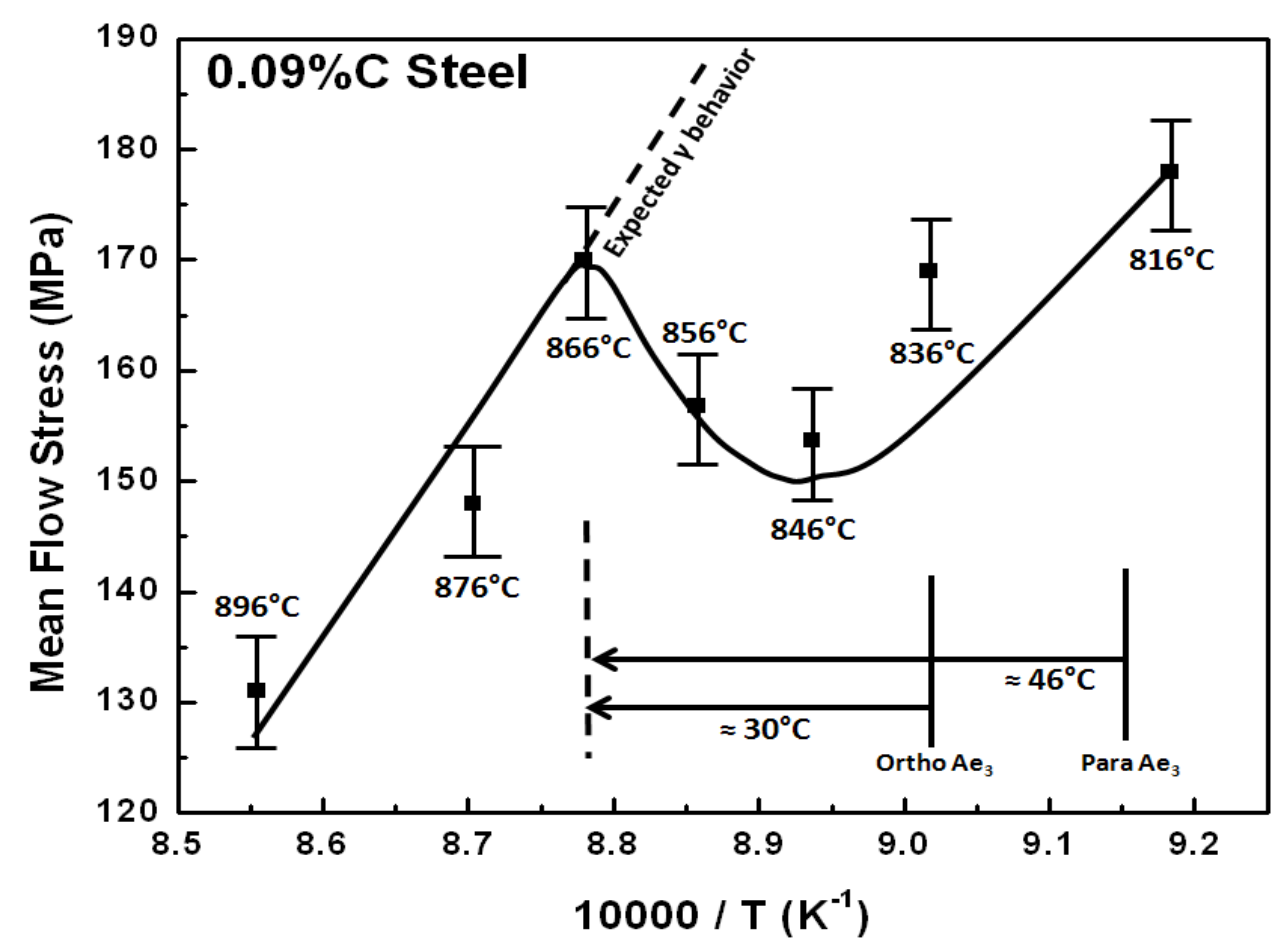

(b)

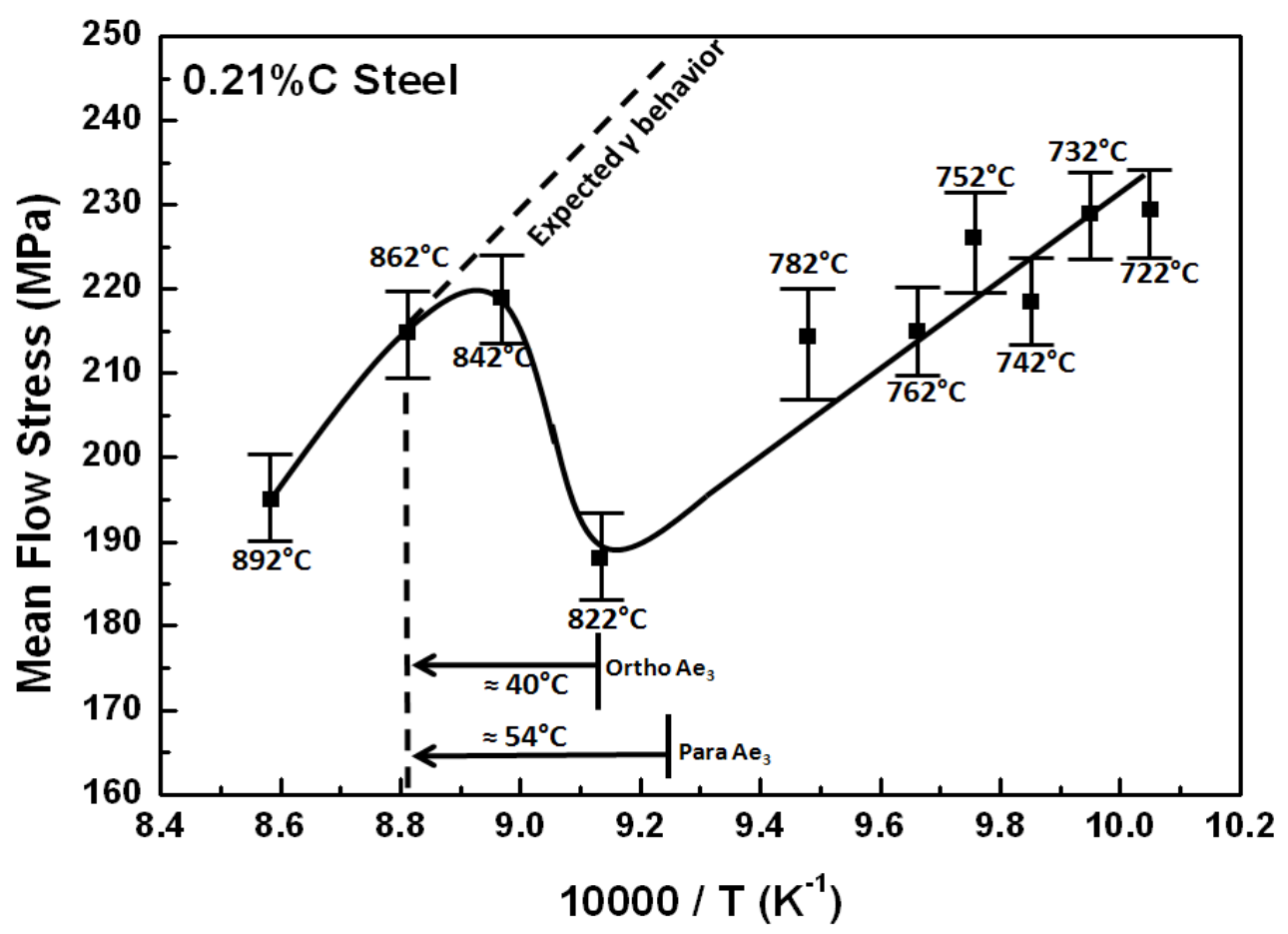

(c) 


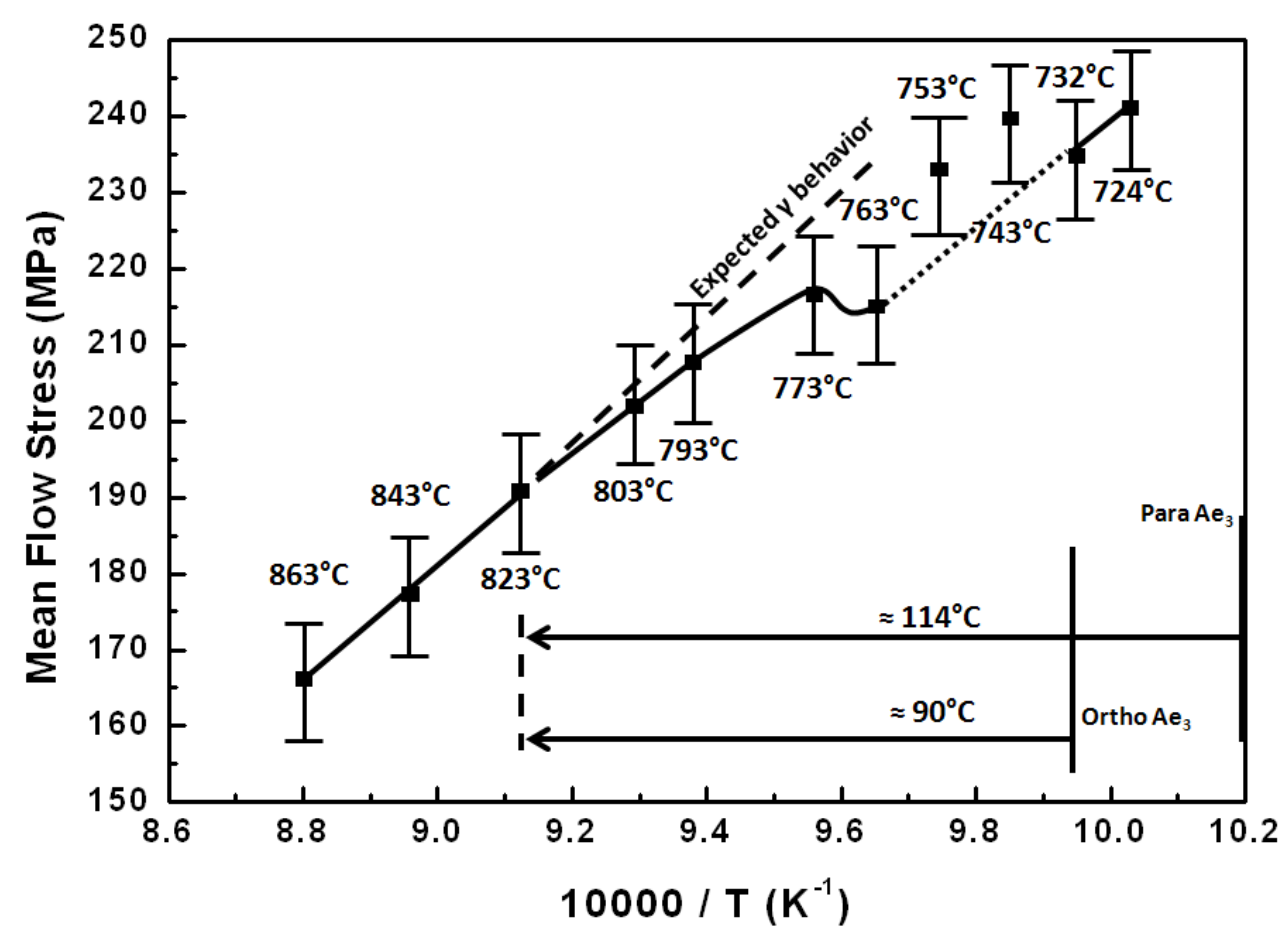

(d)

Fig. 6.2: Mean flow stress (MFS) values for the (a) $0.06 \% \mathrm{C}$, (b) $0.09 \% \mathrm{C}$, (c) $0.21 \% \mathrm{C}$ and (d) $0.79 \% \mathrm{C}$ steels displayed as a function of inverse absolute temperature $[6.8,6.11]$. The paraequilibrium and orthoequilibrium $\mathrm{Ae}_{3}$ temperatures are shown for comparison with the experimental suggested $A_{r 3} *$ temperatures. The broken lines in (a), (b) and (c) indicate the expected MFS behavior in the absence of dynamic transformation. The fits in these diagrams were drawn by fitting smooth curves to the experimental points.

\subsection{Discussion}

There are several important features that can be observed in Fig. 6.2. First of all, it should be noted that all of the plots exhibit an extrapolated $A_{r 3}{ }^{*}$, i.e. the point at which the MFS begins to drop. Clearly, more points would have been desirable for the $0.06 \%$ C steel (Fig. 6.2(a)), but the tendencies shown are consistent with Figs. 6.2(b), (c) and (d), where the trends were established using a larger number of experiments. This behaviour is displayed even though the temperature is decreasing, so that the MFS is expected to rise. The expected increase with decreasing temperature is represented by the broken lines in Figs. 6.2(a), (b), (c) and (d). It is evident from these diagrams that the MFS takes appreciably lower 
values at the lower temperatures than would be consistent with the behavior of single phase austenite. A possible reason for this behaviour is the formation of DT ferrite, which is softer than austenite at the temperature of interest. Another important observation is that, in every case, the drop temperature is well above the equilibrium upper critical $\mathrm{Ae}_{3}$ temperature, which is normally associated with phase transformation [6.11].

The importance of the tendencies shown in these diagrams $[6.8,6.11]$ is that they provide a possible explanation for the load drops frequently observed in industrial practice [6.12], which have not been satisfactorily explained to date. In the present author's opinion, the interpretation proposed here is somewhat more realistic than the one advanced to date [6.13], which has hypothesized the initiation of dynamic recrystallization as the cause of the load drops.

In rolling mills, the short times available for DT during a rolling pass do not permit any diffusion of $\mathrm{Mn}$ or $\mathrm{Si}$, i.e., there is no diffusion of the substitutional alloying elements [6.7]. Therefore the formation of DT ferrite can only take place under paraequilibrium conditions, i.e., under conditions that permit the diffusion of $\mathrm{C}$ and $\mathrm{N}$ during the transformation, but not that of the substitutional elements [6.7]. It is apparent from Fig. 6.2 that the postulated $A_{r 3}{ }^{*}$ temperature for each steel is considerably higher than the paraequilibrium value of $\mathrm{Ae}_{3}$. In the present case, the "superequilibrium" temperature intervals are $37,46,54$ and $114^{\circ} \mathrm{C}$, respectively, above these values for the four steels. In a similar manner, they are about $30,30,40$ and $90^{\circ} \mathrm{C}$, respectively, above the orthoequilibrium $\mathrm{Ae}_{3}$ 's.

It must first be noted that DT has been observed to be initiated as much as 150 $[6.14,6.15]$ and $100^{\circ} \mathrm{C}[6.7,6.10]$ above the $\mathrm{Ae}_{3}$. Therefore the obvious question arises as to why the rolling load drops identified above are not seen at much higher temperatures? Although a detailed quantitative response to this problem cannot be provided at the moment, the following semi-quantitative considerations suggest a possible explanation. First of all, the formation of DT 
ferrite can only take place from deformed austenite; this is because the free energy of the strained austenite has been increased to values well above those corresponding to the undeformed ferrite. In this manner, as discussed in more detail in Chapter 7, the effective transformation temperature can be increased by as much as 100 - 150 degrees. Now in order for the MFS to decrease to a noticeable degree with a reduction in temperature, DT must produce enough softening to overcome the hardening due to dislocation accumulation in the austenite as well as with the decreased level of thermal activation (and therefore the higher flow stress) associated with the temperature decrease [6.8,6.11].

Typical austenite work hardening rates, $(\partial \sigma / \partial \varepsilon)$, at hot rolling temperatures are about 5 - $15 \mathrm{MPa} / 1 \%$ strain [6.16]. By contrast, the softening produced by DT is fairly low and is about $-1 \mathrm{MPa} / 1 \%$ strain, i.e., about an order of magnitude lower $[6.8,6.11]$. In terms of ferrite volume fraction, the transformation can be estimated from Fig. 6.2 to produce about $0.2-0.4 \mathrm{MPa}$ of softening per $1 \%$ of ferrite formed. Thus a ferrite volume fraction of about $35 \%$ must be produced before an appreciable load drop can be detected. This occurs relatively slowly because the rate of formation of DT ferrite is only about $0.5-1.0$ volume percent per 1\% strain [6.17-6.21]. As a result, the overall flow stress of a steel generally continues to increase during straining as well as temperature reduction even though low flow stress ferrite is being formed continuously. It is not until an appreciable volume fraction of ferrite has been produced that the overall flow stress is able to drop. An even greater volume fraction of ferrite is required for the MFS (integrated flow stress) to drop. Thus, despite the fact that DT ferrite begins to be formed well above the $\mathrm{Ae}_{3}$, the temperature must drop into the range of rapid ferrite formation before the volume fraction transformed is sufficient to produce a noticeable load drop [6.8,6.11].

Another feature of interest concerns the effect of accumulated strain on the stress drop behavior. First of all, it appears that increasing the strain does not affect the stress drop temperature or $\mathrm{A}_{\mathrm{r}}{ }^{*}$, at least as can be determined from 
the fairly large temperature intervals employed in the present study. It can also be seen that, while the amount of the stress drop increases slightly with accumulated strain, the percentage drop is nearly constant in each steel over the strain range investigated. The percentage drops appear to decrease with increasing $\mathrm{C}$ concentration, ranging from about about about $35 \%$ for the $0.06 \% \mathrm{C}$ steel, to $22 \%, 19 \%$ and $6 \%$ for the $0.09 \% \mathrm{C}, 0.21 \% \mathrm{C}$ and $0.79 \% \mathrm{C}$ steels, respectively [6.11].

A detailed thermodynamic analysis of this phenomenon, see Chapter 7 and Ref. 6.7, shows that the saturation volume fractions of ferrite formed by DT decrease with temperature above the $\mathrm{Ae}_{3}$. At a strain of 1 and say $50^{\circ} \mathrm{C}$ above the paraequilibrium $\mathrm{Ae}_{3}$, only a maximum of about 30 volume percent ferrite is formed in the $0.21 \% \mathrm{C}$ and $0.79 \% \mathrm{C}$ steels [6.7]. At higher temperature intervals above the $\mathrm{Ae}_{3}$, the saturation volume fraction of DT ferrite is even less. Thus, although DT ferrite is being produced continuously during straining, leading to decreases in the net work hardening rate below that applicable to fully austenitic samples, the mean flow stress or MFS does not decrease as long as the deformation temperature remains at least $30^{\circ} \mathrm{C}$ above the $\mathrm{Ae}_{3}[6.8]$.

From a practical point of view, there are several important conclusions to be drawn from conjectural MFS diagrams such as those of Fig. 6.2. Primarily the extrapolated $A_{r 3}{ }^{* \prime} s$ estimated from laboratory measurements and interpreted using Boratto diagrams are generally higher than the conventional $\mathrm{Ae}_{3}$ 's determined from the chemical composition using the ThermoCalc or any other thermodynamic software. The latter provides undeformed $\mathrm{Ae}_{3}{ }^{\prime} \mathrm{s}$; these are shown in this work not to apply to deformed austenite because of the increase in the free energy of this phase introduced by the deformation. The second is that, due to DT, rolling loads can frequently be unexpectedly lower than estimates based on the increasing flow stress behavior of single-phase austenite when cooled down to the conventional $\mathrm{Ae}_{3}$. This is because, despite the absence of such ferrite in the conventional phase diagram, appreciable volume fractions of 
the softer ferrite can be present at a given superequilibrium temperature. Finally, the presence of a dynamic $A_{r 3}{ }^{*}$ that is higher than the $\mathrm{Ae}_{3}$ has the practical effect of decreasing the expected temperature interval over which pancaking strains can be applied during controlled rolling [6.11].

Although, from a theoretical point of view, it is the interval above the paraequilibrium critical temperature that is particularly relevant, it is the interval above the orthoequilibrium critical temperature that is of practical importance and is more likely to be noted. Although such discrepancies may even be detected during the rolling of plain $\mathrm{C}$ steels, because of the importance of strain accumulation in producing this phenomenon (i.e., of rolling below the $T_{n r}[6.6]$ ), such drops are expected to occur most frequently during the rolling of microalloyed steels [6.8].

\subsection{Conclusions}

The following conclusions can be drawn from the present results.

1. The softening produced by the DT of austenite to ferrite was investigated by means of torsion testing. MFSs were calculated from the experimental flow curves by integration. When plotted in the form of Boratto diagrams, unexpectedly low values of MFS were detected in the temperature range extending below $37,46,54$ and $114^{\circ} \mathrm{C}$ above the paraequilibrum $\mathrm{Ae}_{3}$ 's of the $0.06 \% \mathrm{C}, 0.09 \% \mathrm{C}, 0.21 \% \mathrm{C}$ and $0.79 \% \mathrm{C}$ steels, respectively.

2. In a similar manner, the drops begin about $30,30,40$ and $90^{\circ} \mathrm{C}$ above the orthoequilibrium $\mathrm{Ae}_{3}$ of the four steels.

3. Below the hypothesized $A_{r 3}{ }^{* \prime}$ s, the MFS values are 10 to $40 \mathrm{MPa}$ less than the values expected from the flow stress trends established above these temperatures. These deficiencies correspond to rolling load or separation force decreases of $10-20 \%$ below expected values. It is concluded that these unexpected drops probably result from the DT of austenite to ferrite during deformation. 


\section{References}

6.1 T.M. Maccagno, J.J. Jonas, S. Yue, B.J. McCrady, R. Slobodian and D. Deeks; ISIJ Int., Vol. 34, (1994), p. 917.

6.2 K. Minami, F. Siciliano, T.M. Maccagno and J.J. Jonas; ISIJ Int., Vol. 36, (1996), p. 1507.

6.3 F. Boratto, R. Barbosa, S. Yue and J.J. Jonas; Proceedings of the $1^{\text {st }}$ Conference on Physical Metallurgy of Thermomechanical Processing of Steels and Other Metals (THERMEC-88): Tamura I (Ed.). ISIJ, Tokyo, (1988), p. 383.

6.4 R.I.L. Guthrie and J.J. Jonas; Steel Processing Technology, ASM Metals Handbook, $10^{\text {th }}$ Edition, Vol 1, Properties and Selection: Irons, Steels and High Performance Alloys, (1990), p. 107.

6.5 S. Yue and J.J. Jonas; Mater. Forum, Vol. 14, (1990), p. 245.

6.6 S. Vervynckt, K. Verbeken, B. Lopez and J.J. Jonas; Int. Mater. Rev., Vol. 57, (2012), p. 187.

6.7 C. Ghosh, V.V. Basabe, J.J. Jonas, Y.M. Kim, I.H. Jung and S. Yue; Acta Mater., Vol. 61, (2013), p. 2348.

6.8 J.J. Jonas, C. Ghosh and V.V. Basabe; Steel Res. Int., Vol. 84, (2013), p. 253.

6.9 E. Poliak and J.J. Jonas; Acta Mater., Vol. 44, (1996), p. 127.

6.10 C. Ghosh, V.V. Basabe and J.J. Jonas; Steel Res. Int., in press (DOI: 10.1002/srin.201200188).

6.11 J.J. Jonas, C. Ghosh, X. Quelennec and V.V. Basabe; Proceeding of SimPro'12, $3^{\text {rd }}$ Int. Conf. on Thermo-Mechanical Simulation and Processing of Steel, RDCIS, SAIL, Ranchi, India, Dec. 12-14, (2012), p. 3.

6.12 E. Poliak; Arcelor-Mittal Global Research \& Development Center, East Chicago, IL, private communication.

6.13 J.J. Jonas; Mater. Sci. and Engg.A, Vol. 184, (1994), p. 155.

$6.14 \mathrm{H}$. Yada, Y. Matsumura and T. Senuma; Proc. of the Int. Conf. on Martensitic Transformation, JIM (1986), p. 515.

$6.15 \mathrm{H}$. Yada, Y. Matsumura and T. Senuma; Proc. 1st Conf. Physical Metallurgy of Thermomechanical Processing of Steels and Other Metals (THERMEC-88), ed. by I. Tamura, ISIJ, Tokyo, (1988), p. 200.

6.16 T. Sakai and J.J. Jonas; Acta Metall., Vol. 32, (1984), p. 189.

6.17 V.V. Basabe, J.J. Jonas and H. Mahjoubi; ISIJ Int., Vol. 51, (2011), p. 612.

6.18 V.V. Basabe and J.J. Jonas; ISIJ Int., Vol. 50, (2010), p. 1185.

6.19 V.V. Basabe, J.J. Jonas and C. Ghosh; Adv. Mater. Res., Vol. 409, (2012), p. 829.

6.20 J.J. Jonas and V.V. Basabe; Proceeding of Conference in Solid-Solid Phase Transformation in Inorganic Material (PTM2010), Solid State Phenomena, Avignon, Vol. 172-174, (2011), p. 372.

6.21 C. Ghosh, V.V. Basabe, J.J. Jonas, S. Yue and X.Y. Xiong; ISIJ Int., Vol. 53, (2013), p. 900. 
Chapter 7

\section{Thermodynamics of Dynamic Transformation}




\section{Thermodynamics of Dynamic Transformation ${ }^{*}$}

\subsection{Background}

The transformation of austenite to ferrite at high temperatures is generally thought to be accelerated with the aid of deformation. There are several parameters that can affect this transformation. The transformation of undeformed austenite to ferrite at temperatures above the equilibrium transformation temperature (i.e. above the $\mathrm{Ae}_{3}$ ) is not of course possible. However, the transformation of deformed austenite above the $\mathrm{Ae}_{3}$ is another matter entirely. Furthermore, the exact mechanism of the transformation is not fully known at the moment.

In the current analysis, the main concept is that the deformation stored energy essentially increases the driving force for the transformation at the temperature of interest [7.1]. The deformation stored energy is affected by increasing the dislocation density and by forming new grain boundaries and vacancies. These in turn depend on the deformation conditions such as strain, strain rate and temperature. Observation of the deformation structure in austenite at high temperatures is a difficult task since it is generally destroyed during cooling to room temperature. Thus little is known about its true nature. Nevertheless, the literature on other FCC systems, such as $\mathrm{Ni}, \mathrm{Al}$ and recent findings on $\mathrm{Ni} / \mathrm{Fe}$ based model austenite systems [7.2-7.5], suggests that the dislocation distribution is fairly homogeneous at low strain levels. However, this type of distribution is unlikely to be present beyond a strain of $\varepsilon=0.1$ [7.1]. At high strains, an inhomogeneous distribution of dislocations is likely to have formed, as suggested by Adachi et al. [7.2] in a Ni-30\%Fe model austenite system.

In this chapter the effect of deformation on the Gibbs energy of the austenite in the four steels is estimated by assuming that the austenite continues to work

\footnotetext{
*Some of the material in this chapter has been published in Ref. 7.16.
} 
harden after initiation of the transformation and that its flow stress and dislocation density can be derived from the experimental flow curve by making suitable assumptions about two-phase flow. By further taking into account the inhomogeneity of the dislocation density, Gibbs energy contributions (driving forces) are derived that are sufficient to promote transformation as much as $100^{\circ} \mathrm{C}$ above the $\mathrm{Ae}_{3}$. The Gibbs energy calculations suggest that growth of the Widmanstätten ferrite is followed by $\mathrm{C}$ diffusion at the lower carbon contents, while it is accompanied by $\mathrm{C}$ diffusion at the higher carbon levels.

\subsection{Current Approach}

The Gibbs energy change associated with the $y \rightarrow \alpha$ transformation is generally written as:

$$
\Delta G=\Delta G_{\text {Chemical }}^{\gamma \rightarrow \alpha}
$$

where $\Delta G_{\text {Chemical }}^{\gamma \rightarrow \alpha}<0$ is the chemical driving force for the transformation. When austenite is being deformed, part of the mechanical energy is stored in the austenite, increasing the internal energy and also the Gibbs energy of the system. Under such conditions, Eq. (7.1) can rewritten as:

$\Delta G=\Delta G_{\text {Chemical }}^{\gamma \rightarrow \alpha}-\Delta G_{D(\text { in })}$

where $\Delta G_{D(\text { in } \gamma)}>0$ is the deformation stored energy. This excess stored energy is responsible for the $\gamma \rightarrow \alpha$ transformation being able to take place at temperatures above the $\mathrm{Ae}_{3}$. Now, this stored energy includes three different components, namely, the dislocation energy, the grain boundary energy and the vacancy formation energy, as given by:

$\Delta G_{D(\text { in } \gamma)}=\Delta G_{\text {Dislocation }}+\Delta G_{\text {Grain boundary }}+\Delta G_{\text {Vacancy }}$

A detailed description of the different energies mentioned in Eq. (7.3) (i.e. the dislocation energy, the grain boundary energy and the vacancy formation energy) is given below. 


\subsubsection{Dislocation Energy}

The energy per unit length of dislocation is approximated as [7.6]:

$\tau_{\mathrm{d}} \approx\left(\mu_{\mathrm{T}} \mathrm{b}_{\mathrm{T}}^{2}\right) / 2$

where $\mu_{T}$ is the temperature dependent shear modulus and $b_{T}$ the magnitude of the Burgers vector at a particular temperature T. The latter is in turn given by:

$b_{\mathrm{T}}=b_{0}(1+\alpha T)$

where $\alpha$ is the coefficient of thermal expansion of austenite and $b_{0}=2.5 \times 10^{-10}$ $\mathrm{m}$ (at $300 \mathrm{~K}$ ) [7.6]. The modulus $\mu_{\mathrm{T}}$ can be evaluated using the relationship:

$\mu_{T}=\mu_{0}\left[1+\left\{(T-300) / T_{m}\right\} \times\left(T_{m} / \mu_{0}\right) \times\left(d \mu_{T} / d T\right)\right] \quad \ldots .(7.6)$

where $\mu_{0}=8.1 \times 10^{10} \mathrm{~J} \mathrm{~m}^{-3}$ at $300 \mathrm{~K}, \mathrm{~T}$ the experimental temperature, $\mathrm{T}_{\mathrm{m}}=1810 \mathrm{~K}$ for austenite and $\left(T_{m} / \mu_{0}\right) \times\left(d \mu_{T} / d T\right)=-0.91$ [7.6]. Defining $\rho_{0}$ and $\rho$, respectively as the dislocation densities per unit volume before and after deformation, the stored energy per unit volume due to the new dislocations introduced by the deformation can be expressed as:

$\Delta G_{\text {Dislocation }}=\mu_{\mathrm{T}} \mathrm{b}_{\mathrm{T}}^{2}\left(\rho-\rho_{0}\right) / 2$

It can be seen from the above equation that the dislocation stored energy is proportional to the value of the dislocation density. Therefore, it is of considerable importance to evaluate this quantity as accurately as possible. However, the dislocation density of a heavily worked material is difficult to measure experimentally. This quantity can be estimated analytically from the following relationship:

$\rho=\left(\sigma /\left(k_{m} \times M \times \mu_{T} \times b_{T}\right)\right)^{2}$

where $\sigma$ is the flow stress of the austenite, $k_{m}$ a constant taken as 0.20 , and $M$ the Taylor factor. For FCC structures, the value $M=3.08$ [7.7]. 


\section{The flow stress of work hardened austenite}

It is readily apparent that DT ferrite is formed from deformed austenite. Thus it is the flow stress of work hardened austenite that must be considered for calculating the dislocation density. A typical austenite flow curve for the $0.79 \% \mathrm{C}$ steel at $743^{\circ} \mathrm{C}$ (i.e. $\mathrm{Ae}_{3}+10^{\circ} \mathrm{C}$ ) deformed to a strain of $\varepsilon=4.0$ at $4.0 \mathrm{~s}^{-1}$ is illustrated in Fig. 7.1. The flow curve of the work hardened austenite can be derived from the experimental curve using the method of Jonas et al. [7.8]. Here the austenite work hardening law is determined from the portion of the experimental flow curve prior to the critical strain for the initiation of dynamic transformation, where the latter is calculated by the method of Poliak and Jonas [7.9], as has already been described in more detail in Chapter 5. The current value of the austenite flow stress is then taken from this derived curve and employed to calculate the dislocation density at the various strain levels. In this way, the present analysis differs from the usual methods of evaluating the flow stress and the dislocation density, which are based on the experimental flow curve and therefore on lower values of the dislocation density.

\subsubsection{Grain Boundary Energy}

The grain boundary energy increases during deformation because deformation elongates the grains leading to an increase in $\mathrm{S}_{\mathrm{v}}$, the grain boundary area per unit volume. The contribution from deformation bands can be estimated in a similar manner. Following deformation, the effective grain and sub-boundary surface area per unit volume can be written as [7.6]:

$S_{v}^{e f f}=S_{v}^{g b}+S_{v}^{d b}$

where $S_{v}^{g b}$ and $S_{v}^{d b}$ are the contributions from the grain boundaries and deformation bands, respectively. Deformation also increases the disorder of the grain boundary structure, leading to a further increase in the grain boundary 


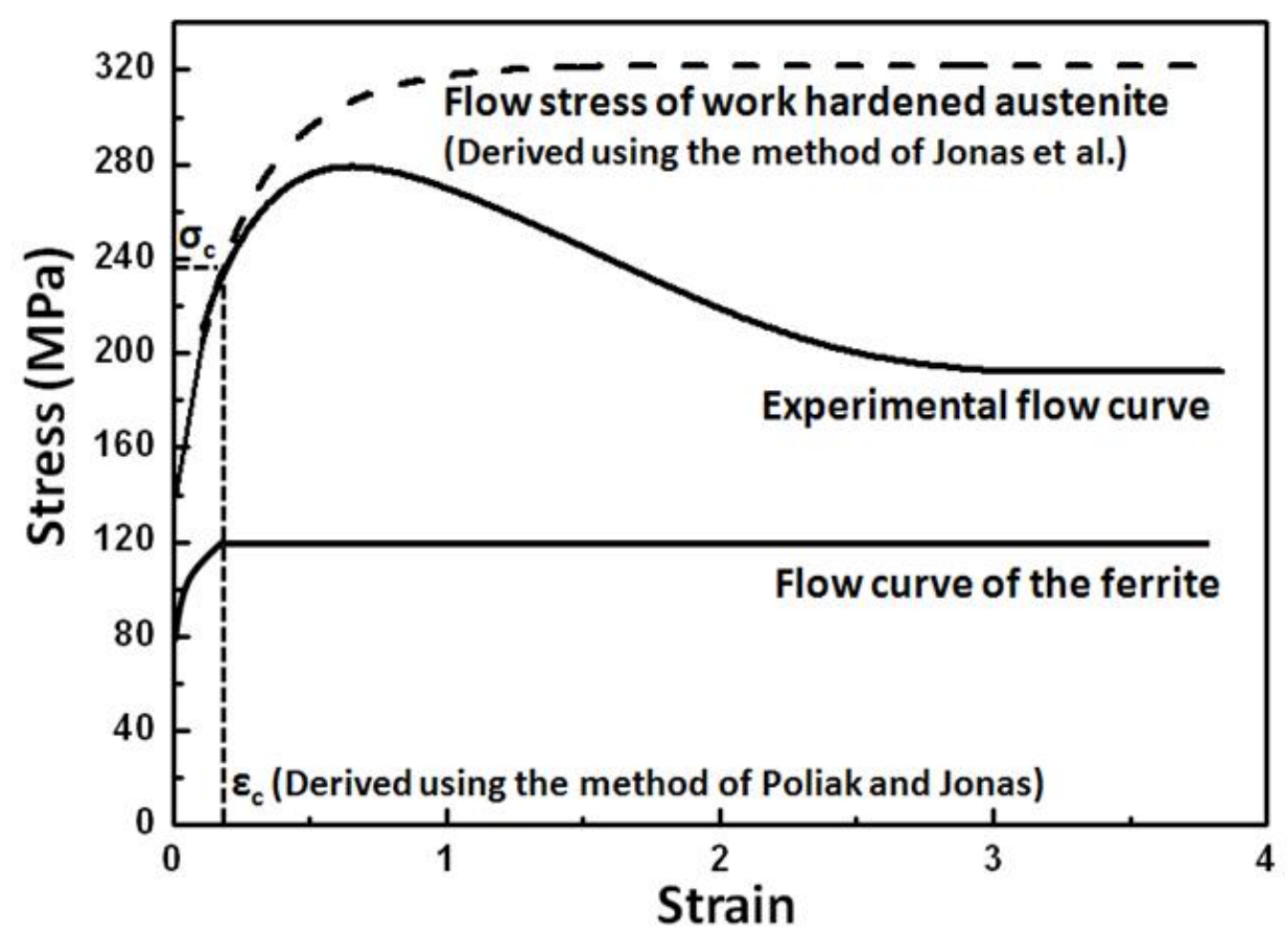

Fig. 7.1: Experimental flow curve of austenite for Steel 4 at $743^{\circ} \mathrm{C}\left(\mathrm{Ae}_{3}+10^{\circ} \mathrm{C}\right)$ deformed to a strain of $\varepsilon=4.0$ at $4.0 \mathrm{~s}^{-1}$. The flow curve of the work hardened austenite was derived using the method of Jonas et al. [7.8]. The critical strain $\left(\varepsilon_{c}\right)$ for DT was determined using the method of Poliak and Jonas [7.9]. The ferrite flow curve is schematic.

energy per unit area of approximately 10\% [7.10]. This effect is neglected in the current calculation. The surface area per unit volume in fully recrystallized austenite is a function of the equiaxed austenite grain size, $d_{\gamma}$, expressed as a mean linear intercept [7.6]:

$S_{v}^{0}=\frac{2}{d_{\gamma}}$

Now, $S_{v}^{g b}$ and $S_{v}^{d b}$ can be estimated using the following empirical relationships [7.11]:

$S_{v}^{g b}=\frac{S_{v}^{0}}{2}\left[1+e^{-\varepsilon}+e^{\varepsilon}\right]$

and 
$S_{v}^{d b}=63(\varepsilon-0.3)$

where $\varepsilon$ is the strain. Setting the grain boundary energy per unit area equal to $0.8 \mathrm{~J} \mathrm{~m}^{-2}[7.10]$, the increase in grain boundary energy can be specified as:

$\Delta G_{\text {Grain boundary }}=\left[\left(S_{v}^{g b}+S_{v}^{d b}\right)-S_{v}^{0}\right] \times 0.8$

\subsubsection{Vacancy Formation Energy}

The presence of excess vacancies in solid materials enhances processes such as diffusion, precipitation, segregation and recrystallization. Such excess vacancies can be generated during high temperature deformation (as in the present case) by the non-conservative movement of thermal jogs. At relatively low strain rates $\left(<0.1 \mathrm{~s}^{-1}\right)$, annihilation of these vacancies can be quite rapid and their effects can be neglected. However, at higher strain rates, their production rate is increased significantly and there is also an additional temperature effect due to the increased concentration of thermal jogs [7.12]. The interaction of excess vacancies with impurities or microalloying elements leads to non-equilibrium grain boundary segregation. This in turn accelerates the nucleation of second phase particles at these locations. The concentrations of deformation-induced vacancies are more significant in FCC than in BCC materials because of their comparatively low diffusivities in the former case.

Therefore, it is important to calculate the excess vacancy concentrations in the present study and to estimate the vacancy formation energy. Here the excess vacancy concentration per unit volume $C_{s}$ attributable to the deformation is evaluated from [7.12]:

$C_{s}=\left(\frac{\chi \sigma}{Q_{f}}+\frac{\xi C_{j}}{4 b_{T}^{3}}\right)\left(\frac{\rho}{\kappa^{2}}+\frac{1}{L^{2}}\right)^{-1} \frac{\Omega_{0}}{D_{v}} \dot{\varepsilon}$

where $\chi$ is the mechanical production term, $\sigma$ the flow stress of the work hardened austenite, $Q_{f}$ the vacancy formation energy in $\gamma-\mathrm{Fe}, \xi$ the 'neutralization' effect (due to annihilation), $C_{j}$ the concentration of thermal jogs 
given by $C_{j}=\exp \left(-E_{j} / k T\right)$ where $E_{j}=\mu b^{3} /(4 \pi(1-v))$ and $v$ the Poisson's ratio, $b_{T}$ the magnitude of the Burgers vector, $\rho$ the dislocation density after deformation, $\aleph$ the structural parameter describing the dislocation distribution, $L$ the austenite grain size, $\Omega_{0}$ the atomic volume, $D_{v}$ the vacancy diffusivity, which is given by $D_{v}=$ $D_{v 0} \exp \left(-Q_{m} / k T\right)$, where $Q_{m}$ the vacancy migration energy and $\dot{\varepsilon}$ the strain rate. The numerical values of the above parameters used in the current study are given in Table 7.1.

Table 7.1. Parameters employed in the calculations.

\begin{tabular}{|c|c|c|}
\hline Parameters & Numerical values & References \\
\hline$\chi$ & 0.1 & 7.13 \\
\hline$Q_{f}$ & $2.47 \times 10^{-19} \mathrm{~J}$ & 7.12 \\
\hline$\xi$ & 0.5 & 7.14 \\
\hline$v$ & 0.3 & 7.15 \\
\hline$\kappa$ & 10 & 7.13 \\
\hline$L$ & $20 \mu \mathrm{m}$ & 7.16 \\
\hline$\Omega_{0}$ & $1.21 \times 10^{-29} \mathrm{~m}^{3}$ & 7.12 \\
\hline$D_{\mathrm{v} 0}$ & $3.3 \times 10^{-5} \mathrm{~m}^{2} \mathrm{~s}^{-1}$ & 7.12 \\
\hline $\mathrm{Q}_{\mathrm{m}}$ & $2.39 \times 10^{-19} \mathrm{~J}$ & 7.12 \\
\hline $\mathrm{k}$ & $1.38 \times 10^{-23} \mathrm{JK}^{-1}$ & 7.17 \\
\hline
\end{tabular}

In this way, the formation energy per unit volume $\Delta G_{\text {Vacancy }}$ associated with the excess vacancies was estimated from the following:

$\Delta G_{\text {Vacancy }}=\mathrm{Q}_{\mathrm{f}} \times \mathrm{C}_{\mathrm{s}}$ ...(7.15)

\subsubsection{The Stored Energy of Deformation}

The total stored energy of austenite $\left(\Delta G_{D(\text { in } \gamma)}\right)$ attributable to deformation at the various temperatures above $\mathrm{Ae}_{3}$ was calculated for all the steels using equations (7.7), (7.13) and (7.15). Some typical results for the $0.06 \% \mathrm{C}, 0.09 \% \mathrm{C}, 0.21 \% \mathrm{C}$ and 0.79\%C steels are shown in Tables 7.2, 7.3, 7.4 and 7.5, respectively. The first 
column specifies the value of $\Delta T$, i.e. the difference between the experimental temperature and the orthoequilibrium $\mathrm{Ae}_{3}$ of the steel. The second and third columns list strains and their corresponding stress values as taken from flow curves such as the one illustrated in Fig. 7.1. The dislocation densities were estimated in turn using these values of the stresses and Eq. (7.8), leading to the values presented in column 4 . Finally, the $\Delta G_{D(\text { in } \gamma)}$ values were calculated using Eq. (7.3), from which the values in column 5 were obtained.

Table 7.2. Deformation stored energies of the $0.06 \% \mathrm{C}$ steel at selected experimental temperatures.

\begin{tabular}{|c|c|c|c|c|c|c|}
\hline \multicolumn{7}{|c|}{$0.06 \% C$ steel } \\
\hline $\begin{array}{c}\Delta \mathrm{T}\left(\mathrm{T}_{\text {expt. }}-\mathrm{Ae}_{3}\right) \\
{ }^{\circ} \mathrm{C}\end{array}$ & $\varepsilon$ & $\begin{array}{c}\sigma \\
(\mathrm{MPa})\end{array}$ & $\rho\left(m^{-2}\right)$ & $\begin{array}{l}\Delta G_{D(\text { in v }} \\
(\mathrm{J} / \mathrm{mol})\end{array}$ & $\begin{array}{l}\Delta G_{\text {(theor) }} \\
(\mathrm{J} / \mathrm{mol})\end{array}$ & H.F. \\
\hline \multirow{6}{*}{10} & 0.25 & 130 & $5.2 \times 10^{14}$ & 7.1 & 34 & 4.8 \\
\hline & 0.50 & 152 & $7.1 \times 10^{14}$ & 9.3 & 34 & 3.7 \\
\hline & 1.00 & 185 & $1.1 \times 10^{15}$ & 13.5 & 34 & 2.5 \\
\hline & 1.50 & 200 & $1.2 \times 10^{15}$ & 16.1 & 34 & 2.1 \\
\hline & 2.00 & 210 & $1.4 \times 10^{15}$ & 18.3 & 34 & 1.9 \\
\hline & 3.00 & 222 & $1.5 \times 10^{15}$ & 23.8 & 34 & 1.4 \\
\hline \multirow{6}{*}{20} & 0.25 & 129 & $5.2 \times 10^{14}$ & 7.1 & 76 & 10.8 \\
\hline & 0.50 & 150 & $7.1 \times 10^{14}$ & 9.2 & 76 & 8.3 \\
\hline & 1.00 & 175 & $9.6 \times 10^{14}$ & 12.3 & 76 & 6.2 \\
\hline & 1.50 & 190 & $1.1 \times 10^{15}$ & 14.8 & 76 & 5.1 \\
\hline & 2.00 & 198 & $1.2 \times 10^{15}$ & 16.6 & 76 & 4.6 \\
\hline & 3.00 & 210 & $1.4 \times 10^{15}$ & 22.1 & 76 & 3.4 \\
\hline \multirow{6}{*}{40} & 0.25 & 118 & $4.5 \times 10^{14}$ & 6.2 & 128.7 & 20.8 \\
\hline & 0.50 & 145 & $6.9 \times 10^{14}$ & 8.8 & 128.7 & 14.6 \\
\hline & 1.00 & 165 & $8.9 \times 10^{14}$ & 11.3 & 128.7 & 11.4 \\
\hline & 1.50 & 177 & $1.0 \times 10^{15}$ & 13.3 & 128.7 & 9.7 \\
\hline & 2.00 & 185 & $1.1 \times 10^{15}$ & 15.1 & 128.7 & 8.5 \\
\hline & 3.00 & 195 & $1.2 \times 10^{15}$ & 20.1 & 128.7 & 6.4 \\
\hline
\end{tabular}


Table 7.3. Deformation stored energies of the $0.09 \% \mathrm{C}$ steel at selected experimental temperatures.

\begin{tabular}{|c|c|c|c|c|c|c|}
\hline \multicolumn{7}{|c|}{$0.09 \% C$ steel } \\
\hline $\begin{array}{c}\Delta T\left(T_{\text {expt. }}-\mathrm{Ae}_{3}\right) \\
{ }^{\circ} \mathrm{C}\end{array}$ & $\boldsymbol{\varepsilon}$ & $\begin{array}{c}\sigma \\
(\mathrm{MPa})\end{array}$ & $\rho\left(m^{-2}\right)$ & $\begin{array}{l}\Delta G_{D(\text { in } \gamma)} \\
(\mathrm{J} / \mathrm{mol})\end{array}$ & $\begin{array}{l}\Delta G_{(\text {theor })} \\
(\mathrm{J} / \mathrm{mol})\end{array}$ & H.F. \\
\hline \multirow{5}{*}{20} & 0.25 & 155 & $4.1 \times 10^{14}$ & 6.7 & 38.3 & 5.7 \\
\hline & 0.50 & 185 & $5.8 \times 10^{14}$ & 8.8 & 38.3 & 4.4 \\
\hline & 1.00 & 210 & $7.4 \times 10^{14}$ & 10.7 & 38.3 & 3.6 \\
\hline & 1.50 & 215 & $7.8 \times 10^{14}$ & 11.4 & 38.3 & 3.4 \\
\hline & 2.00 & 217 & $8.0 \times 10^{14}$ & 12.3 & 38.3 & 3.1 \\
\hline \multirow{5}{*}{60} & 0.25 & 130 & $3.0 \times 10^{14}$ & 5.3 & 102.4 & 19.4 \\
\hline & 0.50 & 152 & $4.2 \times 10^{14}$ & 6.6 & 102.4 & 15.4 \\
\hline & 1.00 & 175 & $5.5 \times 10^{14}$ & 8.1 & 102.4 & 12.6 \\
\hline & 1.50 & 185 & $6.2 \times 10^{14}$ & 9.2 & 102.4 & 11.1 \\
\hline & 2.00 & 186 & $6.2 \times 10^{14}$ & 10 & 102.4 & 10.2 \\
\hline
\end{tabular}

Table 7.4. Deformation stored energies of the $0.21 \% \mathrm{C}$ steel at selected experimental temperatures.

\begin{tabular}{|c|c|c|c|c|c|c|}
\hline \multicolumn{7}{|c|}{$0.21 \% C$ steel } \\
\hline $\begin{array}{c}\Delta T\left(T_{\text {expt. }}-\mathrm{Ae}_{3}\right) \\
{ }^{\circ} \mathrm{C}\end{array}$ & $\varepsilon$ & $\begin{array}{c}\sigma \\
(\mathrm{MPa})\end{array}$ & $\rho\left(m^{-2}\right)$ & $\begin{array}{l}\Delta G_{D(\text { in })} \\
(\mathrm{J} / \mathrm{mol})\end{array}$ & $\begin{array}{l}\Delta G_{(\text {theor })} \\
(\mathrm{J} / \mathrm{mol})\end{array}$ & H.F. \\
\hline \multirow{6}{*}{20} & 0.25 & 190 & $5.9 \times 10^{14}$ & 9.8 & 76.6 & 7.8 \\
\hline & 0.50 & 254 & $1.1 \times 10^{15}$ & 14.5 & 76.6 & 5.3 \\
\hline & 1.00 & 300 & $1.5 \times 10^{15}$ & 19.4 & 76.6 & 3.9 \\
\hline & 1.50 & 320 & $1.7 \times 10^{15}$ & 22.2 & 76.6 & 3.5 \\
\hline & 2.00 & 335 & $1.8 \times 10^{15}$ & 24.9 & 76.6 & 3.1 \\
\hline & 3.00 & 340 & $1.9 \times 10^{15}$ & 29.2 & 76.6 & 2.6 \\
\hline \multirow{6}{*}{40} & 0.25 & 185 & $5.8 \times 10^{14}$ & 9.5 & 108.1 & 11.4 \\
\hline & 0.50 & 245 & $1.0 \times 10^{15}$ & 13.7 & 108.1 & 7.9 \\
\hline & 1.00 & 290 & $1.4 \times 10^{15}$ & 18.5 & 108.1 & 5.8 \\
\hline & 1.50 & 305 & $1.6 \times 10^{15}$ & 20.7 & 108.1 & 5.2 \\
\hline & 2.00 & 320 & $1.7 \times 10^{15}$ & 23.3 & 108.1 & 4.6 \\
\hline & 3.00 & 330 & $1.9 \times 10^{15}$ & 28.2 & 108.1 & 3.8 \\
\hline \multirow{6}{*}{70} & 0.25 & 170 & $5.2 \times 10^{14}$ & 8.6 & 138.7 & 16.1 \\
\hline & 0.50 & 220 & $8.7 \times 10^{14}$ & 11.8 & 138.7 & 11.8 \\
\hline & 1.00 & 260 & $1.2 \times 10^{15}$ & 15.6 & 138.7 & 8.9 \\
\hline & 1.50 & 275 & $1.4 \times 10^{15}$ & 17.6 & 138.7 & 7.9 \\
\hline & 2.00 & 290 & $1.5 \times 10^{15}$ & 20.1 & 138.7 & 6.9 \\
\hline & 3.00 & 300 & $1.6 \times 10^{15}$ & 24.9 & 138.7 & 5.6 \\
\hline
\end{tabular}


Table 7.5. Deformation stored energies of the $0.79 \% \mathrm{C}$ steel at selected experimental temperatures.

\begin{tabular}{|c|c|c|c|c|c|c|}
\hline \multicolumn{7}{|c|}{$0.79 \% C$ steel } \\
\hline $\begin{array}{c}\Delta \mathrm{T}\left(\mathrm{T}_{\text {expt. }}-\mathrm{Ae}_{3}\right) \\
{ }^{\circ} \mathrm{C}\end{array}$ & $\varepsilon$ & $\begin{array}{c}\sigma \\
(\mathrm{MPa})\end{array}$ & $\rho\left(m^{-2}\right)$ & $\begin{array}{l}\left.\Delta G_{D(\text { in }}\right) \\
(\mathrm{J} / \mathrm{mol})\end{array}$ & $\begin{array}{l}\Delta G_{\text {(theor) }} \\
(\mathrm{J} / \mathrm{mol})\end{array}$ & H.F. \\
\hline \multirow{6}{*}{ 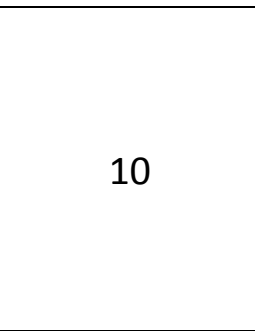 } & 0.25 & 245 & $8.4 \times 10^{14}$ & 13.3 & 45.7 & 3.4 \\
\hline & 0.50 & 275 & $1.1 \times 10^{15}$ & 15.8 & 45.7 & 2.9 \\
\hline & 1.00 & 318 & $1.4 \times 10^{15}$ & 20.3 & 45.7 & 2.2 \\
\hline & 1.50 & 355 & $1.8 \times 10^{15}$ & 25.1 & 45.7 & 1.8 \\
\hline & 2.00 & 365 & $1.9 \times 10^{15}$ & 27.2 & 45.7 & 1.7 \\
\hline & 3.00 & 375 & $2.0 \times 10^{15}$ & 32.1 & 45.7 & 1.4 \\
\hline \multirow{6}{*}{30} & 0.25 & 235 & $7.9 \times 10^{14}$ & 12.5 & 88.7 & 7.1 \\
\hline & 0.50 & 265 & $1.0 \times 10^{15}$ & 14.9 & 88.7 & 5.9 \\
\hline & 1.00 & 300 & $1.3 \times 10^{15}$ & 18.5 & 88.7 & 4.8 \\
\hline & 1.50 & 325 & $1.5 \times 10^{15}$ & 21.7 & 88.7 & 4.1 \\
\hline & 2.00 & 330 & $1.6 \times 10^{15}$ & 23.1 & 88.7 & 3.8 \\
\hline & 3.00 & 350 & $1.8 \times 10^{15}$ & 29.2 & 88.7 & 3.0 \\
\hline \multirow{6}{*}{50} & 0.25 & 227 & $7.7 \times 10^{14}$ & 11.9 & 128.4 & 10.7 \\
\hline & 0.50 & 260 & $1.0 \times 10^{15}$ & 14.6 & 128.4 & 8.8 \\
\hline & 1.00 & 295 & $1.3 \times 10^{15}$ & 18.2 & 128.4 & 7.1 \\
\hline & 1.50 & 315 & $1.5 \times 10^{15}$ & 20.8 & 128.4 & 6.2 \\
\hline & 2.00 & 325 & $1.6 \times 10^{15}$ & 22.8 & 128.4 & 5.6 \\
\hline & 3.00 & 326 & $1.6 \times 10^{15}$ & 26.5 & 128.4 & 4.8 \\
\hline \multirow{6}{*}{70} & 0.25 & 215 & $7.1 \times 10^{14}$ & 11.1 & 164.7 & 14.8 \\
\hline & 0.50 & 249 & $9.6 \times 10^{14}$ & 13.7 & 164.7 & 12.0 \\
\hline & 1.00 & 277 & $1.2 \times 10^{15}$ & 16.5 & 164.7 & 9.9 \\
\hline & 1.50 & 300 & $1.4 \times 10^{15}$ & 19.3 & 164.7 & 8.5 \\
\hline & 2.00 & 315 & $1.5 \times 10^{15}$ & 21.8 & 164.7 & 7.5 \\
\hline & 3.00 & 345 & $1.8 \times 10^{15}$ & 29.1 & 164.7 & 5.7 \\
\hline \multirow{6}{*}{90} & 0.25 & 195 & $6.1 \times 10^{14}$ & 9.9 & 197.6 & 20.0 \\
\hline & 0.50 & 235 & $8.8 \times 10^{14}$ & 12.6 & 197.6 & 15.7 \\
\hline & 1.00 & 270 & $1.2 \times 10^{15}$ & 15.9 & 197.6 & 12.4 \\
\hline & 1.50 & 290 & $1.3 \times 10^{15}$ & 18.4 & 197.6 & 10.7 \\
\hline & 2.00 & 302 & $1.5 \times 10^{15}$ & 20.6 & 197.6 & 9.6 \\
\hline & 3.00 & 315 & $1.6 \times 10^{15}$ & 25.7 & 197.6 & 7.7 \\
\hline
\end{tabular}




\subsubsection{Inhomogeneity of the Dislocation Density}

Several workers $[7.1,7.6]$ have previously estimated $\Delta G_{D(\text { in } \gamma)}$ and obtained results similar to, but somewhat lower than, those of Tables 7.2, 7.3, 7.4 and 7.5. Such values of the deformation energy have the shortcoming that they can only account for $\mathrm{Ae}_{3}$ temperature increases of about $10^{\circ} \mathrm{C}$ or so $[7.1,7.6]$. It has therefore been suggested that the relatively high temperatures above $\mathrm{Ae}_{3}$ at which DT has been observed can be attributed to the inhomogeneous distribution of the dislocations and sub-boundaries due to the heterogeneous strain distribution in the austenite matrix [7.1,7.10]. In other words, the energy at some local locations can be much higher than the average value, leading to a local increase in the $\mathrm{Ae}_{3}$ temperature. In this section, this suggestion is considered more closely by first evaluating the amount of energy increase required to account for the appearance of ferrite at such high temperatures. Then, by comparing the amounts of $\Delta G_{D(\text { in } \gamma)}$ necessary to obtain a consistent phase diagram and those calculated using Eq. (7.3), an estimate of the likely degree of inhomogeneity will be derived.

The amounts of excess Gibbs energy, $\Delta G_{(\text {theor })}$ required to account for an increment in $\mathrm{Ae}_{3}$ were evaluated from thermodynamic calculations (carried out under paraequilibrium conditions); these are displayed in column 6 of Tables 7.2 - 7.5*. The ratios of the column 6 over column 5 values can thus be taken as a measure of the inhomogeneity in the distribution of the stored deformation energy in the austenite matrix. This factor is referred to here as the heterogeneity factor (H.F.) and is displayed in the final column. The dependence of the heterogeneity factor on strain at different values of $\Delta T$ is displayed in Fig. 7.2 for the $0.06 \% \mathrm{C}, 0.09 \% \mathrm{C}, 0.21 \% \mathrm{C}$ and $0.79 \% \mathrm{C}$ steels. In all cases, the factor

\footnotetext{
*At a strain of $\varepsilon=2.0$, the ratio of $\Delta G_{\text {Dislocation }}: \Delta G_{\text {Grain boundary }}: \Delta G_{\text {Vacancy }}$ was $60: 5: 1$. Thus, the stored energy due to dislocations is generally the preponderant part of the deformation energy. When the heterogeneity factor (H.F.), see below, is taken into account, the other two contributions can be neglected when first order estimates are made.
} 


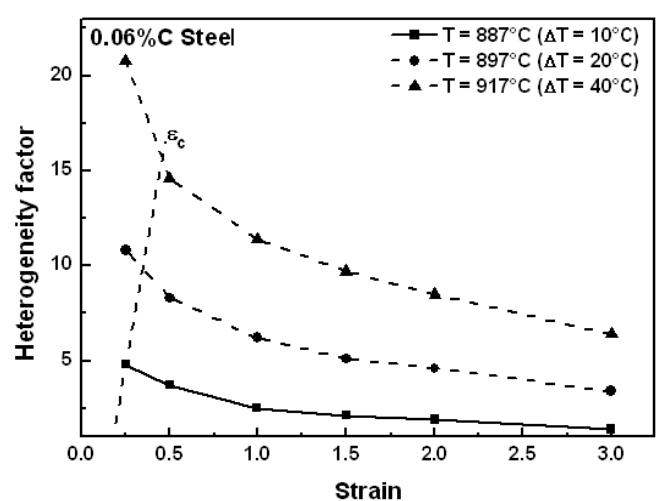

(a)

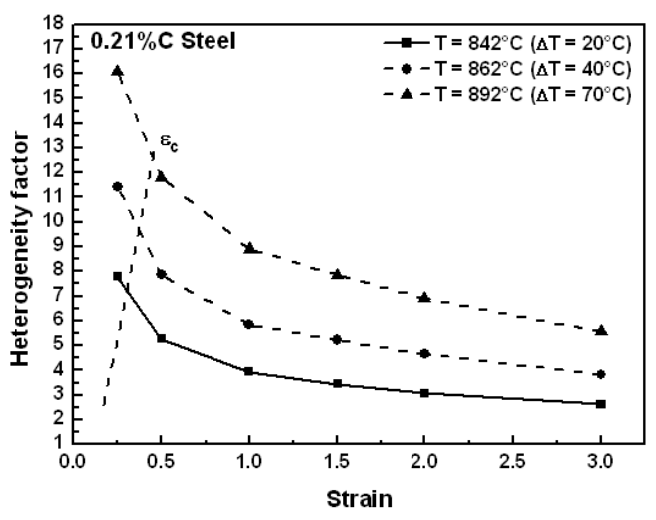

(c)

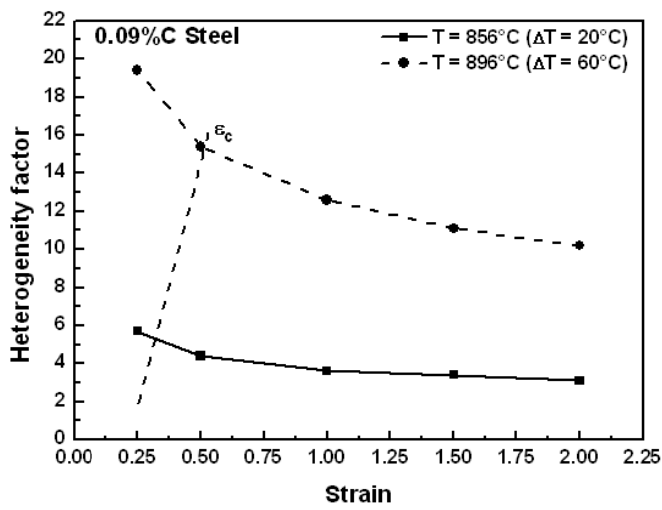

(b)

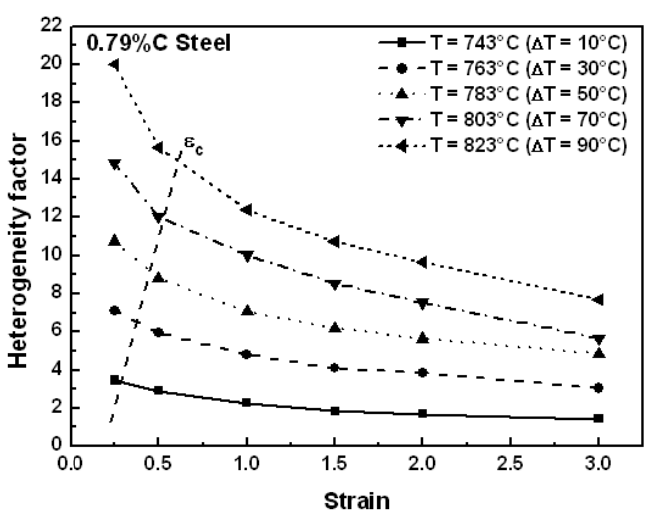

(d)

Fig. 7.2: Dependence of the heterogeneity factor on strain at different values of $\Delta \mathrm{T}:$ (a) $0.06 \% \mathrm{C}$, (b) $0.09 \% \mathrm{C}$, (c) $0.21 \% \mathrm{C}$ and (d) $0.79 \% \mathrm{C}$ steels.

decreases with strain as expected and increases with $\Delta T$. That is, it is easier to produce DT ferrite at higher strains and lower temperatures. In Fig. 7.2, the critical strain required to initiate DT is represented by setting the maximum attainable H.F. as falling in the range 2 to 15.

\subsubsection{Gibbs Energy Implications}

\subsubsection{1 $\underline{0.06 \% C \text { Steel }}$}

In this section, the possible Gibbs energy changes associated with this phenomenon are discussed. Fig. 7.3 was constructed based on the chemical 
composition of the $0.06 \% \mathrm{C}$ steel, where the free energies were evaluated at two different temperatures, namely $897^{\circ} \mathrm{C}$ (i.e. $\mathrm{Ae}_{3}+20^{\circ} \mathrm{C}$ ), Fig. $7.3(\mathrm{a})$ and $917^{\circ} \mathrm{C}$ (i.e. $\mathrm{Ae}_{3}+40^{\circ} \mathrm{C}$ ), Fig. 7.3(b). The Gibbs energies of the various phases are the paraequilibrium values and the substitutional element concentrations remain fixed across the two diagrams. A database entry was created for deformed austenite in order to take into account the dependence of its Gibbs energy on carbon concentration.

It can be seen from the figures that the Gibbs energy of deformed austenite is higher than that of superequilibrium ferrite at both temperatures as long as the C content does not exceed about $0.15 \% C$. (Here the small free energy difference between Widmanstätten ferrite and polygonal ferrite, estimated to be about 30 $\mathrm{J} / \mathrm{mol}$ at this temperature, could not be taken into account because of limitations inherent in the FactSage program.). This supports the view that Widmanstätten ferrite can form from deformed austenite at this composition and temperature. As indicated in Fig. 7.3(a) and (b), at 0.06 wt\% C, the austenite Gibbs energy can decrease "instantly" down to the ferrite line (during nucleation, a purely displacive reaction) and then displacive growth can take place without requiring any cementite formation, i.e. without any $\mathrm{C}$ diffusion being required. This finding is consistent with the absence of any detectable cementite in the micrographs presented in Chapter 4 (Fig. 4.1) and also in Ref. 7.16.

\subsubsection{2 $\underline{0.09 \% C \text { Steel }}$}

The Gibbs energy changes associated with the $0.09 \% \mathrm{C}$ steel were calculated in a similar fashion and are illustrated for two different temperatures in Fig. 7.4. As shown in Fig. $7.4(\mathrm{a})$, at $856^{\circ} \mathrm{C}$ (i.e. $\mathrm{Ae}_{3}+20^{\circ} \mathrm{C}$ ), deformed austenite can readily transform into Widmanstätten ferrite as long as the $\mathrm{C}$ level is below about $0.15 \% \mathrm{C}$. However the present calculation shows that at $896^{\circ} \mathrm{C}$ (i.e. $\mathrm{Ae}_{3}+60^{\circ} \mathrm{C}$ ), the driving force for the transformation is close to zero. Nevertheless, the critical strain measurements described in Chapter $\mathbf{5}$ and Ref. 7.18 indicate that DT can 


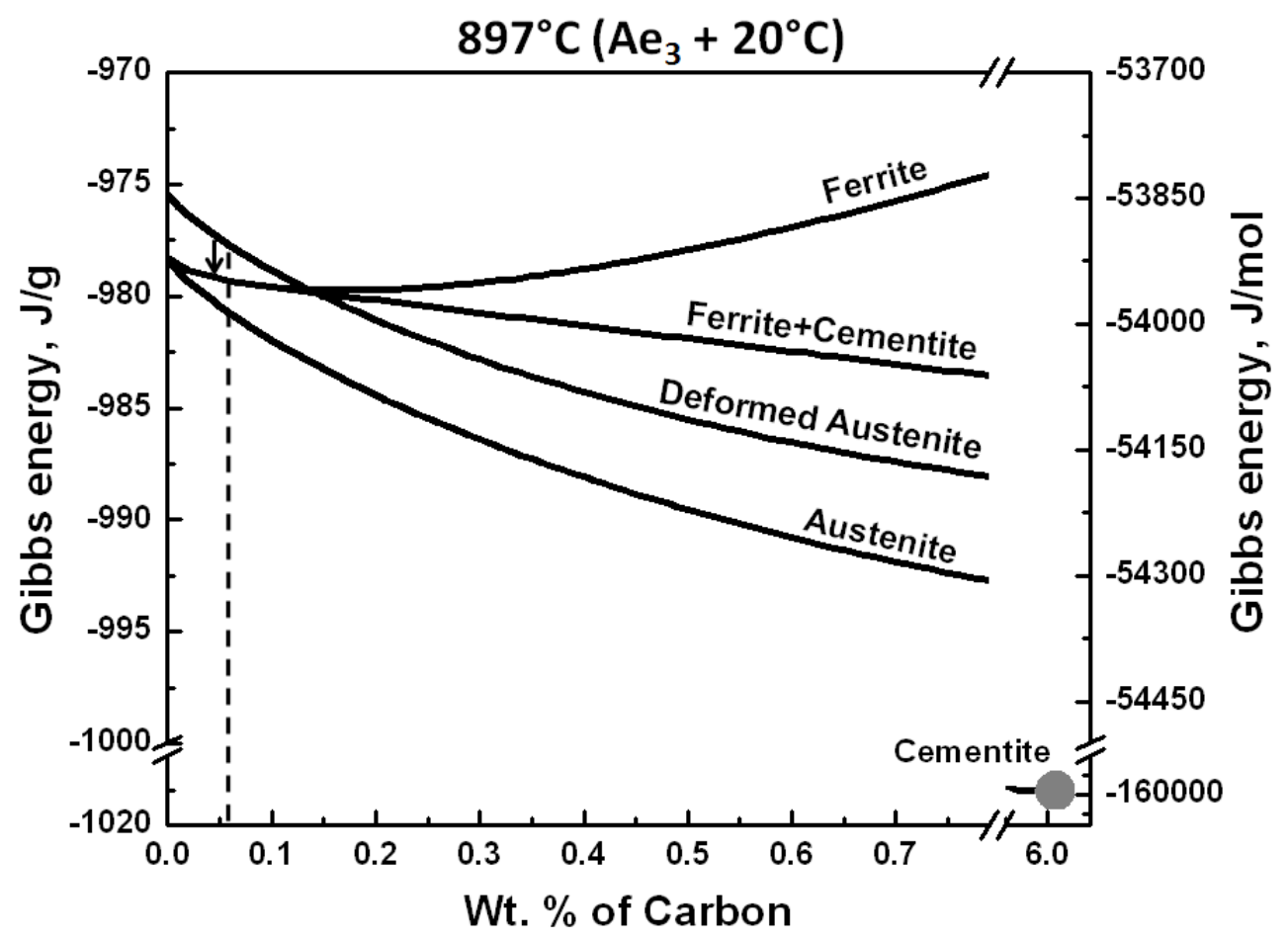

(a)

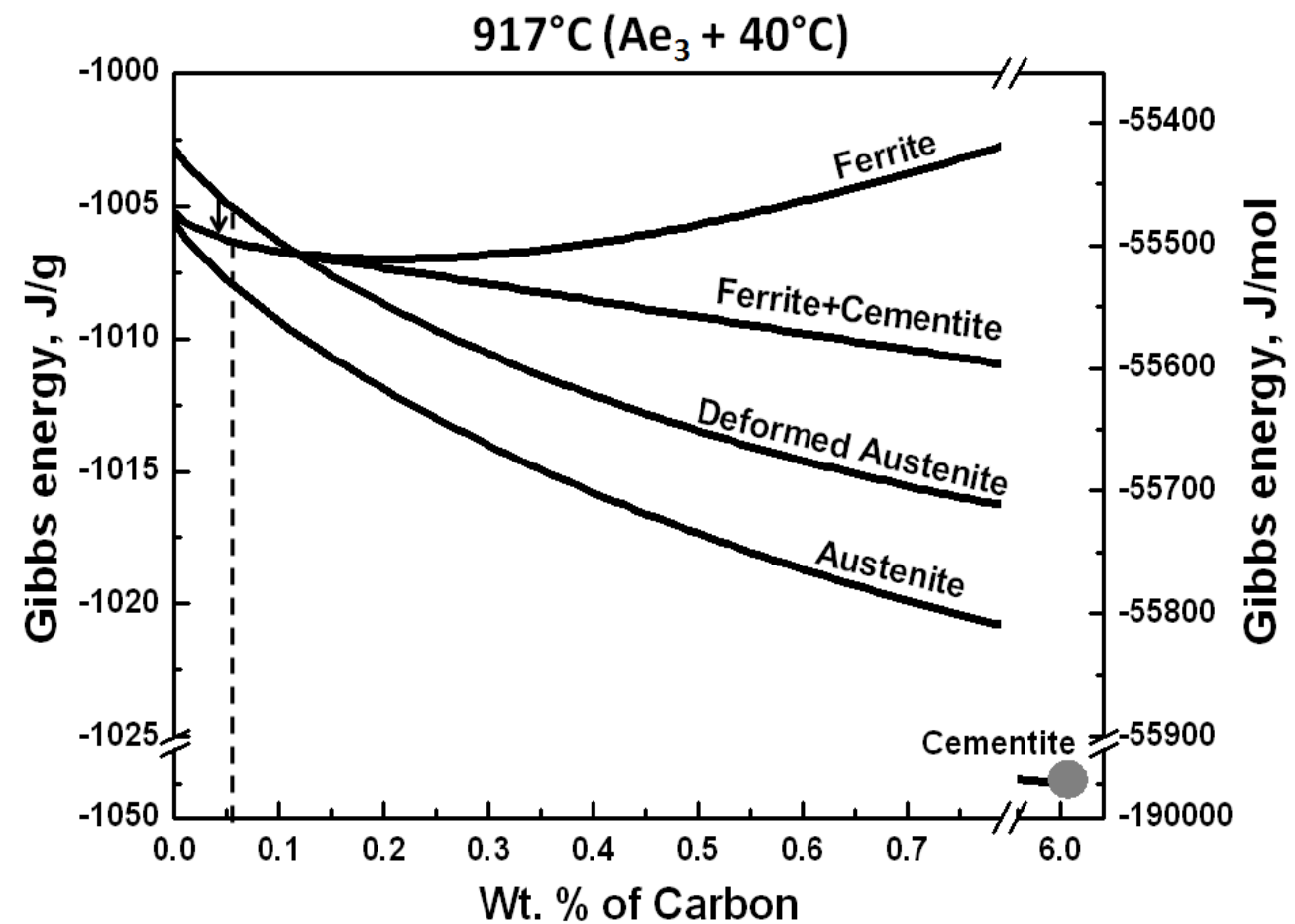

(b)

Fig. 7.3: Gibbs energy-composition diagrams for the $0.06 \% \mathrm{C}$ steel pertaining to (a) $897^{\circ} \mathrm{C}$ (i.e. $\mathrm{Ae}_{3}+20^{\circ} \mathrm{C}$ ) and (b) $917^{\circ} \mathrm{C}$ (i.e. $\mathrm{Ae}_{3}+40^{\circ} \mathrm{C}$ ) illustrating the Gibbs energy changes taking place during dynamic transformation. 


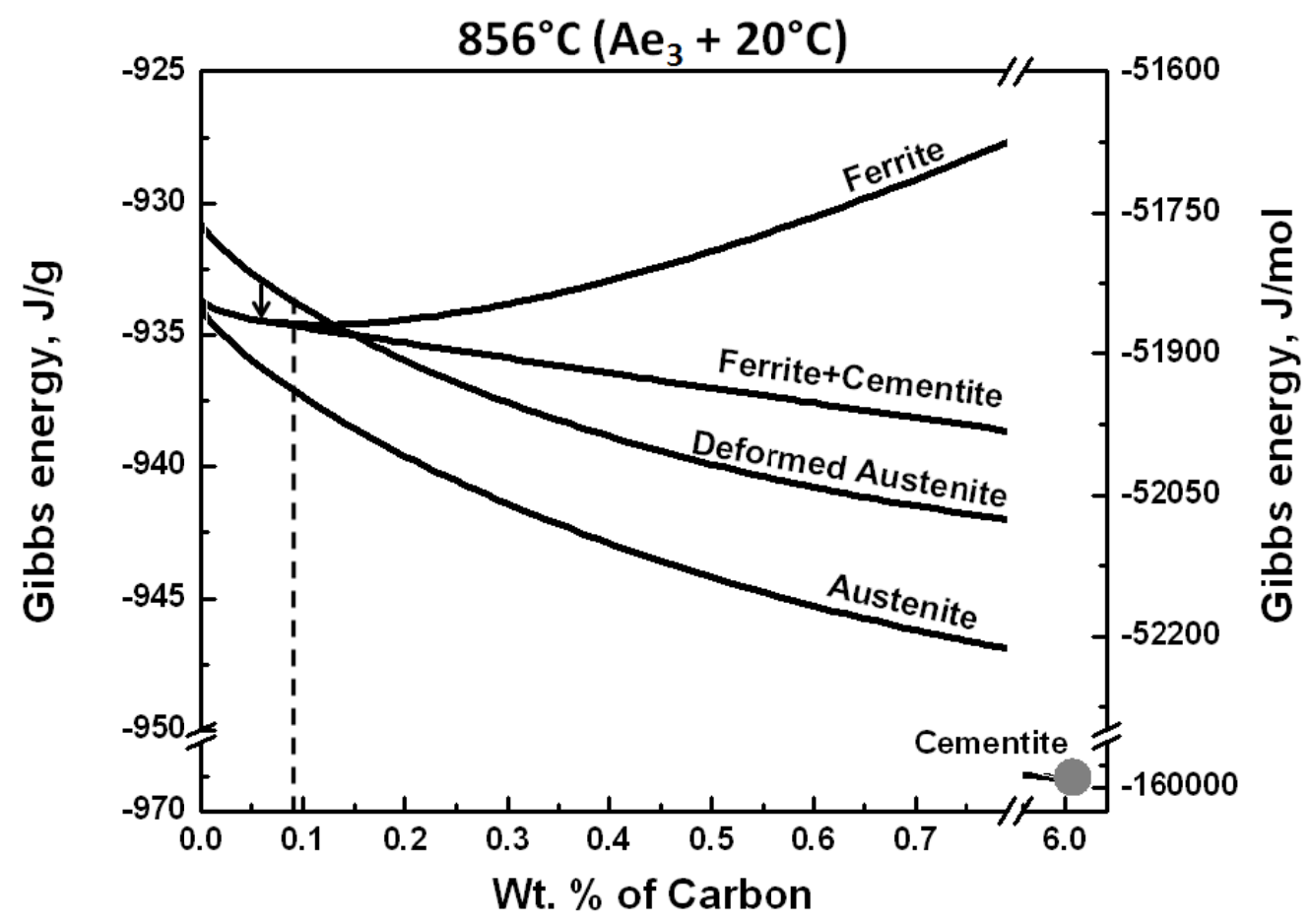

(a)

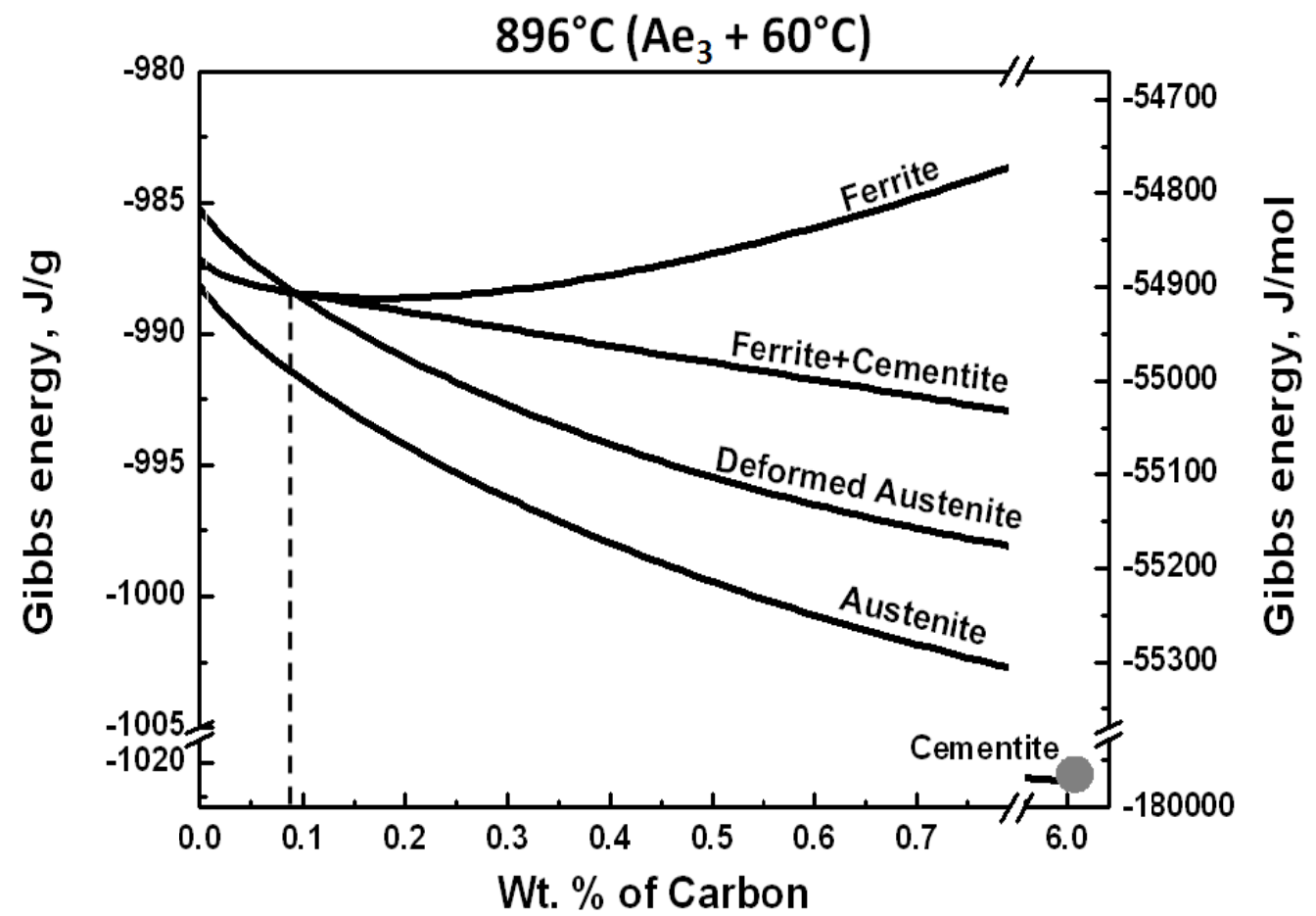

(b)

Fig. 7.4: Gibbs energy-composition diagrams for the $0.09 \% \mathrm{C}$ steel pertaining to (a) $856^{\circ} \mathrm{C}$ (i.e. $\mathrm{Ae}_{3}+20^{\circ} \mathrm{C}$ ) and (b) $896^{\circ} \mathrm{C}$ (i.e. $\mathrm{Ae}_{3}+60^{\circ} \mathrm{C}$ ) illustrating the Gibbs energy changes taking place during dynamic transformation. 
take place at considerably higher temperatures than $896^{\circ} \mathrm{C}$. This therefore suggests that the present method for estimating the increases in free energy is far too conservative.

\subsubsection{3 $\underline{0.21 \% C \text { Steel }}$}

Gibbs energy-composition diagrams for the $0.21 \% \mathrm{C}$ steel at two different temperatures are depicted in Fig. 7.5. Here, at both temperatures, i.e. $862^{\circ} \mathrm{C}$ (i.e. $\mathrm{Ae}_{3}+40^{\circ} \mathrm{C}$ ) and $892^{\circ} \mathrm{C}$ (i.e. $\mathrm{Ae}_{3}+70^{\circ} \mathrm{C}$ ), the Gibbs energy of the deformed austenite is higher than that of the ferrite as long as the $C$ level remains below about $0.40 \%$ C. Above these levels, ferrite formation must be accompanied by carbide formation, i.e. C diffusion. This signifies that a displacive transformation from deformed austenite to ferrite is feasible in the $0.21 \% \mathrm{C}$ steel at these two temperatures. However, once the ferrite has formed, there is a driving force for cementite formation, which requires $C$ diffusion. These further changes are not displacive. In Chapter 4, the presence of Widmanstätten ferrite in the $0.21 \% \mathrm{C}$ steel was illustrated in Fig. 4.6. Cementite particles were also observed in this particular steel, as determined in the SEM investigation and demonstrated in Figs. 4.4 and 4.5. Therefore, the thermodynamic analysis can be seen to be in good agreement with the microstructural characterization described in Chapter 4 and also summarized in Table 4.2 .

\subsubsection{4 $\underline{0.79 \% C \text { Steel }}$}

Changes in the Gibbs energies of the different phases and their dependences on carbon concentration are represented for the $0.79 \% \mathrm{C}$ steel in Fig. 7.6. As shown in Fig. $7.6(\mathrm{a})$, at $803^{\circ} \mathrm{C}$ (i.e. $\mathrm{Ae}_{3}+70^{\circ} \mathrm{C}$ ), ferrite formation must be accompanied by carbide formation, i.e. C diffusion. The SEM and TEM micrographs, coupled with the selected area diffraction patterns clearly demonstrate the presence of cementite and ferrite in the $0.79 \% \mathrm{C}$ steel; see Figs. 4.8, 4.9, 4.13 in Chapter 4. Thus the presence of these two phases is in line with the thermodynamic analysis. However, as depicted in Fig. $7.6\left(\right.$ b), at $863^{\circ} \mathrm{C}$ (i.e. $\mathrm{Ae}_{3}+130^{\circ} \mathrm{C}$ ), the 


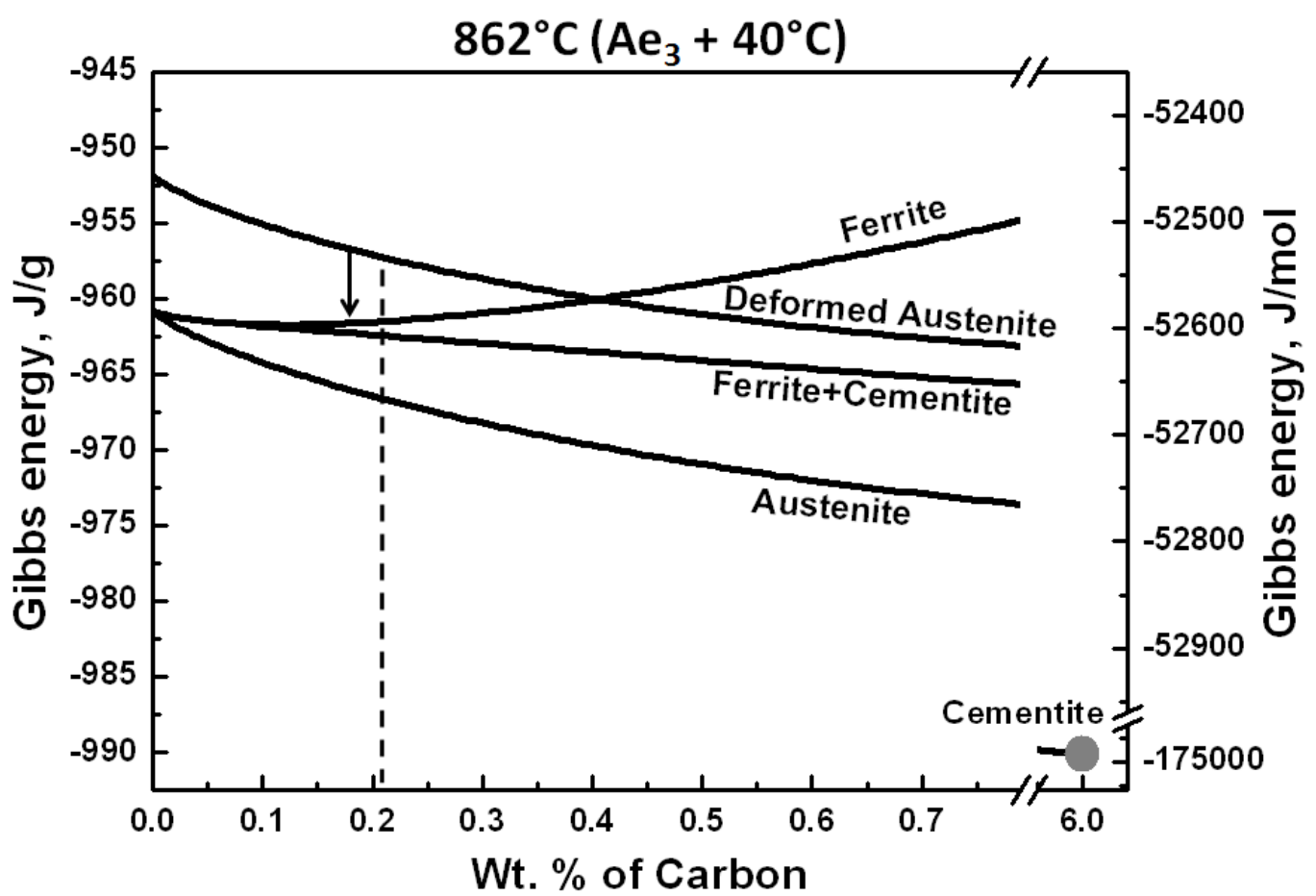

(a)

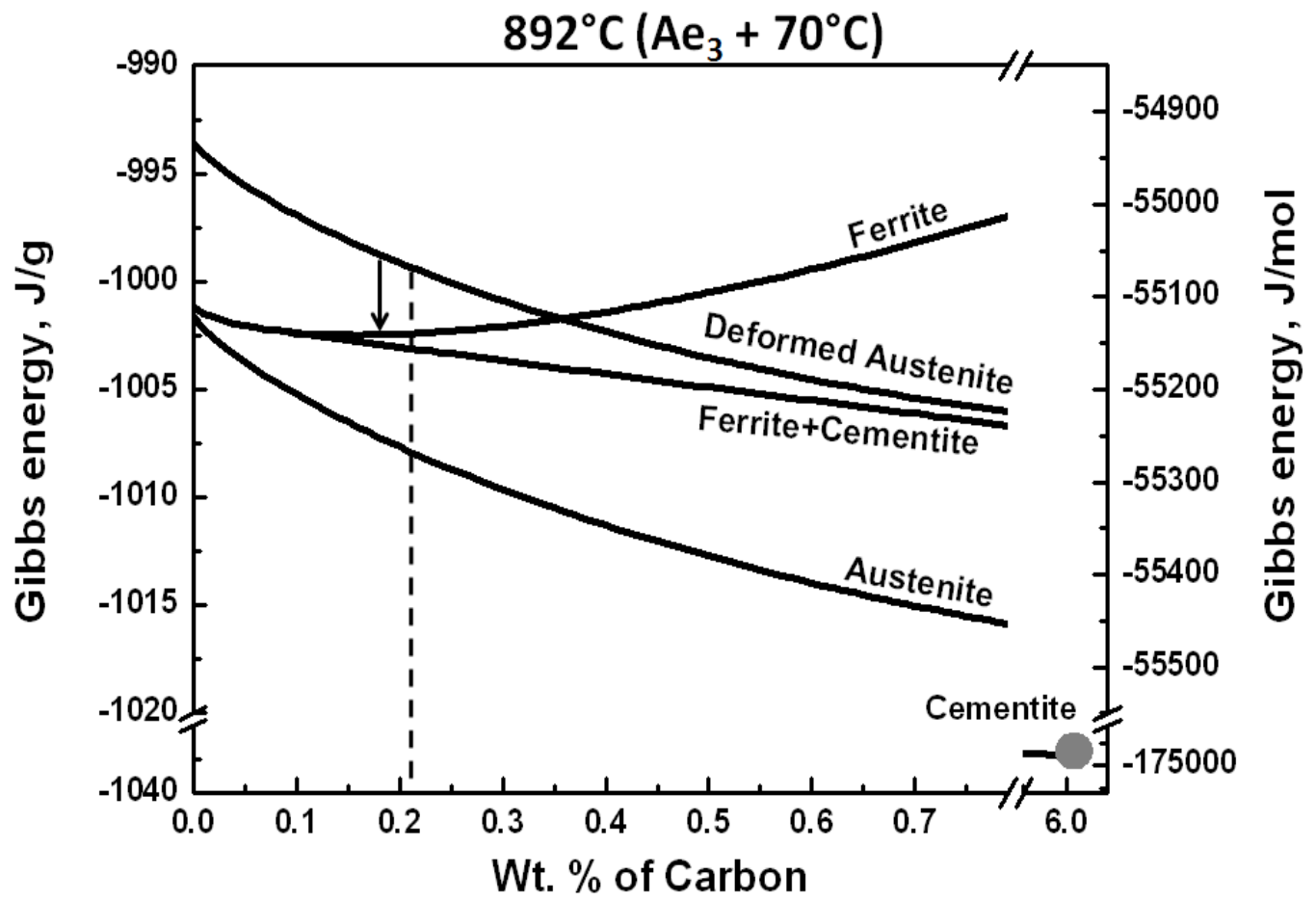

(b)

Fig. 7.5: Gibbs energy-composition diagrams for the $0.21 \% \mathrm{C}$ steel pertaining to (a) $862^{\circ} \mathrm{C}$ (i.e. $\mathrm{Ae}_{3}+40^{\circ} \mathrm{C}$ ) and (b) $892^{\circ} \mathrm{C}$ (i.e. $\mathrm{Ae}_{3}+70^{\circ} \mathrm{C}$ ) illustrating the Gibbs energy changes taking place during dynamic transformation. 


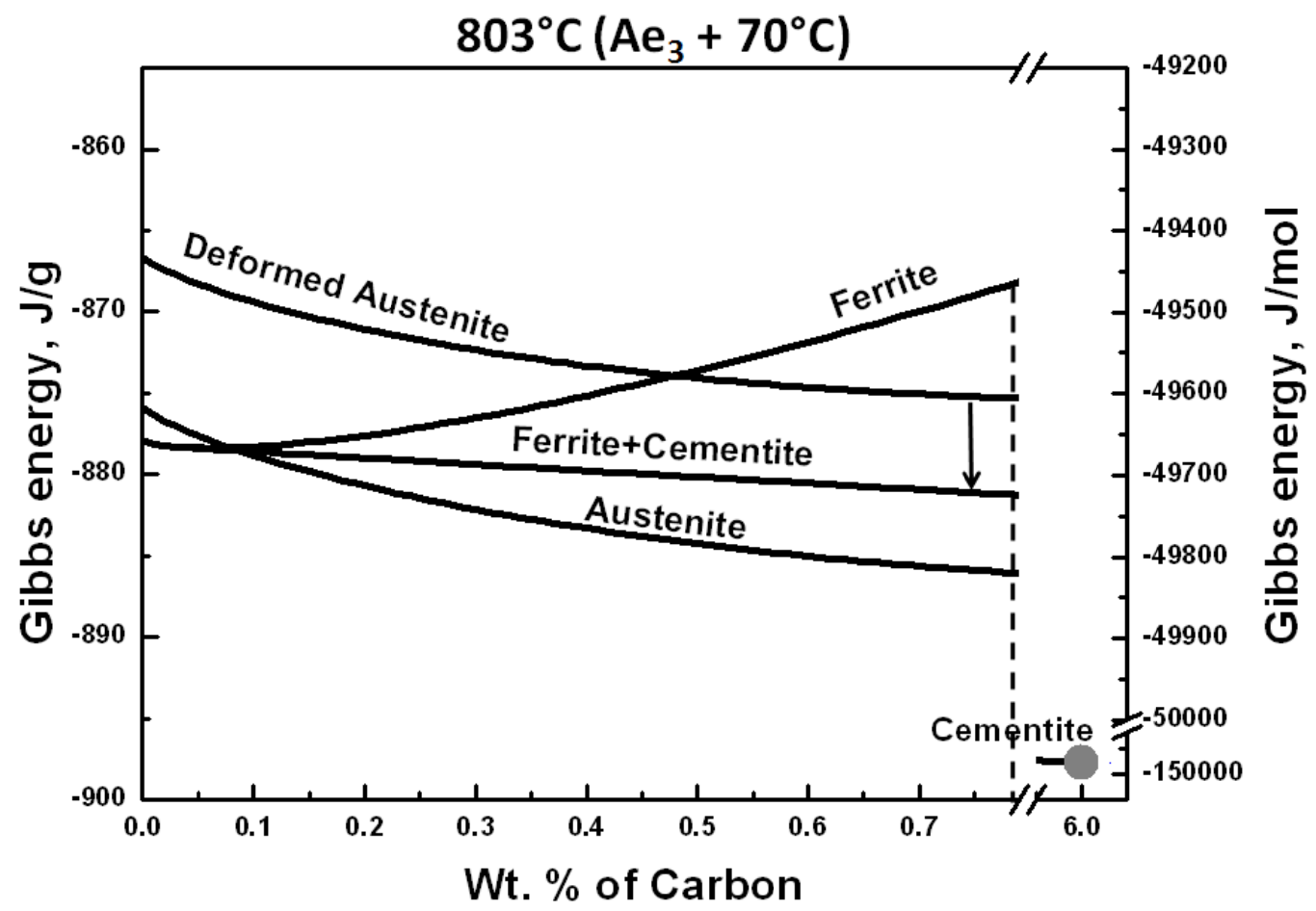

(a)

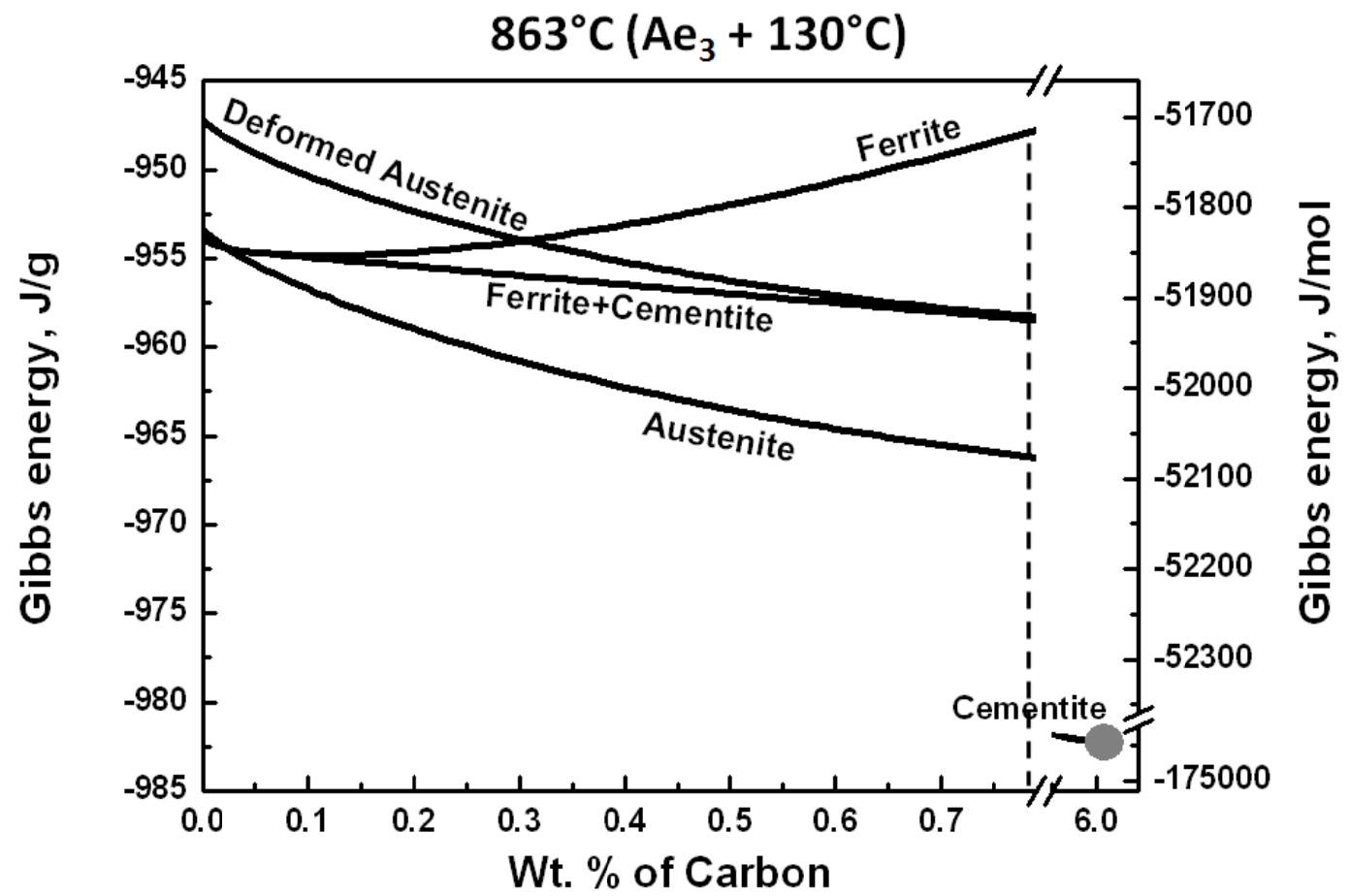

(b)

Fig. 7.6: Gibbs energy-composition diagrams for the $0.79 \% \mathrm{C}$ steel pertaining to (a) $803^{\circ} \mathrm{C}$ (i.e. $\mathrm{Ae}_{3}+70^{\circ} \mathrm{C}$ ) and (b) $863^{\circ} \mathrm{C}$ (i.e. $\mathrm{Ae}_{3}+130^{\circ} \mathrm{C}$ ) illustrating the Gibbs energy changes taking place during dynamic transformation. 
driving force for the transformation has become vanishingly small. This is consistent with the view that the present estimates of the free energy increases due to deformation, while higher than those proposed earlier [7.1,7.6], are still too low.

\subsubsection{Effect of Strain on the Phase Diagram}

When the increase in Gibbs energy attributable to deformation is included in the calculations in the manner described in section 3.8, the transformation temperature levels of the pseudo-binary diagram are raised. An example is provided in Fig. 7.7 for steels containing the Mn (0.65 wt.\%) and Si (0.24 wt.\%) concentrations of the $0.79 \% \mathrm{C}$ steel. Here the Gibbs energy increase employed was $200 \mathrm{~J} / \mathrm{mol}$ and it can be seen that the $\mathrm{Ae}_{3}$ is increased by 80 to as much as $200^{\circ} \mathrm{C}$, increasing as the $\mathrm{C}$ content is decreased. By contrast, the $\mathrm{Ae}_{1}$ temperature is not markedly affected by $\mathrm{C}$ concentration, increasing by a relatively fixed 80 degrees. Thus, the temperature range of the two-phase region is broadened by straining. Here the presence of a three-phase region just below the $\mathrm{Ae}_{1}$ should be noted in both diagrams. This field may in fact be much wider than called for by these simulations, as suggested by the metallographic observations.

A pseudo-binary diagram for the $0.21 \% \mathrm{C}$ steel was also calculated and is depicted in Fig. 7.8. Here the diagram for the $0.79 \%$ C steel of Fig. $\mathbf{7 . 7}$ is included for comparison purposes. It can be observed that, with the increase in the $\mathrm{Mn}$ level from $0.65 \mathrm{wt} . \%$ in the $0.79 \% \mathrm{C}$ steel to $1.3 \mathrm{wt.} \%$ in the $0.21 \% \mathrm{C}$ steel, the $\mathrm{Ae}_{3}$ and $\mathrm{Ae}_{1}$ temperatures are lowered by about $20^{\circ} \mathrm{C}$.

A pseudo-binary diagram for another steel with the same composition as that of the $0.06 \% \mathrm{C}$ steel of the present study but containing 0.50 wt.\% Si was calculated and is illustrated in Fig. 7.9. This material was prepared together with Steel 1 (i.e. $0.06 \% \mathrm{C}$ steel) but its microstructural characteristics were not studied in this investigation. The diagram for the $0.79 \% \mathrm{C}$ steel of Fig. $\mathbf{7 . 7}$ is again included for comparison purposes. From this figure it can be observed that, with the decrease 


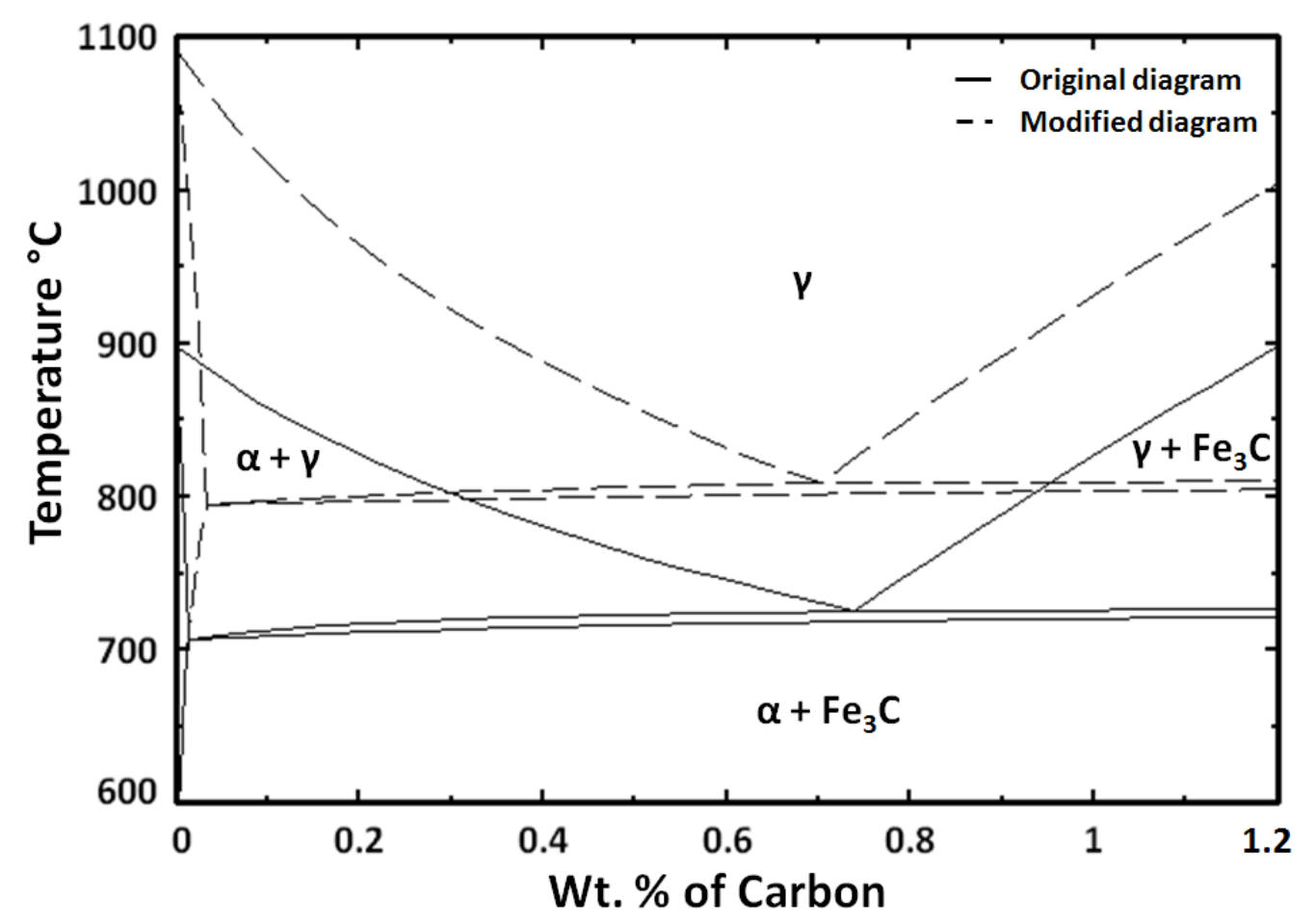

Fig. 7.7: Calculated quasi-binary paraequilibrium phase diagram for the $0.79 \% \mathrm{C}$ steel undergoing deformation compared with the conventional diagram for the undeformed material.

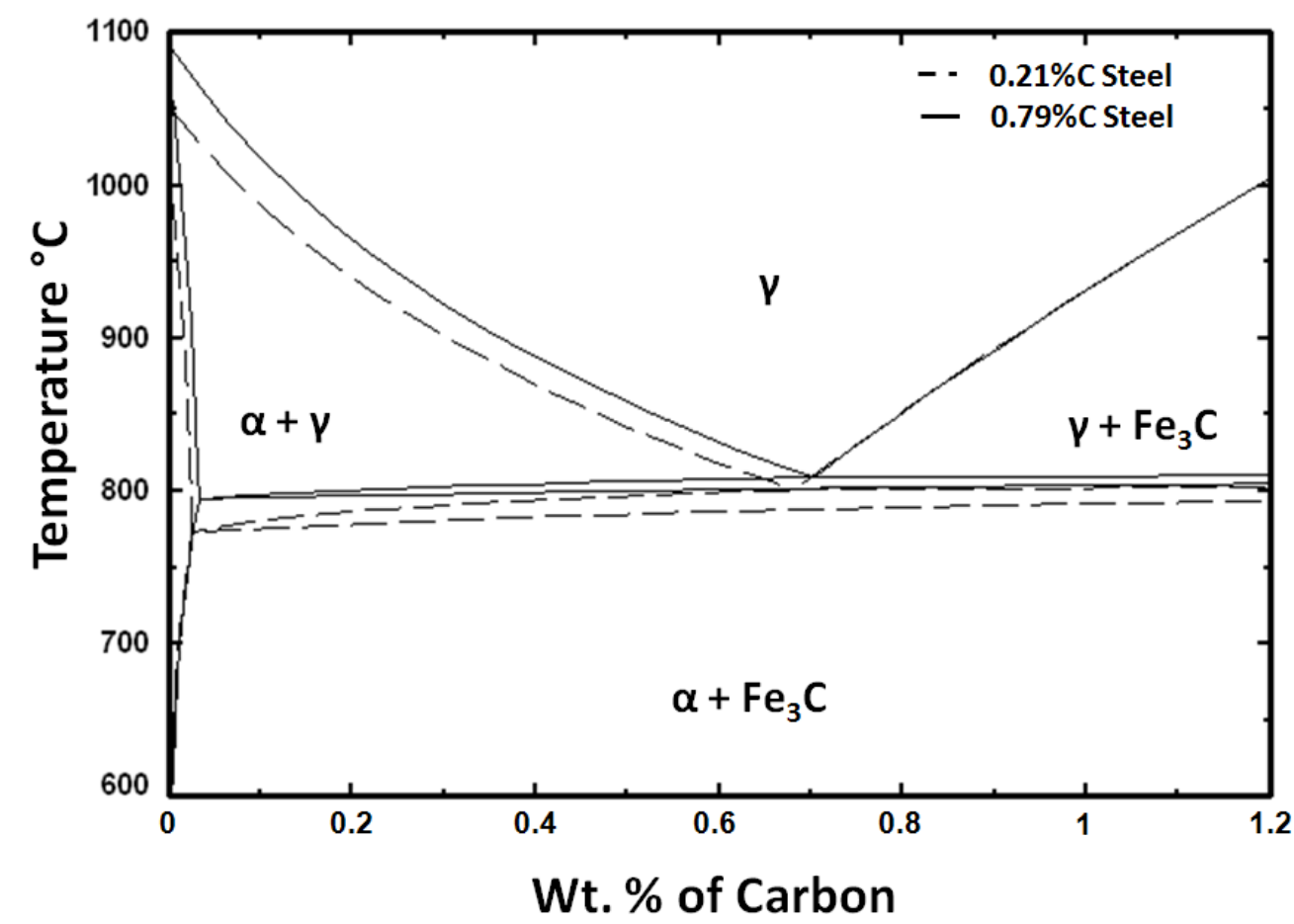

Fig. 7.8: Calculated quasi-binary paraequilibrium phase diagram for the $0.21 \% \mathrm{C}$ steel compared with that of the $0.79 \% \mathrm{C}$ steel of Fig. 7.7. 


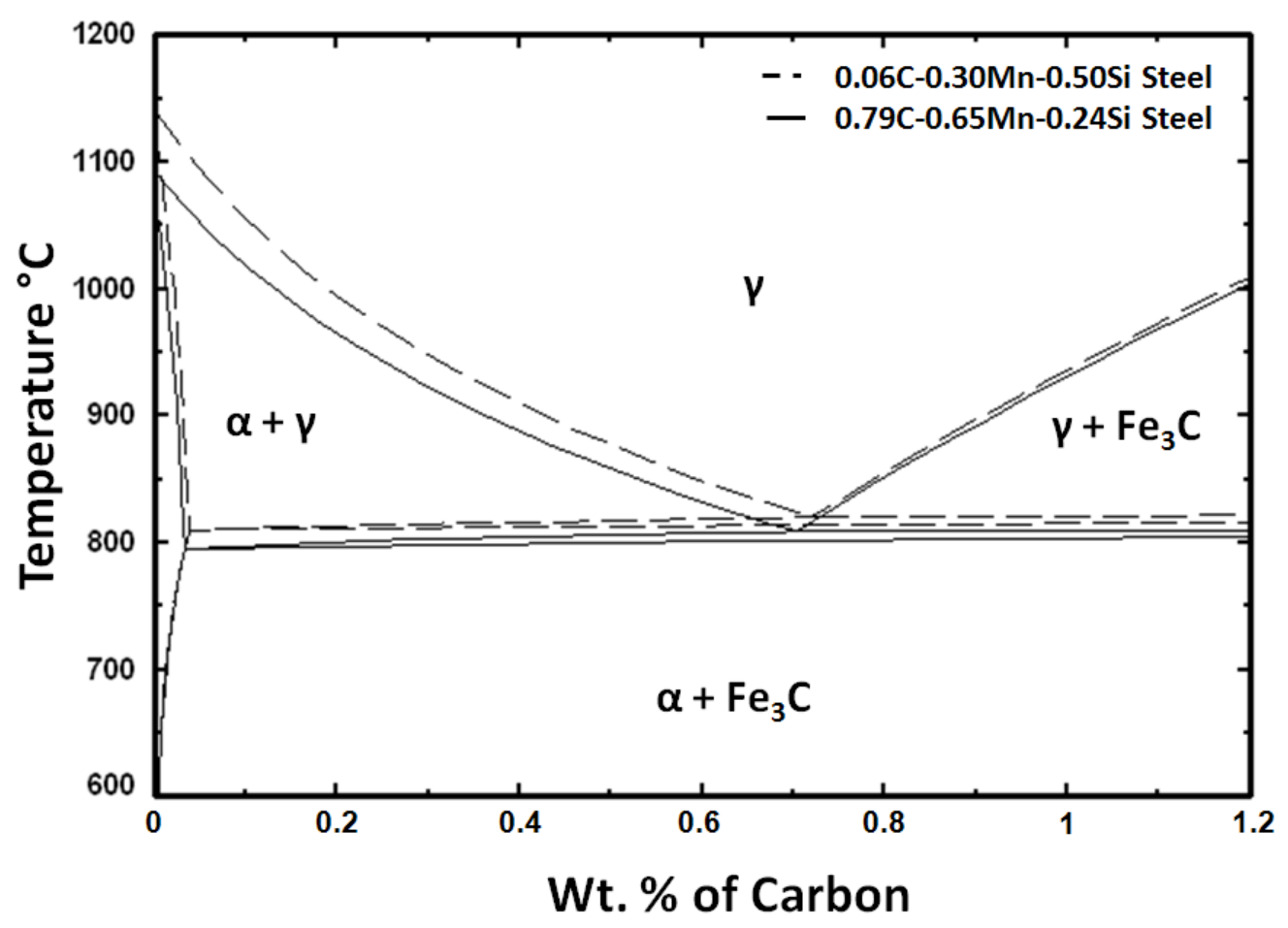

Fig. 7.9: Calculated quasi-binary paraequilibrium phase diagram for the $0.06 \mathrm{C}$ $0.30 \mathrm{Mn}-0.50 \mathrm{Si}$ steel compared with that of the $0.79 \% \mathrm{C}$ steel of Fig. 7.7.

in $\mathrm{Mn}$ content from $0.65 \mathrm{wt} . \%$ in the $0.79 \% \mathrm{C}$ steel to $0.30 \mathrm{wt} . \%$ in the other steel coupled with an increase in Si level from 0.24 wt.\% in the $0.79 \% \mathrm{C}$ steel to 0.50 wt.\% in the other one, the $\mathrm{Ae}_{3}$ temperature actually increases by about $30^{\circ} \mathrm{C}$.

\subsection{Conclusions}

The following conclusions can be drawn from the present results.

1. The effect of deformation on the Gibbs energy of austenite can be estimated by assuming that the austenite continues to work harden after the initiation of the transformation and that its flow stress and dislocation density can be estimated from the experimental flow curve for the two-phase material. This leads to higher austenite flow stresses and therefore higher dislocation densities than those employed to model dynamic transformation by previous researchers. 
2. The dislocation densities in the regions that undergo transformation are higher than the average values. The present analysis suggests that inhomogeneity or heterogeneity factors in the range 2 to 15 are involved. Such an approach (together with item 1 above) leads to driving forces of about $200 \mathrm{~J} / \mathrm{mol}$ and can thus readily account for transformation temperatures as much as $100^{\circ} \mathrm{C}$ above the $\mathrm{Ae}_{3}$.

3. At $\mathrm{C}$ levels below about $0.15 \% \mathrm{C}$ and at temperatures above the $\mathrm{Ae}_{3}$, the Gibbs energy calculations indicate that the deformed austenite energy can decrease "instantly" down to the ferrite line (during nucleation, a purely displacive reaction) and then displacive growth can take place without requiring any cementite formation, i.e. without any $\mathrm{C}$ diffusion being required. This finding is consistent with the absence of any detectable cementite in the micrographs presented in Chapter 4.

4. At $\mathrm{C}$ levels in the range from $0.15 \% \mathrm{C}$ to about $0.40 \% \mathrm{C}$ and at temperatures above the $\mathrm{Ae}_{3}$, similar calculations indicate that the Widmanstätten ferrite can form "instantly", i.e. displacively, from deformed austenite. It can then decompose more slowly into ferrite + cementite while localized $\mathrm{C}$ diffusion is taking place, a two-step process requiring about $50 \mu \mathrm{s}$. This is in agreement with the presence of the cementite particles described in Chapter 4.

5. At $\mathrm{C}$ levels above about $0.40 \% \mathrm{C}$ and at temperatures above the $\mathrm{Ae}_{3}$ in the $0.79 \% \mathrm{C}$ steel, the Gibbs energy calculations indicate that the formation of ferrite is accompanied by cementite formation and involves concurrent $\mathrm{C}$ diffusion.

6. The formation and presence of DT ferrite at temperatures more than $100^{\circ} \mathrm{C}$ above the $\mathrm{Ae}_{3}$ corresponding to the steel in question suggest that the present estimates of the free energy increases are still too low. 
7. Increasing or decreasing the $\mathrm{Mn}$ level in steels of the present type leads to dynamic $\mathrm{Ae}_{3}$ temperature decreases or increases, respectively. Similar modifications in the Si levels lead to $\mathrm{Ae}_{3}$ temperature changes of similar magnitude but of opposite sign of up to 20 or $30^{\circ} \mathrm{C}$.

\section{References}

7.1 D.N. Hanlon, J. Sietsma and S. van der Zwaag; ISIJ Int., Vol. 41, (2001), p. 1028.

7.2 Y. Adachi, T. Tomida and S. Hinatoni; ISIJ Int., Vol. 40, (2000), p. S194.

7.3 P.J. Hurley, B.C. Muddle, P.D. Hodgson, C.H.J. Davies, B.P. Wynne, P. Cizek and M.R. Hickson; Mater. Sci. Forum, Vol. 284-286, (1998), p. 159.

7.4 B. Bay, N. Hansen, D.A. Hughes and D. Kuhlmann-Wilsdorf; Acta Metall. Mater., Vol. 40, (1992), p. 205.

7.5 D.A. Hughes and N. Hansen; Mater. Sci. Tech., Vol. 7, (1991), p. 544.

7.6 S.V. Parker; Ph.D. Thesis, Cambridge University, Cambridge, 1997.

7.7 H. Mecking; Strength of Metals and Alloys: P. Haasen, V. Gerold, G. Kostorz (Eds.); (1979), p. 1573.

7.8 J.J. Jonas, X. Quelennec, L. Jiang and E. Martin; Acta Mater., Vol. 57, (2009), p. 2748.

7.9 E. Poliak and J.J. Jonas; Acta Mater., Vol. 44, (1996), p. 127.

$7.10 \mathrm{H}$. Dong and X. Sun; Current Opinion in Solid State and Mater. Sci., Vol. 9, (2005), p. 269.

7.11 G.R. Speich, L.J. Cuddy. C.R. Gordon and A.J. DeArdo; Phase Transformations in Ferrous Alloys, A. R. Marder and J. I. Goldstein (Eds.), TMS-AIME, Warrendale, PA, (1984), p. 341.

7.12 M. Militzer, W.P. Sun and J.J. Jonas; Acta Metall. Mater., Vol. 42, (1994), p. 133.

7.13 H. Mecking and Y. Estrin; Scripta Metall., Vol. 14, (1980), p. 815.

7.14 W. Witzel; Z. Metallk., Vol. 64, (1973), p. 585.

7.15 G.E. Dieter; Mechanical Metallurgy, McGraw-Hill Book Company, (1988).

7.16 C. Ghosh, V.V. Basabe, J.J. Jonas, Y.M. Kim, I.H. Jung and S. Yue; Acta Mater., Vol. 61, (2013), p. 2348.

7.17 D.A. Porter and K.E. Easterling; Phase Transformations in Metals and Alloys- $2^{\text {nd }}$ Edition, Taylor-Francis Group, 2004.

7.18 C. Ghosh, V.V. Basabe and J.J. Jonas; Steel Res. Int., in press (DOI: 10.1002/srin.201200188). 
Chapter 8

Conclusions 


\section{Conclusions}

In the present investigation, the dynamic transformation behavior of deformed austenite was studied in four steels of increasing carbon contents that had been deformed over the temperature range $743-917^{\circ} \mathrm{C}$. These experiments were carried out in torsion under an atmosphere of argon and $5 \% \mathrm{H}_{2}$ and the experimental temperatures were above the ortho and para-equilibrium $\mathrm{Ae}_{3}$ temperatures of the steels. Strains of $0.15-5$ were applied at strain rates of 0.4 $4.5 \mathrm{~s}^{-1}$.

As mentioned earlier, the aims of this investigation were threefold: i) to find a theoretical justification for the increases in $\mathrm{Ae}_{3}$ of $100^{\circ} \mathrm{C}$ or even $150^{\circ} \mathrm{C}$ that have been observed; ii) to determine the characteristics of this type of dynamic transformation, i.e. the displacive vs. diffusional nature of the phase change; and iii) to consider how dynamic transformation can affect the operation and control of rolling mills.

The first problem was addressed by drawing up the thermodynamic model for deformed austenite described in Chapter 7. This analysis led to the following general conclusions and accounts for the formation of DT ferrite as much as $100^{\circ} \mathrm{C}$ above the conventional $\mathrm{Ae}_{3}$ 's.

1. The effect of deformation on the Gibbs energy of austenite can be estimated by assuming that the austenite continues to work harden after the initiation of the transformation and that its flow stress and dislocation density can be estimated from the experimental flow curve for the two-phase material. This leads to higher austenite flow stresses and therefore higher dislocation densities than those employed to model dynamic transformation by previous researchers.

2. The dislocation densities in the regions that undergo transformation are higher than the average values. The present analysis suggests that 
inhomogeneity or heterogeneity factors in the range 2 to 15 are involved. Such an approach (together with item 1 above) leads to driving forces of about $200 \mathrm{~J} / \mathrm{mol}$ and can thus readily account for transformation temperatures as much as $100^{\circ} \mathrm{C}$ above the $\mathrm{Ae}_{3}$.

3. At $\mathrm{C}$ levels below about $0.15 \% \mathrm{C}$ and at temperatures above the $\mathrm{Ae}_{3}$, the Gibbs energy calculations indicate that the deformed austenite energy can decrease "instantly" down to the ferrite line and then displacive growth takes place without any $\mathrm{C}$ diffusion being required. At $\mathrm{C}$ levels in the range from $0.15 \% \mathrm{C}$ to about $0.40 \% \mathrm{C}$, similar calculations indicate that the Widmanstätten ferrite can form "instantly", i.e. displacively, from deformed austenite. It then decomposes more slowly into ferrite + cementite while localized $\mathrm{C}$ diffusion is taking place. At $\mathrm{C}$ levels above about $0.40 \% \mathrm{C}$, the Gibbs energy calculations indicate that the formation of ferrite is accompanied by cementite formation and involves concurrent C diffusion.

The second objective required an analysis of diffusion rates and a detailed interpretation of atom probe tomography, TEM, SEM and EBSD micrographs. This part of the work led to the following broad conclusions, which suggest that DT ferrite forms displacively in times of the order of milliseconds. This type of ferrite was shown to be of Widmanstätten morphology.

1. DT ferrite is first nucleated in the form of Widmanstätten plates $200 \mathrm{~nm}$ thick by a displacive mechanism. As the applied strain is increased, some of the plates are gradually converted into approximately equiaxed grains.

2. The carbon diffusion distances associated with the formation of ferrite plates and cementite particles are consistent with elapsed times of less than a millisecond over the experimental temperature range. Thus there is sufficient time for interstitial diffusion to take place during DT. However, the times available do not allow for any substitutional diffusion. 
The third objective was accomplished in two ways: i) First, by determining the critical strains associated with the initiation of DT; these are attained early in every pass of commercial rolling. ii) Second, by plotting experimental mean flow stresses (MFS's) against inverse absolute temperature $(1 / T)$. These MFS's are distinctly below the values expected for single phase austenite at temperatures that are below the hypothesized $\mathrm{A}_{\mathrm{r}}{ }^{* \prime} \mathrm{s}$ and are ascribed to the softening influence of DT. In this way, the present work has provided a possible explanation for the load drops commonly observed in industry in this temperature range. This part of the work also led the following general conclusions.

1. The occurrence of dynamic transformation during the high temperature deformation of austenite signifies that two softening mechanisms (DT and DRX) are jointly responsible for the shape of the familiar single peak flow curve and not just dynamic recrystallization alone.

2. The MFS drops of 10 to $40 \mathrm{MPa}$ correspond to rolling load or separation force decreases of $10-20 \%$ below expected values. It was shown here that these unexpected drops can be ascribed to the DT of austenite to ferrite during deformation. 
Chapter 9

\section{Contributions to Original Knowledge}




\section{Contributions to Original Knowledge}

The dynamic transformation (DT) behavior of deformed austenite in four different steels of increasing carbon contents was studied systematically in the current investigation. These were deformed over the temperature range $743-$ $917^{\circ} \mathrm{C}$. Strains of $0.15-5$ were applied at strain rates of $0.4-4.5 \mathrm{~s}^{-1}$. All the tests were carried out in torsion under an atmosphere of argon and $5 \% \mathrm{H}_{2}$ and all the experimental temperatures were above the calculated ortho- and paraequilibrium $\mathrm{Ae}_{3}$ temperatures of the steels. The results described above include the following original contributions to knowledge.

1. The carbon diffusion distances associated with the formation of Widmanstätten type of ferrite were estimated in this work and found to be consistent with elapsed times of less than a millisecond over the present experimental temperature range. This demonstrated that the times involved in the formation of DT ferrite are sufficient for interstitial diffusion, but do not allow time for substitutional distribution. These calculations provide the first detailed support for the view that DT microstructures form under paraequilibrium conditions.

2. Single peak austenite flow curves are generally thought to result from a single softening mechanism (in addition to dynamic recovery), i.e. dynamic recrystallization (DRX). However, using the double differentiation technique, the present study has shown for the first time that the occurrence of dynamic transformation during the high temperature deformation of austenite signifies that two softening mechanisms (DT and DRX) are jointly responsible for the shape of the familiar single peak flow curve and not just dynamic recrystallization alone. 
3. The onsets of both DT and DRX were evaluated analytically for the first time in this work from the austenite flow curves using the double differentiation method. The critical strains for DT were shown to be lower than for DRX in the current experimental temperature range. This contrasts sharply with the critical strains for DRX, which decrease with temperature in the usual way.

4. Mean flow stresses (MFS's) were calculated from the experimental flow curves by integration in this study. When plotted in the form of Boratto diagrams, unexpectedly low values of MFS were detected above both the ortho and para-equilibrium $\mathrm{Ae}_{3}$ temperatures of the steels. These unexpected drops have not previously been ascribed to the DT of austenite to ferrite during deformation.

5. The effect of deformation on the Gibbs energy of austenite was estimated by assuming that the austenite continues to work harden after the initiation of the transformation and that its flow stress and dislocation density can be estimated from the early part of the experimental flow curve for the two-phase material. This led to higher austenite flow stresses and therefore higher dislocation densities than those employed to model dynamic transformation by previous researchers.

6. The present calculations indicate that the dislocation densities in the regions that experience transformation are 2 to 15 times higher than the average values. Such an approach (together with item 7 above) leads to driving forces of about $200 \mathrm{~J} / \mathrm{mol}$ and can thus readily account for $\mathrm{Ae}_{3}$ temperatures as much as $100^{\circ} \mathrm{C}$ above the conventional value. These 
increases are much higher than those proposed earlier. Similar remarks apply to the $\mathrm{Ae}_{1}$.

7. At $\mathrm{C}$ levels below about $0.15 \% \mathrm{C}$ and at temperatures above the $\mathrm{Ae}_{3}$, the Gibbs energy calculations indicate that the deformed austenite energy can decrease "instantly" down to the ferrite line and then displacive growth takes place without any $\mathrm{C}$ diffusion being required. At $\mathrm{C}$ levels in the range from $0.15 \% \mathrm{C}$ to about $0.40 \% \mathrm{C}$, similar calculations indicate that the Widmanstätten ferrite can form "instantly", i.e. displacively, from deformed austenite. It then decomposes more slowly into ferrite + cementite while localized $\mathrm{C}$ diffusion is taking place. At $\mathrm{C}$ levels above about $0.40 \% \mathrm{C}$, the Gibbs energy calculations indicate that the formation of ferrite is accompanied by cementite formation and involves concurrent C diffusion.

8. A thermodynamic model has been developed in this study that predicts the quantitative effect of increasing the Mn level in deformed steels of the present type. This shows that the dynamic $\mathrm{Ae}_{3}$ and $\mathrm{Ae}_{1}$ temperatures decrease, as observed in static transformations. Similar modifications in the $\mathrm{Si}$ levels were shown to lead to $\mathrm{Ae}_{3}$ and $\mathrm{Ae}_{1}$ temperature changes of similar magnitude but of opposite sign. 